ADVANCED STEEL CONSTRUCTION

An International Journal

Volume 9 Number 3

September 2013

CONTENTS

\section{Technical Papers}

Seismic Performance and Design of Reduced Steel Beam Section with

Concrete Filled Square Tubular Column

Yanli Guo and Xingyou Yao

Hysteretic Behavior of Shear Panel Dampers under High Axial Compression Loading Zhiyi Chen, Guoqiang Bian and Yu Huang

Review on Web Buckling and Hysteretic Behavior of Shear Panel Dampers Zhiyi Chen, Guoqiang Bian and Yu Huang

Rotation Performance of Cold-Formed Steel Portal Frames M. Dundu

Behavior of High Strength Concrete Filled Square Steel Tube Columns with Inner CFRP Circular Tube under Bi-Axial Eccentric Loading

G.C. Li, Z.J. Yang, Y. Lang and C. Fang

Experimental Study and Application in Steel Structure of 'Dual Functions' Metallic Damper Gang Li and Hong-Nan Li

Conference Announcement

\section{Copyright $\odot 2013$ by}

The Hong Kong Institute of Steel Construction

Website: $h t t p: / / w w w . h k i s c . o r g$

ISSN 1816-112X

Science Citation Index Expanded, Materials Science Citation Index and ISI Alerting

Cover: The Tamar Headquarters of Hong Kong SAR Government

Top five floors sparning over the two mega cores are made of composite trusses with concrete infilled

rectangular sections and designed by second-order direct analysis

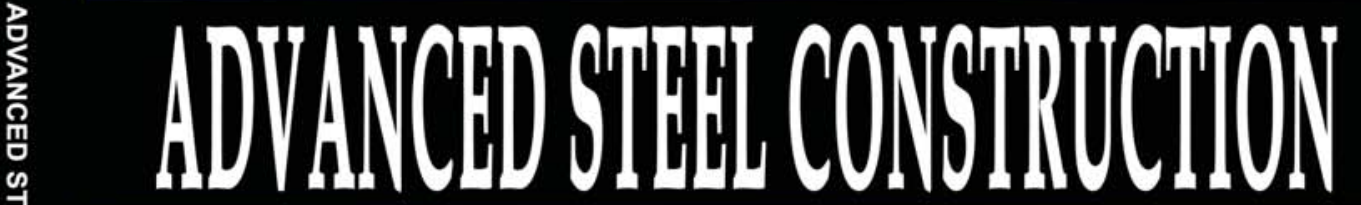

an International Journal

ISSN 1816-112X

Volume 9 Number 3

September 2013

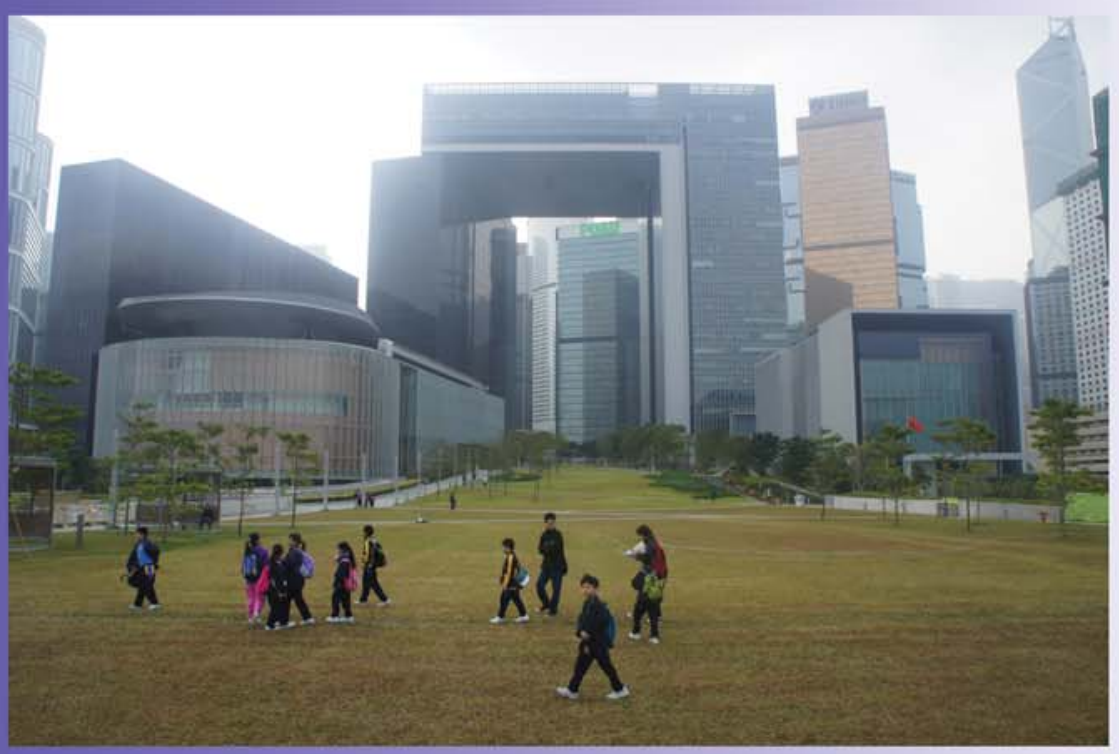

Editors-in-Chief

S.L. Chan, The Hong Kong Polytechnic University, Hong Kong

W.F. Chen, University of Hawaii at Manoa, USA

R. Zandonini, Trento University, Italy 


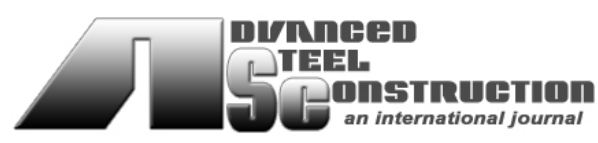

ISSN 1816-112X

Science Citation Index Expanded, Materials Science Citation Index and ISI Alerting

\section{EDITORS-IN-CHIEF}

Asian Pacific, African and organizing Editor

S.L. Chan

The Hong Kong Polyt. Univ., Hong Kong

American Editor
W.F. Chen
Univ. of Hawaii at Manoa, USA

\section{European Editor}

R. Zandonini

Trento Univ., Italy

\section{INTERNATIONAL EDITORIAL BOARD}

F.G. Albermani

The Univ. of Queensland, Australia

I. Burgess

Univ. of Sheffield, UK

F.S.K. Bijlaard

Delft Univ. of Technology, The Netherlands

R. Bjorhovde

The Bjorhovde Group, USA

M.A. Bradford

The Univ. of New South Wales, Australia

D. Camotim

Technical Univ. of Lisbon, Portugal

C.M. Chan

Hong Kong Univ. of Science \& Technology, Hong Kong

T.H.T. Chan

Queensland Univ. of Technology, Australia

S.P. Chiew

Nanyang Technological Univ., Singapore

W.K. Chow

The Hong Kong Polyt. Univ., Hong Kong

K.F. Chung

The Hong Kong Polyt. Univ., Hong Kong

G.G. Deierlein

Stanford Univ., California, USA

L. Dezi

Univ. of Ancona, Italy

D. Dubina

The Politehnica Univ. of Timosoara, Romania

\section{Advanced Steel \\ Construction an international journal}

R. Greine

Technical Univ. of Graz, Austria

L. Gardner

Imperial College of Science, Technology and

Medicine, UK

L.H. Han

Tsinghua Univ. China

S. Herion

University of Karlsruhe, Germany

G.W.M. Ho

Ove Arup \& Partners Hong Kong Ltd., Hong Kong

B.A. Izzuddin

Imperial College of Science, Technology and

Medicine, UK

J.P. Jaspart

Univ. of Liege, Belgium

S. A. Jayachandran

IIT Madras, Chennai, India

S.E. Kim

Sejong Univ., South Korea

S. Kitipornchai

The Univ., of Queensland, Australia

D. Lam

Univ. of Bradford, UK

G.Q. Li

Tongji Univ., China

J.Y.R. Liew

National Univ. of Singapore, Singapore

E.M. Lui

Syracuse Univ., USA

Y.L. Mo

Univ. of Houston, USA

J.P. Muzeau

CUST, Clermont Ferrand, France

D.A. Nethercot

Imperial College of Science, Technology and

Medicine, UK

Y.Q. Ni

The Hong Kong Polyt. Univ., Hong Kong

D.J. Oehlers

The Univ. of Adelaide, Australia

K. Rasmussen

The Univ. of Sydney, Australia

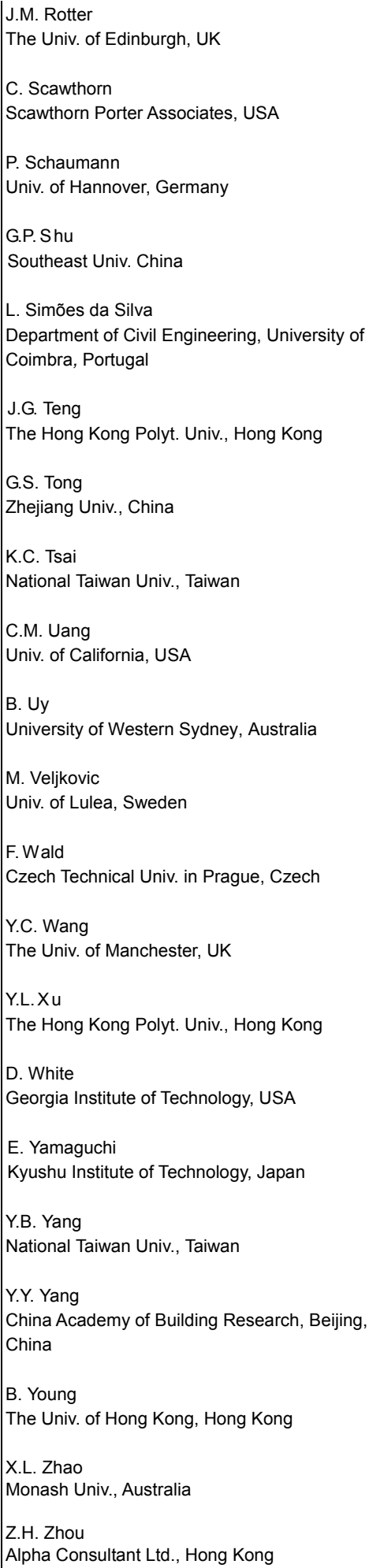




\begin{tabular}{ll}
\hline \hline & General Information \\
& Advanced Steel Construction, an international journal \\
\hline \hline Aims and scope
\end{tabular}

\section{Aims and scope}

The International Journal of Advanced Steel Construction provides a platform for the publication and rapid dissemination of ori ginal and up-to-date research and tec hnological developments in steel c onstruction, design and anal ysis. Scope of research $p$ apers published in this journal includes but is not limite $d$ to theor etical and expe rimental research on elements, assemblages, sy stems, material, design philosophy and codification, standards, fabrication, projects of innov ative nature an d computer tech niques. The journal is specifically $t$ ailored to channel the e xchange of tec hnological know-ho $w$ bet ween $r$ esearchers an $d$ practitioners. Contributions from all aspects related to the recent developments of advanced steel construction are welcome.

\section{Instructions to authors}

Submission of the manuscript. Authors may submit double-spaced manuscripts preferably in MS Word by emailing to one of the chief editors as follows for arrangement of review. Alternatively papers can be submitted on a diskette to one of the chief editors.

Asian Pacific, African and organizing editor: Professor S.L. Chan, Email: ceslchan@polyu.edu.hk

American editor :

European editor :

Professor S.L. Chan, Email: ceslchan@polyu.edu

Professor R. Zandonini, Email: riccardo_zandonini@ing.unitn.it

All manuscripts submitted to the journal are recommended to accompany with a li st of four potential reviewers suggested by the author(s). This list should include the complete name, add ress, telephone and fax num bers, em ail address, and at least five keywords that identify the expertise of each reviewer. This scheme will improve the process of review.

Style of manuscript

General. Author(s) should provide full postal and email addresses and fax number for correspondence. The manuscript including abstract, keywords, references, figures and tables should be in English with pages numbered and typed with double line spacing on single side of A4 or letter-sized paper. The front page of the article should contain:

a) a short title (reflecting the content of the paper);

b) all the name(s) and postal and email addresses of author(s) specifying the author to whom correspondence and proofs should be sent;

c) an abstract of $100-200$ words; and

d) 5 to 8 keywords.

The paper must contain an introduction and a conclusion. The length of paper should not exceed 25 journal pages (approximately 15,000 words equivalents).

Tables and figures. Tables and figures including photographs should be typed, numbered consecutively in Arabic numerals and with short titles. They should be referred in the text as Figure 1, Table 2, etc. Originally drawn figures and photographs should be provided in a form suitable for photographic reproduction and reduction in the journal.

Mathematical expressions and units. The Systeme Internationale (SI) should be followed whenever possible. The numbers identifying the displayed mathematical expression should be referred to in the text as Eq. (1), Eq. (2).

References. References to published literature should be referred in the text, in the order of citation with Arabic numerals, by the last name(s) of the author(s) (e.g. Zandonini and Zanon [3]) or if more than three authors (e.g. Zandonini et al. [4]). References should be in English $w$ ith occasional allow ance of 1-2 e xceptional referenc es in local lang uages and $r$ eflect the curren $t$ state-of-technology. Journal titles should be abbreviated in the style of the Word List of Scientific Periodicals. References should be cited in the following style $[1,2,3]$.

Journal: [1] Chen, W.F. and Kishi, N., "Semi- rigid Steel Beam-to-column Connections, Data Base and Modellin g", Journal of Structural Engineering, ASCE, 1989, Vol. 115, No. 1, pp. 105-119.

Book: [2] Chan, S.L. and Chui, P.P.T., "Non-linear Static and Cyclic Analysis of Semi-rigid Steel Frames", Elsevier Science, 2000 .

Proceedings: [3] Zandonini, R. a nd Zanon, P., "Experimental Analy sis of S teel Beams with Semi -rigid Joint s", Proceedings of International Conference on Advances in Steel Structures, Hong Kong, 1996, Vol. 1, pp. 356-364.

Proofs. Proof will be sent to the c orresponding author to correct an y typesetting errors. Alternations to the original manuscript at this stage will not be accepted. Proofs should be returned within 48 hours of receipt by Express Mail, Fax or Email.

Copyright. Submission of an article to "Advanced Steel Construction" implies that it presents the original and unpublished work, and not under consideration for publication nor published elsewhere. On acceptance of a manuscript submitted, the copyright thereof is transferred to the publisher $b y$ the Transfer of $C$ opyright Agreement and upon the acceptance of publication for the $p$ apers, the corresponding author must sign the form for Transfer of Copyright.

Permission. Quoting from this journal is granted provided that the customary acknowledgement is given to the source.

Page charge and Reprints. There will be no page charges if the length of paper is within the limit of 25 journal pages. A total of 30 free offprints will be supplied free of charge to the corresponding author. Purchasing orders for additional offprints can be made on order forms which will be sent to the authors. These instructions can be obtained at the Hong Kong Institute of Steel Construction, Journal website: http://www.hkisc.org

The International Journal of Advanced Steel Construction is published quarterly by non-profit making learnt society, The Hong Kong Institute of Steel Construction, c/o Department of Civil \& Structural Engineering, The Hong Kong Polytechnic University, Hung Hom, Kowloon, Hong Kong.

Disclaimer. No responsibility is assumed for a ny injury and / or damage to per sons or property as a matter of products liability, negligence or otherwise, or from any use or operation of any methods, products, instructions or ideas contained in the material herein.

Subscription inquiries and change of address. Address all subscription inquiries and correspondence to Member Records, IJASC. Notify an address change as soon as possible. All communications should include both old and new addresses with zip codes and be accompanied by a mailing label from a recent issue. Allow six weeks for all changes to become effective.

The Hong Kong Institute of Steel Construction

HKISC

c/o Department of Civil and Environmental Engineering,

The Hong Kong Polytechnic University,

Hunghom, Kowloon, Hong Kong, China.

Tel: 852- 27666047 Fax: 852- 23346389

Email: ces/chan@polyu.edu.hk Website: http://www.hkisc.org/

ISSN 1816-112X

Science Citation Index Expanded, Materials Science Citation Index and ISI Alerting

Copyright $\odot 2013$ by:

The Hong Kong Institute of Steel Construction. 


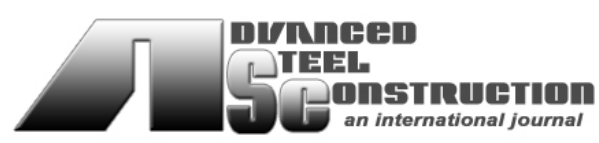

ISSN 1816-112X

Science Citation Index Expanded, Materials Science Citation Index and ISI Alerting

\section{EDITORS-IN-CHIEF}

Asian Pacific, African and organizing Editor

S.L. Chan

The Hong Kong Polyt. Univ., Hong Kong

Email: ceslchan@polyu.edu.hk

\section{American Editor}

W.F. Chen

Univ. of Hawaii at Manoa, USA

Email:waifah@hawaii.edu

\section{European Editor}

R. Zandonini

Trento Univ., Italy

Email: riccardo.zandonini@ing.unitn.it

\section{Advanced Steel \\ Construction an international journal}

VOLUME 9 NUMBER 3 SEPTEMBER 2013

Technical Papers

Seismic Performance and Design of Reduced Steel Beam Section 173 with Concrete Filled Square Tubular Column

Yanli Guo and Xingyou Yao

Hysteretic Behavior of Shear Panel Dampers under High Axial 190 Compression Loading

Zhiyi Chen, Guoqiang Bian and Yu Huang

Review on Web Buckling and Hysteretic Behavior of Shear Panel 205 Dampers

Zhiyi Chen, Guoqiang Bian and Yu Huang

Rotation Performance of Cold-Formed Steel Portal Frames M. Dundu

Behavior of High Strength Concrete Filled Square Steel Tube

Columns with Inner CFRP Circular Tube under Bi-Axial Eccentric Loading

G.C. Li, Z.J. Yang, Y. Lang and C. Fang

Experimental Study and Application in Steel Structure of

'Dual Functions' Metallic Damper

Gang Li and Hong-Nan Li

Conference Announcement 


\title{
SEISMIC PERFORMANCE AND DESIGN OF REDUCED STEEL BEAM SECTION WITH CONCRETE FILLED SQUARE TUBULAR COLUMN
}

\author{
Yanli Guo ${ }^{1}$ and Xingyou Yao ${ }^{1,2, *}$ \\ ${ }^{1}$ Lecture, School of Civil and Building Engineering, Nanchang Institute of Technology, Nanchang, China \\ ${ }^{2}$ College of Civil Engineering, Tongji University, Shanghai, China \\ *(Corresponding author: E-mail: yaoxingyoujd@163.com)
}

Received: 6 September 2011; Revised: 18 February 2012; Accepted: 29 February 2012

\begin{abstract}
According to the anti-seismic design principle of strong column and weak beam, and of strong joint and weak member, reduced beam section (RSB) is often used to shift away plastic hinge from end of beam to the weaken region of the beam. The non-linear finite element models are established for concrete-filled steel square tubular column and reduced steel beam with holes in flange or in flange and web, considering geometric large deformation and material nonlinear. Comparison is made on load-displacement curves, the stress distribution of reduced beams, the ultimate load-carrying capacity, the ductility, and the energy-dissipating ability between analysis results of different RBS section and experimental results. It shows that the stiffness and ultimate load-carrying capacity of new RBS section are close to traditional RBS section, the plastic hinge in the new section with reduced beam section can be moved to the reduced region, and the new section display good ductility, energy-dissipating ability and seismic behavior. Based on Chinese codes and analysis results, the seismic design method of concrete-filled steel square tubular column and reduced steel beam section are proposed in this paper.
\end{abstract}

Keywords: Shape optimization, seismic design, Concrete-filled steel square tubular column, Beam-column joint, Reduced beam section, Nonlinear FEM

\section{INTRODUCTION}

Since the earthquake of 1994 in Northridge and of 1995 in Kobe, intensive research and testing efforts have been underway to find better methods to design and construct seismic resistant steel frames. A number of improved beam-to-column connection design strategies have been proposed. According to the research results(CECS159-2004 [1], Cai [2], Ru et al.[3], FEMA-350 [4]) of researchers and considering the tradition connection of steel frame, 'Technical specification for structures with concrete-filled rectangular steel tube members'(CECS159:2004[1]) gives two kind of beam-to-column section, one with short-beam and inner diaphragm(Figure 1a) and the other with inner diaphragm(Figure 1b). Because the beam section in connection can't reach equal-strength for the tradition connection joint, the beam-to-column connection should adopt reduced beam section with shift-away of plastic hinge in seismic fortification intensity 8 of site-class 3 and 4 and seismic fortification intensity 9 according to the research results of steel frame section. The research results (FEMA-350 [4], Liu [5]) show arc-shape cutting is the best way to avoid stress concentration, but this cutting mode is difficult to operate. Cutting hole in web of beam is easy to operate and the hole in web of beam can convenient to arrange pipeline. Two new kinds of section with holes in flange or flange and web are suggested to use for concrete-filled steel square tubular column and reduced steel beam in this paper, Seismic performance of these two new kinds of section under monotonic and cyclic loading are analysis by finite element method (FEM), and the dimension of the new reduced beam section with high stiffener, load-carrying capacity, good ductility, and energy- dissipating ability are suggested for engineering. Based on Chinese codes (CECS159-2004 [1], GB50011-2008 [6], JGJ99-98 [7]) and analysis results, the seismic design method of concrete-filled steel square tubular column and reduced steel beam section are proposed in this paper. 


\section{STYLE OF REDUCED BEAM SECTION}

The styles of reduced beam section include two kinds, reduced region in flange or in web (Guo [8]).

\subsection{Reduced Beam Section with Drilled Flange}

RBS with radius cut is the tradition shapes cutout (Figure 2a), which behaves with the highest rotational capacity. But it is difficult to trim away. Drilled hole is easy to operate. Three kinds of drilled flanges are suggested as shown in Figure $2 b$, Figure $2 c$, and Figure $2 d$. Figure $2 b$ is single-row hole with same diameter. Figure $2 \mathrm{c}$ is single-row hole with different diameter. Figure $2 \mathrm{~d}$ is two-row hole with same diameter. The dimension and location of drilled hole are reference to radius cut to ensure the same reduced area and location. The geometrical characteristics of the RBS section is $a=(0.5 \sim 0.75) b_{f}, \quad b=(0.65 \sim 0.85) h_{b}, c \leq=0.25 b_{f}, R \leq=\left(4 c^{2}+b^{2}\right) /(8 c)$, where $h_{\mathrm{b}}$ is beam depth, $b_{\mathrm{f}}$ is the flange width, and $l$ is the distance of the intended plastic hinge ate the centre of the RBS from the column face.

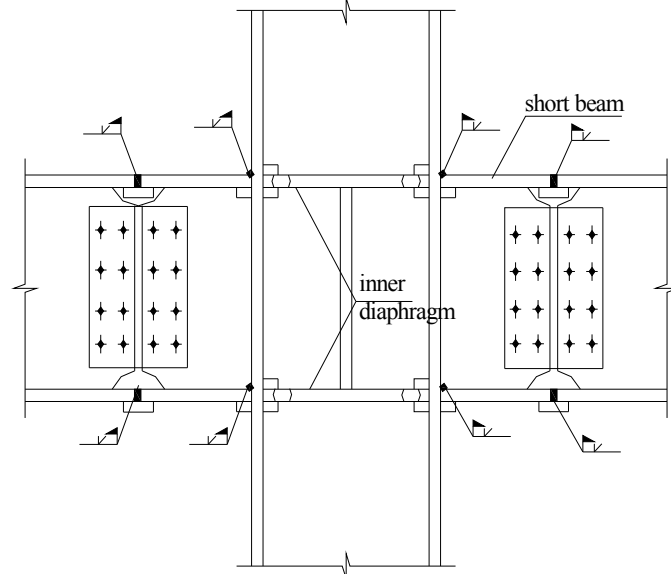

(a) Short Beam and Inner Diaphragm

Figure 1. RBS Joint

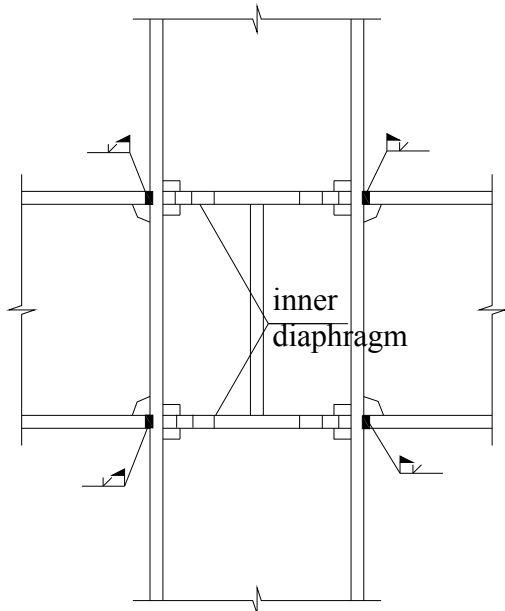

(b) Inner Diaphragm

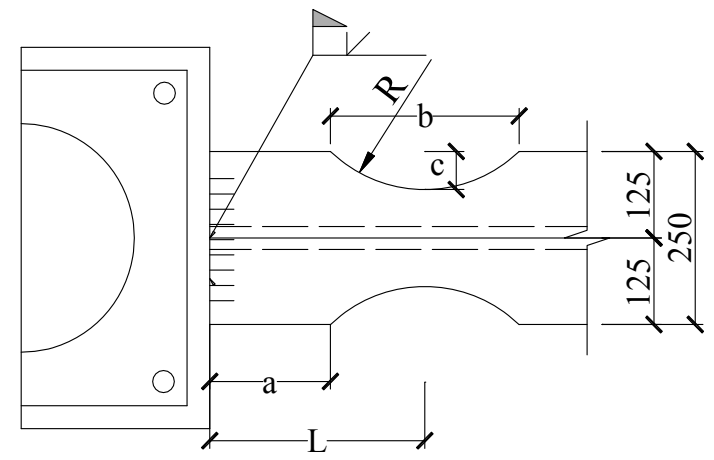

(a) Radius Cut

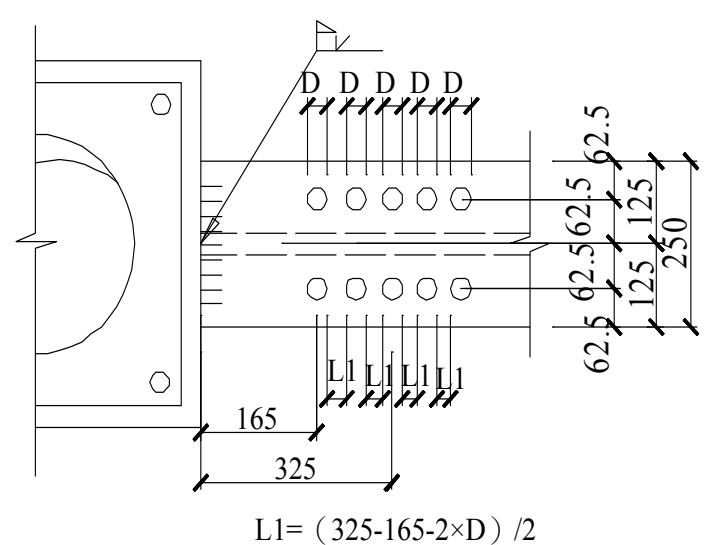

(b) Drilled Single-row Same Hole 


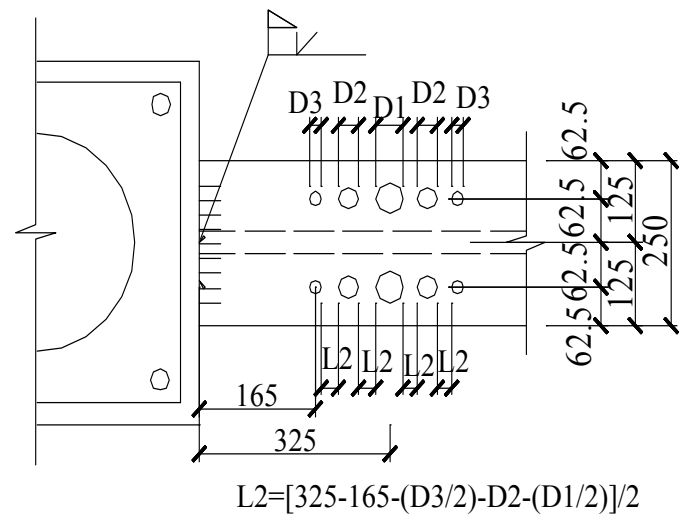

(c) Drilled Single-row Different Hole

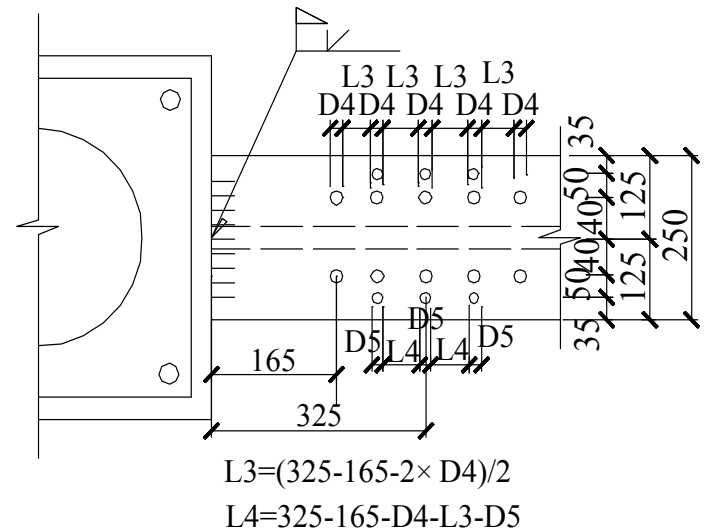

(d) Drilled Two-row Same Hole

Figure 2. Style of RBS Joint with Drilled Hole in Flange

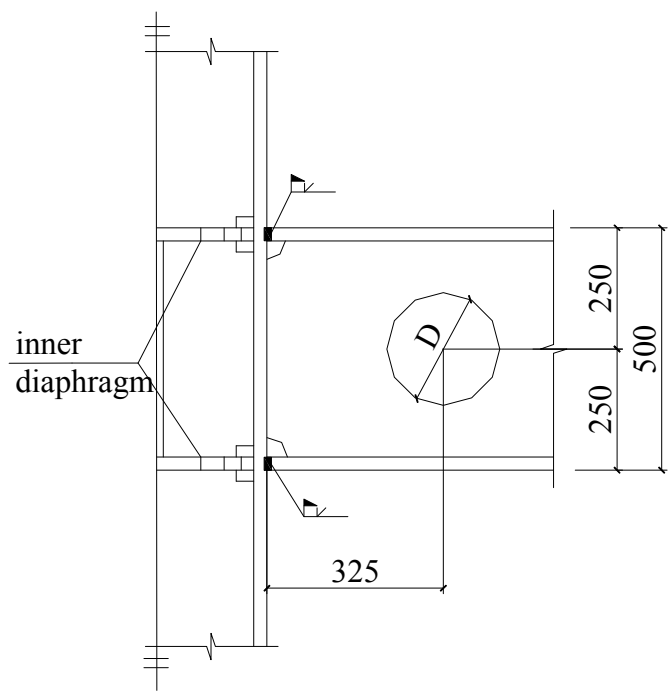

(a) Circular Hole in Web

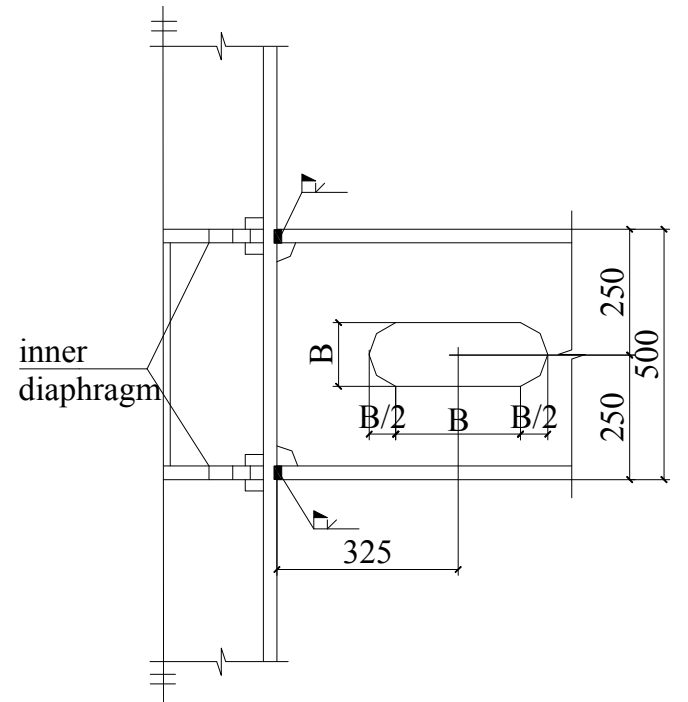

(b) Long-circular Hole in Web

Figure 3. Style of RBS Joint with Cut Hole in Web 


\subsection{Reduced Beam Section with Drilled Flange and Web}

The flange and web bear shear of section bear moment and shear respectively. In order to ensure the maximum stress in flange and web to shift away the reduced zone simultaneously and easy to operate and use, the mode of section with drilled flange and web as shown in Figure 4 are suggested based on the drilled flange in Figure 2 and drilled web in Figure 3. Figure 4a is flange with single-row hole with different diameter and web with circular hole. Figure $4 \mathrm{~b}$ is flange with single-row hole with different diameter and web with long-circular hole. Figure $4 \mathrm{c}$ is flange with single-row hole with same diameter and web with circular hole. Figure $4 \mathrm{~d}$ is flange with single-row hole with same diameter and web with long-circular hole.

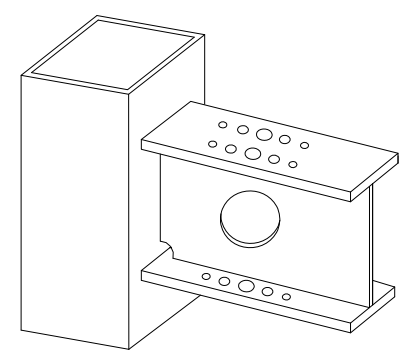

(a)Different hole in flange circular hole in web

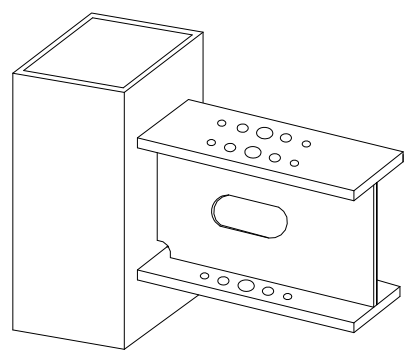

(b)Different hole in flange long- circular hole in web

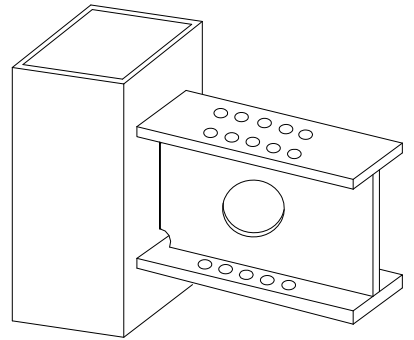

(c) Same hole in flange circular hole in web

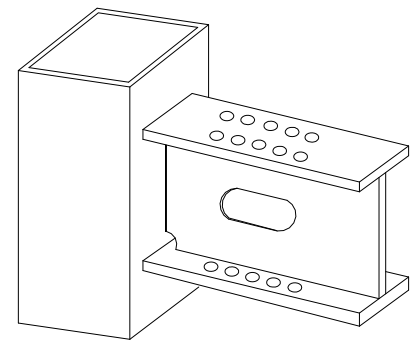

(d) Same hole in flange long-circular hole in web

Figure 4. Section of Reduced Web and Reduced Flange

\section{FINITE ELEMENT MODELING}

\subsection{Specimens, Element and Model}

The dimension of specimens analyzed by FEM can be found in reference(Zhou [9]). The yield stress of steel is $345 \mathrm{~N} / \mathrm{mm}^{2}$. Compressive strength of concrete is $26.8 \mathrm{~N} / \mathrm{mm}^{2}$. The dimension of tube is $500 \times 500 \times 25 \mathrm{~mm}$ and beam is $\mathrm{H} 500 \times 250 \times 8 \times 16$. The thickness of inner diaphragm is $28 \mathrm{~mm}$ and the diameter of big hole and litter hole in inner diaphragm are 250 and $25 \mathrm{~mm}$ respectively. The number and dimension of reduced zone are shown in Table 1, where JD-3B is the experimental specimens in reference (Zhou [9]). The meanings of label of section are as follows, $Y, K, S, D, F, C$, and $R$ indicate the flange, hole, same diameter, different diameter, web, circular hole and long-circular hole respectively. The finite element program ANSYS7.1 considering the material non-linear and geometry large deformation was used to simulate section. Element of solid45 is used to simulate steel beam and column, which have 8 nodes and every node have three degrees of freedom. Element of solid92 is used to simulate inner diaphragm, which have 10 nodes and every node have three degrees of freedom. Element of solid65 is used to simulate concrete (Zhou et al.[10], Zhou et al.[11]). The FEM use Newton-Raphson method. Figure 5 shows a typical finite element meshing used in this study. As observed in Figure $5 \mathrm{~b}$ a more refined mesh was applied at the regions near the RBS. 


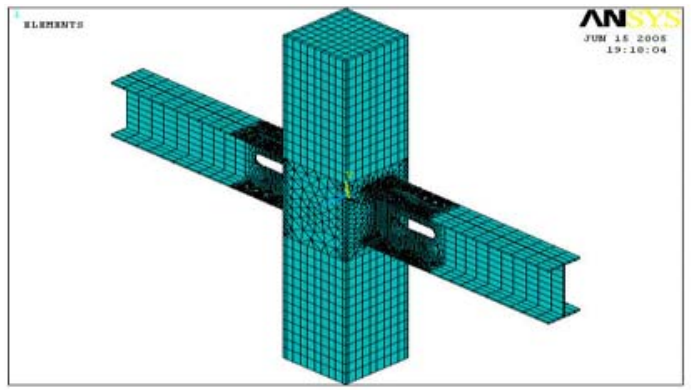

(a) FEM model

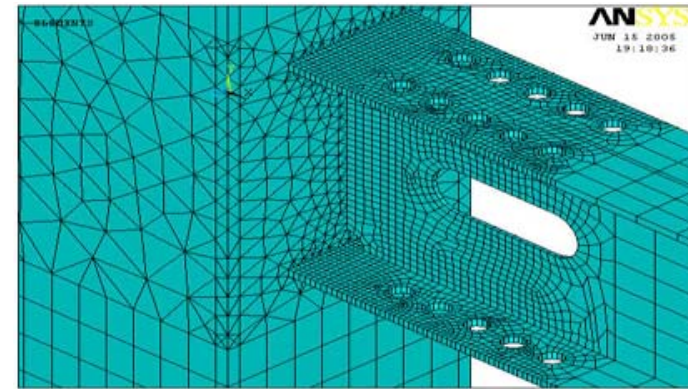

(b) Refined mesh near reduced zone

Figure 5. FEM Model

Table 1. Dimensions of New Reduced Beam Section

\begin{tabular}{|c|c|c|c|c|c|}
\hline number & place & specimen & $\begin{array}{c}\text { practical style of } \\
\text { RBS }\end{array}$ & label of RBS section & dimension of reduced zone \\
\hline 0 & no & JD-3B & no & no & no \\
\hline 1 & \multirow{6}{*}{ flange } & RBS(tradition) & radius cut & radius cut & $a=150, R=290, b=325$ \\
\hline 2 & & YK1S & same hole & YK1S40 & D6 $=40$ \\
\hline 3 & & \multirow{3}{*}{ YK1D } & \multirow{3}{*}{ different hole } & YK1D30,40,50 & $\mathrm{D} 1=50, \mathrm{D} 2=40, \mathrm{D} 3=30$ \\
\hline 4 & & & & YK1D30,50,60 & $\mathrm{D} 1=60, \mathrm{D} 2=50, \mathrm{D} 3=30$ \\
\hline 5 & & & & YK1D30,40,60 & $\mathrm{D} 1=60, \mathrm{D} 2=40, \mathrm{D} 3=30$ \\
\hline 6 & & YK2 & $\begin{array}{l}\text { two row same } \\
\text { hole }\end{array}$ & YK2,30,30 & $\begin{array}{c}\mathrm{D} 1=30 \begin{array}{c}(\text { inner row }), \mathrm{D} 2=20 \\
(\text { out row })\end{array}\end{array}$ \\
\hline 7 & \multirow{16}{*}{$\begin{array}{l}\text { flange } \\
\text { and } \\
\text { web }\end{array}$} & \multirow{7}{*}{ YK1SFKC } & \multirow{7}{*}{$\begin{array}{l}\text { same hole in } \\
\text { flange and } \\
\text { circular hole in } \\
\text { web }\end{array}$} & YK1SFKC40,150 & $\mathrm{D} 6=40, \mathrm{D}_{\mathrm{F}}=150$ \\
\hline 8 & & & & YK1SFKC30,120 & $\mathrm{D} 6=30, \mathrm{D}_{\mathrm{F}}=120$ \\
\hline 9 & & & & YK1SFKC30,140 & $\mathrm{D} 6=30, \mathrm{D}_{\mathrm{F}}=140$ \\
\hline 10 & & & & YK1SFKC 30,150 & $\mathrm{D} 6=30, \mathrm{D}_{\mathrm{F}}=150$ \\
\hline 11 & & & & YK1SFKC35,120 & $\mathrm{D} 6=35, \mathrm{D}_{\mathrm{F}}=120$ \\
\hline 12 & & & & YK1SFKC35,130 & $\mathrm{D} 6=35, \mathrm{D}_{\mathrm{F}}=130$ \\
\hline 13 & & & & YK1SFKC 35,140 & $\mathrm{D} 6=35, \mathrm{D}_{\mathrm{F}}=140$ \\
\hline 14 & & \multirow{4}{*}{ YK1DFKC } & \multirow{4}{*}{$\begin{array}{l}\text { different hole in } \\
\text { flange and } \\
\text { circular hole in } \\
\text { web }\end{array}$} & YK1DFKC30,40,50,150 & $\begin{array}{c}\mathrm{D} 1=50, \mathrm{D} 2=40, \mathrm{D} 3=30, \\
\mathrm{D}_{\mathrm{F}}=150\end{array}$ \\
\hline 15 & & & & YK1DFKC30,40,50,120 & $\begin{array}{c}\mathrm{D} 1=50, \mathrm{D} 2=40, \mathrm{D} 3=30, \\
\mathrm{D}_{\mathrm{F}}=120\end{array}$ \\
\hline 16 & & & & YK1DFKC30,40,50,100 & $\begin{array}{c}\mathrm{D} 1=50, \mathrm{D} 2=40, \mathrm{D} 3=30, \\
\mathrm{D}_{\mathrm{F}}=100\end{array}$ \\
\hline 17 & & & & YK1DFKC20,40,50,120 & $\begin{array}{c}\mathrm{D} 1=50, \mathrm{D} 2=40, \mathrm{D} 3=20, \\
\mathrm{D}_{\mathrm{F}}=120\end{array}$ \\
\hline 18 & & \multirow{3}{*}{ YK1SFKRC } & \multirow{3}{*}{$\begin{array}{l}\text { same hole in } \\
\text { flange and } \\
\text { long-circular } \\
\text { hole in web }\end{array}$} & YK1SFKRC30,180,90 & $\mathrm{D} 6=30, \mathrm{~B}=90$ \\
\hline 19 & & & & YK1SFKRC30,200,100 & $\mathrm{D} 6=30, \mathrm{~B}=100$ \\
\hline 20 & & & & YK1SFKRC30,220,110 & $\mathrm{D} 6=30, \mathrm{~B}=110$ \\
\hline 21 & & \multirow{2}{*}{ YK1DFKRC } & $\begin{array}{l}\text { different hole in } \\
\text { flange and }\end{array}$ & YK1DFKRC30,40,50,200,100 & $\mathrm{D} 1=50, \mathrm{D} 2=40, \mathrm{D} 3=30, \mathrm{~B}=100$ \\
\hline 22 & & & $\begin{array}{l}\text { long-circular } \\
\text { hole in web }\end{array}$ & YK1DFKRC30,40,50,100,50 & $\mathrm{D} 1=50, \mathrm{D} 2=40, \mathrm{D} 3=30, \mathrm{~B}=150$ \\
\hline
\end{tabular}

\subsection{Loading Procedure}

The model analyzed in this paper is the joint in the inflection point of beam and columns as shown in Figure 6. Hinge is used in end of beam and bottom end of column. Vertical load and horizontal displacement are applied the top of column. The load arrangement is shown in Figure 6. The loading procedure for cyclic loading is as follows, Vertical load applied the top of column is $1000 \mathrm{kN}$ constant, horizontal load are applied at the top of column when load is less than yield load, 
and horizontal displacement are applied at the top of column when load is more than yield load. Horizontal load use 3 5 single cycle up to the yield strength. Then several complete horizontal displacement cycles are applied with displacement amplitudes in multiples of yield displacement. The loading protocol is shown in Figure 7.

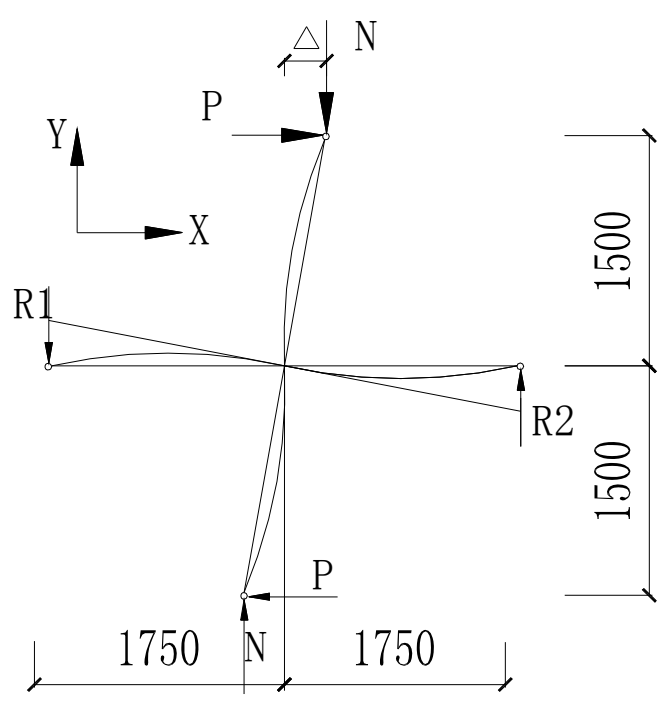

Figure 6. Loading Rrrangement

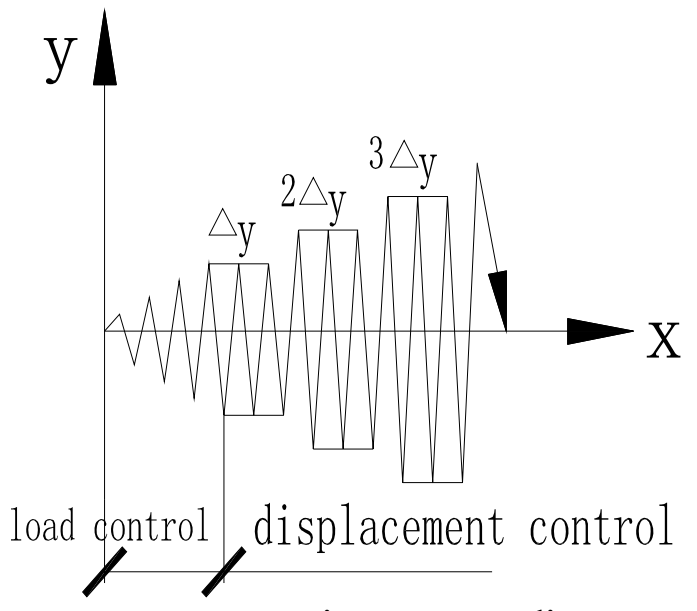

Figure 7. Loading Protocol

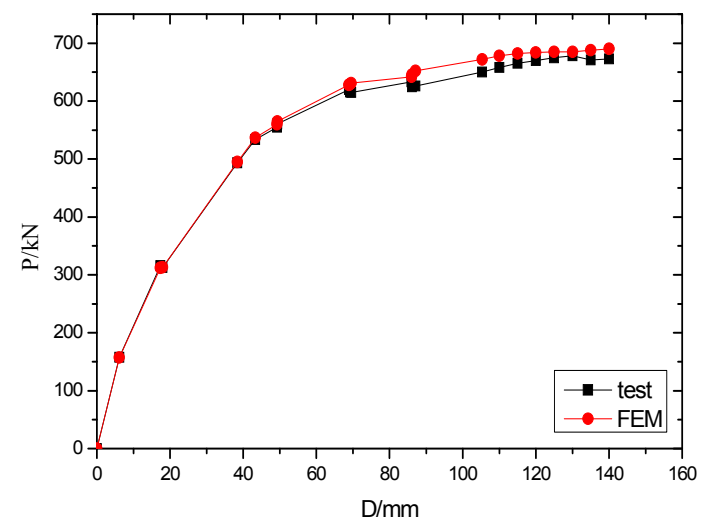

Figure 8. Comparison on JD-3B between Test and Analyzed Result

\subsection{FEM Verification}

The load versus displacement of RBS joint obtained from FEM is compared with which of test as shown in Figure 8. The curve of FEM is close to which of test. The error of yield load and ultimate load are less 5\%. So FEM can be used analysis the seismic performance of different concrete-filled square tubular column and reduced steel beam section under different load style closely.

\section{RESULT UNDER MONOTONIC LOADING}

Two kinds of new RBS section are analyzed by FEM. The ultimate load-carrying capacity and Von-Mises stress of reduced region are compared with traditional RBS, and the dimension of new RBS section with excellent reduced performance are suggested. 


\subsection{Curve of Load Versus Displacement and Stress Distribution of RBS with Drilled Flange}

The curve of load versus displacement and stress distribution of reduced beam section with drilled flange are shown in Figure 9 and Figure 10 respectively.

As shown in Figure 9, the curve of load versus displacement of reduced beam section with different drilled flange is close to which of traditional RBS joint, which observe that the ultimate load-carrying capacity of reduced beam section with different drilled flange don't decrease. The new RBS sections have good load-carrying capacity. As shown in Figure 10, stress distribution of YK1S and YK2 indicate that plastic hinge can't be shifted away column face to center of reduced region. So these two new sections can't be suggested to use. Stress distribution of YK1D30.40.50 indicates that plastic hinge can't be shifted away column face to center of reduced region. But Stress distribution of YK1D30.40.60 and YK1D30.50.60 as reduced region increased indicate that plastic hinge can be shifted away column face to center of reduced region, and the stress of column face are $331 \sim 386 \mathrm{~N} / \mathrm{mm}^{2}$ and $334 \sim 389 \mathrm{~N} / \mathrm{mm}^{2}$ which are less than yield strength. So these two new RBS section can be suggested to use. The dimension of new suggested RBS joint is, $D_{3}=2 D_{1}, D_{2} / H=0.08 \sim 1, D_{1} / H=0.06$, where $D_{1}, D_{2}$, and $D_{3}$ is the diameter of drilled hole.

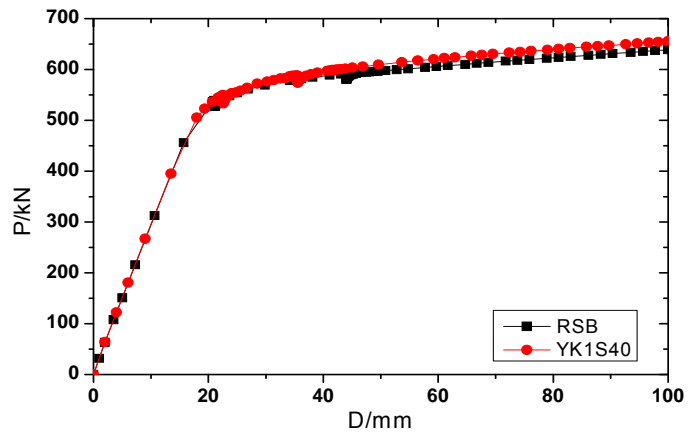

(a) YK1S

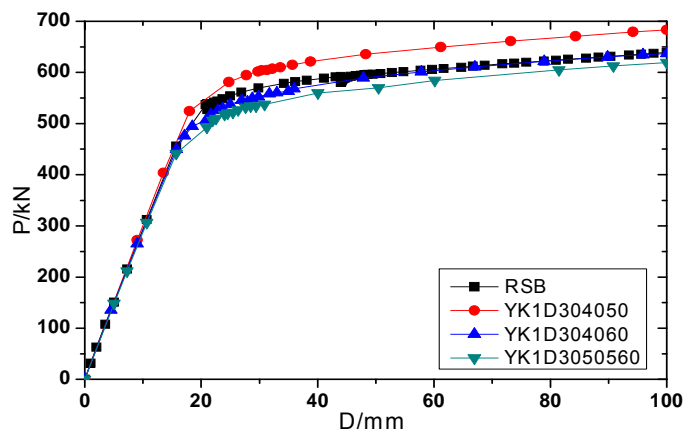

(b) YK1D

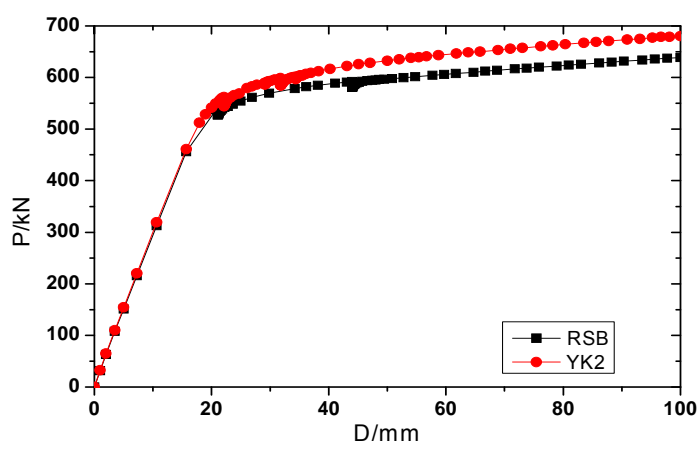

(c) YK2

Figure 9. Load-displacement Curve of Section of Reduced Flange

\subsection{Curve of Load Versus Displacement and Stress Distribution of RSB with Drilled Flange and Web}

The curve of load versus displacement of reduced beam section with drilled flange and web are shown in Figure 11 respectively. The curve of stress distribution of reduced beam section with drilled flange and web are shown in Figure 12, Figure 13, Figure 14, and Figure 15. 


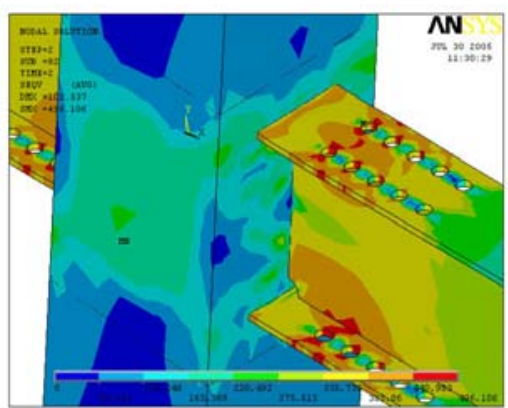

(a)YK1S40

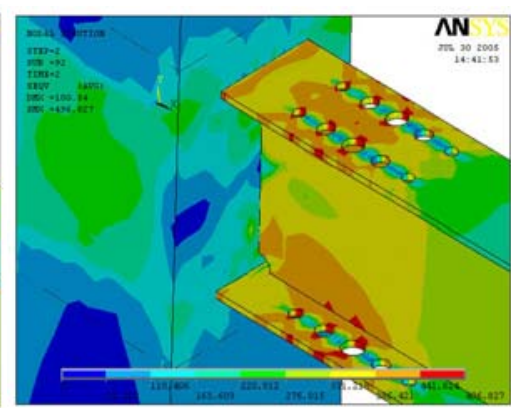

(b)YK1D30,40,50

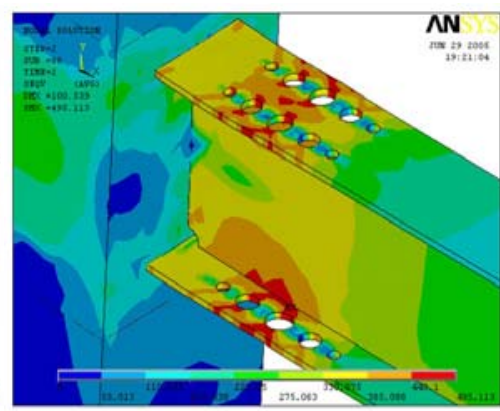

(c)Y1D30,50,60

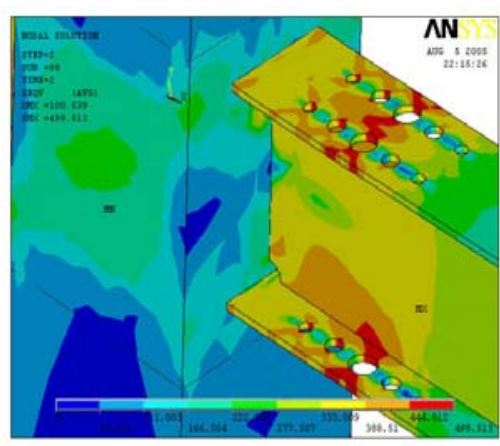

(d)YK1D30,40,60

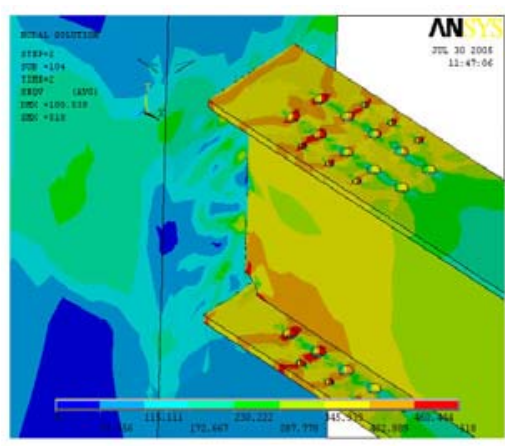

(e)YK2,30,30

Figure 10. Stress Distribution of Section of Reduced Flange

As shown in Figure 11a, the curve of load versus displacement of YK1SFKC is close to which of traditional RBS joint, which indicate the new RBS section have good load-carrying capacity. As shown in Figure 12, stress distribution of YK1SFKC indicate that plastic hinge can be shifted away column face to reduced region, but only plastic hinge of YK1SFKC 30.140 can be shifted to center of reduced region and the stress of column face are $340 \sim 400 \mathrm{~N} / \mathrm{mm}^{2}$ which are less than yield strength. So this new joint can be suggested to use. The dimension of new suggested RBS joint is, $D_{\mathrm{F}} / H=0.28, D / H=0.06$, where $D$ and $D_{\mathrm{F}}$ is the diameter of drilled hole of flange and web respectively.

As shown in Figure 11b, the curve of load versus displacement of YK1DFKC is close to which of traditional RBS joint, which indicate the new RBS section have good load-carrying capacity. As shown in Figure 13, stress distribution of YK1SFKC indicates that plastic hinge can't be shifted away column face to the center of reduced region, So these new section can't be suggested to use.

As shown in Figure 11c, the curve of load versus displacement of YK1SFKRC30.180.90 is only close to which of traditional RBS joint, which indicate the new RBS section have good load-carrying capacity. As shown in Figure 13, stress distribution of YK1SFKRC indicate that plastic hinge can be shifted away column face to the center of reduced region and the stress of column face are $340 \sim 400 \mathrm{~N} / \mathrm{mm}^{2}$ which are less than yield strength. So this new joint can be suggested to use. The dimension of new suggested $\mathrm{RBS}$ joint is, $\mathrm{B} / \mathrm{H}=0.18, \mathrm{D} / \mathrm{H}=0.06$, where $\mathrm{D}$ and $\mathrm{B}$ is the diameter of drilled hole of flange and web respectively. 
As shown in Figure 11d, the curve of load versus displacement of YK1DFKRC is close to which of traditional RBS joint, which indicate the new RBS section have good load-carrying capacity. As shown in Figure 15, stress distribution of YK1DFKRC indicate that plastic hinge can be shifted away column face to the center of reduced region, but these new joint have too many holes and are difficult to operate. So these new section can't be suggested to use.

According to comparison on analysis results by FEM of two kinds of new RBS section under monotonic loading, four new RBS section are suggested to use, YK1D30.40.60 and YK1D30.50.60 of reduced beam section with drilled flange and YK1SFKC30.140 and YK1SFKRC30.180.90 of reduced beam section with drilled flange and web.

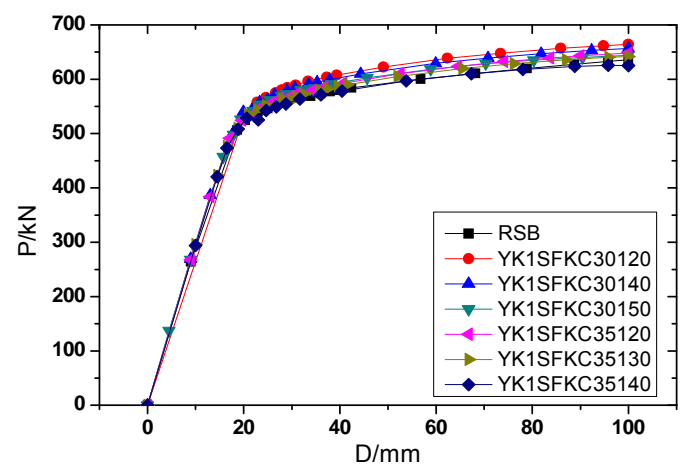

(a) YK1SFKC

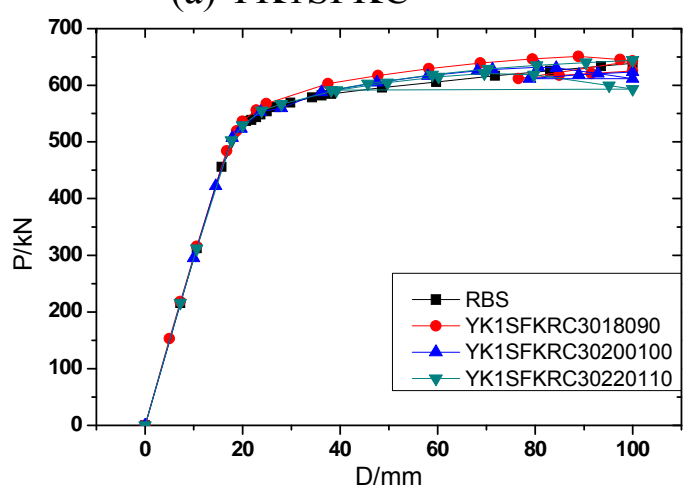

(c) YK1SFKRC

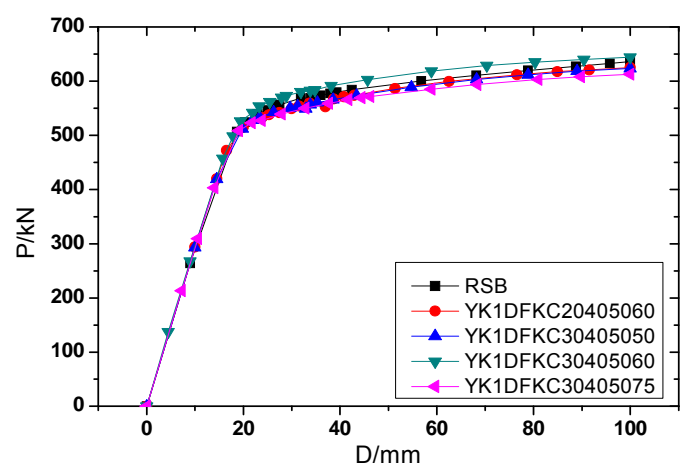

(b) YK1DFKC

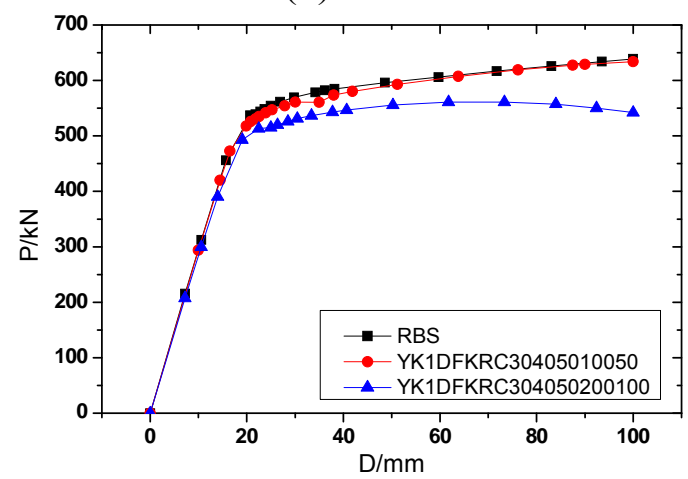

(d) YK1DFKRC

Figure 11. Load-displacement Curve of Section of Reduced Flange and Web

\subsection{Stress Distribution of Suggested Reduced Beam Section}

The stress along length of beam of four new suggested RBS section is shown in Figure 16 as $100 \mathrm{~mm}$ lateral displacement, and the stress along width of beam at column face and beam reduced region is shown in Figure 17. The stress along width of beam of four new suggested RBS section at column face and beam reduced region is shown in Figure 18 as yield load. As shown in Figure 16 and 17, the stress of column face is less than which of beam region as $100 \mathrm{~mm}$ lateral displacement, and as shown in Figure 18 the stress of column face is less than which of beam region and yield strength as joint reach yield. These show that the plastic hinge of new suggested RBS joint can shift away column face to reduced region effectively. 


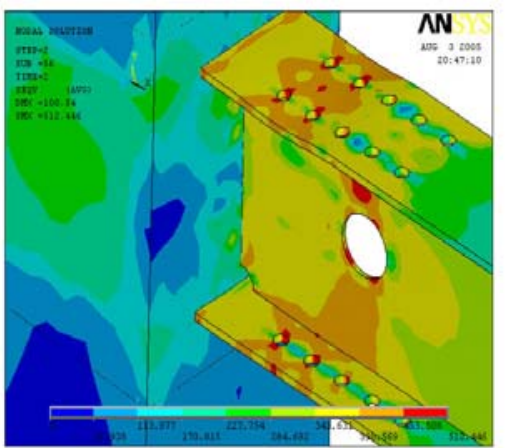

(a) YK1SFKC30,120

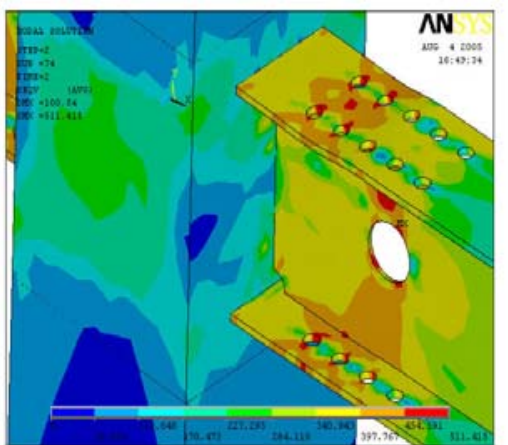

(d) YK1SFKC 35,120

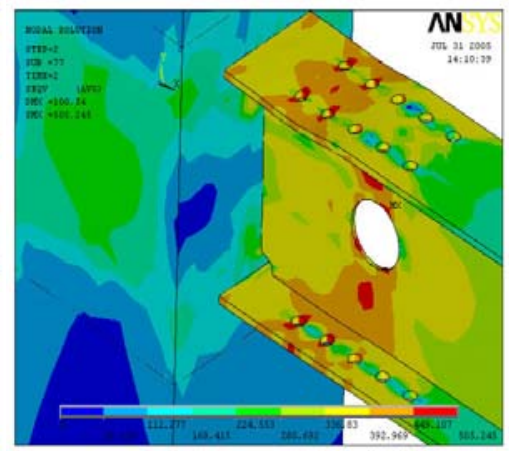

(b) YK1SFKC 30,140

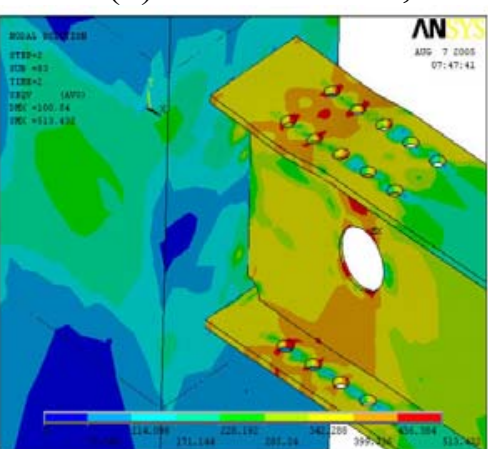

(e) YK1SFKC 35,130

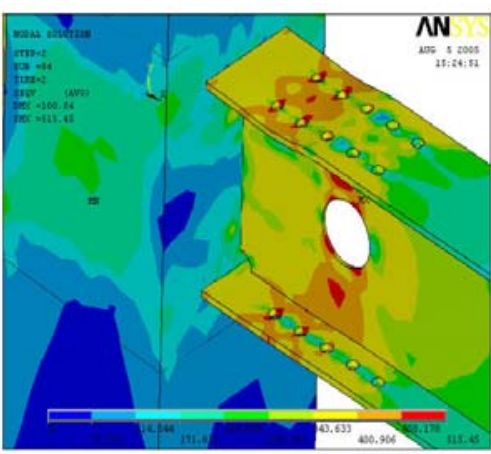

(c) YK1SFKC 30,150

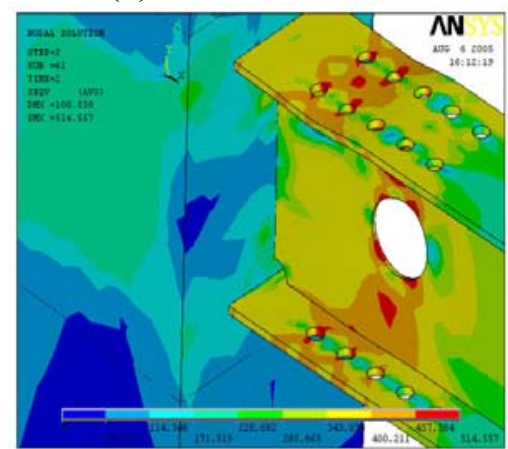

(f) YK1SFKC 35,140

Figure 12. Stress Distribution of Section of YK1SFKC

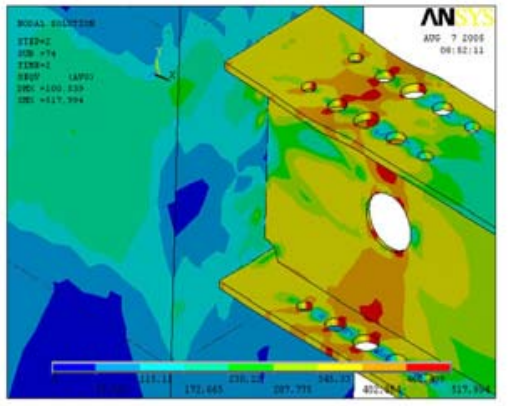

(a) 304050120

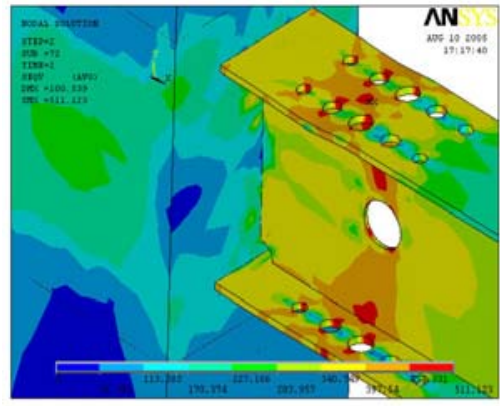

(b) 304050100

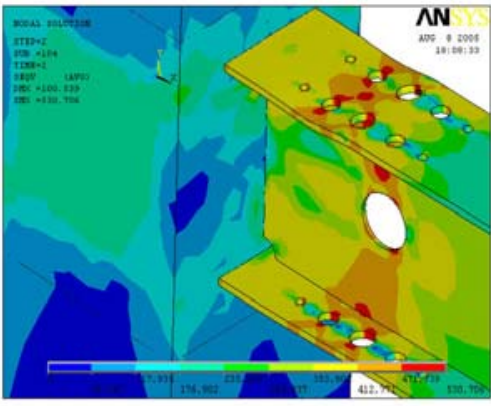

(c) 204050120

Figure 13. Stress Distribution of Section of $Y K 1 D F K C$

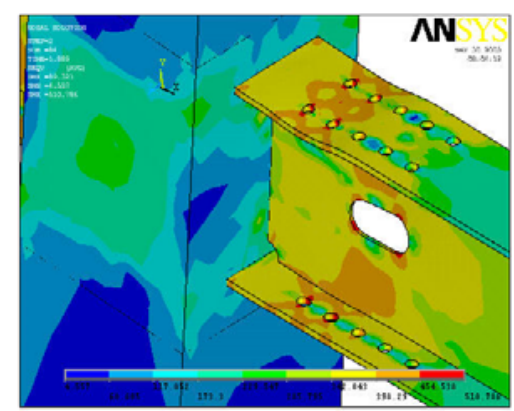

(a) YK1SFKRC30,180,90

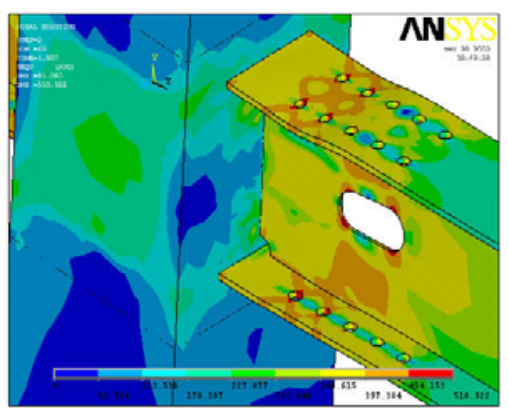

(b) YK1SFKRC30,200,100

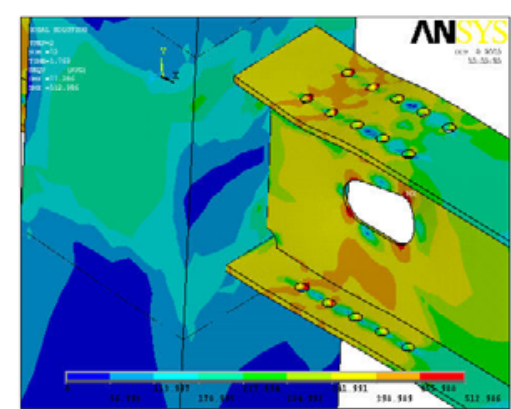

(c)YK1SFKRC30,220,110

Figure 14. Stress Distribution of Section of YK1SFKRC 


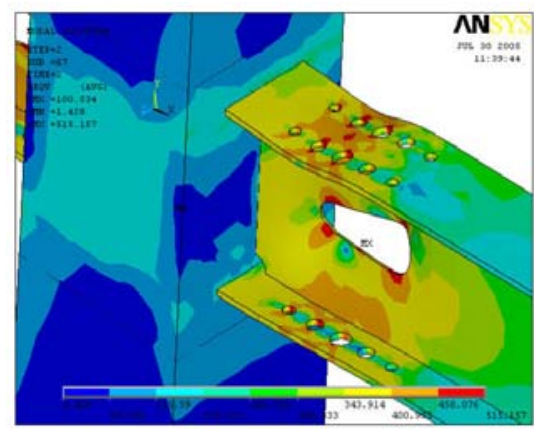

(a)YK1DFKRC30,40,50,200,100

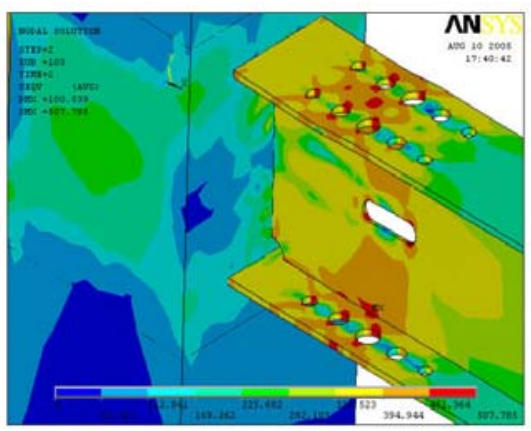

(b) YK1DFKRC 30,40,50,100,50

Figure 15. Stress Distribution of Section of YK1DFKRC

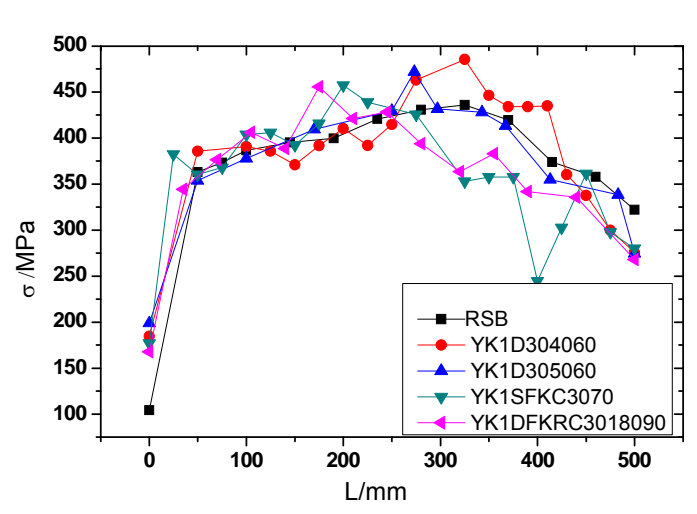

(a) Column face

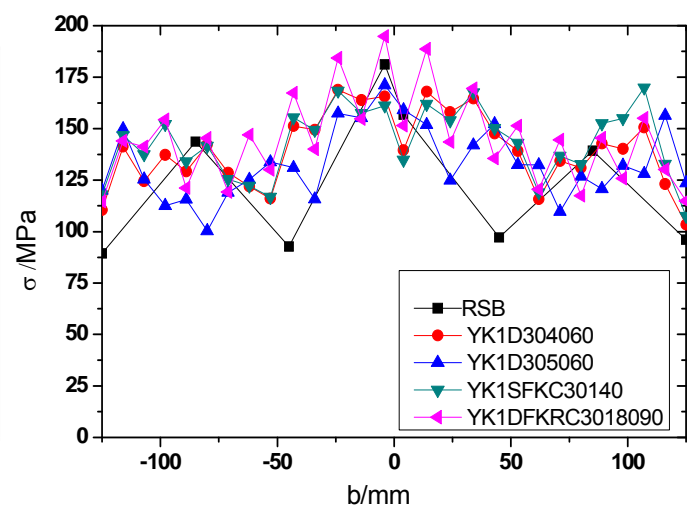

(b) Reduced zone

Figure 16. Stress Distribution of Beam along Beam Length

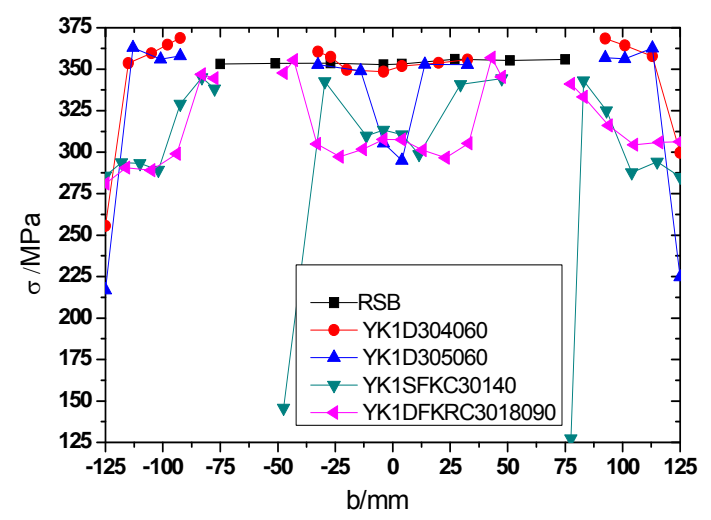

Figure 17. Stress Distribution of Beam along Beam Width when Displacement is $100 \mathrm{~mm}$

\section{RESULT UNDER CYCLIC LOADING}

The suggested RBS sections are analyzed under cyclic loading by finite element method. The hysteretic curves are shown in Figure 19. The curves of $J D-3 B$ and $R B S$ are obtained in reference (Zhou et al. [9]).

As shown in Figure 19, the suggested RBS section show plump hysteretic curve as $J D-3 B$ and $R B S$, which indicate that the suggested RBS section have good energy-dissipating ability. 


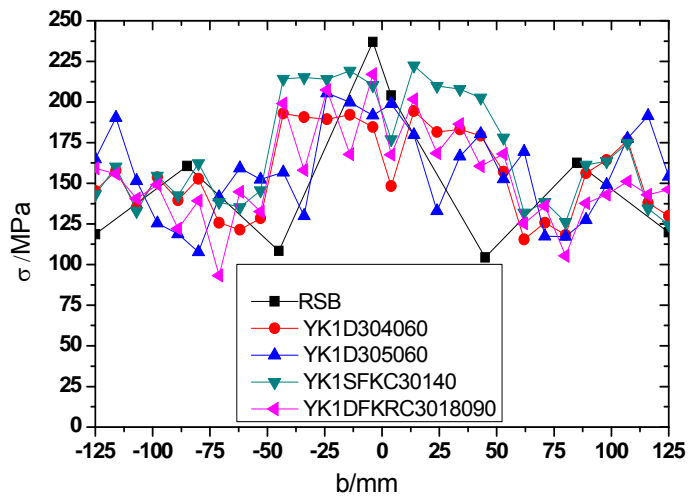

(a) Column face

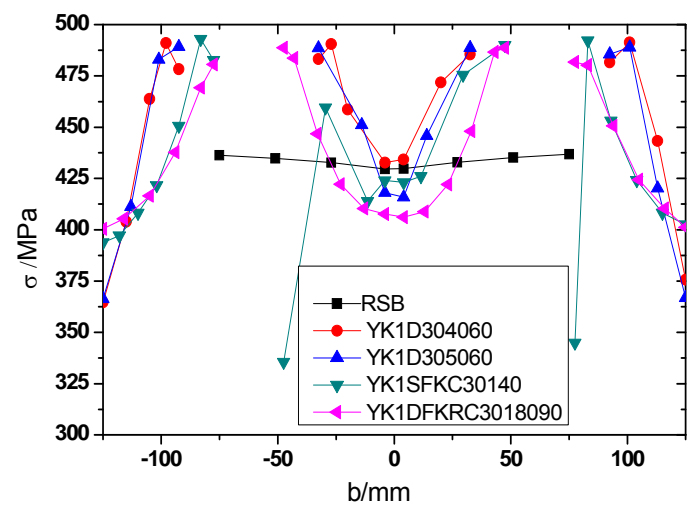

(b) Reduced zone

Figure 18. Stress Distribution of Beam along Beam Width when Section Yield

Comparison on skeleton curve of suggested RBS section under cyclic loading and curve of load versus displacement of traditional RBS joint under monotonic loading are shown in Figure 20. As shown in Figure 20, the skeleton curve are close to curve of load versus displacement when the displacement is less $60 \mathrm{~mm}$, which indicate that the load-carrying capacity don't decrease in previous eight cycle. The load-carrying capacity have less decrease in last other cycle, and the suggested RBS section can continue to bear capacity when initial yielding occurred.

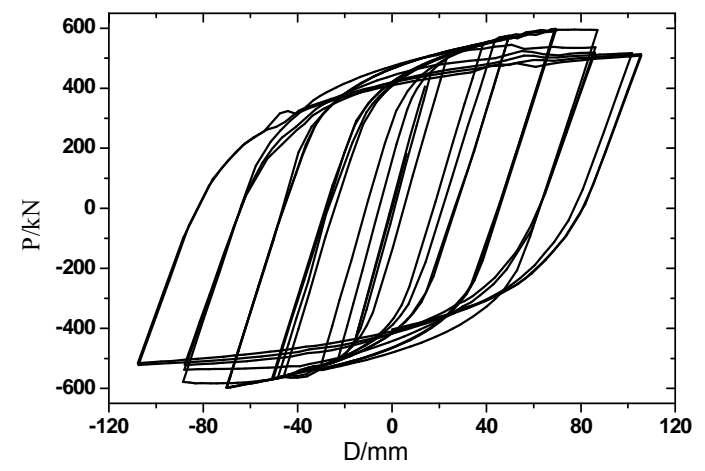

(c)YK1D30,40,60

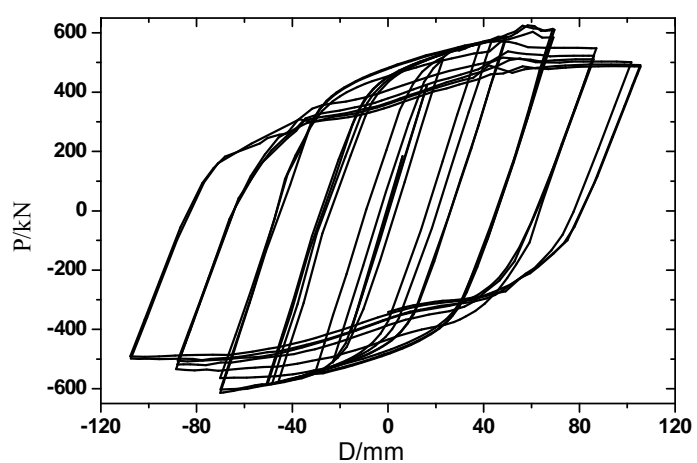

(e)YK1SFKC30,140

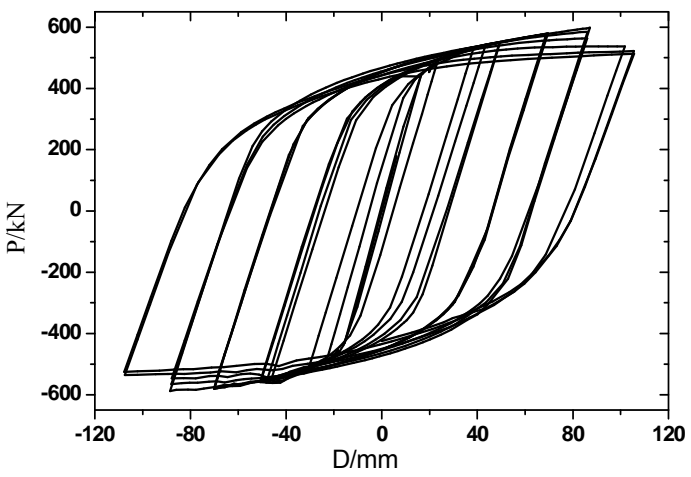

(d)YK1D30,50,60

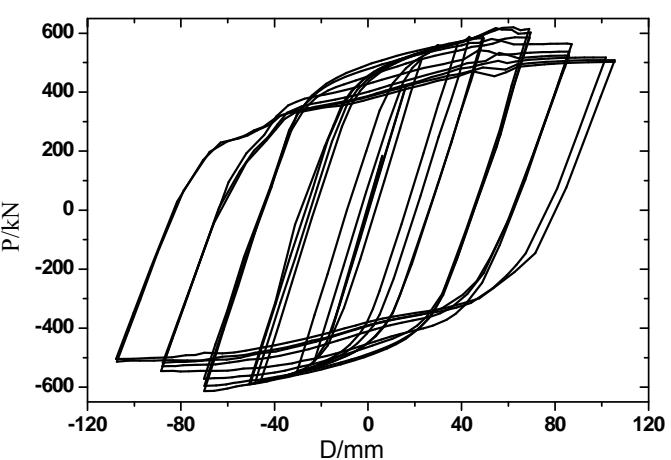

(f) YK1SFKRC30,180,90

Figure 19. Hysteretic Curve 


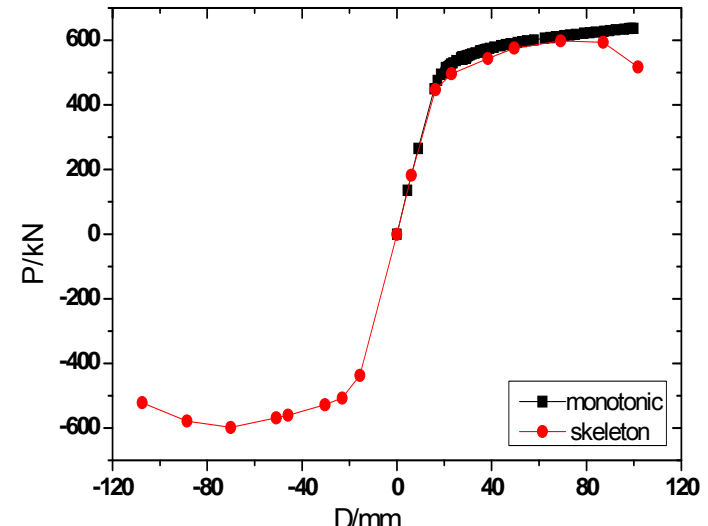

(a)YK1D30,40,60

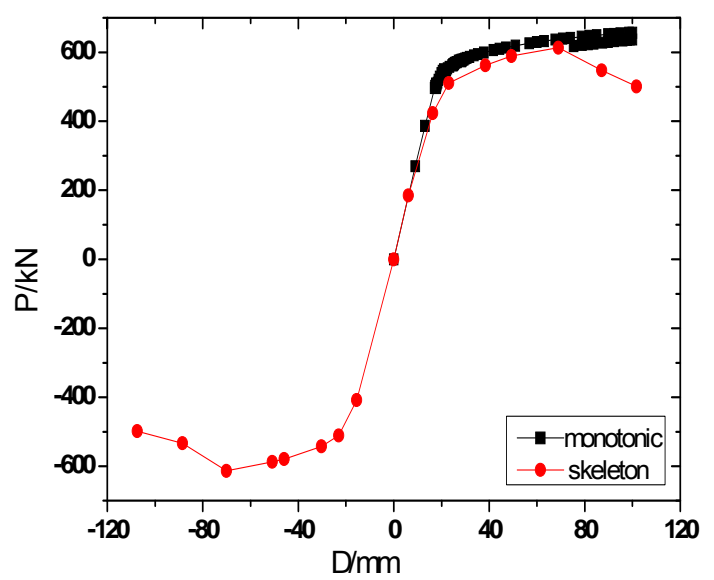

(c)YK1SFKC30,140

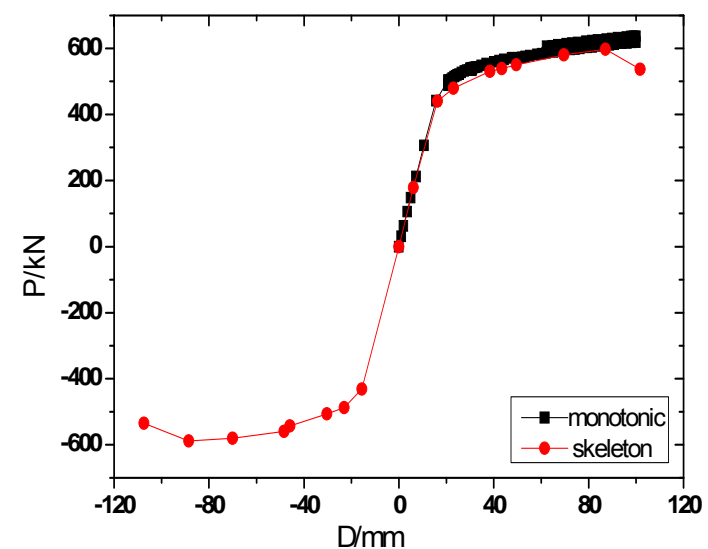

(b) YK1D30,50,60

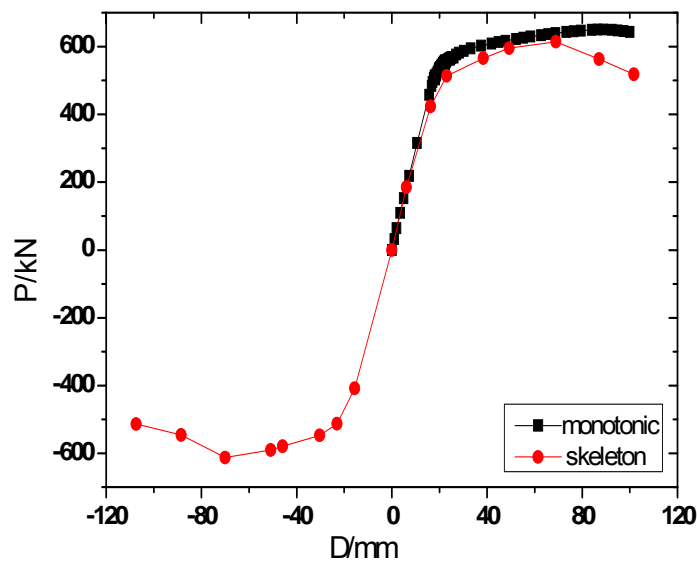

(d) YK1SFKRC30,180,90

Figure 20. Load-displacement Curve of RBS and Recommended Models

Ductility coefficient of story drift and equivalent viscous damping coefficient of suggested and traditional RBS section are shown in Table 2.

As shown in Table 2, the ductility coefficient of story drift of suggested RBS section are less $8 \%$ than which of traditional RBS, and equivalent viscous damping coefficient of suggested RBS section are less 5\% than which of traditional RBS. Thus the new suggested RBS sections have excellent dissipating energy ability and deformability.

Table 2. Story Drift Ductility Coefficient and Equivalent Viscous Damping Coefficient

\begin{tabular}{ccccc}
\hline specimen & $\Delta_{\mathrm{y}}(\mathrm{mm})$ & $\Delta_{\mathrm{u}}(\mathrm{mm})$ & $\mu$ & $\mathrm{h}_{\mathrm{e}}$ \\
\hline JD-3B & 39.1 & 105 & 2.68 & 2.205 \\
RBS & 28 & 112 & 4.0 & 2.362 \\
YK1D304060 & 26.8 & 106 & 3.96 & 2.398 \\
YK1D305060 & 27.5 & 108 & 3.9 & 2.462 \\
YK1SFKC30140 & 26 & 96 & 3.69 & 2.378 \\
YK1SFKRC3018090 & 26.5 & 105 & 3.9 & 2.413 \\
\hline
\end{tabular}




\section{SEISMIC DESIGN OF SUGGESTED RBS SECTION}

'Technical specification for structures with concrete-filled rectangular steel tube members' give the regulation that the beam-to-column connection should adopt reduced beam section with shift-away of plastic hinge in seismic fortification intensity 8 of site-class 3 and 4 and seismic fortification intensity 9. The suggested RSB sections have the same behaviors with the traditional RBS. So the seismic design of suggested RBS section can be proposed according to related Chinese codes.

\subsection{Bending Load-carrying Capacity}

1) Bending load-carrying capacity of beam-to-column joint and connection under frequent earthquake. The design bending stress of the beam-to-column joint and connection shall satisfy the following:

$\sigma=\frac{M_{\mathrm{b}}}{W_{\mathrm{nx}}} \leq f / \gamma_{\mathrm{RE}}$

Where

$\sigma-$ bending stress of welds of column face and beam of reduced zone of RBS section considering combination of seismic action for connection and joint respectively,

$M_{\mathrm{b}}$ - design bending moments of welds of column face and beam of reduced zone of RBS section considering combination of seismic action for connection and joint respectively,

$W_{\mathrm{nx}}$-net section modulus of weld of column face and beam of reduced zone of RBS section respectively,

$f-$ design value of material strength of steel,

$\gamma_{\mathrm{RE}}-$ seismic adjusting factor for load-load-carrying capacity, 0.9 and 0.75 for connecting weld of column face and beam of reduced zone of RBS section respectively according to reference (CECS159-2004[1], GB50011-2008[6], JGJ99-98[7]).

2) Bending load-carrying capacity of beam-to-column joint and connection under rarely earthquake. In order to make the plastic hinge shifting to RBS zone under rarely earthquake, the follow equation should be check.

$$
M_{1} / \gamma_{\mathrm{RE}}^{\mathrm{w}} \geq\left(\frac{M_{\mathrm{b} 1}}{M_{\mathrm{b} 2}}\right) M_{2} / \gamma_{\mathrm{RE}}
$$

Where

$M_{1}$ - elastic ultimate bending load-carrying capacity of weld, $M_{1}=W_{\mathrm{nx} 1} f_{\mathrm{wy}}$,

$M_{2}$ - elastic ultimate bending load-carrying capacity of reduced zone of beam, $M_{2}=W_{\mathrm{nx} 2} f_{\mathrm{y}}$,

$\gamma_{\mathrm{RE}}, \gamma_{\mathrm{wRE}}-$ seismic adjusting factor for load-load-carrying capacity, 0.9 and 0.75 for connecting weld of column face and beam of reduced zone of RBS section respectively according to reference (CECS159-2004[1], GB50011-2008[6], JGJ99-98[7]).

$f_{\mathrm{wy}}, f_{\mathrm{y}}-$ yield strength of weld and steel.

Eq. 2 can be expressed as Eq.2a, 
$M_{1} \geq 1.2\left(\frac{M_{\mathrm{b} 1}}{M_{\mathrm{b} 2}}\right) M_{2}$

The reduced zone of beam shall satisfy the following equation in order to have enough strength reserves,

$\mathrm{M}_{\mathrm{u} 2} \geq 1.2 \mathrm{M}_{\mathrm{p} 2}$

Where

$M_{\mathrm{u} 2}-$ ultimate bending load-carrying capacity of top and bottom flange of reduced zone of beam,

$M_{\mathrm{u} 2}=A_{\mathrm{f}}\left(H_{\mathrm{b}}-t_{\mathrm{bf}}\right) f_{\mathrm{u}}$,

$M_{\mathrm{p} 2}-$ plastic bending load-carrying capacity of reduced zone of beam, $M_{\mathrm{p} 2}=W_{\mathrm{p} 2} f_{\mathrm{y}}$,

$W_{\mathrm{p} 2}-$ plastic section modulus of reduced zone of beam,

$f_{\mathrm{u}}, f_{\mathrm{y}}-$ tensile and yield strength of steel.

According to Eq. 1, 2, and 3, the basic seismic design rule can be seen. Firstly, Eq. 1 makes the connection and reduced zone in elastic stage under frequent earthquake. Secondly, the Eq. 2 can make the plastic hinge shifting away to reduced zone and protect the end of beam. Lastly, the Eq.3 make the reduced zone of beam have some strength reserves, so the building don't collapse under rarely earthquake.

\subsection{Shear Strength}

1) The shear strength of weld connection of section shall be check by the following formula under frequent earthquake:

$$
\tau_{1}=\frac{V_{\mathrm{b}} S_{\mathrm{w} 2}}{I_{\mathrm{wx} 2} t_{\mathrm{w}}} \leq f_{\mathrm{v}}^{\mathrm{w}} / \gamma_{\mathrm{RE}}^{\mathrm{w}}
$$

Where

$V_{\mathrm{b}}$ - shear force of column face;

$I_{\mathrm{w} \times 2}, S_{\mathrm{w} 2}-$ moment of inertia and static moment of gross section;

$f_{\mathrm{vw}}$ - design value of shear strength of weld.

2) The ultimate shear strength of weld connection of section shall be check by the following formula

$$
V_{\mathrm{b}} \leq V_{\mathrm{u}} / \gamma_{\mathrm{RE}}
$$

Where

$V_{\mathrm{b}}-$ design value of shear strength of beam at column face, $V_{\mathrm{b}}=1.1\left(2 M_{\mathrm{p}} / l_{\mathrm{n}}\right)+V_{\mathrm{Gb}}, V_{\mathrm{u}}=0.58 A_{\mathrm{w}} f_{\mathrm{u}}$, $V_{\mathrm{u}}$ - ultimate shear strength of weld, 
$\gamma_{\mathrm{RE}}$ - seismic adjusting factor for load-load-carrying capacity, 0.9 for connecting weld according to reference(CECS159-2004[1], GB50011-2008[6], JGJ99-98[7]),

$M p-$ plastic bending load-carrying capacity of beam at column face, $M_{\mathrm{p}}=W_{\mathrm{p}} f_{\mathrm{y}}$,

$l_{\mathrm{n}}-$ net length of beam;

$V_{\mathrm{Gb}}$ - design shear of beam at column face under the representative value of gravity load,

$f_{\mathrm{u}}-$ tensile strength of steel.

\section{CONCLUSION}

Based on the non-linear finite element models established for concrete-filled steel square tubular column and reduced steel beam with holes in flange or flange and web, considering geometric large deformation and material nonlinear and related Chinese codes, the main conclusions are summarized as follows.

Comparison was made on load-displacement curves, the stress distribution of reduced beams, the ultimate load-carrying capacity, the ductility, and the energy-dissipating ability between suggested RBS section and traditional RBS section. The stiffness and ultimate load-carrying capacity of four kinds of new RBS sections cutting hole in flange or flange and web which are easy to operate and convenient to arrange pipeline are close to traditional RBS, the plastic hinge in the section with reduced beam section can be moved away to the reduced region. So these four kinds of new RBS sections are suggested to use in engineering.

The new suggested RBS section under cyclic loading show plump hysteretic curve, ductility coefficient of story drift is up to 2.68 4, and equivalent viscous damping coefficient is 2.205 2.462. Thus the new RBS sections have excellent Seismic performance.

Seismic design method of bending loading-carrying capacity and shear strength of suggested RBS section is proposed according to related Chinese codes.

\section{REFERENCES}

[1] CECS159-2004. "Technical Specification for Structures with Concrete-filled Rectangular Steel Tube Members", China Architecture and Building Press, 2004. (in Chinese)

[2] Cai, Y.Y., "Beam-to-column Connection of Steel Frame Considering Shift-away of Plastic Hinge", Building Structure, 2004, Vol. 34, No. 2, pp. 3-9. (in Chinese)

[3] Ru, J.P., Yang, L., Yang, Q.S., "A Review on the Seismic Performance of Steel Moment Connections with Reduced Beam Sections", Engineering Mechanics. 2004, Vol.21, No. 1, pp. 61-66. (in Chinese)

[4] FEMA-350. "Recommended Seismic Design Criteria for New Steel Moment-frame Buildings", the SAC Joint Venture for the Federal Emergency Management Agency, Washington. D.C.(2000).

[5] Liu, Y., "Seismic Behavior of Reduced Steel Beam in Web under Cyclic Loading", Xi'an University of Technology and Architecture, China, 2005. (in Chinese)

[6] GB50011-2008, "Code for Seismic Design of Buildings", China Architecture and Building Press, 2008. (in Chinese)

[7] JGJ99-98, "Technical Specification for Steel Structure of Tall Buildings", China Architecture and Building Press, 1998. (in Chinese)

[8] Guo, Y.L., "Selection and Design of Concrete-filled Steel Square Tubular Column and Steel Beam Section", Chang'an university, China, 2006. (in Chinese) 
[9] Zhou, T.H., "Experimental Studies on Seismic Behavior of Concrete-filled Steel Square Tubular Column and Steel Beam Section", Xi'an University of Technology and Architecture, China, 2004. (in Chinese)

[10] Zhou, T.H., He, B.K., Chen, G.J., et al, "Experimental Studies on Seismic Behavior of Concrete-filled Steel Square Tubular Column and Steel Beam Section under Cyclic Loading”, Journal of Building Structures, 2005, Vol. 25, No. 3, pp. 9-16. (in Chinese)

[11] Zhou, T.H., Guo, Y.L., Lu, L.F. et al, "Nonlinear FEM Analysis of Load-carrying Capacity Behavior of Concrete-filled Square Tubular Column and Steel Beam Section", 2005, Vol. 25, No. 3, pp. 283-287, 316. (in Chinese) 


\title{
HYSTERETIC BEHAVIOR OF SHEAR PANEL DAMPERS UNDER HIGH AXIAL COMPRESSION LOADING
}

\author{
Zhiyi Chen ${ }^{1, *, 2,3}$, Guoqiang Bian $^{3}$ and Yu Huang ${ }^{3,4}$ \\ ${ }^{I}$ Associate Professor, Key Laboratory of Geotechnical and Underground Engineering of \\ the Ministry of Education, Tongji University, Shanghai 200092, China \\ ${ }^{2}$ State Key Laboratory of Geo-Hazard Prevention and Geo-Environment Protection, \\ Chengdu University of Technology, Chengdu 610059, China \\ ${ }^{3}$ Department of Geotechnical Engineering, Tongji University, Shanghai 200092, China \\ ${ }^{4}$ Professor, Key Laboratory of Geotechnical and Underground Engineering of the Ministry of Education, \\ Tongji University, Shanghai 200092, China \\ *(Corresponding author: E-mail: zhiyichen@tongji.edu.cn)
}

Received: 30 October 2011; Revised: 31 March 2012; Accepted: 12 April 2012

\begin{abstract}
This paper aims to investigate the hysteretic behavior of shear panel dampers (SPDs) made of mild steel Q235B incorporated in underground structures against earthquakes. Five SPDs were given cyclic shear loading tests, with the axial compression ratio and the web slenderness as test variables. The shear bearing capacity and the ductility decreased continually with increasing axial compression ratio. When the axial compression ratio exceeded 0.6 , the hysteretic behavior was seriously affected. Cumulative energy dissipated by the test specimen with an axial compression ratio of 0.7 was only half that of the one with a ratio of 0.3 . The control group (the SPD without the web) was set to estimate the horizontal resistance of upper and lower flanges that were mostly induced by flexure. The contribution of two flanges in resisting the shear deformation was about $15 \%$.
\end{abstract}

Keywords: Shear panel dampers, Axial compression ratio, Hysteretic behavior, Energy dissipation, Underground structures

\section{INTRODUCTION}

The seismic response and disaster mechanism of underground structures have received increasing attention in theory, numerical simulation and model testing during strong earthquakes. However, studies have failed to involve direct measures or the principle method of seismic damage mitigation for underground structures. For underground structures with large span or complex style, dynamic effects emerge inspired by seismic environment due to its larger scale and fewer soil constraints. Traditional static simplified methods cannot meet requirements for the analysis and design of large span underground structures because dynamic characteristics caused by ground deformation must be considered during an earthquake. Traditional seismic methods, such as increasing section area and reinforcement ratio, will increase the rigidity of underground structures and enhance their internal forces. Meanwhile, such a partial reinforcement approach cannot make a good match to the stiffness and ductility, and will easily lead to stiffness mutation, local stress concentration and weak regional metastasis, which cannot improve the seismic performance of the whole structure.

As a passive control method of structural seismic control, structural seismic energy dissipation technology has had great development and wide application. This technology sets up energy dissipation devices in parts of a structure. The friction and deformation of the device's material reduces the seismic response of the main structure and avoids its damage or collapse. A shear panel damper (SPD) is a passive control device that uses the shear hysteresis of the metal plate as the source of energy dissipation. Such dampers are known to enter the plastic state before the main structure and possess energy dissipation capacity, which makes them cost-effective in ground buildings and bridges. When Nakashima used low-yield steel as a damper material, a test indicated that the SPD had excellent hysteretic behavior and strain-hardening was very conspicuous under cycles with increasing deformation [1,2]. Nakashima also proposed simple models that could 
simulate the hysteretic behavior of shear panels [3]. The results of an SPD frame-structure test done by Chen and Kuo [4] showed that SPDs could effectively dissipate seismic energy during an earthquake and control the main frame structure in the elastic range. Chen et al. [5] studied seismic energy absorption effects of SPDs in a steel bridge structure using numerical simulation. The results showed that the top displacement of bridge piers was reduced to $1 / 2 \sim 1 / 4$, and the effective strain ratio of the bottom of the pier dropped to 0.9 to 3.3 from 23 , which was compared with the structure without dampers.

For the ground structure, shear panel dampers mainly resist lateral earthquake loading, which passes only a little vertical force from the beam to the damper. In designing hysteretic tests of shear panel dampers, vertical axial force is often ignored, and only horizontal shear cyclic loading is applied. However for shear panel dampers to be used in underground structures, it is different. Figure 1(a) illustrates an SPD being replaced in the central column of an underground subway station. As shown in Figure 1(b), the underground structure is racking under horizontal earthquake loading. The SPD deforms in shear and dissipates seismic energy through metal plasticity, being similar to be in the ground structure. However, the failure modes of the central columns in the Daikai subway station, which was a famous and well-documented case for underground structures damaged and collapsed during the 1995 Kobe earthquake, suggested that their collapse was mainly due to overburdened soil and earthquake-induced acceleration. Existing experimental research indicates that a high axial compression ratio decreased the drift capacity of the RC column [6,7]. The soil-structure FEM analysis [7] showed a variation between approximately 1800 and $4800 \mathrm{kN}$ axial load induced in the central column, which were about as high as $30 \%$ and $69 \%$ of the designed axial strength capacity of the central column $(7000 \mathrm{kN})$. Therefore even if post-installation method is used to minimize potential axial compression in SPD, the large axial forces cannot be avoided during application. Recent research [8] on shear beam links (its configuration is somewhat like two or three side-by-side SPDs) in eccentrically braced frames revealed that axial forces would affect the overstrength, result in early flange yielding accompanied with web yielding. Consequently the effect of a high axial compression ratio should be fully accounted for.

$$
\text { Ground surface }
$$

(a)
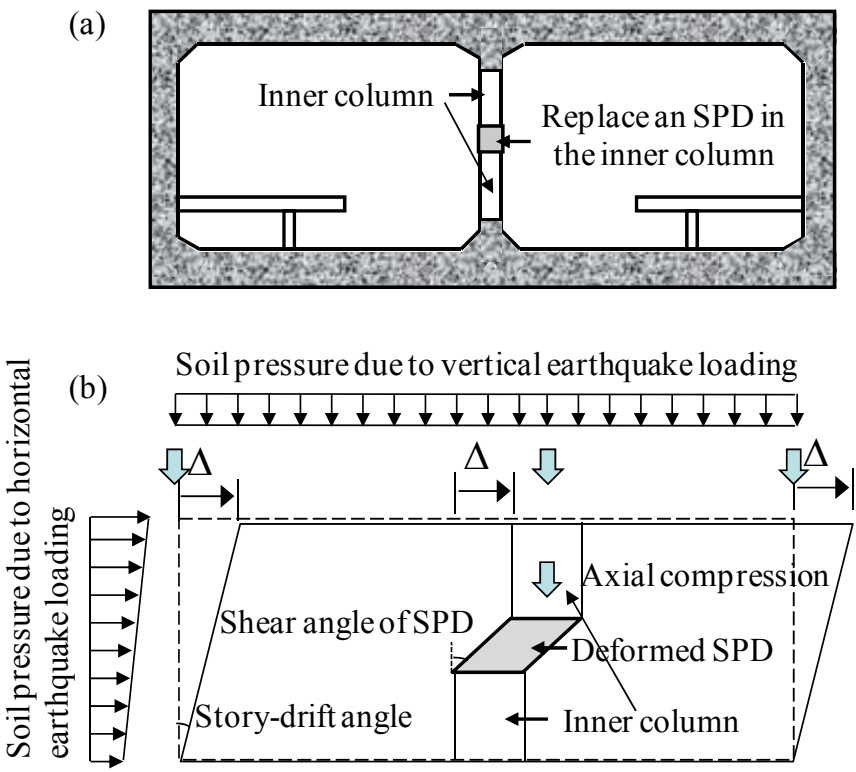

Figure 1. Schematic Design of a Shear Panel Damper in Underground Structures 
In view of this, a series of cyclic shear tests was conducted on SPDs with different axial compression ratios. The main purpose was to quantify their significant hysteretic behavior and energy dissipation capacity, because such quantification is of great importance in estimating seismic damage mitigation by hysteretic dampers.

\section{TEST PROGRAM}

\subsection{Test Specimens}

The SPD specimens are shown in Figure 2. Each specimen consists of a web (shear panel), two flanges, stiffeners and two loading plates, which are made of mild steel Q235B. The clear dimension of each panel is $400 \mathrm{~mm}(\mathrm{~W}) \times 400 \mathrm{~mm}(\mathrm{H})$, and the thicknesses are $5 \mathrm{~mm}$ and $6 \mathrm{~mm}$. Vertical flange thicknesses were $18 \mathrm{~mm}$ and $24 \mathrm{~mm}$, respectively, and the width was $120 \mathrm{~mm}$. The loading plates were $450 \mathrm{~mm} \times 400 \mathrm{~mm}$ (upper) and $880 \mathrm{~mm} \times 400 \mathrm{~mm}$ (lower) respectively, and their thickness was $20 \mathrm{~mm}$. Stiffeners were $40 \mathrm{~mm}$ in width and $6 \mathrm{~mm}$ in thickness. The panel was fillet-welded all around to the flanges and loading plates.

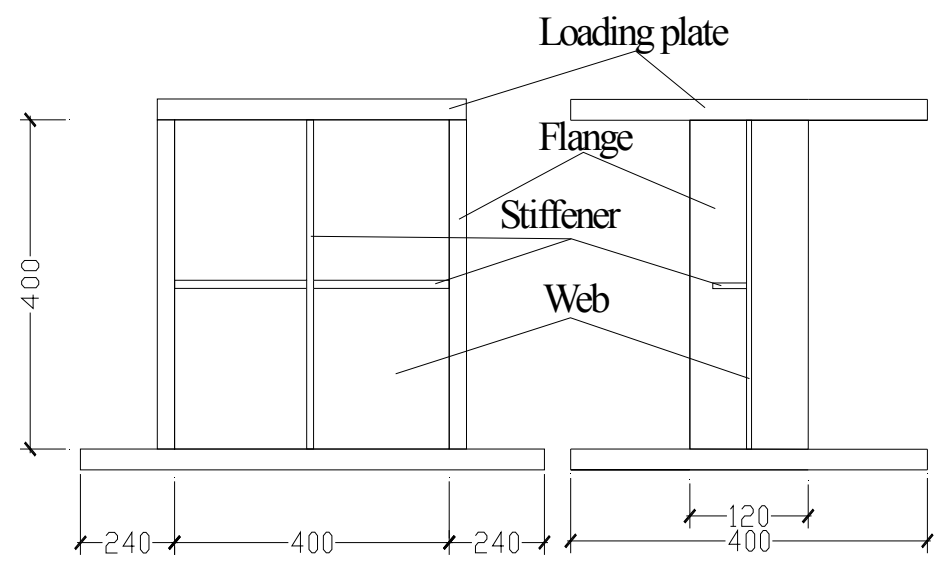

Figure 2. Dimensions of Test Specimen (Unit: mm)

Mild steel Q235B is used as the material of a stiffened SPD. An SPD is characterized by the web slenderness parameter, $R_{w}$, defined as [9]

$R_{w}=\frac{B_{w}}{T_{w}} \sqrt{\frac{12\left(1-v^{2}\right) \tau_{y}}{k_{s} \pi^{2} E}}$

where $B_{w}$ and $T_{w}=$ width and thickness of web respectively, $v=$ Poisson's ratio, $\tau_{y}=$ shear yield of web material, $E=$ Young's modulus of elasticity, and $k_{s}=$ elastic buckling coefficient of a simply-supported plate under shear.

A total of six specimens were tested. These included SPDs (Rw04-z05, Rw03-z03, Rw03-z05, Rw03-z06, Rw03-z07) and the control specimen (Flange). The specimen parameters are shown in Table 1. The meaning of the specimen name, for instance Rw03-z03, is $R_{w}=0.3$ and axial compression ratio $=0.3$. The control specimen "Flange" had only surrounding members, namely, flanges and loading plates without the web and the stiffeners. 
Table 1. Summary of Test Specimens

\begin{tabular}{|c|c|c|c|c|c|c|c|c|c|c|}
\hline$z$ & Specimen & $R_{w}$ & $B_{w}(\mathrm{~mm})$ & $T_{w}(\mathrm{~mm})$ & $T_{f}(\mathrm{~mm})$ & $B_{f}(\mathrm{~mm})$ & $T_{s}(\mathrm{~mm})$ & $B_{s}(\mathrm{~mm})$ & $A\left(\mathrm{~mm}^{2}\right)$ & $P(\mathrm{kN})$ \\
\hline 0.7 & Rw03-z07 & 0.3 & 400 & 6 & 24 & 120 & 6 & 40 & 8400 & 1381.8 \\
\hline 0.6 & Rw03-z06 & 0.3 & 400 & 6 & 24 & 120 & 6 & 40 & 8400 & 1185 \\
\hline \multirow{3}{*}{0.5} & Rw04-z05 & 0.4 & 400 & 5 & 18 & 120 & 6 & 40 & 6560 & 770.8 \\
\hline & & & & & & & & & & \\
\hline & Rw03-z05 & 0.3 & 400 & 6 & 24 & 120 & 6 & 40 & 8400 & 987 \\
\hline 0.3 & Rw03-z03 & 0.3 & 400 & 6 & 24 & 120 & 6 & 40 & 8400 & 600 \\
\hline 0.0 & Flange & 0.3 & - & - & 24 & 120 & - & - & - & 0 \\
\hline
\end{tabular}

Previous researches $[9,10,11]$ have shown that the suitable range of web slenderness parameter $R_{w}$ is $0.2-0.5$ for shear panel dampers. Of these, the values of 0.3 and 0.4 are more flexible for practical design purposes. Therefore, the web slenderness parameter $R_{w}$ was taken as 0.3 and 0.4 in the present experiment. The axial compression ratio was set as the most important parameter to study the hysteretic behavior of SPDs under high axial compression. To find the critical axial compression ratio, a series of axial compression ratios $(0.3,0.4,0.5,0.6$ and 0.7$)$ was set. The axial compression ratio is defined as the ratio of axial force to yield axial force of the SPD. In addition, a control specimen was set up to understand the effect of flanges of an SPD on the shear bearing capacity and energy dissipation performance.

The photos of typical SPD and "Flange" specimens are shown in Figure 3 and Figure 4, respectively.

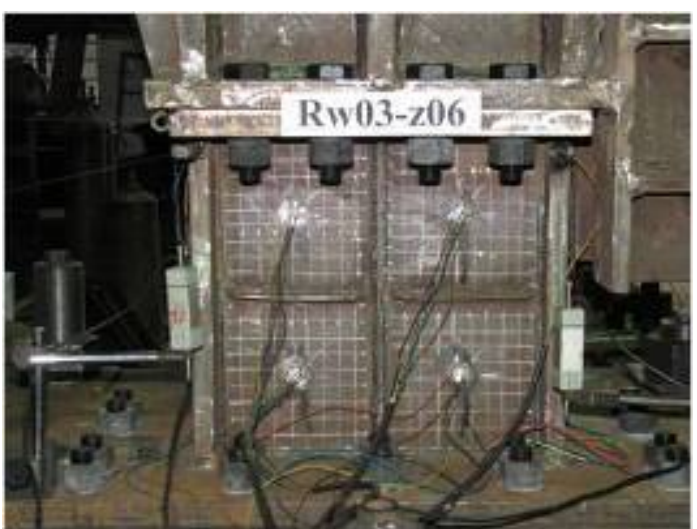

Figure 3. Stiffened Shear Panel Dampers

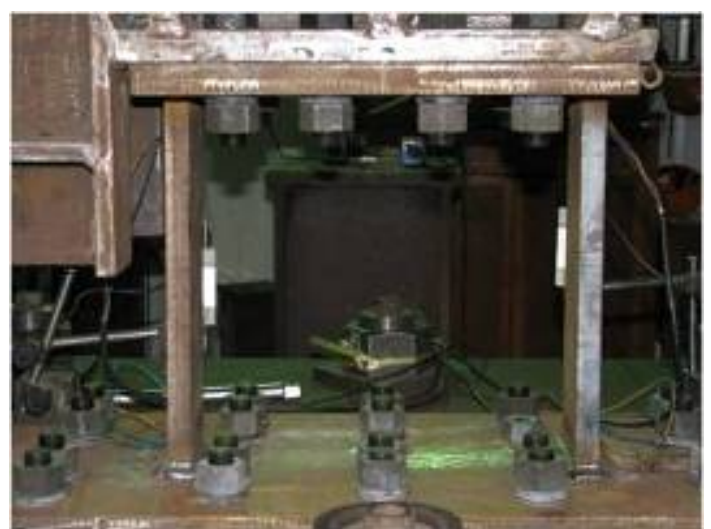

Figure 4. Control Specimen (Flange)

\section{$2.2 \quad$ Test Setup}

Figure 5 shows the loading setup employed in the test. A $10,000 \mathrm{kN}$ multi-functional structure testing machine in Tongji University was used which can apply force and displacement loading by the horizontal and vertical actuators simultaneously. Labels 1, 2, 3 and 4 are loading head, lateral connection, base, and test specimen, respectively. The loading head transfers the axial loading and 
cyclic shear loading to the test specimen; the lateral connection is used to connect the horizontal actuator and the loading head; the base is used to fix the test specimen with anchor bolts.

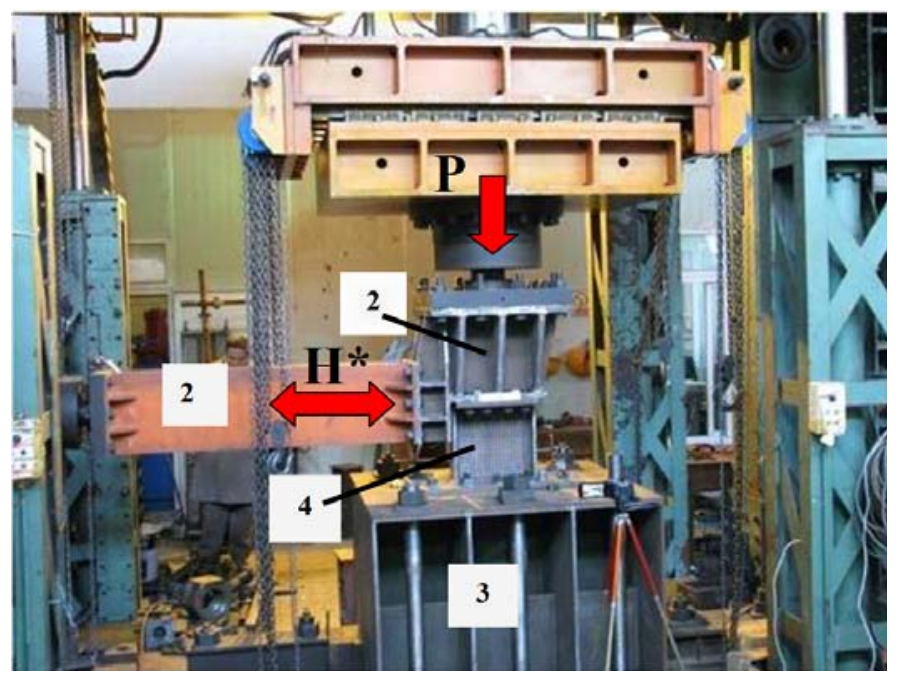

Figure 5. Loading Setup in Test

\subsection{Loading Program and Measurement}

The test machine had four actuators: the vertical main actuator, the first-level actuator, the second-level actuator, and the supporting vertical actuator. The displacement and force of the four actuators was monitored by digital displacement and force transducers. The axial loading was applied by the vertical main actuator, and the horizontal loading was applied by the second-level actuator. The maximum horizontal thrust was 150 tons, the maximum horizontal pull was 100 tons, and the maximum stroke of the actuator was $\pm 400 \mathrm{~mm}$.

The axial force was loaded onto each specimen listed in Table 1, and then the horizontal cyclic shear loading was applied to the specimen by controlling the displacement at the top relative to its bottom. The value of the horizontal cyclic shear loading, as denoted by $H^{*}$ in Figure 5, was monitored by the load cell attached to the second-level actuator of the test machine.

Displacement transducers and strain gauges were arranged as shown in Figures 6 and 7. The horizontal displacement at the top of the specimen relative to its bottom was measured by a digital displacement transducer (1). A pair of displacement transducers (2 and 3) was used to measure the vertical displacement at the top of the specimen relative to its bottom. Four triaxial strain gauges were glued at the center of each subpanel which was divided by transverse and longitudinal stiffeners, and eight uniaxial gauges were pasted on the surfaces of the flanges, with four gauges on the exterior surface of each flange.

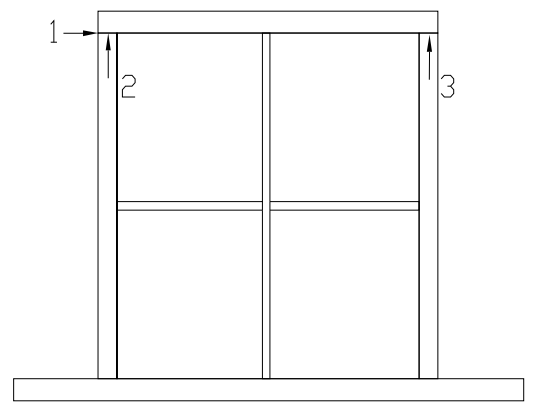

Figure 6. Arrangement of Displacement Transducers 

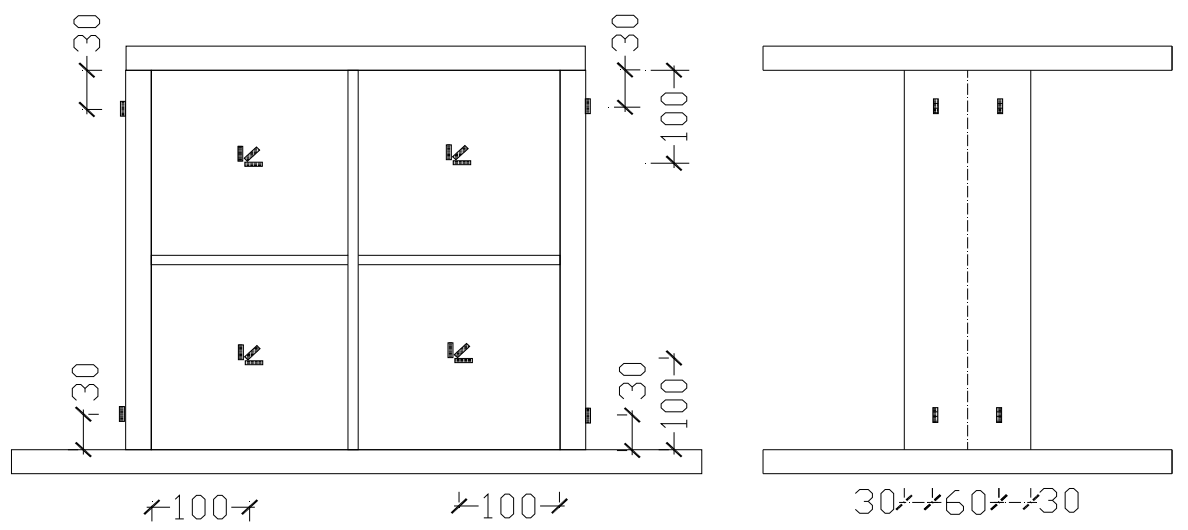

(Unitし mm)

Figure 7. Arrangement of Strain Gauges

\section{TEST PROCESS AND RESULTS}

\subsection{Material Properties}

The results of material tension tests on Q235B mild steel (6 $\mathrm{mm}$ and $24 \mathrm{~mm}$ in thickness), which were used for SPDs in the test, are summarized in Table 2. The yield stress and ultimate stress of the $6 \mathrm{~mm}$ thick plate is about $10 \%$ larger than those of the $24 \mathrm{~mm}$ thick plate.

Table 2. Material Properties

\begin{tabular}{cccccc}
\hline Material & Thickness & $\begin{array}{c}\text { Yield } \\
\text { stress } \\
(\mathrm{MPa})\end{array}$ & $\begin{array}{c}\text { Ultimate } \\
\text { stress } \\
(\mathrm{MPa})\end{array}$ & $\begin{array}{c}\text { Rupture } \\
\text { strain } \\
(\%)\end{array}$ & $\begin{array}{c}\text { Young's } \\
\text { modulus } \\
(\mathrm{GPa})\end{array}$ \\
\hline Q235B & 6.0 & 265.1 & 400.8 & 44.0 & 195.6 \\
Q235B & 24.0 & 239.3 & 360.1 & 43.1 & 202.9 \\
\hline
\end{tabular}

\subsection{Test Process and Test Phenomenon}

The typical damage process in cyclic shear loading can be described as follows: the start of loading, initial web buckling, obvious web buckling, tiny cracks, cracks developing and finally the web failure. The typical failure trend is shown in Figure 8.

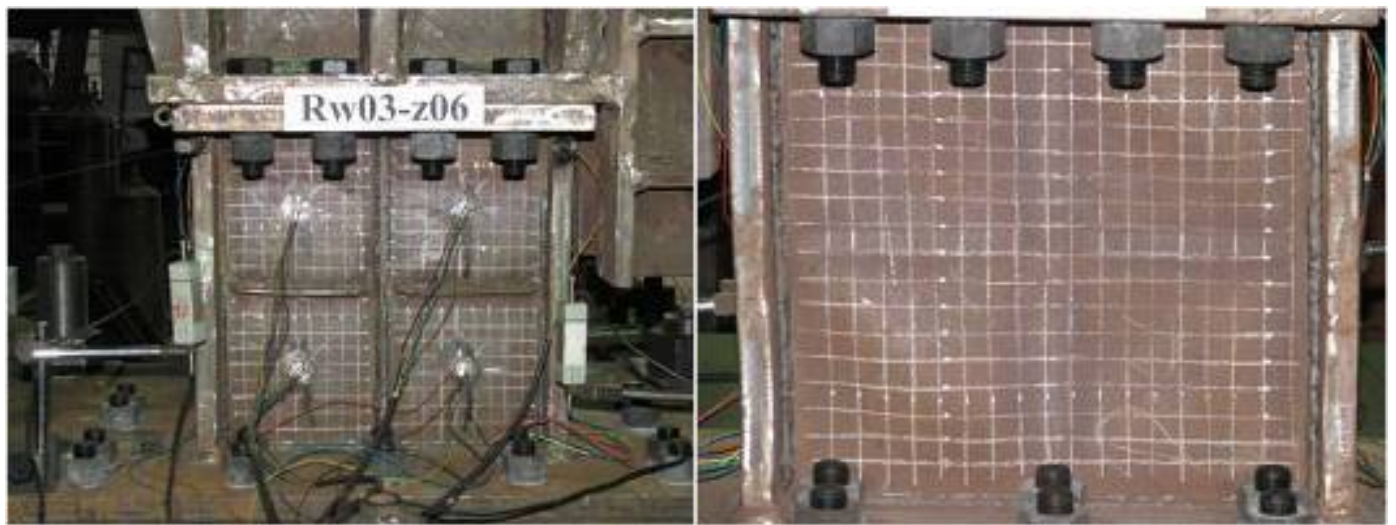

(a) Starting (b) Initial Web Buckling 


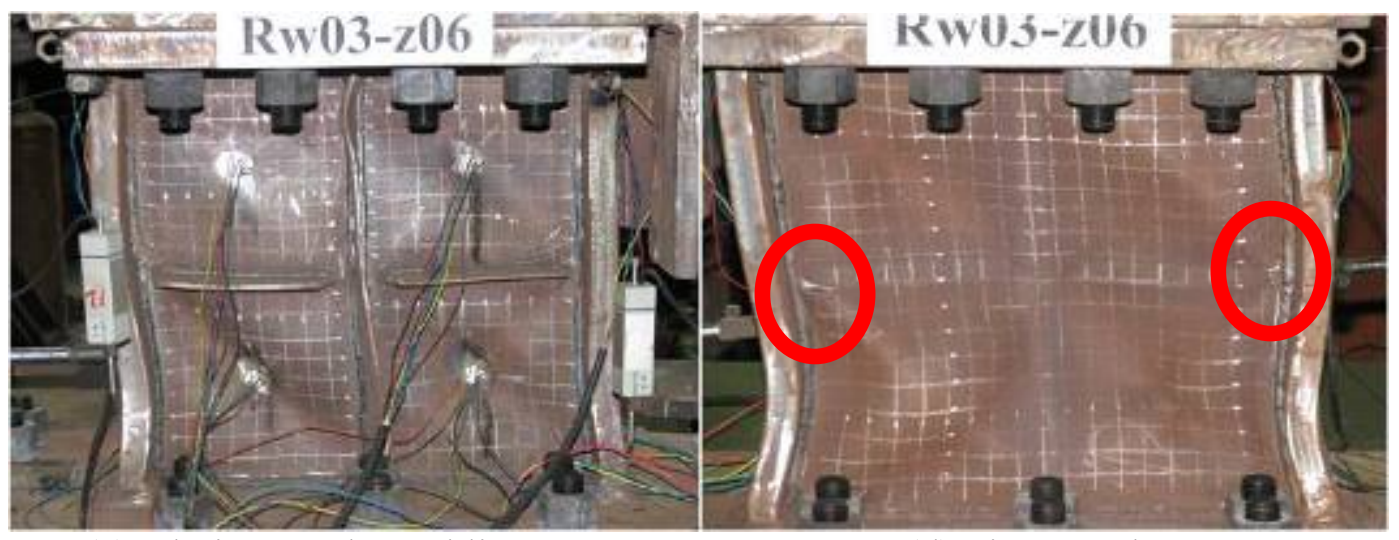

(c) Obvious Web Buckling

(d) Tiny Cracks

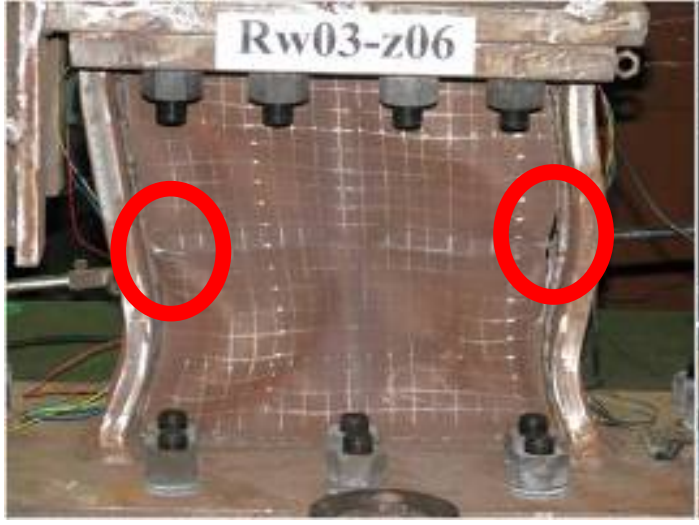

(e) Cracks Developing

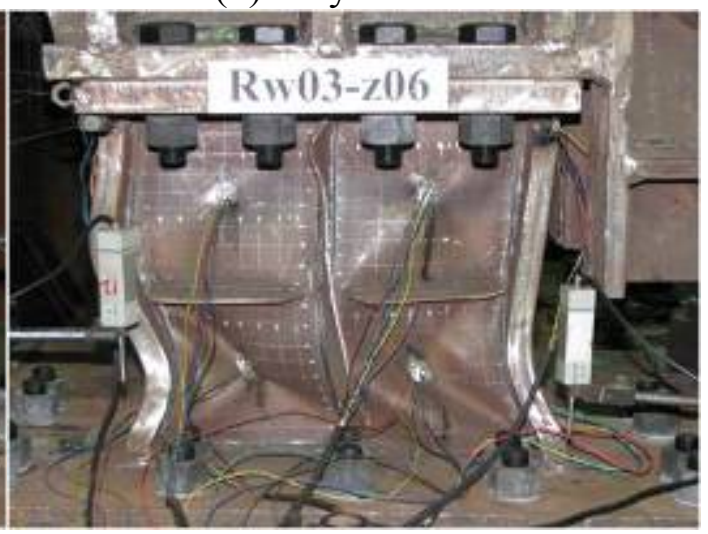

(f) Failure of Test Specimen

Figure 8. Damage Process of SPD under Cyclic Shear Loading

Shear strength increased steadily with increasing shear angle, and reached its peak when obvious web buckling occurred. After keeping smooth for several further loading cycles, shear strength began to decrease as tiny cracks appeared. Soon cracks began to expand and the number of cracks increased, and shear strength quickly degraded. After the web of the SPD was destroyed, flanges could sustain some shear force, but the shear strength quickly degenerated to zero under high axial compression ratio.

The cracks appeared mainly in welded zones between the web, flange and stiffener and local zones with large out-of-plane deformation. The damage details are shown in Figure 9.

\subsection{Horizontal Force versus Shear Angle Relationships}

Hysteretic behavior is of the utmost importance in evaluating the performance of SPDs as energy dissipation devices. The horizontal displacement at the top of the specimen relative to its bottom was measured by digital displacement transducer 1 (see Figure 6). The horizontal force, $H^{*}$, was monitored by the load cell attached to the horizontal actuator (the second-level actuator of the test machine in Figure 5). $H_{y}$ is the yield shear force, = given as the product of the horizontal cross-sectional area of the SPD not including the cross-sectional areas of flanges $\left(B_{w}\right.$ and $T_{w}$ are shown in Table 1$)$, and the yield stress $(265.1 \mathrm{MPa})$ divided by $\sqrt{3}$. The vertical displacement of the two flanges of each specimen, which was measured by transducers 2 and 3 (Figure 6) remained nearly zero before the failure of the test specimen. As a result, the shear angle, $\gamma$, can be calculated by the horizontal displacement $\triangle$ divided by the height of the specimen $(0.4 \mathrm{~m})$. 


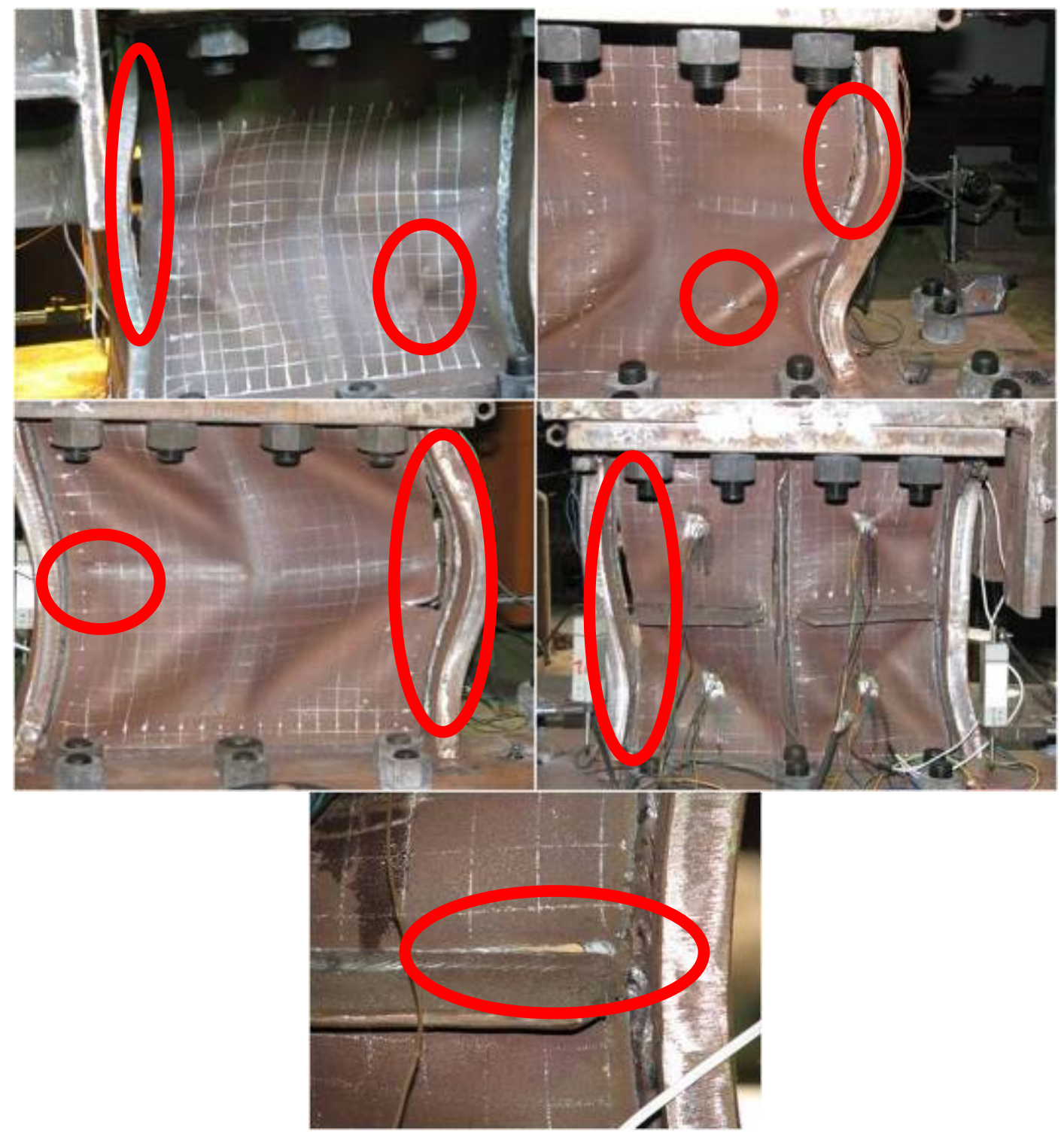

Figure 9. Crack Details

Figure 10 shows the relationship between the normalized horizontal force $\left(H^{*} / H_{y}\right)$ and the shear angle $\gamma$ obtained from the cyclic shear loading test. Yielding can be defined as an apparent departure from the initial linear relationship. It started at a normalized horizontal force of 1.25 (Rw04-z05), 1.21 (Rw03-z03), 1.16 (Rw03-z05), 1.12 (Rw03-z06), 1.01 (Rw03-z07). Comparing the test specimens Rw03-z03, Rw03-z05, Rw03-z06 and Rw03-z07 shows that the normalized horizontal force continually decreased with the increasing axial compression ratio, especially for the high axial compression ratio of 0.7 . The horizontal force increased steadily after yielding and reached 1.83 (Rw04-z05), 1.68 (Rw03-z03), 1.70 (Rw03-z05), 1.74 (Rw03-z06), and 1.66 (Rw03-z07) at the shear range of 0.02 . The influence on SPD shear capacity was very little when the shear angle was less than 0.02 . With the increasing shear angle, obvious strain hardening was observed with the hysteresis curve in Figure 10, and the maximum normalized horizontal forces were 2.18 (at a shear angle of 0.04 for Rw04-z05), 1.89 (at a shear angle of 0.04 for Rw03-z03), 1.79 (at a shear angle of 0.034 for Rw03-z05), 1.75 (at a shear angle of 0.027 for Rw03-z06), 1.67 (at a shear angle of 0.017 ), 0.25 (at a shear angle of 0.08 for Flange). 


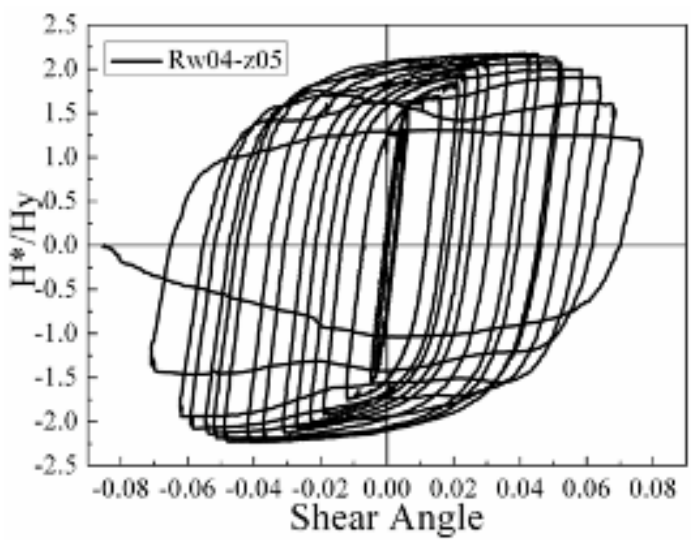

(a)

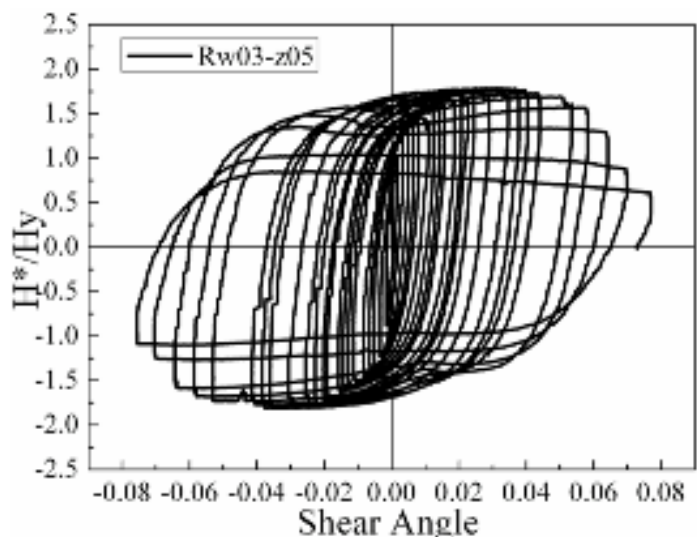

(c)

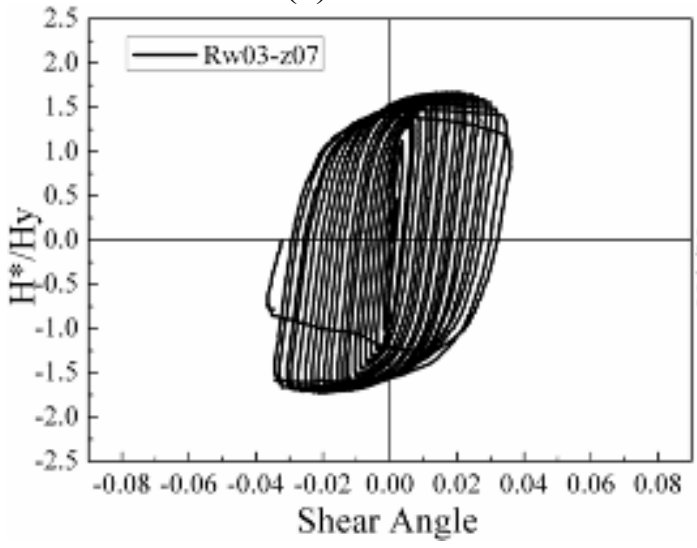

(e)

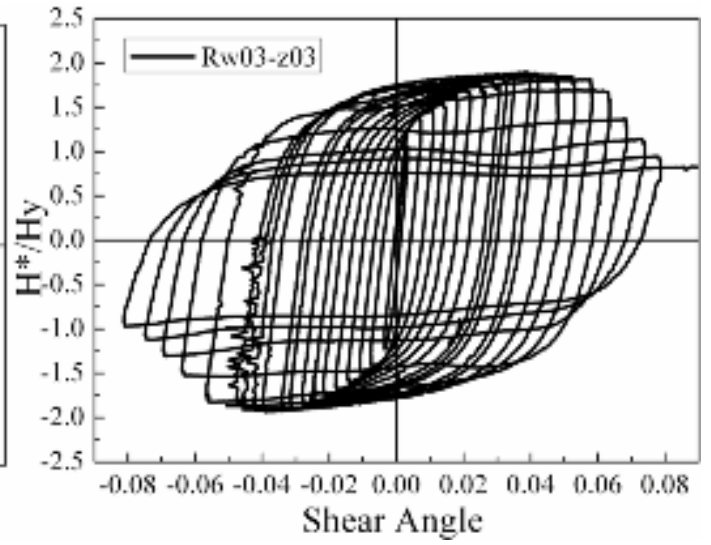

(b)

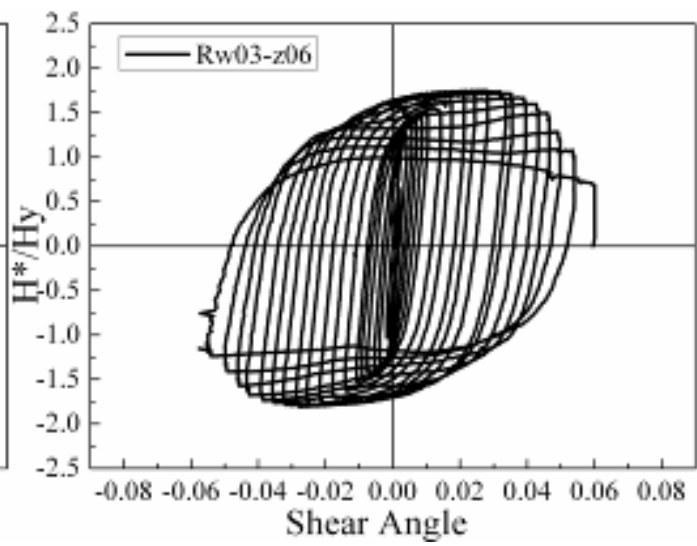

(d)

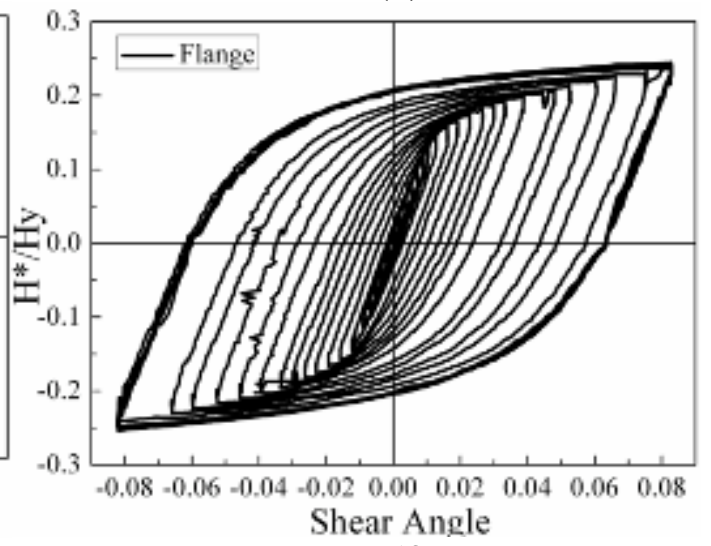

(f)

Figure 10. Horizontal Force Versus Shear Angle

It should be noted that Figure 10(f) presents the horizontal force versus shear angle relationship for the control specimen Flange (Figure 4). Here, $H^{*}$ is obtained in the same way of other specimens. To be consistent with the other plots in Figure 10, $H^{*}$ of the Flange is also normalized by divided by $H_{y}$. Here, $H_{y}$ is the yield shear force of Rw03 series of specimens $(=265.1 * 400 * 6=636.2 \mathrm{kN})$. Comparing the hysteresis curves between Flange and SPDs, it is clear that the frame-type specimen Flange opposes excellent ductility. The Flange is not only being the fix boundary of the web, but also contributes to the total horizontal resistance force. Take Rw03-z05 as an example. At a shear angle of 0.0355 , the peak $H^{*} / H_{y}$ value of Rw03-z05 is 1.53 . While the specimen Flange is about 0.18 at a shear angle of 0.0334 . Then, it might be roughly estimated that the shear force component resisted by flanges is about $11 \%$ of the total shear of an SPD. The contribution of flanges may reach more than this value, considering the interaction effect between the web and flanges. The 
conclusion is identical to the numerical results of Reference [9]. In their numerical analysis, the shear forces resisted by the flanges and the web were obtained separately. The shear force resisted by flanges was then about $13-20 \%$ of the total shear strength.

\subsection{Shear Force versus Shear Angle Relationship}

As shown in Figure 10, the normalized horizontal force was larger for a specimen with a smaller web thickness. This was due to the difference in the contribution of the flanges to the shear capacity among specimens with different web thickness. As discussed above, the flanges have a certain contribution to the total horizontal force. So the horizontal force sustained by the flanges must be subtracted if further understanding of the web shear capacity is needed. Figure 11 shows the relationship between normalized shear force $\left(H / H_{y}\right)$ versus shear angle, in which $H$ represents the shear force sustained only by the web. Since shear force sustained by the web or by the flanges cannot be measured separately from experiments, the shear force $H$ is given as the horizontal force $H^{*}$ subtracted by the resistance of the specimen Flange. This calculation method overestimates evidently the shear force of the web because it does not take account of the interaction between the web and the flanges. In addition, it should be noted that the two flanges for Specimen Rw04-z05 is $18 \mathrm{~mm}$ thick, not $24 \mathrm{~mm}$ as the Specimen Flange. Hence, the shear bearing force of $18 \mathrm{~mm}$-thick flange is firstly converted from $24 \mathrm{~mm}$-thick flange, according to the principle of equivalent area. Then the shear force $H$ sustained by the web of Rw04-z05 is calculated by subtracting the equivalent value from experimental results, $H^{*}$, of Rw04-z05.

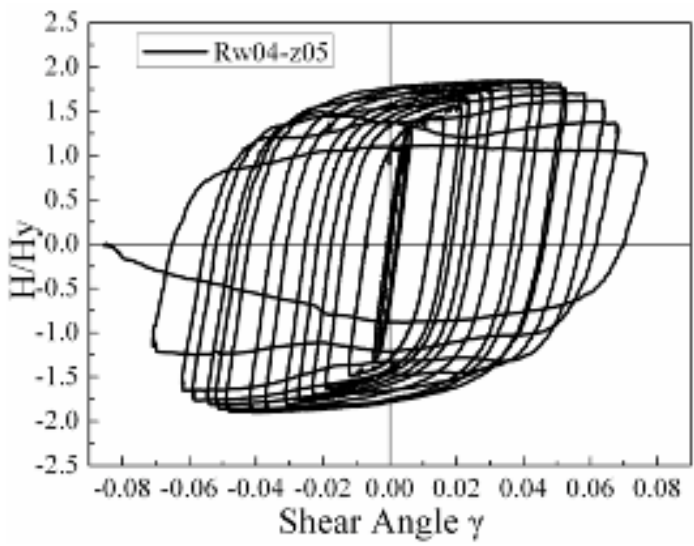

(a)

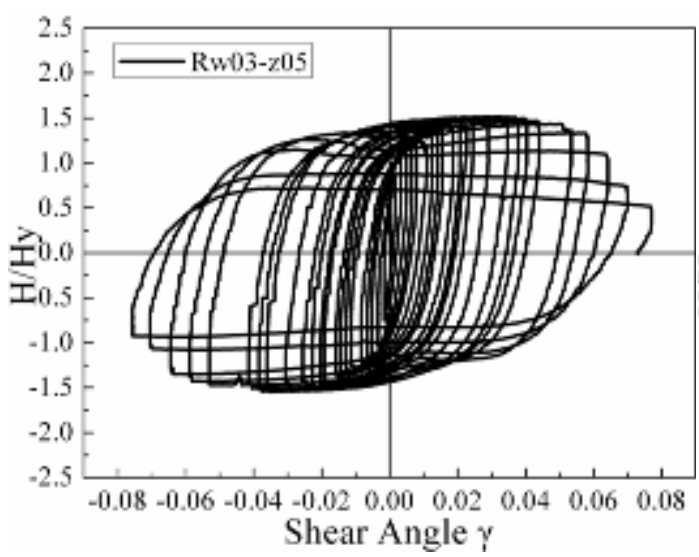

(c)

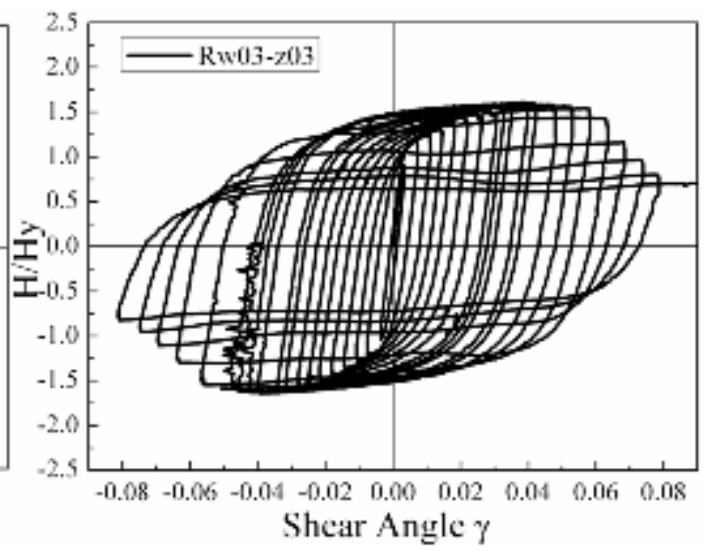

(b)

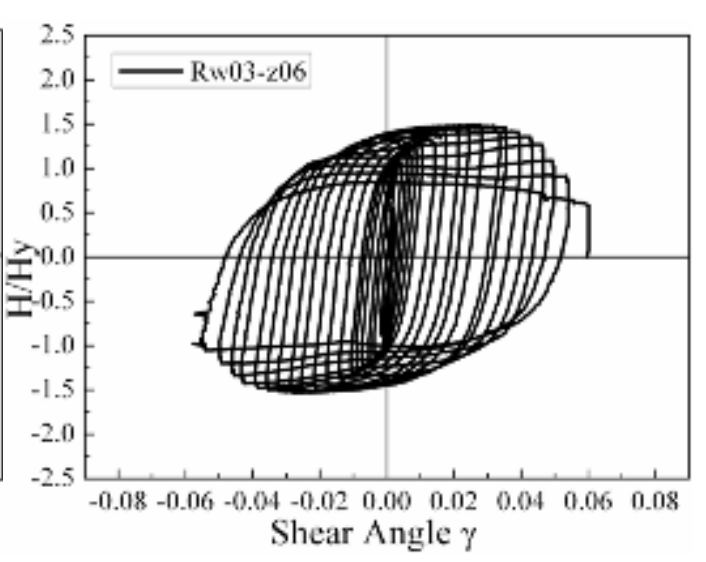

(d) 


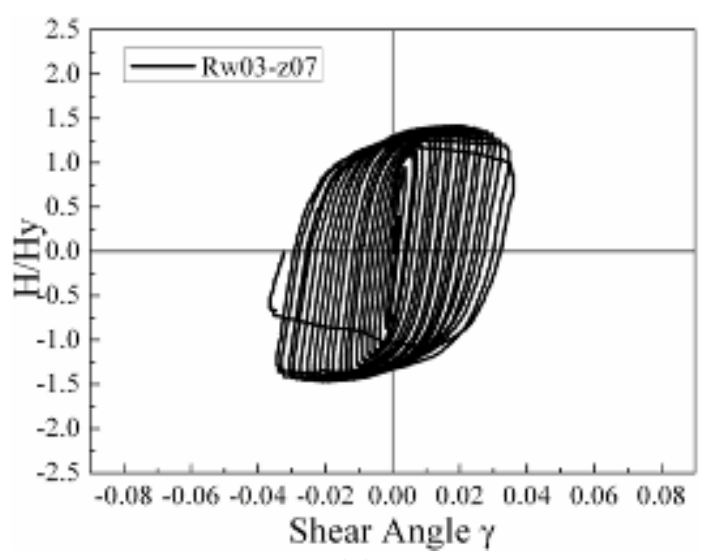

(e)

Figure 11. Shear Force Versus Shear Angle

To vividly describe the information included in the hysteresis curves, the envelopes of the curves are redrawn as shown in Figure 12. The envelope is obtained by plotting the peak shear angle of each cycle along with the corresponding normalized shear forces averaged from positive and negative loading sides. Discussions about the figures will be presented in the following section.

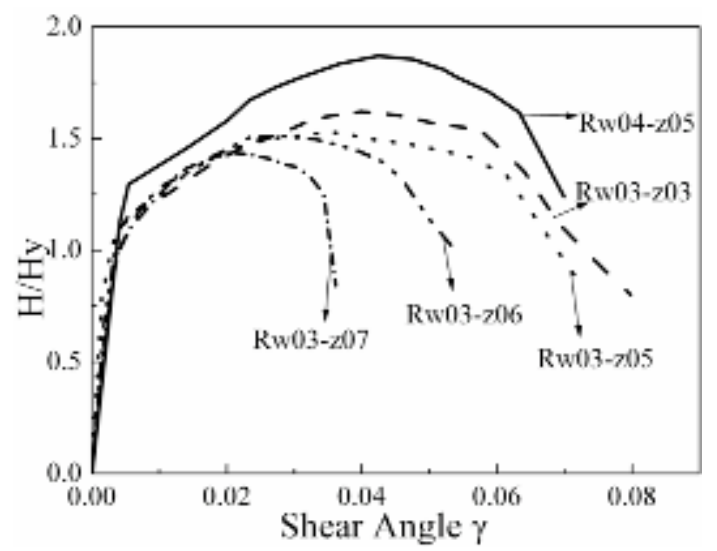

Figure 12. Envelopes of Shear Force Versus Shear Angle

\section{DISCUSSIONS AND COMMENTARY ON DESIGN}

According to the relationships between shear force and shear angle (Figure 11) and between the shear force envelope and shear angle (Figure 12) obtained from cyclic shear loading tests, some important points are discussed herein. These are: the range of shear deformation demand, the effect of axial compression ratio, web buckling, out-of-plane deformation, strain-hardening and energy dissipation behavior.

\subsection{Range of Shear Deformation Demand}

When evaluating the hysteretic behavior of dampers used as energy dissipation devices for an underground structural system, it is important to specify the range of shear deformation, which would be sustained under design loading. The range of deformation demand is also needed when developing hysteresis models for simulating the hysteresis behavior. Under the code for seismic design of subway structures in Shanghai, China [12], 1/250 is the maximum story-drift angle for moderate earthquakes (peak ground acceleration of $0.1 \mathrm{~g}$ ). As shown in Figure 1, assume inner 
columns are rigid enough (without deformation) and the horizontal deflection is totally absorbed by an SPD. Then the shear deformation demand would be calculated as $0.02(1 / 250 \times 3 / 0.6)$ for an SPD with the height of $0.6 \mathrm{~m}$ in a story which is commonly about $3 \mathrm{~m}$ in height. According to Figures 10 and 11, a shear angle of 0.02 can be reached except for the test specimen Rw03-z07. Its shear capacity began to decline when the shear angle exceeded 0.017.

\subsection{The Effect of Axial Compression Ratio}

Figures 11 and 12 show that all specimens had excellent hysteretic behavior below a certain shear angle. When shear angle was less than 0.02 , the axial compression ratio had little influence on the performance of the damper. When the axial compression ratio was less than or equal to 0.5 , test specimens Rw04-z05, Rw03-z03 and Rw03-z05 revealed good ductility, and the maximum shear angle approached or exceeded 0.07 (more than $40 \gamma_{y}=0.002$ ). With the increasing axial compression ratio, the maximum shear angle was $0.052\left(26 \gamma_{y}\right)$ for Rw03-z06. When the axial pressure ratio reached 0.7, the maximum shear angle rapidly decreased to 0.035 (about 17 $\gamma_{y}$ ). In addition, increasing the axial compression ratio resulted in some decrease of shear capacity for the damper. It can be concluded that the shear panel dampers had good hysteresis performance when the shear angle was less than 0.02 , but that the ductility decreased significantly with an increasing axial compression ratio. Thus it is suggested that the axial compression ratio cannot be greater than 0.6 in the design and application of SPDs. The axial compression ratio of 0.6 can be considered as the critical ratio. When the ratio exceeds this critical value, the axial force will become the dominant factor in energy dissipation of SPDs. During design and application, it is recommended that a post-installation method be used. In this way, columns can withstand a great part of vertical loads while the damper mainly absorbs energy through horizontal shear loading.

\subsection{Web Buckling and Out-of-plane Deformation}

During the tests, initial web buckling was observed at a shear angle of 0.027 (Rw04-z05), 0.028 (Rw03-z03), 0.020 (Rw03-z05), 0.021 (Rw03-z06), and 0.012 (Rw03-z07). Web buckling did not lead to any sharp decrease in bearing capacity or energy dissipation capacity. The shear force continued to increase. Out-of-plane deformation started developing with increasing shear angle, and obvious out-of-plane deformation was observed at a shear angle of $0.045,0.042,0.029,0.028$, and 0.017 for Rw04-z05, Rw03-z03, Rw03-z05, Rw03-z06 and Rw03-z07, respectively. At the time, peak shear force was achieved, and no pinching (reduction in strength in the vicinity of zero displacement [2]) was observed. Subsequently, the shear strength began to decline, which was caused by larger out-of-plane deformation. From observing each specimen, it could be concluded that initial buckling did not have a significant impact on the shear force, and the shear force continued to increase with the development of out-of-plane deformation. When out-of-plane deformation became extremely obvious, the shear force reached its peak. With the increasing axial compression ratio, the shear angle capacity of shear panel dampers was reduced. When the axial load ratio reached 0.7 , the shear angle capacity was less than half that of the ratio of 0.3 . It also indicated that if the axial compression ratio exceeded the critical axial compression ratio of 0.6 , the axial force would become the dominant factor in energy dissipation of shear panel dampers.

\subsection{Crack Influence}

As shown in Figure 9, a crack phenomenon could be observed from the test specimens. Tiny cracks happened in welded zones (between web, flange and stiffener) and local zones with large out-of-plane deformation. These soon developed into long cracks which meant the failure of the SPD. So the SPD should be checked in key positions in the process of using dampers or after an earthquake. 


\subsection{Strain-hardening Behavior}

Figures 11 and 12 show that when the shear angle was less than a certain angle (about 0.02), obvious isotropic hardening behavior was observed. However, this changed to combined isotropic and kinematic hardening behavior at shear angles from 0.02 to 0.04 .

\subsection{Energy Dissipation Capacity}

Energy dissipation capacity is very important in evaluating the performance of SPDs as energy dissipation devices. Here, dissipated energy, $E_{\mathrm{i}}$, is normalized by $E_{\mathrm{e}}$, defined as $H_{y} \triangle_{\mathrm{y}} / 2$. The normalized dissipated energy, $E_{i} / E_{e}$, is calculated for each half-cycle as shown in Figure 13 . The cumulative dissipated energy is defined as the sum of previous dissipated energy, $\Sigma E_{i} / E_{e}$. The cumulative dissipated energy versus cumulative shear angle at each half cycle is shown in Figure 14. It indicates that the maximum cumulative dissipated energy and cumulative shear angle decreased with an increasing axial compression ratio. For axial compression ratios of 0.6 and 0.7 , the maximum cumulative energy was about half that of a ratio of 0.3 . But in the range of the shear deformation demand (with a cumulative shear angle of about 0.4 ), cumulative dissipated energy had little difference among the specimens, as shown in Figure 14(a). Thus, when considering the axial compression ratio, the range of shear deformation demand also should be taken as an important factor in the design of SPDs.

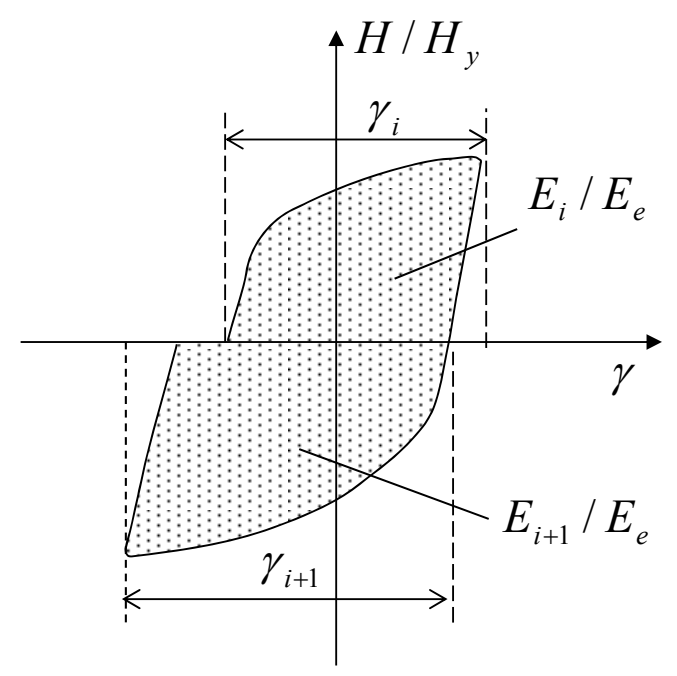

Figure 13. Definition of Dissipated Energy in Each Half Cycle, $E_{i} / E_{e}$

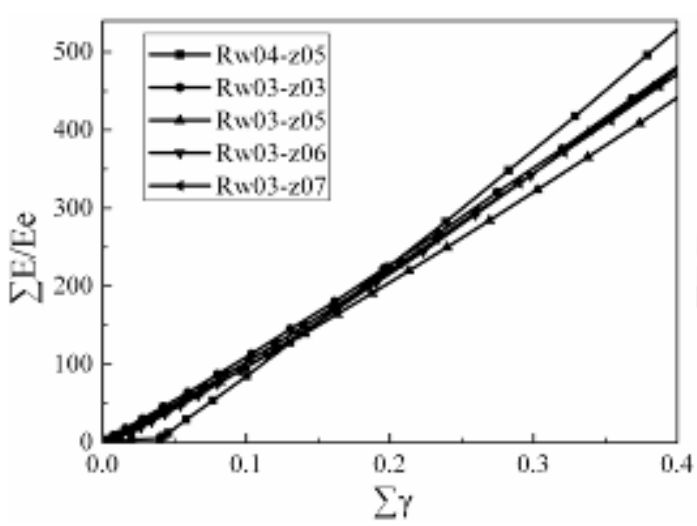

(a)

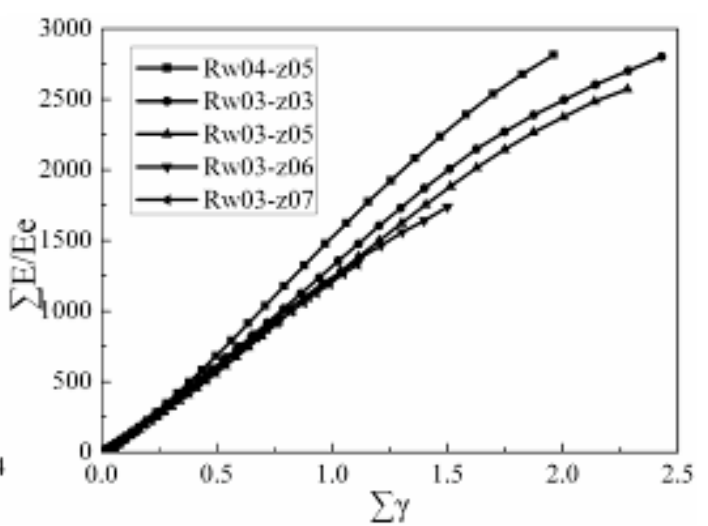

(b)

Figure 14. Cumulative Dissipated Energy versus Cumulative Shear Angle 


\section{CONCLUSIONS}

This paper has presented an experimental study examining the hysteretic behavior of shear panel dampers made of mild steel Q235B. Regarding the axial compression ratio as the most important control parameter, shear capacity, web buckling, hysteretic behavior and energy dissipation behavior were researched. A summary of findings is as follows:

1) With an increasing axial compression ratio, the shear capacity and ductility of SPDs decreased. When the axial compression ratio equals 0.7 , the bearing capacity, ductility and energy dissipation capacity of an SPD decrease sharply. In the case of 0.6, the ductility is slightly affected while its bearing capacity remains stable. So 0.6 can be regarded as the critical axial compression ratio in the design and application of SPDs.

2) From comparisons between SPDs and the control group (Flange), the contribution of flanges of an SPD to resisting shear loading was about $15 \%$.

3) Obvious strain-hardening behavior was observed in the test and no pinching phenomenon occurred in hysteretic curves. With increasing shear angle, isotropic hardening behavior gradually changed to kinematic hardening behavior.

4) When the shear angle is less than 0.02, the shear panel dampers have good hysteresis performance. However, with an increasing axial compression ratio, the ductility and energy dissipation decreased significantly.

\section{ACKNOWLEDGMENTS}

This research was supported by the National Natural Science Foundation of China (Grant No. 50908169), National Basic Research Program of China (973 Program: 2011CB013600), State Key Laboratory of Geo-Hazard Prevention and Geo-Environment Protection (Grant No. SKLGP2011K009), Program for Changjiang Scholars and Innovative Research Team in University (PCSIRT, IRT1029), the Fundamental Research Funds for the Central Universities and the Kwang-Hua Fund for College of Civil Engineering, Tongji University. All supports are gratefully acknowledged.

\section{REFERENCES}

[1] Nakashima, M., Iwai, S., Iwata, M., Takeuchi, T., Konomi, S., Akazawa, T. and Saburi, K., "Energy Dissipation Behavior of Shear Panels Made of Low Yield Steel", Earthquake Engineering and Structural Dynamics, 1994, Vol. 23, No. 12, pp. 1299-1313.

[2] Nakashima, M., "Strain-hardening Behavior of Shear Panels Made of Low-yield Steel.1: Test", Journal of Structural Engineering, 1995, Vol. 121, No. 12, pp. 1742-1749.

[3] Nakashima, M. Akazawa, T. and Tsuji, B., "Strain-hardening Behavior of Shear Panels Made of Low-yield Steel. 2: Model", Journal of Structural Engineering, 1995, Vol. 121, No. 12, pp. 1750- 1757.

[4] Chen, S.J. and Kuo, C.L., "Experimental Study of Vierendeel Frames with LYP Steel Shear Panels", Steel Structures, 2004, Vol. 4, pp. 179-186.

[5] Chen Z.Y., Ge H.B. and Usami T., "Study on Seismic Performance Upgrading for Steel Bridge Structures by Introducing Energy-dissipation Members", Journal of Structural Engineering, JSCE, 2007, Vol. 53, pp. 540-549.

[6] Huo, H., Bobet, A., Fernández, G. and Ramírez, J., "Load Transfer Mechanisms Between Underground Structure and Surrounding Ground: Evaluation of the Failure of the Daikai Station", Journal of Geotechnical and Geoenvironmental Engineering, 2005, Vol. 131, No. 
[7] Gustavo, J.P.M., Bobet, A. and Ramirez, J., "Evaluation of Soil-structure Interaction and Structural Collapse in Daikai Subway Station during Kobe Earthquake", ACI Structural Journal, 2006, Vol. 103, No. 1, pp. 113-122.

[8] Mansour, N., Christopoulos, C. and Tremblay, R., "Experimental Validation of Replaceable Shear Links for Eccentrically Braced Steel Frames", Journal of Structural Engineering, 2011, Vol. 137, No. 10, pp. 1141-1152.

[9] Chen, Z.Y., Ge, H.B. and Usami, T., "Hysteretic Model of Stiffened Shear Panel Dampers", Journal of Structural Engineering, 2006, Vol. 132, No. 3, pp. 478-483.

[10] Chen, Z.Y., Ge, H.B., Kasai, A. and Usami, T., "Simplified Seismic Design Approach for Steel Portal Frame Piers with Hysteretic Dampers”, Earthq. Eng. Struct. Dyn, 2007, Vol. 36, No. 4, pp. 541-562.

[11] Chen, Z.Y., Ge, H.B., Kasai, A. and Usami, T., "Numerical Study on Development of Hysteretic Model for Stiffened Steel Shear Panel Dampers", J. Struct. Eng., JSCE, 2006, Vol. 52, pp. 573-582.

[12] DG/TJ08-2064-2009, “Code for Seismic Design of Subway Structures”, Shanghai Urban Constructions Communications, Shanghai, 2010. (in Chinese) 


\title{
REVIEW ON WEB BUCKLING AND HYSTERETIC BEHAVIOR OF SHEAR PANEL DAMPERS
}

\author{
Zhiyi Chen ${ }^{1,2,3}$, Guoqiang Bian ${ }^{3}$ and Yu Huang ${ }^{3,4, *}$ \\ ${ }^{1}$ Associate Professor, Key Laboratory of Geotechnical and Underground Engineering of the Ministry of Education, \\ Tongji University, Shanghai 200092, China \\ ${ }^{2}$ State Key Laboratory of Geo-Hazard Prevention and Geo-Environment Protection, \\ Chengdu University of Technology, Chengdu 610059, China \\ ${ }^{3}$ Department of Geotechnical Engineering, Tongji University, Shanghai 200092, China \\ ${ }^{4}$ Professor, Key Laboratory of Geotechnical and Underground Engineering of the Ministry of Education, \\ Tongji University, Shanghai 200092, China \\ *(Corresponding author: E-mail: yhuang@tongji.edu.cn)
}

Received: 29 December 2011; Revised: 24 March 2012; Accepted: 2 April 2012

\begin{abstract}
Recently shear panel dampers (SPDs) have been applied to building and bridge structures widely, showing good effects in seismic hazard mitigation as passive energy dissipators. The mechanism of SPDs for dissipating earthquake-induced energy is through inelastic shear deformation of the metal. This paper firstly gives a brief introduction to the new development of configuration and material of SPDs. Then two important issues, namely, web buckling and hysteretic behavior of SPDs are mainly addressed. Several structural parameters, which have influences on bearing capacity, ductility and energy dissipation capacity of SPDs, are also discussed, with regarding to web slenderness ratio, stiffness of stiffeners, and contribution of flanges. Additionally, various restoring models of SPDs, which is developed to be used in evaluation of seismic control structures, are also discussed together with their hysteretic behavior. Finally, application of SPDs in building and bridge structures is presented, pointing out the issues deserving further study and potential application to new field of civil engineering.
\end{abstract}

Keywords: Shear panel damper, Energy dissipation device, Passive energy dissipator, Web buckling, Hysteretic behavior

\section{INTRODUCTION}

Over the past 30 years, the research on structural vibration control in building and bridge structures has been developed greatly. Many types of vibration control strategy are established [1,2]. A passive control system is one of them, referring to a class of control systems which do not require an external power source [1]. According to the way dissipating energy (such as adding internal stressing, rubbing, cracking, and stable plastic deformation), passive control devices can be classified into hysteretic dampers, friction dampers, viscoelastic solid dampers, and viscous fluid dampers, as shown in Figure 1.

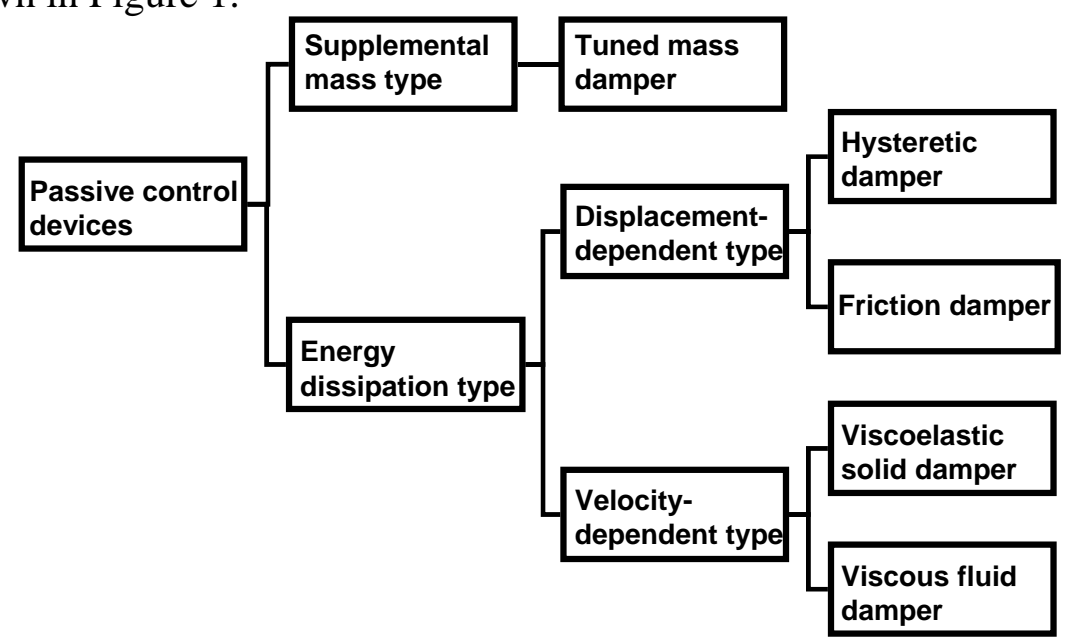

Figure 1. Classification of Passive Control Devices 
A shear panel damper (SPD), as presented in this paper, belongs to the hysteretic damper. For a successful hysteretic damper, it must effectively translate forces developed in response to the structural motion and dissipate as much of the energy input as possible at locations. The SPD has already been applied to many civil structures to control seismic responses and damage of the main members [3-6], due to its advantages of simple configuration, easiness to repair and/or replace. A properly designed shear panel damper may be into plasticity prior to the main structure. Moderate or large shear deformation may develop in the web of an SPD. Then the device absorbs seismic energy introduced into the structure during an earthquake event. Through metal inelastic deformation, SPD devices prevent the main structure from being damaged or destroyed. The working mechanism of an SPD is unlike to other hysteretic dampers, such as ADAS (added damping and stiffness) [7], TADAS (triangular ADAS) [8], Cu-ADAS (copper ADAS) [9], and SSD (steel slit damper) [10], and BRB (buckling restrained braces) [11]. They make use of metal deformation in flexural and axial manner. According to the location of being in main structures, SPDs can be divided into two types: (1) a combined-type that consist of shear panel and braces; (2) an inner column-type, as shown in Figure 2 [12].

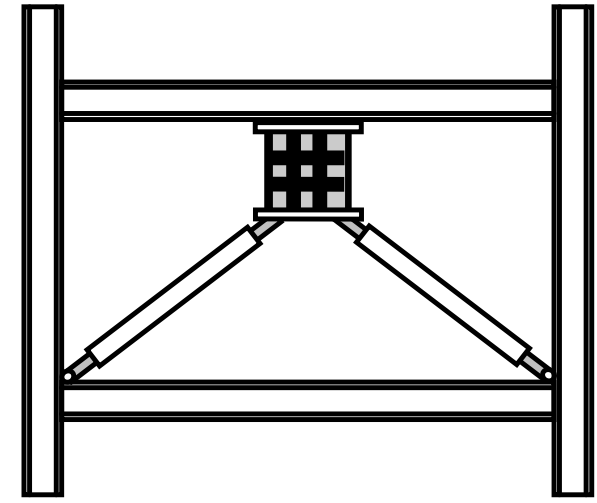

(a) combined type

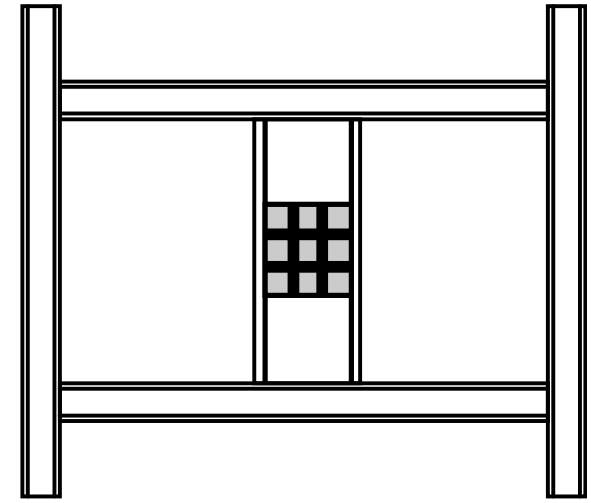

(b) inner column-type

Figure 2. Examples of Shear Panel Dampers Incorporated into Framed Structures

Interest in the development of SPDs has greatly increased in recent years. This leads to a great fruit and have prompt development and use of SPDs in practices. Researchers have pay close attention to SPDs, covering its behavior caused by different metal material and configuration, web buckling and effects of stiffeners, ultimate strength and ductility, as well as hysteretic performance and corresponding restoring models. Of these, two issues, namely web buckling and hysteretic behavior of SPDs are of great concern. Web buckling should be avoided for SPDs during early stages to sustain good hysteretic performance. The hysteretic behavior directly determines energy dissipation capacity of SPDs. In view of this, this paper mainly focuses on the new development of web buckling and hysteretic behavior of SPDs in recent years, points out the main issues which should be considered in practice. The application and suggestions in use of SPDs are also presented at the end of this paper.

\section{CONFIGURATIONS AND MATERIALS}

Configuration and material must firstly be considered for the design of shear panel dampers. They are most important factors and largely determine the web buckling and hysteretic behavior of shear panel dampers. 


\subsection{Configurations}

Indeed, development of shear panel damper is originated from the concept to weaken the beam end so as to mitigate seismic damage to the column and the main part of the beam. The basic configuration of an SPD is somewhat like a connection part of an $\mathrm{H}$ steel beam-column. As shown in Figure 3(a), previously published researches about shear panels focused on unstiffened shear panels $[4,13]$. It is commonly composed of a web which is obviously the main part, acting as a damper, and flanges being welded at the left and right sides of the web. In Figure 3, the rocky steel plates at the top and the bottom of the web are used to fix the SPD to the upper beam or to the bottom braces (see Figure 2(a)). The most advantages of such SPD type is its simple configuration and hence feasibility to manufacture. However due to the large width-thickness ratio of the web, local buckling occurs prior to web yielding. Local buckling is not preferable because it is the main reason to degrade the energy dissipating capacity. Hence the web thickness of the shear panels in the early researches is always designed stocky.

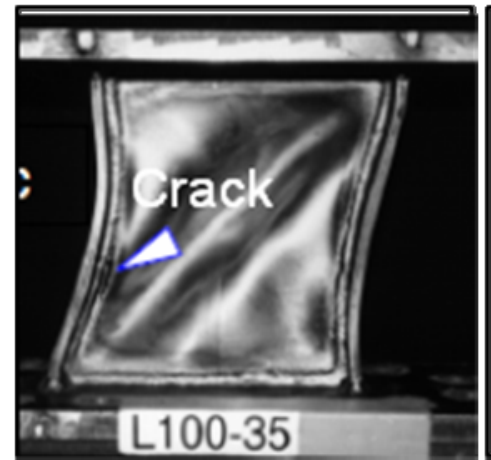

(a) unstiffened [4]

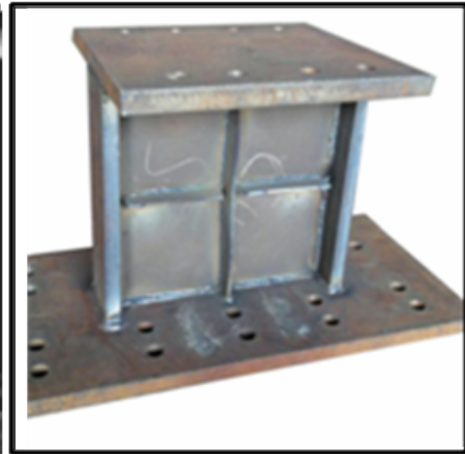

(b) stiffened

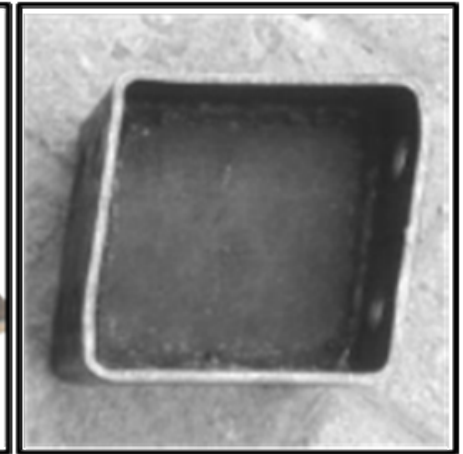

(c) square hollow section type [15]

Figure 3. Various Configurations of SPDs

An alternative way to avoid local buckling is to strengthen the web with stiffeners at one side or both sides. In recent researches [12,14], stiffened shear panel dampers are widely studied, as shown in Figure 3(b). The main purpose of fixing stiffeners is to increase shear buckling strength of the web, being similar to the rib in a girder. With stiffeners, even an SPD of the large width-thickness ratio may possess good hysteretic behavior and energy-dissipation capacity. Another advantage of stiffeners is that it may improve ductility capacity of an SPD remarkably while it may not change the yield strength. As a result, the yield strength can be determined by the cross-section area of an SPD, which simplifies practical design. To a stiffened SPD, however, the fatigue performance at the welds and the centre portion of the web should be verified.

Not only added stiffeners but also enhanced web boundaries may effectively prevent the web from premature local buckling. Chan et al. [15] proposed a so-called yielding shear panel device, in which a thin diaphragm steel plate as a damper is welded inside a square hollow section to improve its anti-buckling performance. The configuration of the device is shown in Figure 3(c).

In addition to the classic configuration, a laminated composite-type [16,17] — fiber orientations and stacking sequence of laminated composite panels are adopted to absorb seismic energy. Laminated composite-type shear panel dampers are usually used in link region between two main building structures. It supplies considerable lateral stiffness by the sandwich type at a high lateral drift level to resist shear displacement [16]. Such a damper is strict on the material demanding, and needs to consider the interaction of interlayer contacts. Aref and Jung [16] designed the passive interface damping layers to enhance damping properties under shear loading. Existing results show that their 
hysteretic performance is not so perfect while their fabrication is relative complex. Such shear panel dampers is easy being damaged, because their physical properties are very different and their boundary problem is a difficult issue which should be solved in the future.

\subsection{Materials}

Compared to structural control devices which are made of viscous liquid, friction of lead materials, uses of hysteretic behavior of metal material is attracted due to its low price, reliability and durability. So far, mild steel, low yield point steel, pure aluminum, aluminum alloy and composite material are often used as the main material to dissipate seismic energy. Their advantages and disadvantages are summarized in Table 1.

Table 1. Advantages and Disadvantages of Metals used as Damper Material

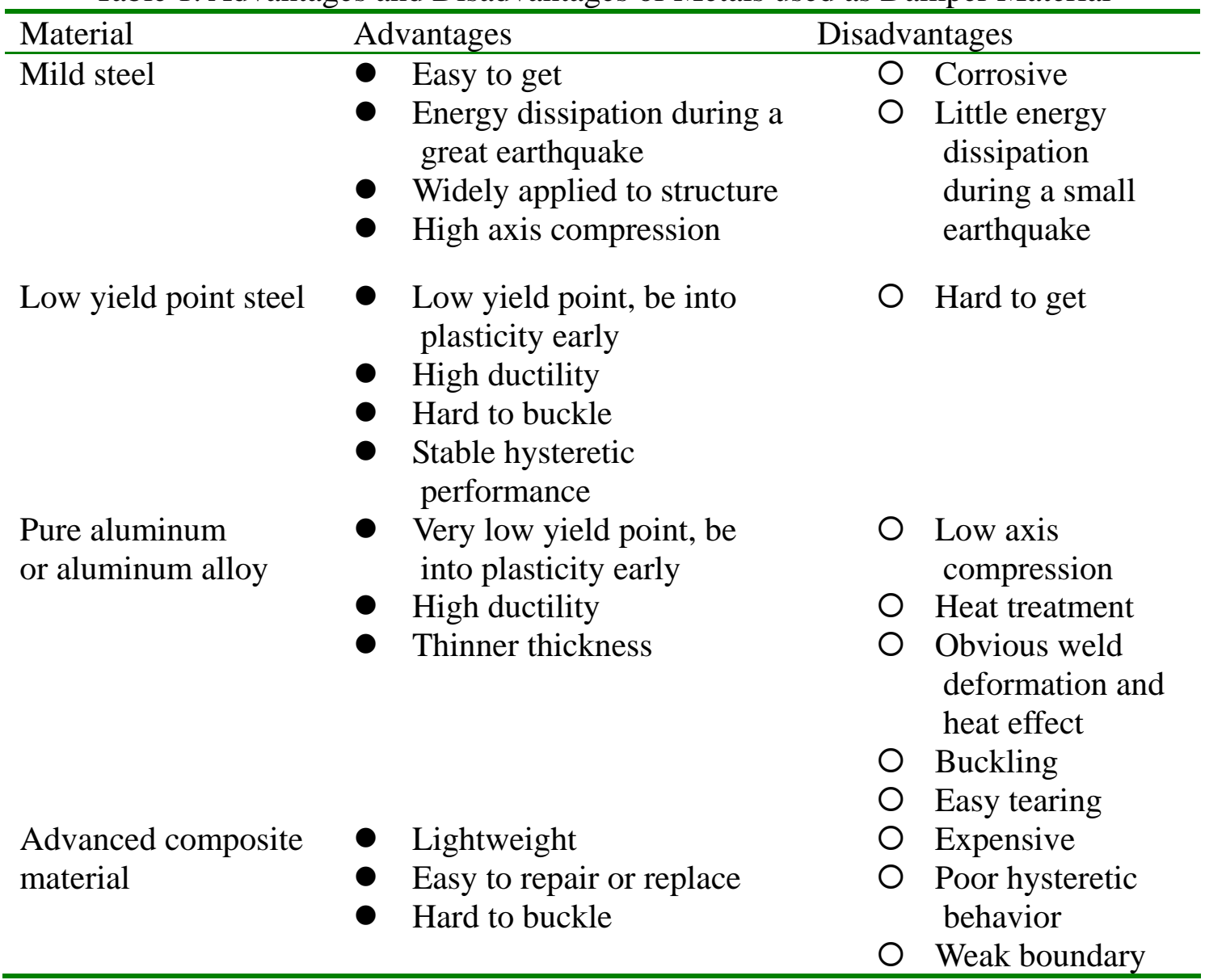

In the early stages of development and research, mild steel is generally used as the energy-dissipating material. Since use of mild steel in structural construction has a long history, its mechanical properties are well known. Shear panel dampers made of mild steel may offer added stiffness to the main structure during a small earthquake, and absorb seismic energy through hysteretic deformation when suffering a great earthquake. It should be noted that such damper fails to work in a small earthquake due to its high strength.

In view of this, low yield point steel is developed lately in Japan. This kind of steel mainly has three levels of yield strength as $100 \mathrm{MPa}$ (or 120MPa), $160 \mathrm{MPa}$, and $225 \mathrm{MPa}$. They have large elongation ranging from 40 to $60 \%$ [3]. Figure 4 shows material test curves of BT-LYP100 and BT-LYP225 provided by Nippon Steel Corporation [18]. In the plot, BT-LYP100 material has a nominal initial yield point of $100 \mathrm{MPa}$, over $50 \%$ rupture strain, and excellent ductility performance 
[18]. Due to the really low yield strength, dampers made of this kind of low yield point steel may yield and take effect even in a small earthquake if compared to those of mild steel. In addition, the manufacturing process of low yield point steel is strictly controlled so that the scatter of the yield strength is very small. The merit of a narrow range of yield strength scatter is that seismic control effect of a metal damper is guaranteed under designed loads. It is because the metal damper is designed to yield prior to the main structure.

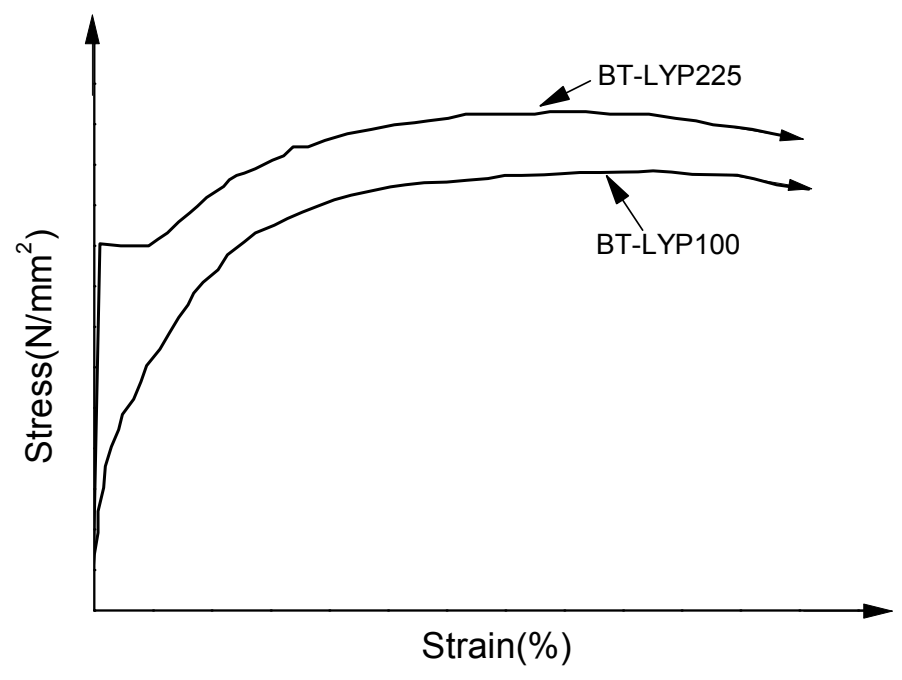

Figure 4. Stress-strain Curve of Low Yield Point Steel [18]

Aluminum is an innovative material recently proposed in the field of seismic engineering, due to its low yield strength and high ductility features $[19,20]$. Table 2 shows the mechanic characteristics of low yield point steel, aluminum and pure aluminum. Rai [21] made use of low yield point aluminum alloy (3003-O). Its yield stress is 35.2MPa after improving its mechanics behavior by heat treatment, and elastic modulus is 62 GPa. De Matteis et al.[19] used AW 1050A alloy, characterized by a high degree of purity (more than 99.50\%), a limited conventional yield strength (about $20 \mathrm{MPa}$ after heat treatment), high hardening ratio (about 4), and high ductility (about 40\%). These features benefit to shear panel dampers. The web can be made very thin while the SPD still has high ductility. However a thin aluminum web tends to remarkable buckling and the web is easily teared. Due to excessive low shear strength of pure aluminum or aluminum alloy, they got into plastic status quickly, and pinching of the hysteretic curve was observed under lateral cyclic load [19].

Table 2. Mechanical Characteristics of Low Yield Point Steel, Aluminum and Pure Aluminum

\begin{tabular}{|c|c|c|c|c|c|}
\hline Material & $\begin{array}{c}0.2 \% \text { offset } \\
\text { yield stress } \\
\left(\mathrm{N} / \mathrm{mm}^{2}\right)\end{array}$ & $\begin{array}{l}\text { Maximum } \\
\text { stress } \\
\left(\mathrm{N} / \mathrm{mm}^{2}\right)\end{array}$ & $\begin{array}{l}\text { Young's } \\
\text { modulus } \\
\left(\mathrm{N} / \mathrm{mm}^{2}\right)\end{array}$ & $\begin{array}{c}\text { Rupture strain } \\
\text { (\%) }\end{array}$ & $\frac{(1)}{(2)}$ \\
\hline & (1) & (2) & (3) & (4) & (5) \\
\hline LYP steel & 86 & 254 & 210000 & 50 & 0.339 \\
\hline $\begin{array}{l}\text { Aluminum alloy } \\
\text { (3003-O) }\end{array}$ & 35.2 & 109.2 & 62000 & -- & 0.322 \\
\hline $\begin{array}{l}\text { Pure aluminum } \\
\text { (AW 1050A) }\end{array}$ & 21.3 & 80 & 70000 & 45 & 0.266 \\
\hline
\end{tabular}


With the development of material science, composite material has been widely used. Composite materials, often shortened to composites, are engineered materials made from two or more constituent materials with significantly different physical or chemical properties which remain separate and distinct on a macroscopic level within the finished structure [22]. The physical properties of composite materials are generally anisotropic, nonhomogeneous, lightweight, easy to cut, thinner thickness and so on. Aref and Jung [16] made use of fiber reinforced polymer matrix composite (PMC) material as the web of an SPD. The PMC material is a semi-rigid PVC foam. It has the superior strength-to-weight ratio, the stiffness-to-weight ratio, excepptional dynamic strength, excellent insulating, superior durability in corrosive environments and better fatigue performance. It is an anisotropic matieral indeed as compared to conventional materials. The thickness of a PMC material can reach $0.3 \mathrm{~mm}$, so fiber orientations and stacking sequence of a PMC material can be adjusted to enhance structural behavior without any limitations given by existing structural configurations. The advanced composite material is an innovative and potential material, but its expansive price and its poor hysteretic performance make it unsuited for the web of shear panel dampers at present. Improving hysteretic behavior of advanced composite material maybe one of the most important and practical works.

\section{WEB BUCKLING}

An SPD usually experiences the following stages when subjected to shear loading: (1) the linear elastic stage, see Figure 5(a); (2) the yield occurrence, see Figure 5(b); (3) the inelastic buckling stage, see Figure 5(c); (4) the nonlinear elasto-plastic postbuckling stage, see Figures 5(d) and (e); and finally (5) the failure, see Figure 5(f). At the beginning of shear loading, shear stress is uniformly distributed across the web of an SPD. The web develops equal tensile and compressive stresses at $45^{\circ}$ and $135^{\circ}$ before buckling, and no out-of-plane deformation is observed. Next, few points reach the yield stress, and the remaining zones remain elastic. In the following process, the web becomes to show increasing elasto-plastic behavior. Once the web suddenly buckles at a certain load, it cannot carry any additional tensile and compressive load (the diagonal compressive stress remaining constant). Then a new load carrying mechanism is formed [23]. Shear stresses are no longer uniformly distributed and bending stresses develop due to local buckling. Large out-of-plane deflections occur and the sustained shear force increases. The SPD cannot carry further loads when yield points of the web form one or more complete narrow diagonal yield region [24]. The damper then fails to work.

In the above loading process, it is found that web buckling may sharply reduce shear strength of an SPD. Pinch phenomena may also be observed in the hysteresis curve. This not only weakens load bearing capacity of the shear panel damper but also leads it to unstable energy dissipation capacity. Hence web buckling should be avoided in the design, especially, in the early loading stage.

So far, great attempt has been made for this purpose. The research concerned covers the thickness of the web[12,15,24,25] and use of stiffeners[12,14,25,26]. Contributions of flanges to shear strength $[12,25]$ is also studied for further understanding mechanical behavior and web buckling of SPDs. The following discussions will be presented with regard to these three aspects. 
(a) initial elastic state

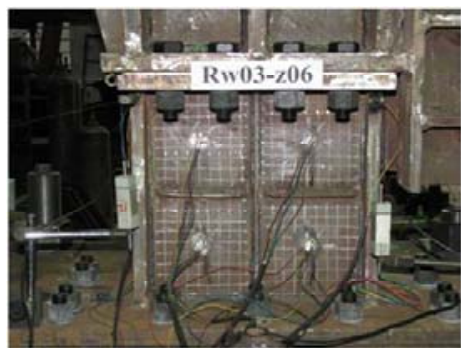

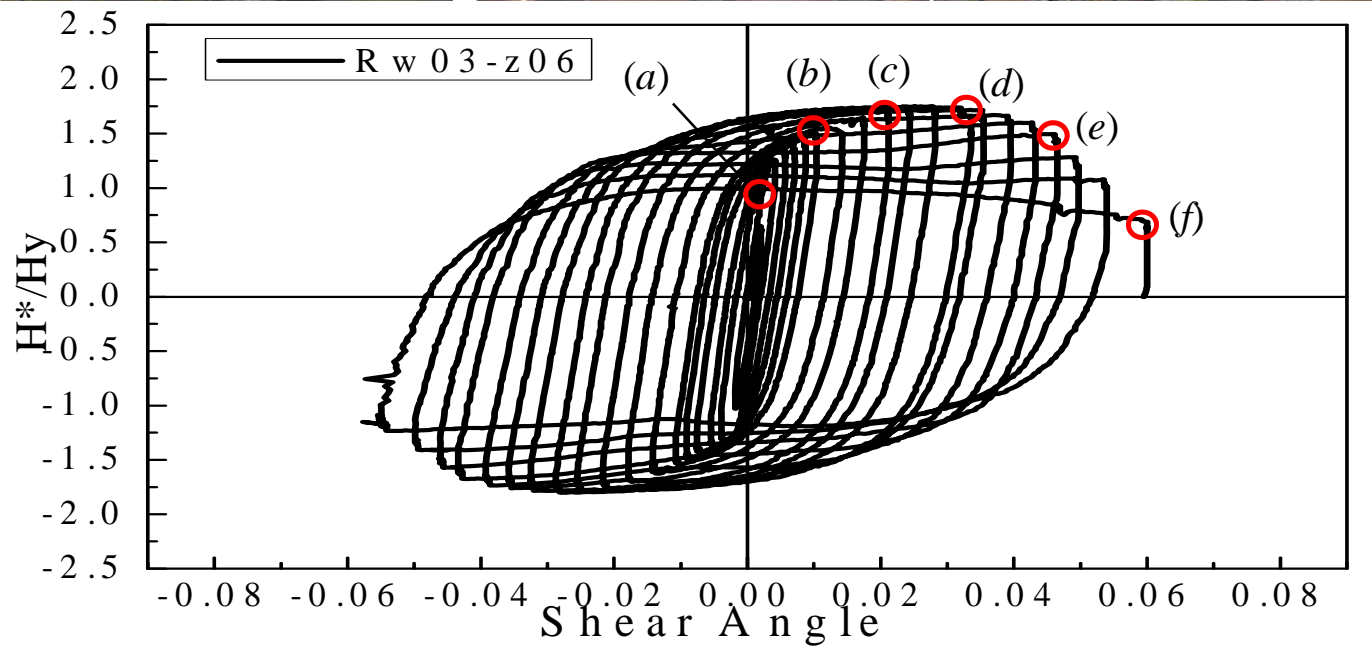

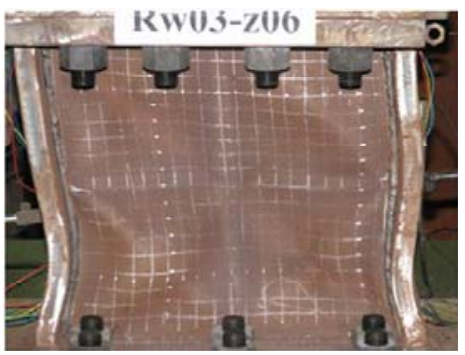

(d) tiny cracks

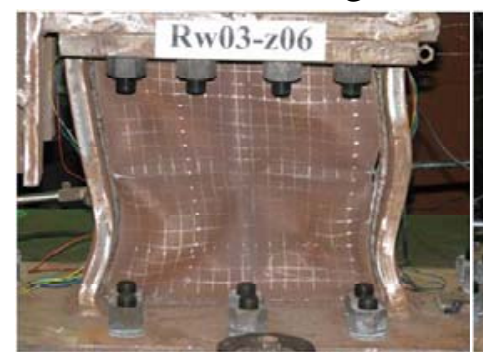

(e) cracks developing (b) yield occurrence and initial web buckling (c) obvious web buckling

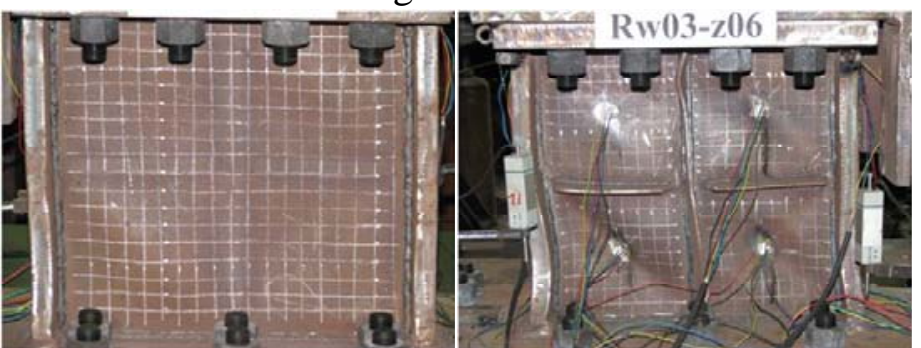

Figure 5. Typical Deformation States of an SPD under Cyclic Loading

\subsection{Web Slenderness Ratio}

Increasing the web thickness can effectively prevent the buckling problem of shear panels during the early stages on lateral load. The effect of web thickness on the panel buckling is quantitatively described through a parameter of the web slenderness ratio or the width-to-thickness ratio. It has been widely agreed that the parameter is an essential parameter, which plays an important role in the design of shear panel dampers. Experimental results obtained by Chan et al. [15] show that slender panels have higher ductility. Inelastic shear buckling was observed in specimens with the web slenderness ratio greater than 38.9. A slight pinch was also observed correspondingly in hysteretic curves. Specimens with small slenderness did not buckle, offering however unsatisfactory strength and energy dissipation due to limited deformation. Experimental results presented by Jain et al. [25] showed that most of shear panels with the web slenderness ratios of 23.5 and 20 presented no buckling phenomenon until the tearing of shear panels. Some specimens with the web slenderness ratio of 38.1 buckled at the strain of 0.1 . In the experiment of Tanaka and Sasaki [4], the panel dampers whose web slenderness ratio was less than 40 exhibited very excellent hysteretic performances. Chen et al. [12] proposed a web slenderness parameter to describe the effect of the web thickness on the web buckling and hysteretic behavior of the shear 
panel dampers. Numerical simulation results show that all the cases have good ductility up to 20 times of shear yield strain if the web slenderness parameter is less than 0.7. In this case, shear strength began deteriorating at 12 times of shear yield strain and hysteretic curve soon was terminated due to significant local buckling.

\subsection{Stiffener Effects}

Buckling phenomenon was often observed in unstiffened shear panel dampers during the early stage of shear loading. This may result in shear strength degradation, and may severely reduce energy dissipation capacity. It is commonly agreed that stiffeners can be effectively used to prevent local buckling during the early stage and avoid pinching and consequent strength degradation, especially for those with relative thin and slender webs.

Results of Chen et al. [12] demonstrated that if the stiffener rigidity, flange rigidity and web aspect ratio are in suggested range, their influence on the yield strength of an SPD are negligible. Then, the yield strength of an SPD is merely obtained from its cross section area. Namely, the merit of uses of stiffeners is to improve SPD ductility (large deformation capacity) while do not increase its strength.

Chen et al. [12] proposed an optimal stiffness ratio to control the number and rocky of stiffeners. Based on the experimental and numerical results, the optimal stiffness ratio of the stiffener was recommended as the value of 3 . In Reference [15], however, 10 was suggested. Clearly, there is a certain gap between two conclusions in determination the optimal value.

\subsection{Contribution of Flanges}

The main function of the flanges is to form fixed boundaries around the whole web. Then it may prevent rotation of web edges so as to increase the web buckling strength [15]. For simplicity, the flange thickness is always determined by several times of the web thickness in design. Generally the flange-to-web thickness ratio is taken as 4.0 in the previous works [3]. The numerical results of Chen et al. [12] also verified that the flanges are stiff enough as fixed web boundaries, given the ratio value of 4.0. It should be noted, however, that the contribution of flanges should be considered into the ultimate shear strength prediction. It is because that in large deformation state the frame action of the flanges also takes effect in addition to the web. The component resisted by flanges may reach as much as $13-20 \%$ of the total ultimate shear strength [12].

\section{HYSTERETIC BEHAVIOR AND RESTORING MODELS}

As energy dissipator, hysteretic behavior of SPDs influences directly seismic responses of a total structure during an earthquake. The seismic energy dissipated by SPDs is also the source of structural damping. Thus, correct understanding of hysteretic behavior and energy dissipating capacity as well as a corresponding restoring model of an SPD are thus an important prerequisite to accurately evaluate seismic responses of a structure with dampers.

\subsection{Hysteretic Behavior and Energy Dissipation}

Mainly due to the material and the web slenderness ratio, SPDs demonstrate different hysteretic behavior and energy dissipation capacity. Figure 6 shows three typical hysteretic curves of SPDs made by different metals $[3,12,19]$. As stated previously, large strain hardening is one remarkable feature of low yield point steel under reversal load. As can be seen from Figure 6(a), the shear force 
is increasing with increase of the SPD deformation. Study in Reference [3] has revealed that the significant strain hardening of the LYP 100 material was involved in the tested shear panels. This material feature resulted in the larger (about 1.5 times) cumulative dissipated energy than the equivalent linear-elastic and perfect-plastic system. However, under repeated equal displacement loading, the hysteretic curves trends to the second hysteretic curve, but the hardening does not occur at the same yield strength. This phenomenon is not the obvious isotropic hardening features either. Many models are developed to describe this special hardening rule, as will be discussed in the next subsection. Figure 6(b) clearly shows the typical kinematic hardening rule for an SPD made of mild steel. Numerical analysis results [12] indicated that for SPDs made of mild steel, the web is stockier, and the kinematical and isotropic effects are mixed together. If the web is medium stockier, the Buschinger effect is significant. For SPDs made of aluminum, its hysteretic curve shows remarkable pinch phenomenon, being similar to the flag shape as shown in Figure 6(c). Although the stable energy-dissipation capacity can be guaranteed through a certain construction details, the total energy dissipated is relatively smaller than that with a full hysteretic curve.

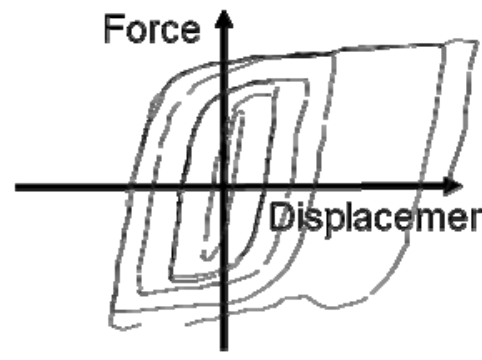

(a) low yield steel[3]

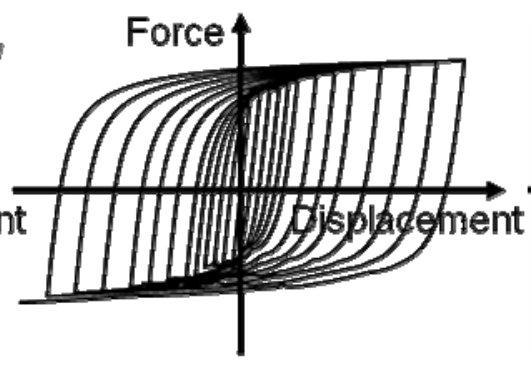

(b) mild steel[12]

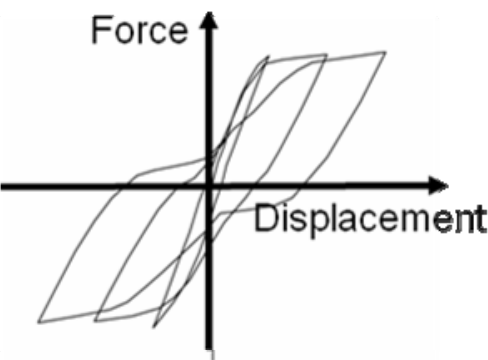

(c) aluminum[19]

Figure 6. Typical Force-displacement Curves of SPDs Made of Different Metal Materials

The web slenderness ratio is another factor which influences hysteretic behavior and energy dissipation capacity of an SPD. It is mainly resulted by the web local buckling. Test results obtained from LYP 100 and LYP 235 SPDs [13] showed that given the SPD made of the same steel material, the energy dissipated by both specimens are almost similar at medium deformation. However, in large deformation state, the increase of dissipating energy decreases for those with relative larger web slenderness ratio.

\subsection{Restoring Models}

The key issue in the numerical study on seismic reduction effect of an SPD is its accurate restoring model. Initially, in order to adopt the restoring model in the overall structure numerical analysis, an elastic-perfectly plastic model is often used due to simplicity. However, study on the ultimate shear strength of SPDs made of mild steel found that the damper has an overstrength which is about 1.1 to 1.6 times the yield strength of shear. This is mainly due to the steel strain hardening. And this feature is particularly evident in an SPD made of low yield point steel [27].

Considering the above feature, Takahashi and Shinabe [13] proposed four-fold-line-type restoring models. Chen et al. [12] proposed a simple bilinear model based on numerical test results, and gave the suitable range of the model. These two models are the simple models, although easy using, they cannot take into account the accurate prediction of strength and energy consumption. For example, due to the softening of steel, the equivalent linear method is often over-estimated the actual energy consumption of the damper during the plastic loading stage. The error can reach 15\% [12]. 
To correctly grasp the damper seismic control effect on the structure damage, the researchers dedicated to develop the restoring model which can accurately predict energy consumption. Kato-Akiyama model [28], as a representative model, divided the stress-strain curve into the skeleton curve, the unloading part and the stress softening part. Of these, the skeleton curve is obtained from the monotonic test. When the stress is not greater than the maximum value of historical stress, the stress-strain relationship is described by the unloading part, the stress softening part, and the stress from the uninstall section to the softening. Otherwise, it will move to the skeleton curve. Another Yamada-Tsuji model [29] is developed based on the Prager kinematic hardening model, combined by the isotropic hardening model and the kinematic hardening model, and then is modified to form a new IK model (ie, isotropic and kinematic model). But the IK model mainly describes hysteretic characteristics of the bilinear model. It is difficult to consider softening effect. To overcome this shortcoming, Nakashima et al. [30] introduced parameters from Ramberg-Osgood model into the IK model, and proposed so called IK RO model. The model not only has all the characteristics of IK model but also can simulate the gradual stiffness degradation behavior.

As can be seen, the above revised or improved restoring models are committed to accurately describe the force-displacement relationship of the dampers before its ultimate failure. But they do not take account of the degradation of strength and energy-dissipating capacity and even the failure of energy-dissipating devices, which result from the metal fatigue. Therefore, if such models are used in the nonlinear response analysis, once the damper deformation response is larger than the actual deformation that can bear, or the damper is damaged due to cumulative damage to a certain degree, then the analytical results will be real great error.

\section{APPLICATION IN CIVIL ENGINEERING}

SPDs described in this paper have already been applied successfully to many building and bridge structures. Two important buildings have been subjected to relatively large earthquakes and their performances have recorded. They are the Sylmar Hospital (in Los Angeles, California, shaken by the 1994 Northridge earthquake) and a 35-story building (in Kobe, Japan shaken by the 1995 Kobe earthquake) [2]. The Sylmar Hospital suffered severe damage to some non-structural elements and the 35-story building was found no visible damage.

The first application of SPDs in bridges is the San Francisco Oakland Bay Bridge east span. It is a $565 \mathrm{~m}$ long single tower steel self-anchored suspension bridge. The tower of the bridge consists of four steel shafts interconnected in the transverse and longitudinal directions by replaceable bolted steel shear panel dampers (they are called shear links in that case) [5]. The shafts were designed to remain elastic under the Safety Evaluation Earthquake (SEE) with a return period of 1,500 years while the SPDs were allowed to deform inelastically to protect the tower from permanent damage. Recently, another successful case is in Tempozan Bridge, Japan [31]. The SPD device is set at the junction (gasket) between the braces and the horizontal beam. The SPD is made of low yield point steel, to be yield plastically and absorb seismic energy to prevent braces from buckling and main girders from damage.

With the development of urban underground space and with the improvement of design and construction techniques, the modern underground structures trends to be of large span and complex structural style. In Shanghai, the most remarkable construction is the World Expo Axis underground complex engineering and Hongqiao integrated transport hub project. The former is $1045 \mathrm{~m}$ in length and $110.5 \mathrm{~m}$ in width. The largest span reaches $22 \mathrm{~m}$. The preliminary design of the width of the latter in the crowded region is not less than $24 \mathrm{~m}$. Their span is 3 times the span of conventional 
underground subway stations. The seismic safety of underground structures has received large attention of engineers and researchers. Due to its simplicity and efficiency, the SPD can be considered as a specific energy dissipation device in large underground structures. However it should be recognized that the seismic performance and damage mechanics of underground structures are different from the ground structures. Firstly, the underground structures are constrained by surrounding soils. As a result, dynamic effect is not so clearly if compared to the ground structures. Secondly, the axial compression ratio in underground structural columns is commonly large. Consequently SPDs will sustain high axial compression load. Further study about influence of high axial compression load on bearing capacity and energy dissipation capacity of SPD is then needed.

\section{CONCLUSIONS}

Due to feasibility and simplicity, research and application of shear panel dampers have become increasingly widespread. SPDs have been succeeded in controlling structural vibrations induced by earthquake ground motions in building and bridge structures. Now its efficiency in large span underground structures was verified and application in this field will become to truth in the soon coming future. At present, mechanical and hysteretic performance of SPDs and its seismic control effect in structures are being comprehensive and being in depth, making great achievements. This paper reviewed only two important issues, namely, web buckling and hysteretic behavior of SPDs. However, it can be seen that these studies have been done separately. Test data and parameters investigated were not unified for clear reference. For example, the web slenderness ratio, which is considered to be the most important parameter determining SPD mechanics and hysteretic performance, is defined by various forms. This leads to different values and optimal ranges that are recommended. The design method and control parameters of SPDs are not uniform, which is not beneficial to promote their application in practical engineering. Moreover, fatigue performance (especially at the conjunction region between the web, stiffeners and flanges) and large deformation behavior were found to be a subject that was worth further study for shear panel dampers to be used in structures.

\section{ACKNOWLEDGMENTS}

This research was supported by the National Natural Science Foundation of China (Grant No. 50908169), National Basic Research Program of China (973 Program: 2011CB013600), State Key Laboratory of Geo-Hazard Prevention and Geo-Environment Protection (Grant No. SKLGP2011K009), Program for Changjiang Scholars and Innovative Research Team in University (PCSIRT, IRT1029), the Fundamental Research Funds for the Central Universities and the Kwang-Hua Fund for College of Civil Engineering, Tongji University. All supports are gratefully acknowledged.

\section{REFERENCES}

[1] Housner, G.W., Bergman, L.A., Caughey, T.K., Chassiakos, A.G., Claus, R.O., Masri, S.F., Skelton, R.E., Soong, T.T., Spencer, B.F. and Yao, J.T.P., "Structural Control: Past, Present, and Future”, J. Eng. Mech., ASCE, 1997, Vol. 123, No. 9, pp. 897-971.

[2] Japanese Society of Steel Construction, "Seismic Response Behavior and Design Method for Frame Structures with Hysteretic Dampers”, Tokyo: Japanese Society of Steel Construction, 1998. (in Japanese) 
[3] Nakashima, M., Iwai, S., Iwata, M., Takeuchi, T., Konomi, S., Akazawa, T. and Saburi, K., “Energy Dissipation Behavior of Shear Panels Made of Low Yield Steel”, Earthquake Engineering \& Structural Dynamics, 1994, Vol. 23, No. 12, pp. 1299-1313.

[4] Tanaka, K. and Sasaki, Y., "Hysteretic Performance of Shear Panel Dampers of Ultra Low-yield-strength Steel for Seismic Response Control of Buildings”, 12WCEE (CD-Rom), Auckland, NZ, 2000.

[5] McDaniel, C.C., Uang, C.M. and Seible, F., "Cyclic Testing of Built-up Steel Shear Links for the New Bay Bridge”, J. Struct. Eng., ASCE, 2003, Vol. 129, No. 6, pp. 801-809.

[6] Abolhassan, A.A., "Seismic Behavior and Design of Steel Shear Walls", the 2001 SEOANC Seminar, Structural Engineers Assoc. of Northern California, November 7, 2001.

[7] Bergman, D.M. and Goel S.C., "Evaluation of Cyclic Testing of Steel-plate Devices for Added Damping and Stiffness”, Report No. UMCE87-10. Univ. of Michigan, Ann Arbor, 1987.

[8] Tsai, K., Chen, H.W., Hong, C.P. and Su Y.F., “Design of Steel Triangular Plate Energy Absorbers for Seismic-resistant Construction”, Earthquake Spectra, 1993, Vol. 9, No. 3, pp. 505-528.

[9] De la Llera, J.C., Esguerra, C. and Almazan, J.L., "Earthquake Behavior of Structures with Copper Energy Dissipators”, Earthquake Engineering \& Structural Dynamics, 2004, Vol. 33, No. 3, pp. 329-358.

[10] Chan, R.W.K. and Albermani, F., "Experimental Study of Steel Slit Damper for Passive Energy Dissipation”, Eng. Struct., 2008, Vol. 30, No. 4, pp. 1058-1066.

[11] Clark, P., Aiken, I., Ko, E., Kasai, K. and Kimura, I., "Design Procedures for Buildings Incorporating Hysteretic Damping Devices”, Proceedings of 1999 Annual Convention of the Structural Engineers Association of California, Santa Barbara, California, 1999.

[12] Chen, Z.Y., Ge, H.B. and Usami, T., "Hysteretic Model of Stiffened Shear Panel Dampers", Journal of Structural Engineering, 2006, Vol. 132, No. 3, pp. 478-483.

[13] Takahashi, Y. and Shinabe, Y., "Experimental Study on Restoring Force Characteristics of Shear Yielding Thin Steel Plate Elements”, J. Struct. Constr. Eng., AIJ, 1997, Vol. 494, pp. 107-114

[14] Alinia, M.M. and Dastfan, M., "Cyclic Behavior, Deformability and Rigidity of Stiffened Steel Shear Panels”, Journal of Constructional Steel Research, 2007, Vol. 63, No. 4, pp. 554-563.

[15] Chan, R.W.K., Albermani, F. and William, M.S., "Evaluation of Yielding Shear Panel Device for Passive Energy Dissipation”, Journal of Constructional Steel Research, 2009, Vol. 65, No. 2, pp. 260-268.

[16] Aref, A.J. and Jung, W.Y., “Advanced Composite Panels for Seismic and Vibration Mitigation of Existing Structures”, Journal of Engineering Materials and Technology, 2006, Vol. 28, No. 4, pp. 618-632.

[17] Mallela, U.K. and Upadhyay, A., "Buckling of Laminated Composite Stiffened Panels Subjected to In-plane Shear: A Parametric Study”, Thin-Walled Structures, 2006, Vol. 44, No. 3, pp. 354-361.

[18] Nippon Steel Corporation, http://www.nsc.co.jp/product/plate/pdf/ac120.pdf, Accessed 19 December 2011.

[19] De Matteis, G., Mazzolani, F.M. and Panico, S., "Experimental Tests on Pure Aluminium Shear Panels with Welded Stiffeners”, Engineering Structures, 2008, Vol. 30, No. 6, pp. 1734-1744.

[20] De Matteis, G., Mazzolani, F.M. and Panico, S., "Pure Aluminium Shear Panels as Dissipative Devices in Moment-resisting Steel Frames”, Earthquake Engineering \& Structural Dynamics, 2007, Vol. 36, No. 7, pp. 841-859.

[21] Rai, D.C., "Inelastic Cyclic Buckling of Aluminum Shear Panels”, Journal of Engineering Mechanics, 2002, Vol. 128, No. 11, pp. 1233-1237. 
[22] Hull, D. and Clyne, T.W., “An Introduction to Composite Materials”, Cambridge University Press, 1996.

[23] Porter, D.M., Rockey, K.C. and Evans, H.R., "The Collapse Behavior of Plate Girders Loaded in Shear”, The Struct. Eng., 1975, Vol. 53, No. 8, pp. 313-325.

[24] Alinia, M.M., Habashi, H.R. and Khorram, A., "Nonlinearity in the Postbuckling Behaviour of Thin Steel Shear Panels”, Thin-Walled Structures, 2009, Vol. 47, No. 4, pp. 412-420.

[25] Jain, S., Rai, D.C. and Sahoo, D.R., "Postyield Cyclic Buckling Criteria for Aluminum Shear Panels”, Journal of Applied Mechanics, 2008, Vol. 75, No. 2, Paper No. 021015.

[26] Ambur, D.R., Jaunky, N. and Hilburger, M.W., "Progressive Failure Studies of Stiffened Panels Subjected to Shear Loading”, Composite Structures, 2004, Vol. 65, No. 2, pp. 129-142.

[27] Nakashima, M., "Strain-hardening Behavior of Shear Panels Made of Low-yield Steel. 1: Test”, Journal of Structural Engineering, 1995, Vol. 121, No. 12, pp. 1742-1749.

[28] Kato, M. and Akiyama, H. "Experimental Principal of Stress-strain Hysteretic Curves for Steel Materials”, Summaries of Technical Papers of Annual Meeting, AIJ, 1973, pp. 937-938.

[29] Yamada, M. and Tsuji, B., "Stress-strain Behavior of Structural Steels. I: Combined Isotropic and Kinematic Hardening Model”, Proc. Annu. Meeting of the Arch. Inst. of Japan, Tokyo, Japan, 1965, pp. 1447-1450.

[30] Nakashima, M., Akazawa, T. and Tsuji, B., "Strain-hardening Behavior of Shear Panels Made of Low-yield Steel. 2: Model”, Journal of Structural Engineering, 1995, Vol. 121, No. 12, pp. 1750-1757.

[31] Nishioka, T., "Seismic Control Techniques for Large-span Bridges, in the Case of Hanshin Expressway”, Journal of Steel Structures \& Construction, 2009, Vol. 72, pp. 7-10. 


\title{
ROTATION PERFORMANCE OF COLD-FORMED STEEL PORTAL FRAMES
}

\author{
M. Dundu \\ University of Johannesburg, Department of Civil Engineering Science, \\ P O Box 524, Auckland Park 2006, South Africa \\ *(Corresponding author: E-mail: mdundu@uj.ac.za)
}

Received: 4 January 2012; Revised: 23 April 2012; Accepted: 11 May 2012

\begin{abstract}
Design based on linear-elastic analysis has been found not to provide an accurate representation of the behaviour of steel structures. The introduction of limit state design created the expectation that ultimate limit state would be based on inelastic behaviour. Opportunities for ultimate resistances to be calculated using plastic stress blocks is available in design codes, however designers still assess ultimate load and action effects using elastic analysis. An experimental and theoretical investigation of a cold-formed steel portal frame is done to try and address this problem. The rafter and column members are formed from single cold-formed channel sections, which are bolted, back-to-back at the eaves and apex joints, and connected to the foundation through angle irons. The design of the frame members follows the traditional approach of applying the effective width method to control local buckling, followed by an assessment of cross-sectional and buckling requirements. However, the yield and overall buckling requirements are modified by a factor of 0.8 to account for stress concentrations, shear lag and bearing deformations in the connections. The non-linear moment-rotation response exhibited late in the loading sequence of structures 1,3 and 4 is attributed, primarily, to bolt-bearing deformation and local yielding of the flange below the inside bolt. It is demonstrated both experimental and conveniently using the mixed flexibility approach that such frames can achieve the required rotation capacity needed for inelastic analysis.
\end{abstract}

Keywords: Frame, Single cold-formed channels, Eaves and apex joints, Points of contraflexure, Mixed flexibility approach, Rotation capacity, Plastic analysis.

\section{INTRODUCTION}

In plastic design of hot-rolled portal frames, various regions in the structure are required to form plastic hinges. Plastic hinges progressively form at points of maximum moment until a mechanism is formed. The hinges must be capable of reaching the plastic moment $\left(\mathrm{M}_{\mathrm{p}}\right)$ and maintaining the plastic moment for a suitable amount of plastic hinge rotation, to allow for redistribution of bending moments in a frame. For this to happen, the points where the hinge is formed must have sufficient ductility to allow adequate rotation before the frame collapses. To provide adequate hinge rotation, the plastic deformation may occur within the connection or in the adjacent member. Since the connections under consideration are not stiffened as in hot-rolled portal frames the required hinge rotation must be provided by the connection. Ductility of the connection is therefore an important aspect of this investigation, as the frames are made of cold-formed channels and cold-formed channels are known to possess limited rotation capacity. The purpose of this investigation is to assess rotation performance of the connections and their ability to form plastic hinges, and thus allow for the redistribution of moments.

Several benefits can be realised if the ductility of a structure can be incorporated into design. Such benefits include:

- Greater structural efficiency in terms of both flexural strength and stiffness through continuity of members,

- Provision of alternative load paths when the actual behaviour does not accord with the design assumptions, or these assumptions are in error, and

- Improved safety when loads of an unexpected or rare nature occur, such as explosions or earthquakes. 
In a typical portal frame under vertical loading a plastic hinge is expected to form at the eaves first, since this is the point of maximum moment. Vertical downward loading caused by permanent and imposed load is frequently the critical load case for low-rise structures in South Africa and the rest of the Southern African region. Assuming pinned base conditions, the bending moment diagram, shown in Figure 1, is the normal mode of failure for this region unless the frame is very tall or there is an exceptionally high wind pressure.

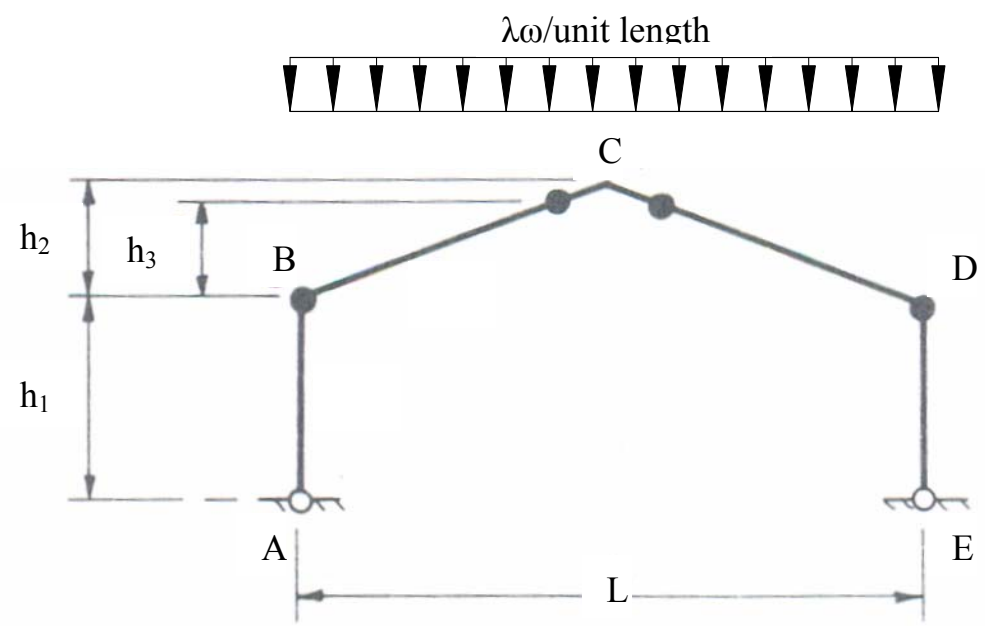

(a) Pinned Base Portal Frame with Hinges

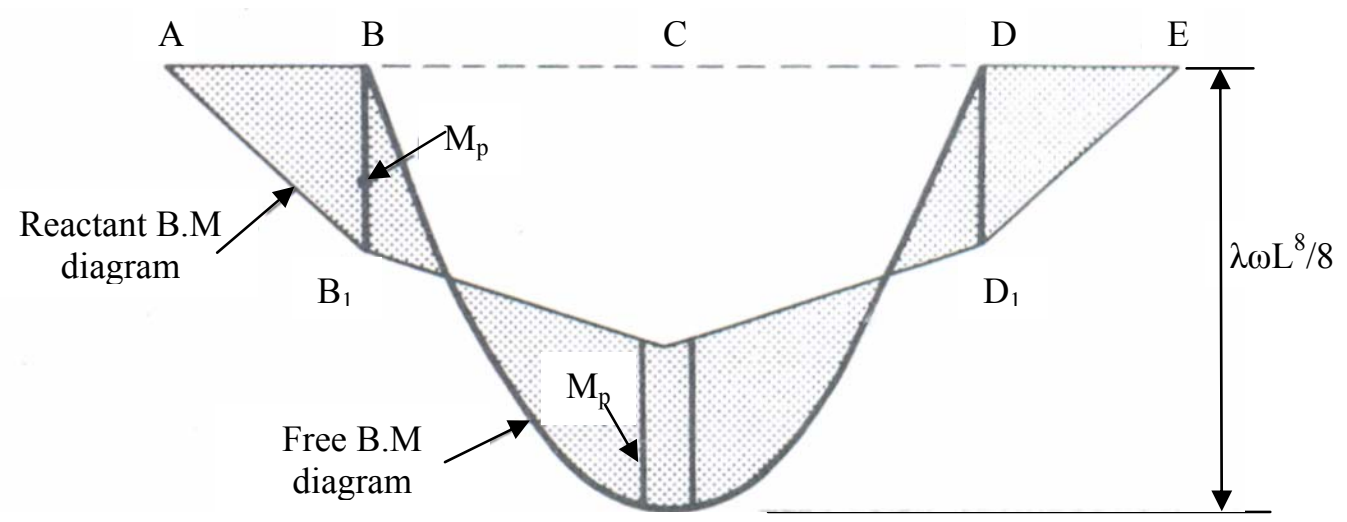

(b) Bending Moment Diagram

Figure 1. Portal Frame Subjected to Downward Loading

\section{EXPERIMENTAL MODEL}

The spans of the frames investigated ranged from $10 \mathrm{~m}-14 \mathrm{~m}$, with a constant eaves height of $3 \mathrm{~m}$ and a pitch of $10^{\circ}$. Preliminary calculations, based on SANS 10162-2-2005 [1], showed that $300 \times 50 \times 20 \times 3,300 \times 65 \times 20 \times 3$ and $300 \times 75 \times 20 \times 3$ cold-formed channel sections would be suitable for $10 \mathrm{~m}, 11$, and $12 \mathrm{~m}$ spans, respectively. This code is based on the Canadian Code, CAN/CSA-S16.01 [2]. Full-scale testing of the portal frames was avoided so that the structure could be accommodated in the laboratory and to reduce the cost. The model of the two frames was extracted from the eaves joint to the points of contraflexure in the rafter and column respectively. This represents the portion on the bending moment diagram in a typical full portal frame from the eaves joint to the point of zero moment on either side of the joint. The eaves' joint is the most highly stressed portion of the 
portal frame under vertical loading, and vertical loading is the most critical load condition in South Africa and the region.

A typical schematic diagram of the general layout of the test set-ups and degrees of freedom at the supports of structures are shown in Figure 2. The diagram was laid on the laboratory to simplify the testing procedure. The photograph in Figure 3 show the actual test arrangement, viewed from the other side. In this figure, the column and rafter sections (both of cold-formed channels) are joined together, back-to-back, by a system of bolts to generate increased strength in the connection due to counterbalancing moments and forces. One of the fundamental decisions taken at the planning stage was that the tests should simulate, as realistically as possible, the actual conditions to which a portal frame structure could be subjected under vertical loading. In a typical portal frame building, internal frames are subjected to similar loading and it is also logical to assume that when the frames are acted upon by the load they deflect downwards by the same amount. For this reason two portal frames were used in the experimental model, and subjected to equal loading. In addition these two frames would allow for interaction to occur between themselves, while at the same time avoiding structural complications and higher costs that are expected as a result of testing more frames. K-bracings (size $50 \times 50 \times 2 \mathrm{~mm}$ ) and $100 \times 50 \times 20 \times 2 \mathrm{~mm}$ cold-formed channel purlins are used to stabilise the frames.

To allow for horizontal movements to occur, $3 \mathrm{~mm}$ roller bearings were introduced into the model. A $30 \mathrm{~mm}$ diameter steel ball was introduced to allow all supports the freedom to rotate in any direction. The balls were positioned at the shear centre of the frames in order to reduce eccentricity in the set-up. The two portal frame joints were subjected to equal loads applied through pins at the points of contraflexure using two 16-tonne, hand-operated jacks. To simulate the condition of the eaves joint in Figure 1, the frames in Figure 3 were jacked inwards to create an external moment at the joint.

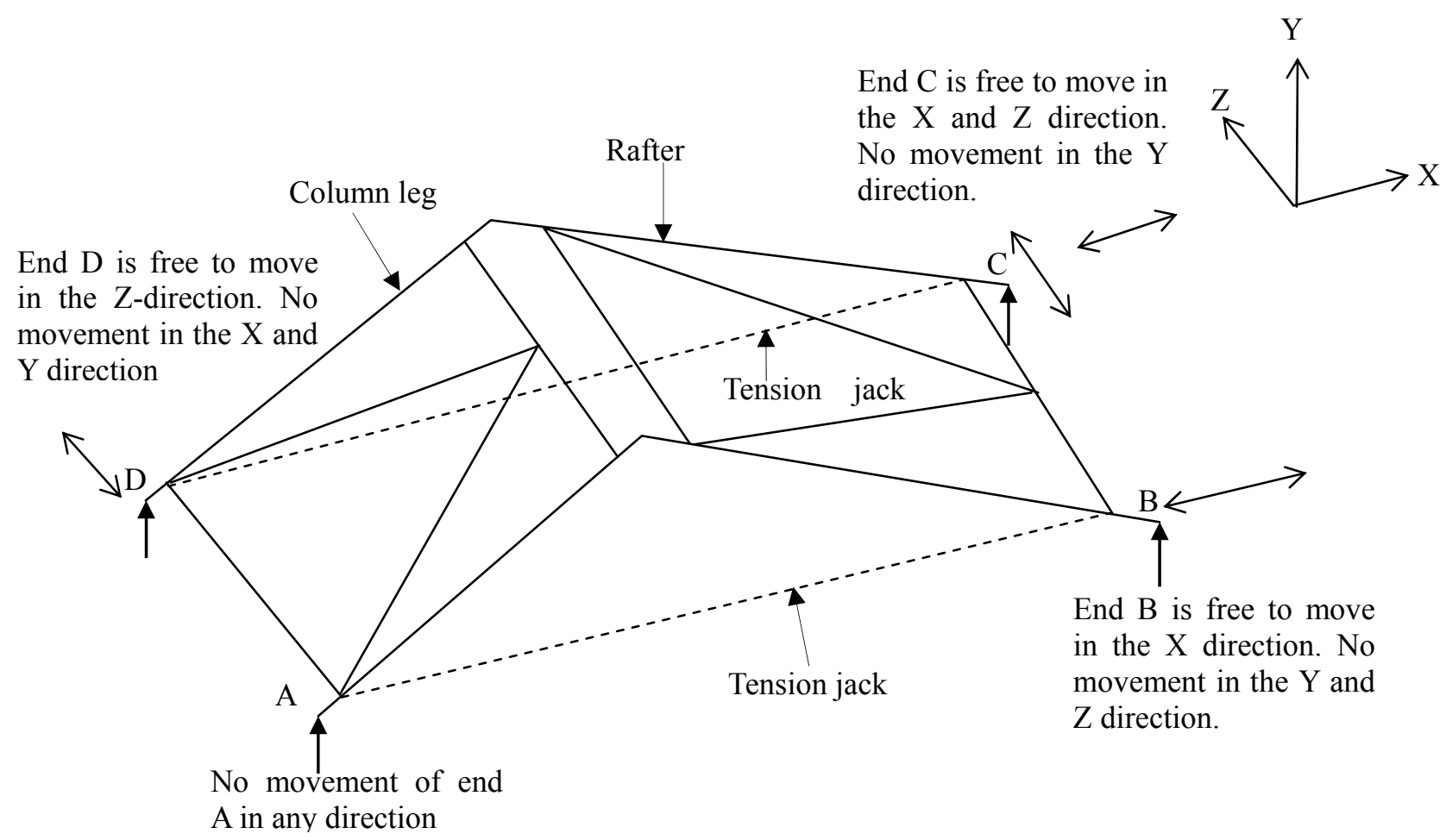

Figure 2. Schematic Test Set-Up 


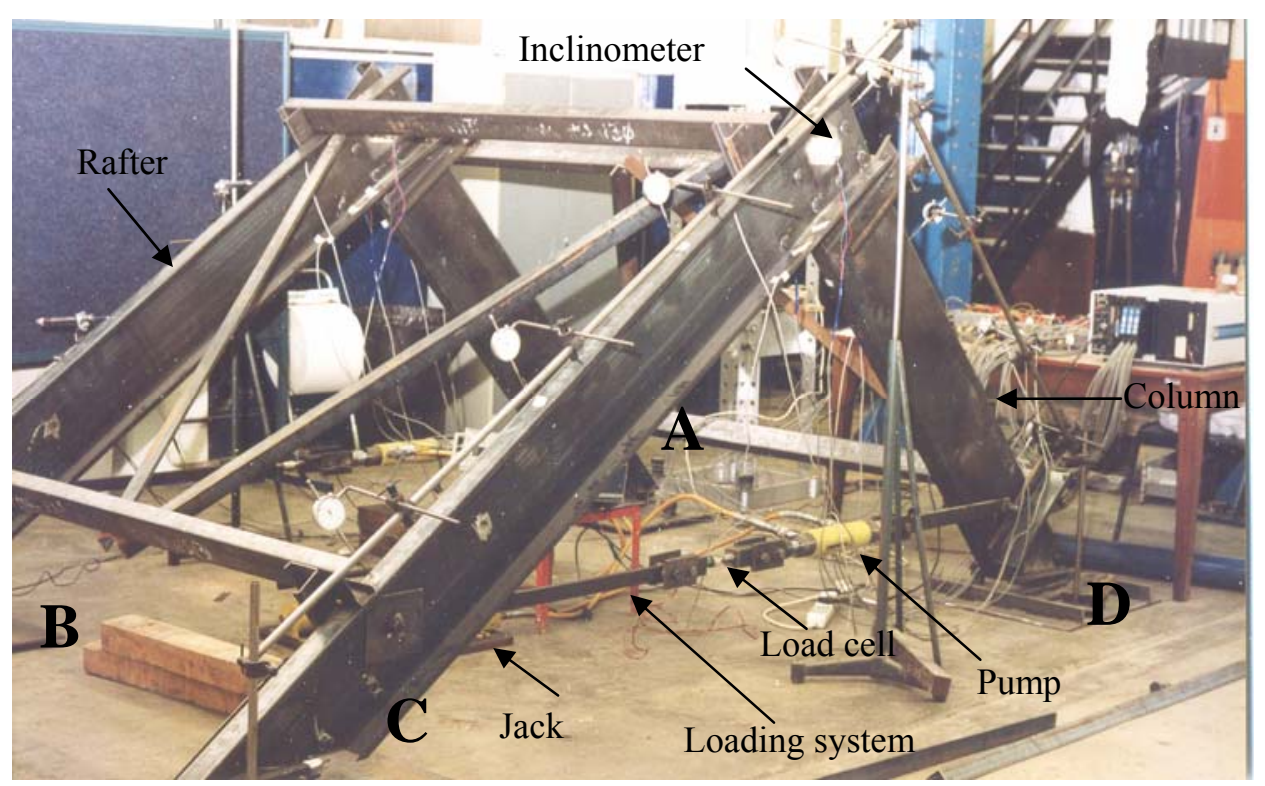

Figure 3. Test Set-Up

Variables in the 4 tests include the number and size of bolts in the connection, and the yield and ultimate strength of the cold-formed channels. A list of these variables and the corresponding structures are given in Table 1 . The study of the results shows that the longitudinal web coupons have on average the smallest yield strength. The behaviour of the longitudinal coupons from the web may be considered consistent with the mechanical properties associated with the virgin steel sheet, suggesting that the cold-rolling operation may have minimally affected that part of the section. The average yield stress for the $300 \times 75 \times 20 \times 3$ and $300 \times 65 \times 20 \times 3$ longitudinal flange coupons are almost the same as that of the longitudinal web coupons. The yield stress for the $300 \times 50 \times 20 \times 3$ flange coupons is $23 \%$ greater than the longitudinal web coupons. This increase is probably influenced by the rolling at the corners of the channels. The smaller the flange width, the more likely will the properties of the flange resemble those at the corners.

The average yield stress for the flange coupons is used to calculate the moment of resistance of the channels, whilst the average ultimate stress for the web coupons is used to calculate the moment of resistance of the connections (Table 3). This is based on the assumption that the flanges resist the moment whilst the web resists the bearing forces in the connections. Young's modulus of elasticity $(\mathrm{E}=207 \mathrm{GPa})$ is used in the buckling calculations. The bolts at the eaves joint were increased to 8 in structure 2 to find out whether this would change the mode of failure of structure 1, which failed due to local buckling as a result of stress concentrations below the inside lower bolt. Increasing the number of bolts would result in a revised distribution of the bolt forces. Details of the bolt configurations of the tested frames are given in Figure 4.

In-plane rotation of eaves' joints was monitored using high-precision digital rotation transducers (also known as AccuStar Electronic Clinometers). The heart of the system is a patented, capacitance-based sensor with no moving parts. When rotated about its sensitive axis, this unique sensor provides an exceedingly linear variation in capacitance, which is electronically converted into angular data. The clinometer has a total range of $\pm 60^{\circ}$ and a linear range of $\pm 45^{\circ}$. All clinometers were calibrated to read $20.3446^{\circ}$ volt. Each clinometer was screwed onto a $70 \times 70 \times 10 \mathrm{~mm}$ piece of wood and then glued to the centre of the joint. All dirt particles were removed from the mounting plane and the mounting of the piece of wood so that the two could bond together well. The centre of each joint was installed with two rotation transducers, with one 
transducer on each side of the joint as shown in Figure 4. The holes of the clinometers were aligned vertically so as to read zero on the multimeter in the unloaded condition.

Table 1. Variables in the Structures

\begin{tabular}{|c|c|c|c|c|c|c|c|c|}
\hline Structure & Section & Span $(\mathrm{m})$ & \multirow{2}{*}{$\begin{array}{c}\text { No. of } \\
\text { Bolts }\end{array}$} & \multirow{2}{*}{$\begin{array}{c}\text { Size of } \\
\text { Bolts }\end{array}$} & & \multicolumn{2}{|c|}{$\mathrm{f}_{\mathrm{y}}$} & \multicolumn{3}{|c|}{$\mathrm{f}_{\mathrm{u}}$} \\
\hline Structure 1 & $300 \times 75 \times 20 \times 3$ & 12 & 4 & M20 & 468.88 & 475.05 & 541.32 & 546.95 \\
\hline Structure 2 & $300 \times 75 \times 20 \times 3$ & 12 & 8 & M20 & 468.88 & 475.05 & 541.32 & 546.95 \\
\hline Structure 3 & $300 \times 65 \times 20 \times 3$ & 11 & 4 & M16 & 344.77 & 346.05 & 473.09 & 473.90 \\
\hline Structure 4 & $300 \times 50 \times 20 \times 3$ & 10 & 4 & M16 & 254.31 & 311.68 & 346.22 & 370.60 \\
\hline
\end{tabular}

LWC - longitudinal web coupon, LFC - longitudinal flange coupon

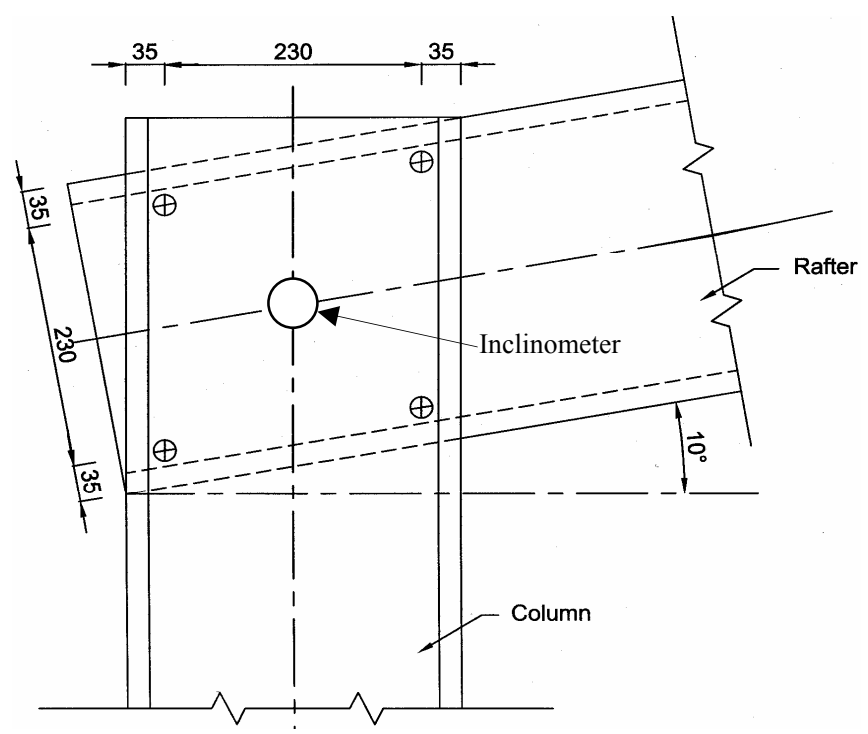

(a) 4-Bolt Connection

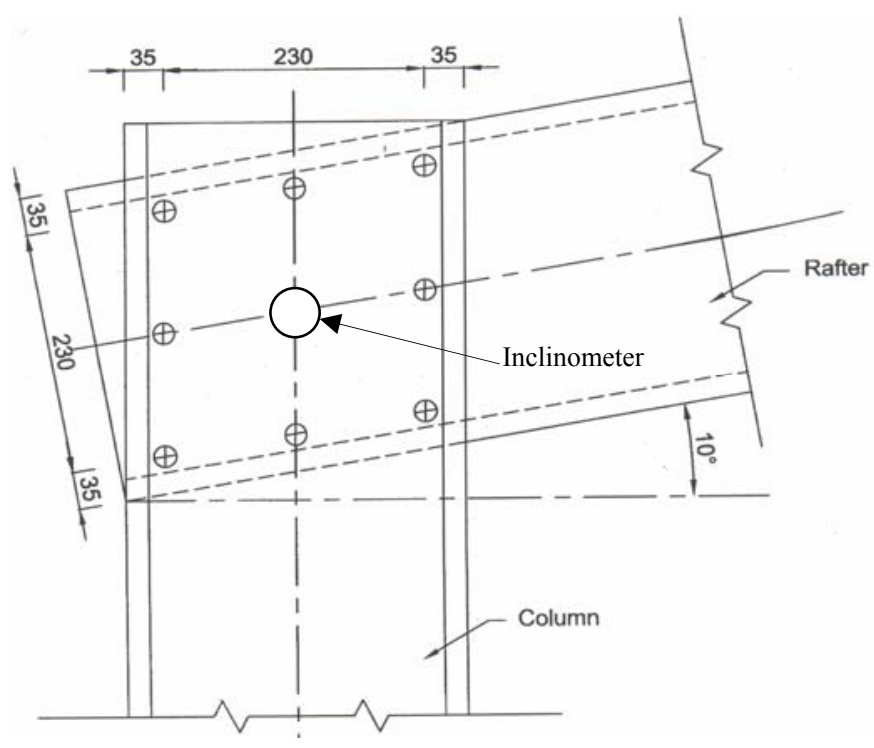

(b) 8-Bolt Connection

Figure 4. Bolt Configurations of Eaves Connections

\section{FAILURE MODES}

The modes of failure of the frames include local buckling of the compression zone of the flange and web of the channels, lateral torsional buckling of the channels between points of lateral support and bolts in bearing. Local buckling was the ultimate failure mode in all tests in virtually the same position, and it occurred after considerable rotation of the channel section at the eaves connection. This considerable rotation is responsible for redistributing moments from the eaves joint to other parts of the frame. A typical local buckling failure is shown in Figure 5 and is initiated in the bottom flange by stress concentrations, shear lag and bearing deformations, directly below the inside lower bolt, followed by buckling of the web. After local buckling, the applied load dropped slowly. 


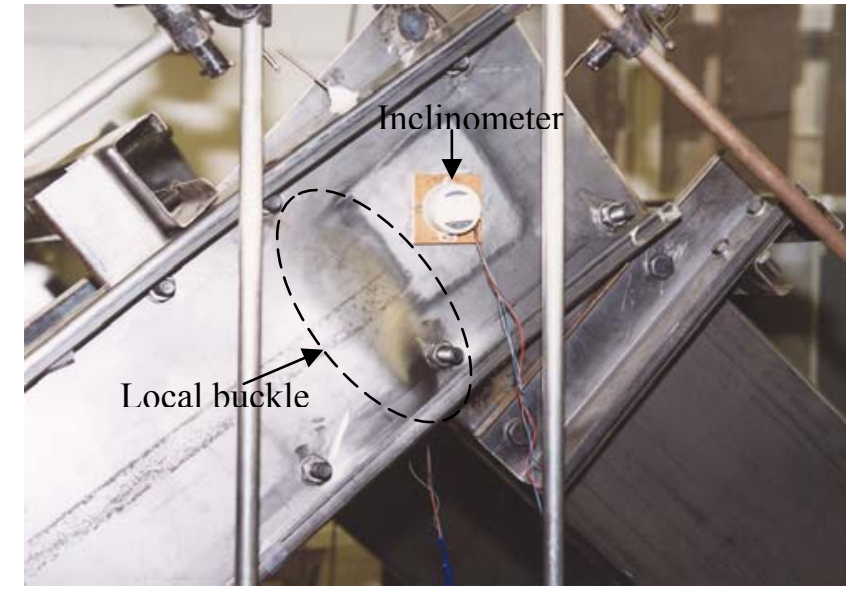

(a) Local Buckling Failure

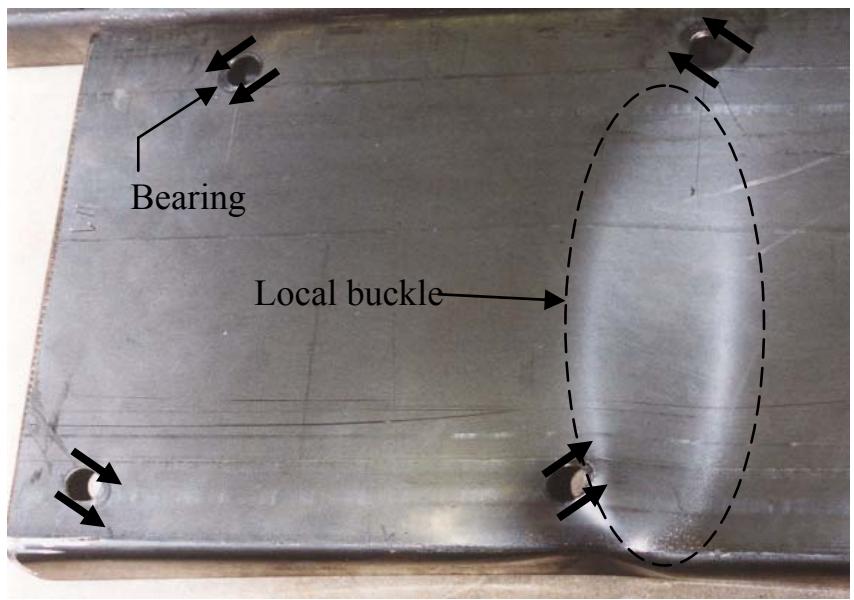

(b) Local Buckling and Bearing deformation

Figure 5. Failure Modes

Lateral-torsional buckling was the second mode of failure of concern. Although the longer laterally unsupported leg (rafter) did not ultimately fail due to lateral-torsional buckling there was considerable lateral movement and twisting of the leg near the maximum load. This was more evident in frames where the points of contraflexure were moved further away from the eaves connection (structures 2, 3 and 4) and narrower flanges were used to promote lateral-torsional instability (structures 3 and 4). Lateral-torsional buckling did not contribute to a loss of moment up to a slenderness ratio $\left(\mathrm{KL} / \mathrm{r}_{\mathrm{y}}\right)$ of about 101 . After testing, the frame members were disassembled for inspection. It was observed that the frames 1, 3 and 4 showed considerable bolt-bearing deformation around the bolt-holes. This type of distortion was more pronounced at the inside lower bolt-hole as shown in Figure 5(b), where the bolt-holes were distorted significantly. The distortions were influenced more by the larger moment than by the resultant of the axial and shear forces. This is demonstrated by the direction of the elongation of the bolt-hole (see arrows in Figure 5(b)). Bearing distortion of steel around bolt-holes is a ductile mode of failure and is intended to provide the ductility required for moment redistribution.

\section{MOMENT-ROTATION GRAPHS}

The flexural behaviour of a connection is best described by the relationship between the moment transmitted by the connection (M) and the relative rotation of the two members fastened by the connection $(\phi)$. The axial and shear deformations are usually small compared to the rotational deformation, consequently, only the connection's rotational deformation was considered. The moment adopted in these graphs is calculated using the initial lever arm between the joint centroid and the line of action of the tension jacks. No secondary effects were considered in calculating this moment. The rotation represents the change in angle between the rafter and the column at the centre of the connection. The slope of the moment-rotation curve is a measure of the rigidity or stiffness of the connection at any particular value of rotation.

Figure 6 show the average graphs for the two connections of each test structure. No rotation of the connections was experienced during the initial stages of loading since the applied load was probably carried by the frictional resistance between the webs of the channels in the connection. This might also have been caused by the fact that, before testing, considerable caution was exercised to make sure that all measuring instruments were working. To achieve this, the structures 
were initially loaded with relatively low intensities of load relative to the estimated failure load until the instrumentation was performing satisfactorily. The response of the connections for structures 1, 3 and 4 became progressively non-linear as ductile bearing distortions took place, in the presence of strain hardening, until failure occurred due to local buckling of the flange of the channel. Although the flange and web of the channel failed in local buckling there was also considerable deformation of the holes in bearing. The moment-rotation response in test 2 with 8 bolts is different from that in structures 1, 3 and 4 with 4 bolts, as the moment-rotation relationship remained largely linear-elastic until failure. The graph shows little evidence of non-linear deformation in the joint. There was no apparent bearing failure of the holes.

All connections except the ones for structure 2 gave a relatively smooth bilinear moment-rotation response, which eventually flattened out, at levels close to the ultimate moment. It can be noted from the moment-rotation curve that none of the tests has a well-defined yield point. The non-linear response and decreasing connection stiffness exhibited late in the loading sequence is attributed, primarily, to local yielding, bolt-bearing deformations and eventual yielding at the flange below the inside bolt. All connections are able to develop continually increasing moments through the full range of rotations imposed during the tests. The maximum rotation for each connection of approximately 0.02 radians is shown in Figure 6 and Table 2 and reflects useful ductility [3]. Considerably more ductility is achieved in mild steel channels (structures 3 and 4) than for high strength material (structures 1 and 2). Thus, there is greater moment redistribution capability in structures 3 and 4 than structures 1 and 2. No significant advantage in ultimate strength is gained by using 8 bolts as in the connections of test 2 .

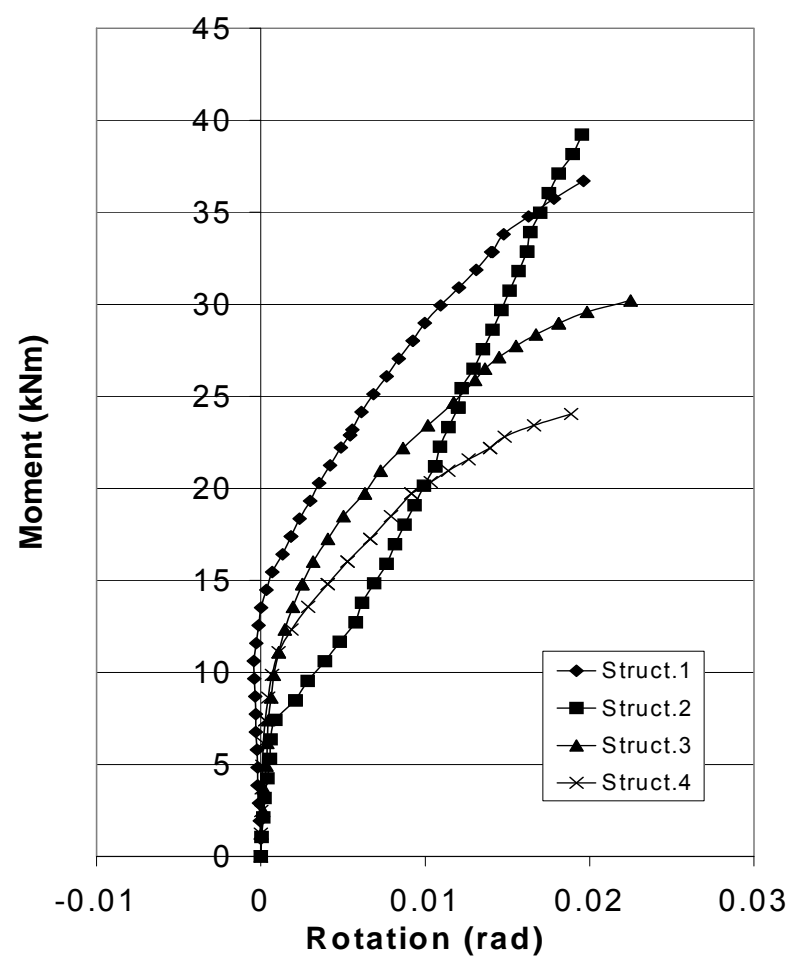

Figure 6. Moment-Rotation Curves 
Table 2. Rotation of Joint

\begin{tabular}{|c|c|c|c|c|c|c|}
\hline Structure & Section & Frames & $\begin{array}{c}\text { Column } \\
\text { rotation }\left(\phi_{\mathrm{c}}\right)\end{array}$ & $\begin{array}{c}\text { Rafter } \\
\text { rotation }\left(\phi_{\mathrm{r}}\right)\end{array}$ & $\begin{array}{c}\text { Joint } \\
\text { rotation }\left(\phi_{\mathrm{j}}\right)\end{array}$ & $\begin{array}{c}\text { Average } \\
\text { joint rotation } \\
\left(\phi_{\mathrm{ja}}\right)\end{array}$ \\
\hline Structure 1 & $300 \times 75 \times 20 \times 3$ & Frame 1 & 0.0105 & 0.0091 & 0.0196 & 0.0196 \\
& & Frame 2 & - & - & - & - \\
\hline Structure 2 & $300 \times 75 \times 20 \times 3$ & Frame 1 & 0.0127 & 0.0055 & 0.0182 & 0.0195 \\
& & Frame 2 & 0.0159 & 0.0049 & 0.0208 & \\
\hline Structure 3 & $300 \times 65 \times 20 \times 3$ & Frame 1 & 0.0116 & 0.0102 & 0.0218 & 0.0225 \\
& & Frame 2 & 0.0139 & 0.0093 & 0.0232 & \\
\hline Structure 4 & $300 \times 50 \times 20 \times 3$ & Frame 1 & 0.0100 & 0.0099 & 0.0199 & 0.0189 \\
& & Frame 2 & 0.0091 & 0.0087 & 0.0178 & \\
\hline
\end{tabular}

\section{ROTATION CAPACITY OF THE FRAMES}

A numerical investigation into the formation of hinges is carried out on the three frames using a mixed flexibility approach. This method simplifies elastic and inelastic structural analysis of frames, and is useful in determining the required inelastic rotation capacity or ductility of these frames and characteristics of semi-rigid connections. It is not the purpose of this paper to describe the mixed flexibility method in detail as this description is available in others papers [4-6]. However, a brief description of the method will be given here.

\subsection{Theory of Solving Unknown Moments}

The mixed flexibility method treats the end moments of all elements in a frame and independent sway deflections as the unknowns. The unknown moments are solved using rotation compatibility and moment equilibrium equations. Consider a substructure in Figure 7(a), with all members meeting at joint $i$. Joint $i$ can be assumed to be located at the point of maximum internal moment or at the centre of the member if no internal maximum moment exists. This makes it possible for inelastic behaviour within the element to be considered with the associated member loads. If element $i j$ is one of two elements in member $i j m$, then other elements meeting at joint $i$ are $i k$, and $i l$. The notation and sign convention for element $i j$ are illustrated in Figure 7(b) based on local $x$ and $y$ axes. Assuming that the displacements are small, the flexibility matrix relating end rotations $\theta$ to end moments $M$ and relative end deflections due to sway $d_{y}$ (all positive anti-clockwise) in element $i j$ is:

$$
\begin{aligned}
\left\{\begin{array}{c}
\theta_{i j} \\
\theta_{j i}
\end{array}\right\} & =\frac{L}{E I}\left[\begin{array}{cc}
1 / 3 & -1 / 6 \\
-1 / 6 & 1 / 3
\end{array}\right]\left\{\begin{array}{l}
M_{i j} \\
M_{j i}
\end{array}\right\}+\left\{\begin{array}{l}
d_{y j i} / L \\
d_{y j i} / L
\end{array}\right\} \\
& =[f]\{M\}+\left\{d_{y j i} / L\right\}
\end{aligned}
$$

where, $[f]$ is the normal flexibility matrix, $L$ and $E I$ are the length and elastic flexural rigidity of the element, respectively, and $d_{y j i}$ is the relative sway deflection normal to the element (see Figure $7(b))$. 

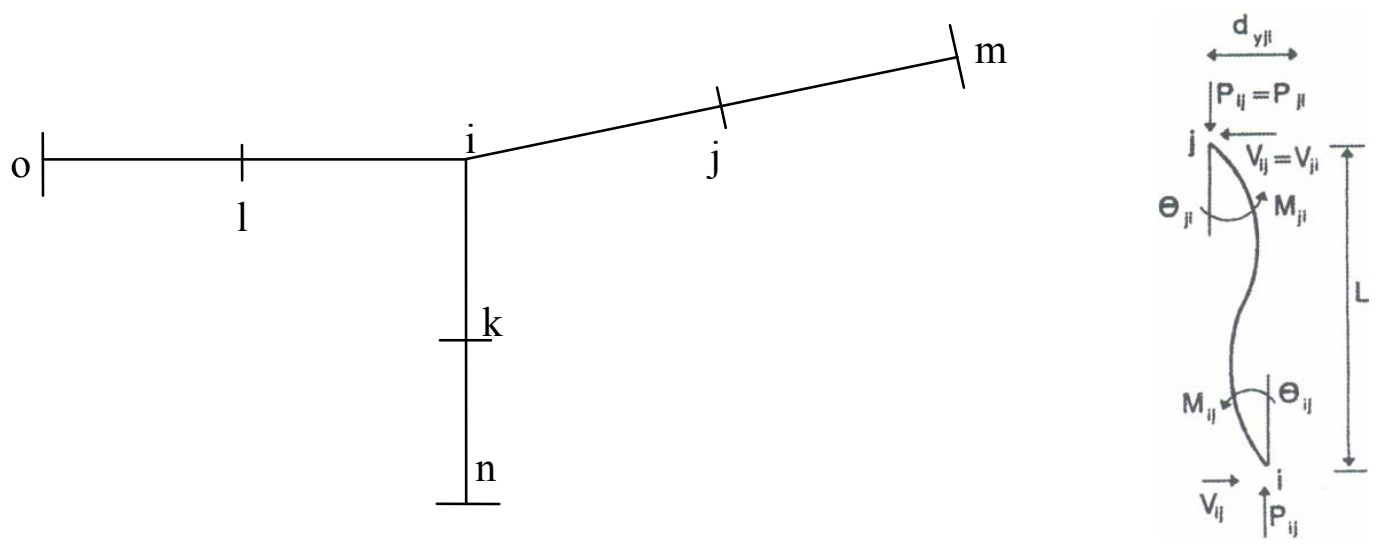

(a) Elements of Substructure

(b) Notation of Element $i j$

Figure 7. Substructure and Notation of Element $i j$

Changes in the flexibility of the element, caused by axial forces, can be accommodated by introducing Berry stability functions, $b_{1}$ and $b_{2}$ into Eq. 1 .

$$
\left\{\begin{array}{c}
\theta_{i j} \\
\theta_{j i}
\end{array}\right\}=\frac{L}{E I}\left[\begin{array}{cc}
b_{1} / 3 & -b_{2} / 6 \\
-b_{2} / 6 & b_{1} / 3
\end{array}\right]\left\{\begin{array}{l}
M_{i j} \\
M_{j i}
\end{array}\right\}+\left\{\begin{array}{l}
d_{y j i} / L \\
d_{y j i} / L
\end{array}\right\}
$$

Note that when second-order effects are neglected, the value of $b_{1}=b_{2}=1$. The moments $(n)$ at the end of the elements $(n)$ meeting at joint $i$ can be calculated by initial considering the equilibrium of the end moments at joint $i$, that is,

$$
\sum_{1}^{n} M_{i}=M_{i j}+M_{i k}+M_{i l}=M_{u}
$$

where, $M_{u}$ is the external moment applied at joint $i$. For three elements meeting at joint $i$ in Figure 7(a), there are two (n-1) independent compatibility equations representing equal rotations at end $i$ of elements $i j$ and $i k$; $i j$ and $i l$; as follows:

$$
\theta_{t i k}-\theta_{t i j}=0 ; \quad \theta_{t i l}-\theta_{t i j}=0
$$

where, $\theta_{t i j}, \theta_{t i k}, \theta_{t i l}$ are the total rotations at end $i$ of members $i j, i k$, and $i l$, respectively. Each of these total rotations may be calculated using the principle of superposition, for example in element ij:

$\theta_{t i j}=\theta_{i j}+\theta_{e i j}+\theta_{y i j}+\theta_{c i j}$

where, $\theta_{i j}$ is the elastic end rotation due to the unknown end moments and sway deflections (see Eq. 1), $\theta_{e i j}$ is the elastic end rotation in a simply-supported element due to element loads (i.e. when unknown end moments are equal to zero), $\theta_{y i j}$ is the inelastic rotation at end $i$ of the element, obtained by integrating the inelastic portion of the moment-curvature relationship over the length of the element $i j$, and $\theta_{c i j}$ is the elastic or inelastic rotation due to the end connection at end $i$ of element $i j$. These components of end rotation can be expressed in terms of the unknowns or the applied loads. When considering second-order effects, the end rotations due to the applied loads $\theta_{e i j}$ 
should also be adjusted for axial force using Berry functions. It must be recognised in the compatibility equations for a fixed support that each element has zero rotation.

The derivation of unknown end moments given above is sufficient for a structure without independent modes of sway. For a structure subjected to independent modes of sway refer to Kemp [5]. Several benefits are realized from the mixed flexibility over stiffness methods, namely; unknown moments easily converge towards known ultimate moment capacities, rotation compatibility equations easily accommodate inelastic end connections or inelastic behaviour of the adjacent elements, and that there is no back-substitution to calculate end moments. Equilibrium equations of moments at each joint are expressed in terms of unknown end moments, and these equations do not change in nonlinear analysis. The independent modes of sway deflection are the only unknown components of displacement and relate uniquely to the classical modes of instability, plastic sway or vibration. Axial forces in elements, which form the basis of iteration in nonlinear analysis, are determined by equilibrium considerations from the calculated end moments, and not as a function of small differences in large joint displacements, as is common in the stiffness method. The method requires the same number and arrangement of unknowns as in an elastic analysis. It provides an efficient and accurate solution to general non-linear analysis of steel frames which incorporates yielding and strain hardening of the elements and non-linear behaviour of semi-rigid joints. It also provides a direct calculation of the required inelastic rotation of the hinges in plastic analysis.

\subsection{Application to Cold-Formed Portal Frames}

Inelastic material behaviour is represented by bi-linear moment-rotation relationships, and can accommodate the effects of member loads. Bi-linear moment-rotation relationship models the moment-rotation curves in Figure 6 accurately. To determine the rotation capacity, the moment of resistance of the regions where the hinges are expected to occur had to be determined for the vertical loading case. The regions are denoted by the letters $\mathrm{A}, \mathrm{B}$ and $\mathrm{C}$ in the left half of a symmetrical portal frame, shown in Figure 8, and the moment capacities are given in Table 3. In Table 3, $\mathrm{M}_{\mathrm{y}}$ and $\mathrm{M}_{\mathrm{rb}}$ are the factored cross-sectional and buckling moment of resistance respectively. The buckling moment of resistance $\mathrm{M}_{\mathrm{rb}}$ is determined at the eaves under linear moment gradient in the region $\mathrm{B}$, assuming an effective length factor of 0.85 . It has been indicated before that the ultimate mode of failure of all structures tested was that of local buckling at the joint and that this type of failure was initiated in the bottom flange and web by stress concentrations, shear lag and bearing deformations. This means that the joint was more critical than the members. Local buckling occurred after considerable rotation of the channel section at the eaves connection. A decision was taken to reduce the moment of resistance of the channels so that it almost matches the moment of resistance of the joint. Thus, a factor of 0.8 is applied to $\mathrm{M}_{\mathrm{y}}$ and $\mathrm{M}_{\mathrm{rb}}$ in Table 3, to take account of stress concentrations, shear lag and bearing deformations in the connections [7]. The moment of resistance of the channel at first yield was found to be almost equal to the buckling moment of resistance of the channel. This was a clear indication that the channels were adequately restrained against lateral-torsional buckling. 
Uniformly distributed load

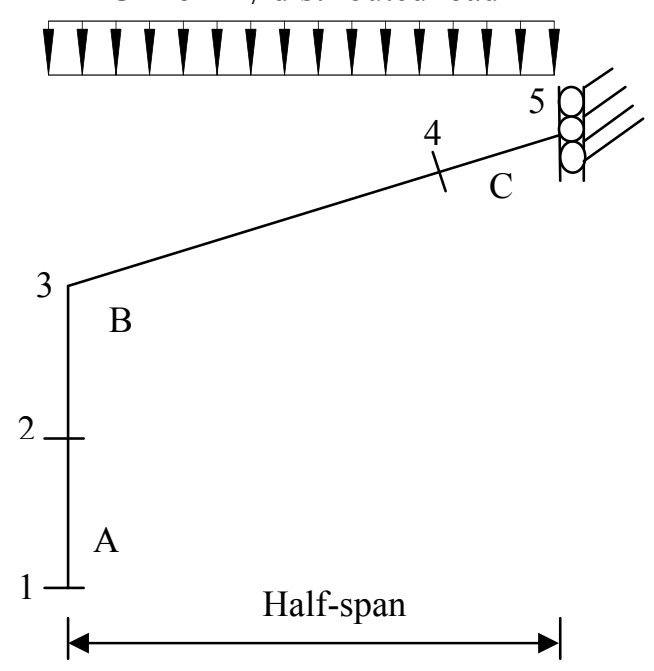

Figure 8. Half-Portal Frame

Table 3. Moment of Resistance of the Frames

\begin{tabular}{|c|c|c|c|c|c|c|c|c|c|}
\hline \multirow[t]{3}{*}{ Frame } & \multirow[t]{3}{*}{ Section } & \multirow{3}{*}{$\begin{array}{l}\text { Span } \\
\text { (m) }\end{array}$} & \multicolumn{7}{|c|}{ Moment of resistance $(\mathrm{kNm})$} \\
\hline & & & Region A & \multicolumn{2}{|c|}{ Region B } & \multicolumn{2}{|c|}{ Region $\mathrm{C}$} & \multirow{2}{*}{$\begin{array}{c}\text { Eaves } \\
\text { joint }\end{array}$} & \multirow{2}{*}{$\begin{array}{c}\text { Apex } \\
\text { joint }\end{array}$} \\
\hline & & & $0.5 \mathrm{M}_{\mathrm{B}}$ & $0.8 \mathrm{M}_{\mathrm{v}}$ & $0.8 \mathrm{M}_{\mathrm{rb}}$ & $0.8 \mathrm{M}_{\mathrm{v}}$ & $0.8 \mathrm{M}_{\mathrm{rb}}$ & & \\
\hline 1 & $300 \times 75 \times 20 \times 3$ & 10 & 9.39 & 19.64 & $18.78^{\mathrm{B}}$ & 19.64 & $17.93^{\mathrm{C}}$ & 22.35 & 22.76 \\
\hline 2 & $300 \times 65 \times 20 \times 3$ & 11 & 13.13 & 26.70 & $26.26^{\mathrm{B}}$ & 26.70 & $25.00^{\mathrm{C}}$ & 30.54 & 31.11 \\
\hline 3 & $300 \times 50 \times 20 \times 3$ & 12 & 17.48 & 37.13 & 35.86 & 37.13 & $33.58^{\mathrm{C}}$ & $34.95^{\mathrm{B}}$ & 35.60 \\
\hline
\end{tabular}

The critical moment of resistance of a particular region is used in the plastic analysis of the frames. This analysis is done for $50 \%$ base fixity and pinned base conditions. The moment capacity of the base is made half the moment capacity of the eaves joint following investigation by Robertson [8], and Heldt and Mahendran [9]. The investigations showed that a bolted base is about $50 \%$ fixed (having stiffness halfway between fixed and pinned conditions). This situation puts the base connection at between $40 \%-50 \%$ of the eaves connection. Possible points of hinge formation are numbered 1-5 in the portal frames considered (see Figure 8). As indicated in the derivation of unknown end moments, instability and inelastic behavior within the length of a member can be considered by providing one additional joint within the length of that particular member. The load and moments that cause the hinges to occur and the actual points where hinges are formed are given in Table 4 . The hinge at 6 occurs between points 4 and 5 in Figure 8.

In the lower bound analysis [4-6] the first hinge develops at point 1 because the relative moment capacity at that point is less than other points. The load causing the second hinge to form at 3 is slightly less for a pinned base than for a partially fixed base. The collapse loads in Table 4 are much greater than the factored applied ultimate load of $2.92 \mathrm{kN} / \mathrm{m}$. Collapse occurs when the third hinge forms between points 4 and 5 in Figure 8. The plastic rotations required for the three frames at hinges 1 and 3 are shown in Table 5. The required hinge rotations at failure of the pinned base are less than that of the partially fixed base. The largest hinge rotations are required at hinge 3 . Considering all 3 frames and both foundation conditions it is apparent from Table 5 that plastic collapse will develop if the available plastic hinge rotation $\theta_{\mathrm{p}}$ at 3 is between 0.01 and 0.02 radians. This rotation was achieved by all the structures tested, showing that plastic collapse is feasible. 
Table 4. Load, Moment and Points of Hinge Formation

\begin{tabular}{|c|c|c|c|c|c|c|c|c|c|}
\hline \multirow[t]{2}{*}{ Frame } & \multirow[t]{2}{*}{ Section } & \multirow{2}{*}{$\begin{array}{l}\text { Span } \\
\text { (m) }\end{array}$} & \multirow{2}{*}{$\begin{array}{l}\text { Base } \\
\text { fixity }\end{array}$} & \multicolumn{2}{|c|}{ Hinge 1} & \multicolumn{2}{|c|}{ Hinge 3} & \multicolumn{2}{|c|}{ Hinge 6} \\
\hline & & & & $\begin{array}{c}\text { Load } \\
(\mathrm{kN} / \mathrm{m})\end{array}$ & $\begin{array}{c}\text { Moment } \\
(\mathrm{kNm})\end{array}$ & $\begin{array}{c}\text { Load } \\
(\mathrm{kN} / \mathrm{m})\end{array}$ & $\begin{array}{c}\text { Moment } \\
(\mathrm{kNm})\end{array}$ & $\begin{array}{c}\text { Load } \\
(\mathrm{kN} / \mathrm{m})\end{array}$ & $\begin{array}{c}\text { Moment } \\
(\mathrm{kNm})\end{array}$ \\
\hline \multirow[t]{2}{*}{1} & \multirow[t]{2}{*}{$300 \times 75 \times 20 \times 3$} & \multirow[t]{2}{*}{10} & $50 \%$ & 2.05 & -9.39 & 3.03 & 18.78 & 3.58 & 18.78 \\
\hline & & & $0 \%$ & - & - & 2.95 & 18.78 & 3.36 & 18.78 \\
\hline \multirow[t]{2}{*}{2} & \multirow[t]{2}{*}{$300 \times 65 \times 20 \times 3$} & \multirow[t]{2}{*}{11} & $50 \%$ & 2.30 & -13.13 & 3.52 & 26.26 & 4.20 & 26.26 \\
\hline & & & $0 \%$ & - & - & 3.40 & 26.26 & 3.93 & 26.26 \\
\hline \multirow[t]{2}{*}{3} & \multirow[t]{2}{*}{$300 \times 50 \times 20 \times 3$} & \multirow[t]{2}{*}{12} & $50 \%$ & 2.51 & -17.48 & 3.97 & 34.95 & 4.81 & 34.95 \\
\hline & & & $0 \%$ & - & - & 3.90 & 35.86 & 4.54 & 35.86 \\
\hline
\end{tabular}

Table 5. Plastic Rotation

\begin{tabular}{|c|c|c|c|c|c|c|}
\hline \multirow[t]{2}{*}{ Frame } & \multirow[t]{2}{*}{ Section } & \multirow{2}{*}{$\begin{array}{l}\text { Span } \\
\text { (m) }\end{array}$} & \multirow[t]{2}{*}{ Base fixity } & \multirow{2}{*}{$\begin{array}{c}\text { Plastic collapse } \\
\text { load }(\mathrm{kN} / \mathrm{m})\end{array}$} & Hinge 1 & Hinge 3 \\
\hline & & & & & $\theta_{\mathrm{p}}$ & $\theta_{\mathrm{p}}$ \\
\hline \multirow[t]{2}{*}{1} & \multirow[t]{2}{*}{$300 \times 75 \times 20 \times 3$} & \multirow[t]{2}{*}{10} & $50 \%$ & 3.58 & 0.0032 & 0.009 \\
\hline & & & $0 \%$ & 3.36 & - & 0.007 \\
\hline \multirow[t]{2}{*}{2} & \multirow[t]{2}{*}{$300 \times 65 \times 20 \times 3$} & \multirow[t]{2}{*}{11} & $50 \%$ & 4.20 & 0.0048 & 0.015 \\
\hline & & & $0 \%$ & 3.93 & - & 0.011 \\
\hline \multirow[t]{2}{*}{3} & \multirow[t]{2}{*}{$300 \times 50 \times 20 \times 3$} & \multirow[t]{2}{*}{12} & $50 \%$ & 4.81 & 0.0071 & 0.021 \\
\hline & & & $0 \%$ & 4.54 & - & 0.016 \\
\hline
\end{tabular}

\section{CONCLUSION}

The tests demonstrate the considerable ductility that is achieved in the back-to-back bolted connections, which should be sufficient in many cases to accommodate plastic analysis of the portal frames. Adjacent column and rafter channels are oriented in opposite directions to take advantage of the counter-balancing moments and forces in the back-to-back connections. This system is important in enhancing the lateral buckling strength of the channels. Three modes of failure were observed [7], namely: local buckling of the compression zone of the flange and web of the channels, lateral torsional buckling of the channels between points of lateral support and bolts in bearing. The source of failure in all structures was local buckling of the compression flange and web. This occurred after considerable rotation of the channel sections within the eaves connection. Local buckling was made more critical by stress concentrations, shear lag and bearing deformations caused by back-to-back bolted connections.

Test observation shows joint resistance to be critical. This is necessary for inelastic rotation. The experimental maximum rotation of the connections of approximately 0.02 radians shows that there is substantial ductility that can be salvaged from cold-formed portal frames. Figure 6 also shows that considerably more ductility is achieved in mild steel channels (structures 3 and 4) than for high strength material (structures 1 and 2). This implies that there is greater moment redistribution capability in structures 3 and 4 than structures 1 and 2. As indicated previously, no significant advantage in ultimate strength is gained by using 8 bolts as in the connections of test 2 .

Kemp's mixed flexibility approach [4-6] is used to determine the required inelastic rotation of the hinges rotations of the three frames at the eaves joints. The analysis is done for both $50 \%$ base fixity and pinned base conditions. The collapse loads in Table 4 are much greater than the factored applied ultimate load of $2.92 \mathrm{kN} / \mathrm{m}$ (Table 3 ) used to design these frames. It is apparent from Table 
5 that plastic collapse will develop if the available plastic hinge rotation $\theta_{\mathrm{p}}$ at 3 is between 0.01 and 0.02 radians. This rotation was achieved by all the structures tested, showing that plastic collapse is feasible. A comparison of the experimental and theoretical rotations shows that they are within the same range.

\section{References}

[1] SANS 10162-2., "South Africa Standard Code of Practice for the Structural Use of Steel, Part 2 - Limit States Design of Cold-formed Steelwork", South African Bureau of Standards, Pretoria, 2005.

[2] CAN/CSA-S16-01., "Steel Structures for Buildings - Limit States Design, Canadian Standards Association, Rexdale (ON), 2001.

[3] Chen, W.F. "Practical Aanalysis for Semi-rigid Frame Design", World Scientific, 2000.

[4] Kemp, A.R., "A Mixed Flexibility Approach for Simplifying Elastic and Inelastic Structural Analysis of Frames", Journal of Construction Steel Research, 2002, Vol. 58, pp. 1297-1313.

[5] Kemp, A.R., "Compatibility Relationships in a Mixed Flexibility-based Method of Frame Analysis", Engineering Structures, 1997, Vol. 19, No. 3, pp. 267-275.

[6] Kemp, A.R., "A Consistent Mixed Approach to Computer Analysis of Frames", Civil Eng. South Africa, 1989, Vol. 30 No. 7, pp. 317-322.

[7] Dundu, M. and Kemp, A.R., "Strength Requirements of Single Cold-formed Channels Connected Back-to-back", Journal of Construction Steel Research, 2006, Vol. 62, pp. 250-261.

[8] Robertson, A.P., “A Study of Base Fixity Effects on Portal Frame Behavior”, The Structural Engineer, 1991, Vol. 69, No. 2, pp. 17-24.

[9] Heldt, T.J. and Mahendran, M., "Full Scale Experiments of a Steel Portal Frame Building", Australian Institute of Steel Construction, 1998, Vol. 32 No. 4, pp. 2-15. 


\title{
BEHAVIOR OF HIGH STRENGTH CONCRETE FILLED SQUARE STEEL TUBULAR COLUMNS WITH INNER CFRP CIRCULAR TUBE UNDER BI-AXIAL ECCENTRIC LOADING
}

\author{
G.C. Li ${ }^{1, *}$, Z.J. Yang ${ }^{2}$, Y. Lang ${ }^{3}$ and C. Fang ${ }^{1}$ \\ ${ }^{1}$ School of Civil Engineering, Shenyang Jianzhu University, Shenyang, 110168, China \\ ${ }^{2}$ School of civil Engineering, Tianjin University, Tianjin, 300072, China \\ ${ }^{3}$ Department of building Engineering, Suqian College, Jiangsu Province, 223800, China \\ *(Corresponding author: E-mail: cegcli@sjzu.edu.cn)
}

Received: 16 January 2012; Revised: 18 May 2012; Accepted: 22 May 2012

\begin{abstract}
This paper presents a theoretical study of high strength concrete filled square steel tubular columns with inner CFRP (carbon fiber-reinforced polymer) circular tube subjected to bi-axial eccentric loading. The new type of composite member is composed of a CFRP inner tube and a outer steel tube with concrete filled in the two tubes. The finite element analysis (FEA) is made by ABAQUS software on the behavior of high strength concrete filled square steel tubular columns with inner CFRP circular tube subjected to bi-axial eccentric loading. The results obtained from the finite element analysis were verified with the experimental results. An extensive parametric study was conducted to investigate the effects of steel yielding strength, concrete strength, steel ratio, slenderness ratio on the interaction curve $N / N_{u}-M / M_{u}$ of column subjected to bi-axial eccentric loading. The parametric studies provide information for the development of formula to calculate the bearing capacity. The experimental failure load and the predicted failure load calculated by the formula showed good agreement.
\end{abstract}

Keywords: CFRP tube, Square steel tube, High strength concrete, Bi-axial eccentric load, Finite element analysis (FEA)

\section{INTRODUCTION}

Concrete-filled square steel tubular (CFST) column has a higher bearing capacity, better ductility performance and fatigue resistance than common reinforced concrete and hollow steel section columns. And it also has some unique characteristics: (1) the simple type of beam-to-column connection, (2) the flexible building layout, (3) the stable behavior with large cross-section moment of inertia, (4) convenient construction. In recent, CFST were used widely in modern civil engineering, especially in high-rise buildings. Taipei 101, a 508-m high office tower, used rectangular columns with a maximum cross-sectional dimension of $2400 \mathrm{~mm} \times 3000 \mathrm{~mm}$, and finally the section of the column was reduced to $1600 \mathrm{~mm} \times 2000 \mathrm{~mm}$ [1]. Hangzhou Ruifeng commercial building was a 24-storey building with the height $88.2 \mathrm{~m}$, and the maximum section of $600 \times 600 \mathrm{~mm}$ CFST column was used in the structure.

Many research projects have been conducted in the past few decades to investigate the behaviors of CFST columns subjected to axial compression and concentric load (Dalin Liu (2003, 2004, 2006) [2-4], Ehab Ellobody[5-6], F.W. Lu (2007) [7], Manojkumar V(2010)[8], Han. ect ( 2001, 2002 ) [9-10], Mursi and Uy $(2001,2003,2004)$ [11-13]. It is well known that concrete-filled steel tubes, such as the columns (particularly at corners) of a tall building under horizontal wind or earthquake, may be subjected to bi-axial bending in practice. At present, the researches about column under bi-axial eccentric loading are seldom. Mursi and Uy have presented experimental and theoretical studies of fabricated high strength steel tubular columns subjected to biaxial bending [14-15]. Jie-Peng Liu and Hua Tian illustrated the pertinence relation for the three-dimensional bearing capacity of the members and presented the simplified formula [16-17]. Tokgoz, S reported the test results of 16 concrete-filled steel tubular columns subjected to bi-axial bending and short-term axial loading [18]. 
The concrete filled square steel tubular column with inner CFRP circular tube is composed of a CFRP inner tube, a outer steel tube, and concrete filled in the two tubes, as shown in Figure 1. In order to study the mechanical behavior of high strength concrete filled square steel tubular columns with inner CFRP circular tube (HCFSTF), the test of HCFSTF subjected to bi-axial eccentric loading has been done. The specimens finally quit working owing to the unstable failure [19]. FEA on HCFSTF subjected to bi-axial eccentric loading is presented in this paper. The calculating results of the model show good agreement with testing results.

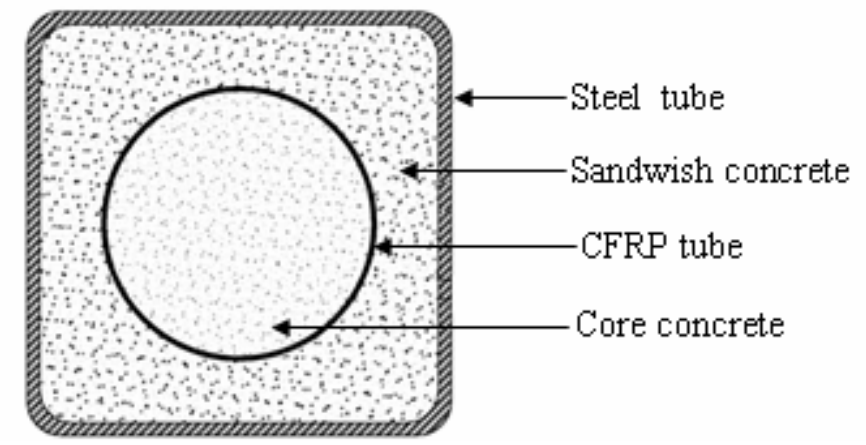

Figure 1. Cross Section of CFST with Inner CFRP Tube

\section{FINITE ELEMENT ANALYSIS}

\subsection{Material Constitutive Model}

\subsubsection{Steel}

The elastic-plastic behavior provided by ABAQUS was used to describe the constitutive behavior of the steel. Since cold-formed steel tubes were used in the test, different strengths and residual stresses in the corner zone and the flat zone should be considered. Therefore, an idealized multi-linear stress-strain model (as shown in Figure 2), which was developed by Abdel-Rahman and Sivakumaran [20], was adopted in this analysis. The first part of the multi-linear curve represents the elastic part up to the proportional limit stress with Young's modulus $E_{s}=206 \mathrm{GPa}$, and Poisson's ratio $(v)$ was taken as 0.3 .

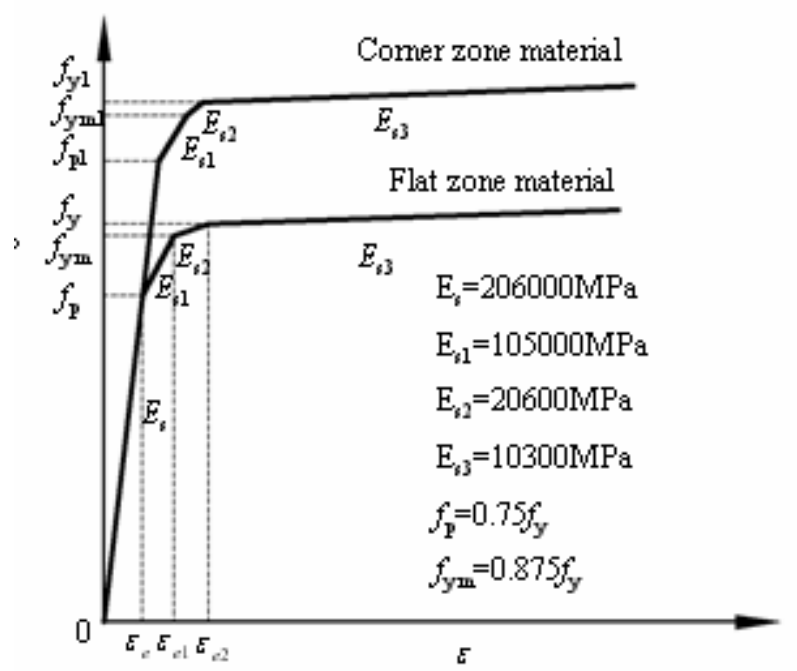

Figure 2. Idealized Stress-strain Relationships for Cold-formed Steel 


\subsubsection{Concrete}

The damaged plastic model provided by the ABAQUS library was adopted to simulate the concrete. Considering the concrete was confined by steel tube and CFRP tube, the stress-strain relationship of the core concrete proposed by Han was applied for ABAQUS finite element analysis [21]. The fracture energy-crack displacement model was used to emulate the tension stress-strain of concrete [22].

\subsubsection{FRP}

To reduce these possible complexities, the CFRP was assumed to be a linear elastic material. The CFRP confinement was also linear elastic. When the confinement reached its maximum fracture strength, the CFRP confinement was removed from the analysis. The specific expression is as follows:

$$
\begin{array}{ll}
\varepsilon \leq \varepsilon_{\mathrm{f}}, & \sigma_{\mathrm{f}}=E_{\mathrm{f}} \varepsilon \\
\varepsilon>\varepsilon_{\mathrm{f}}, & \sigma_{\mathrm{f}}=0
\end{array}
$$

Where $\sigma_{\mathrm{f}}$ is the ultimate stress of the fiber, $E_{\mathrm{f}}$ is the modulus of elasticity, $\varepsilon_{\mathrm{f}}$ is the ultimate strain.

\section{$2.2 \quad$ Finite Element Model}

The steel tube and concrete were modeled with 8-node brick elements (C3D8R), and a quad-node first-order reduced integration shell element (S4R) was chosen for CFRP tube. In order to simplify the problem and to reduce computational effort, only one quarter of the specimen was modeled in the analysis due to symmetry. Symmetric boundary conditions were enforced on the symmetric planes which were XSYMM and ZSYMM boundary conditions, shown in Figures 2. The meshes of the finite element models are shown in Figures 3. The nonlinear calculation exerted by displacement control was easier to be convergent. The incremental iterative method was used to solve nonlinear equations. More details of the FEA modeling can be found in the reference [19].

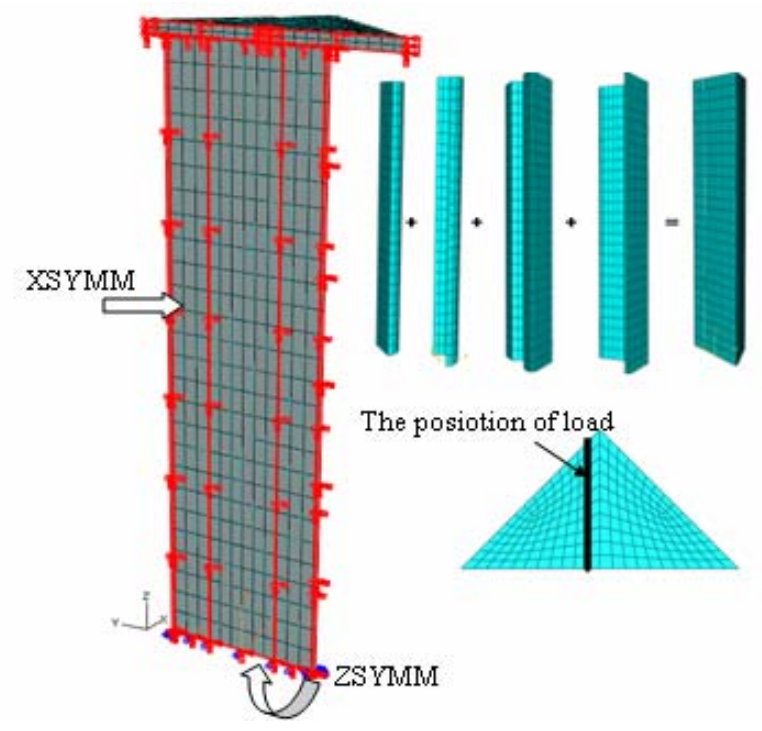

Figure 3. Boundary Condition of Analytical Model 
The FEA model established through the ABAQUS/Standard solver was used to simulate the concrete-filled square steel tube column with inner circular CFRP tube subjected to bi-axial eccentric loading. Table 1 shows the full details of the specimens and the comparisons between the finite element results and the experimental results. The average ratio of $M_{c 1} / M_{e}$ is 1.018 and the standard deviation is 0.073. It can be seen that the experimental results math the numerical modeling results well. Where $t_{s}$ is nominal thickness of steel tube; $t_{c}$ is measured thickness of CFRP tube; $f_{y}$ is yield strength of steel; $f_{C F R P}$ is ultimate tensile strength of CFRP; $e_{x}, e_{y}$ is the eccentricity along x and y axis; $N_{e}$ is the ultimate load of experimental result, $N_{c l}$ is the ultimate load of finite element calculation, and $N_{c 2}$ is the ultimate load of the simplified formula calculation.

\subsection{Load-deflection Relationship of Columns}

The predicted curves of load versus the lateral deflection at the mid-height of the columns are verified with the experimental data in Figures 4. The numerical results show a good agreement with the experimental data. As the Figures 4 shown, after the ultimate load, when the load declined to $80 \%$ of the ultimate load, the bearing capacity sharply declined because the CFRP at the mid-height of the columns reached the ultimate load, which caused the constraint deprivation of the core concrete. In addition, the numerical results and the experimental data in Figures 3 (b), (g), (h) do not match well at the last phase of the curves because local buckling is occurred at the end of specimens after the peak load.

Table 1. Test Results and Calculation Results

\begin{tabular}{cccccccccccc}
\hline Specimen & $\begin{array}{c}t_{s} \\
(\mathrm{~mm})\end{array}$ & $\begin{array}{c}f_{y} \\
(\mathrm{MPa})\end{array}$ & $\begin{array}{c}f_{u} \\
(\mathrm{MPa})\end{array}$ & $\begin{array}{c}t_{c} \\
(\mathrm{~mm})\end{array}$ & $\begin{array}{c}f_{\text {CFRP }} \\
(\mathrm{MPa})\end{array}$ & $\begin{array}{c}e_{x}=e_{y} \\
(\mathrm{~mm})\end{array}$ & $\begin{array}{c}N_{e} \\
(\mathrm{kN})\end{array}$ & $\begin{array}{c}N_{c 1} \\
(\mathrm{kN})\end{array}$ & $\begin{array}{c}N_{c 2} \\
(\mathrm{kN})\end{array}$ & $N_{c 1} / N_{e}$ & $N_{c 2} / N_{e}$ \\
\hline ESF4-5-28 & 4.5 & 291 & 79.7 & 0.334 & 3718 & 20 & 2483 & 2602 & 2793 & 1.048 & 1.125 \\
ESF4-5-71 & 4.5 & 291 & 79.7 & 0.334 & 3718 & 50 & 1761 & 1774 & 1608 & 1.008 & 0.914 \\
ESF4-5-113 & 4.5 & 291 & 79.7 & 0.334 & 3718 & 70 & 1063 & 1266 & 1155 & 1.191 & 1.086 \\
ESF6-5-28 & 4.5 & 291 & 79.7 & 0.334 & 3718 & 20 & 2618 & 2566 & 2731 & 0.980 & 1.043 \\
ESF6-5-71 & 4.5 & 291 & 79.7 & 0.334 & 3718 & 50 & 1463 & 1526 & 1559 & 1.043 & 1.065 \\
ESF6-5-113 & 4.5 & 291 & 79.7 & 0.334 & 3718 & 70 & 1146 & 1150 & 1109 & 1.002 & 0.967 \\
ESF8-5-28 & 4.5 & 291 & 79.7 & 0.334 & 3718 & 20 & 2417 & 2413 & 2661 & 0.998 & 1.101 \\
ESF8-5-71 & 4.5 & 291 & 79.7 & 0.334 & 3718 & 50 & 1508 & 1541 & 1454 & 1.022 & 0.965 \\
ESF8-5-113 & 4.5 & 291 & 79.7 & 0.334 & 3718 & 70 & 1022 & 1064 & 1058 & 1.040 & 1.035 \\
ESF10-5-28 & 4.5 & 291 & 79.7 & 0.334 & 3718 & 20 & 2346 & 2326 & 2586 & 0.992 & 1.102 \\
ESF10-5-71 & 4.5 & 291 & 79.7 & 0.334 & 3718 & 50 & 1477 & 1362 & 1356 & 0.922 & 0.918 \\
ESF10-5-113 & 4.5 & 291 & 79.7 & 0.334 & 3718 & 70 & 1004 & 957 & 1007 & 0.953 & 1.003 \\
ES4-4-71 & 3.5 & 306 & 79.7 & 0 & -- & 50 & 1524 & 1637 & 1501 & 1.074 & 0.985 \\
ES4-6-71 & 5.8 & 333 & 79.7 & 0 & -- & 50 & 1896 & 1899 & 1828 & 1.002 & 0.964 \\
ES6-4-71 & 3.5 & 306 & 79.7 & 0 & -- & 50 & 1548 & 1546 & 1406 & 0.999 & 0.908 \\
ES6-6-71 & 5.8 & 333 & 79.7 & 0 & -- & 50 & 1845 & 1818 & 1723 & 0.986 & 0.934 \\
ES8-4-71 & 3.5 & 306 & 79.7 & 0 & -- & 50 & 1517 & 1455 & 1314 & 0.959 & 0.867 \\
ES8-6-71 & 5.8 & 333 & 79.7 & 0 & -- & 50 & 1717 & 1738 & 1619 & 1.012 & 0.943 \\
\hline
\end{tabular}

The specimen type (for example:ESF4-5-28) in Table 1 is labeled as follows: letter E stands for specimen subjected to bi-axial eccentric loading; S stands for steel; F stands for FRP; 4 stands for ratio of specimen length to size of section side, $L / B=4,6,8,10$; next $5,4,6$ stands for the thickness of steel tube respectively in $\mathrm{mm} ; 28,71,113$ stands for eccentricity respectively in mm.. 


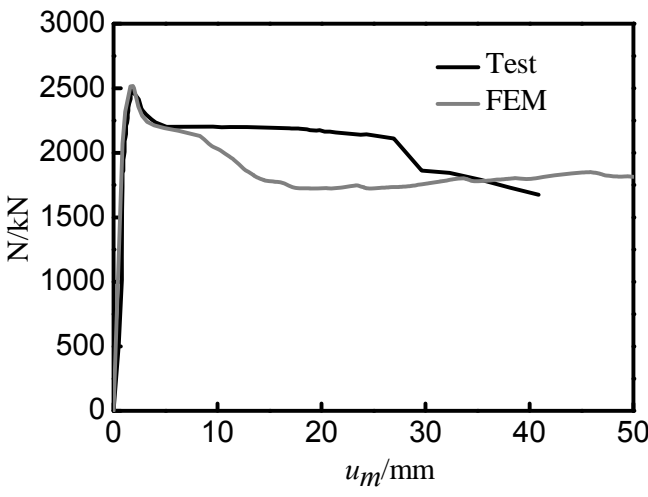

(a) ESF4-5-28

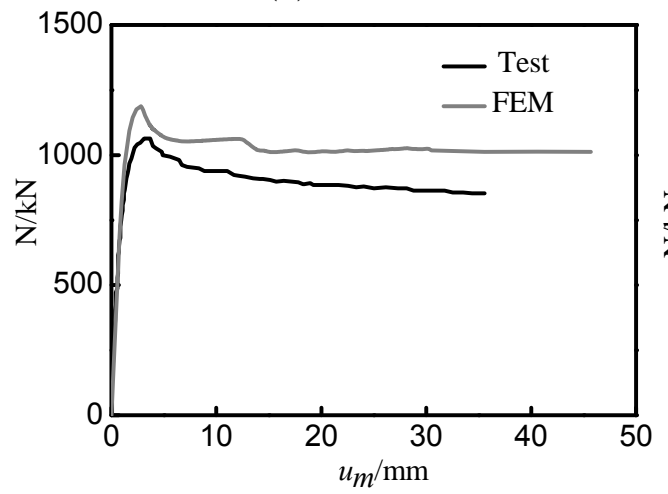

(c) ESF4-5-113

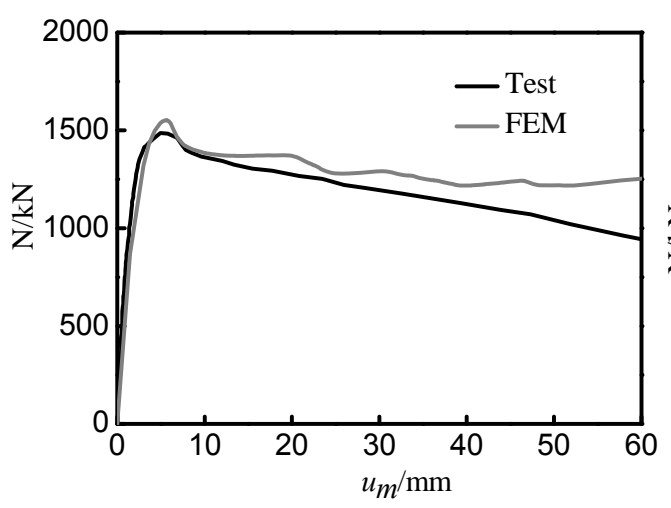

(e) ESF6-5-71

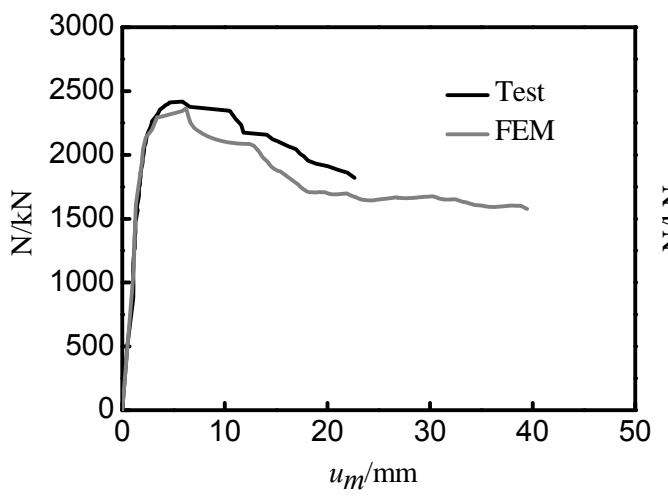

(g) ESF8-5-28

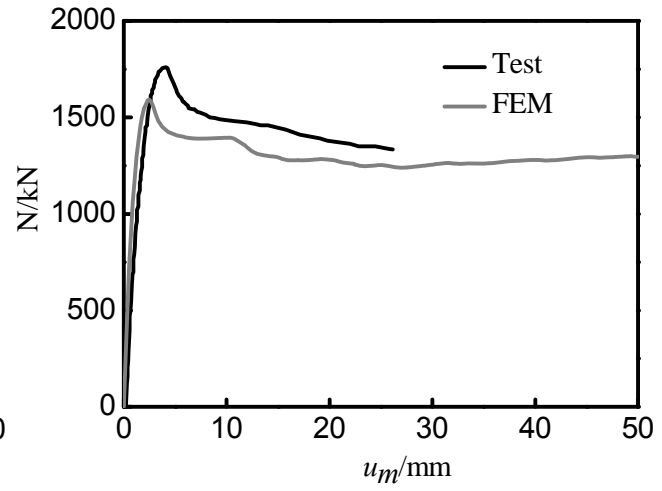

(b) ESF4-5-71

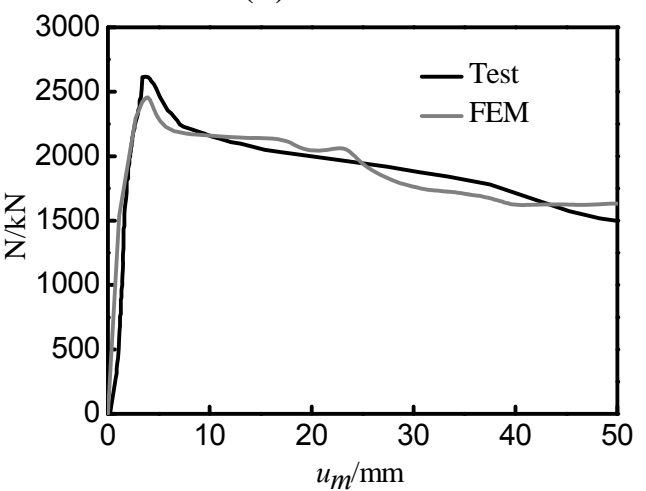

(d) ESF6-5-28

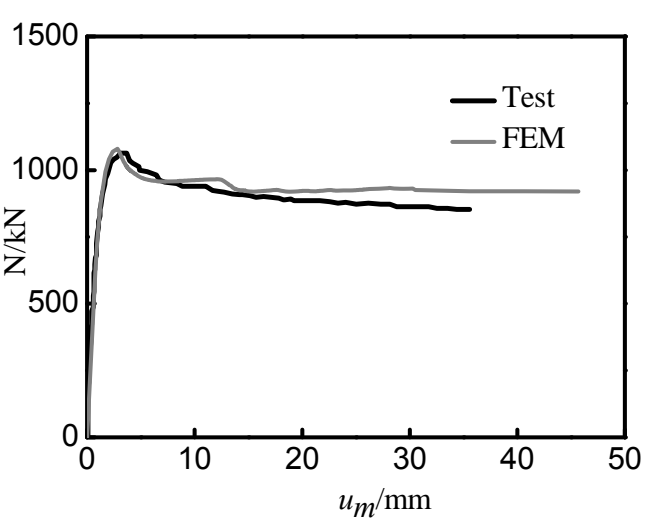

(f) ESF6-5-113

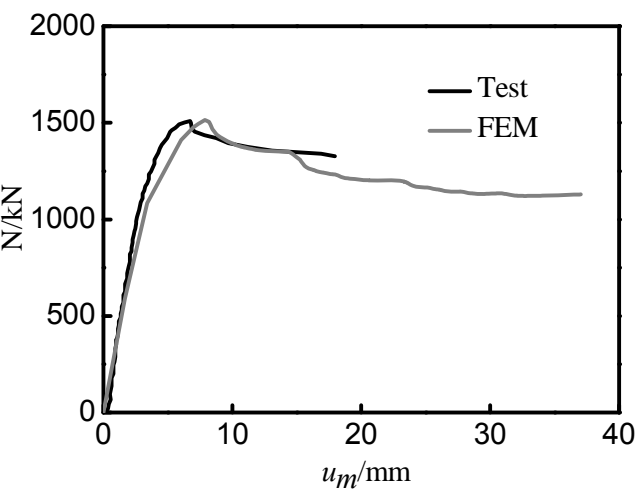

(h) ESF8-5-71 


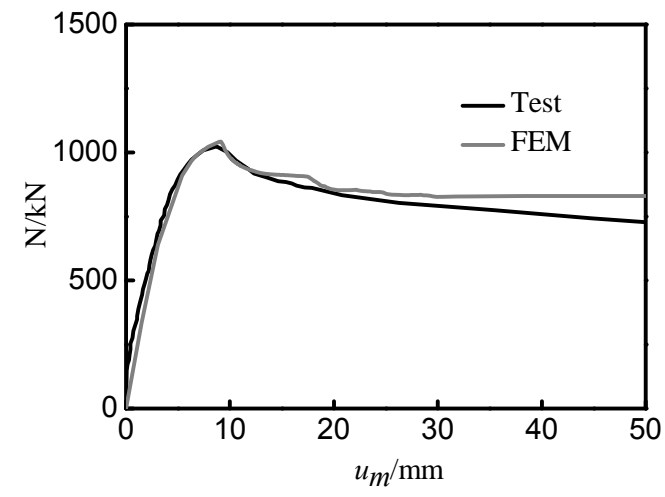

(i) ESF8-5-113

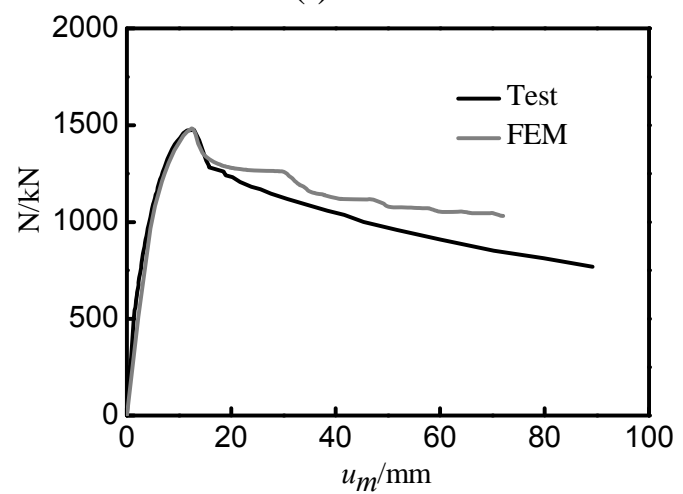

(k) ESF10-5-71

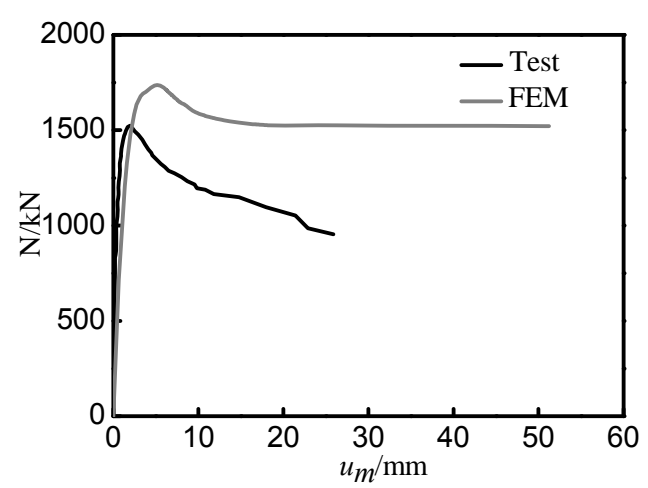

(m) ES4-4-71

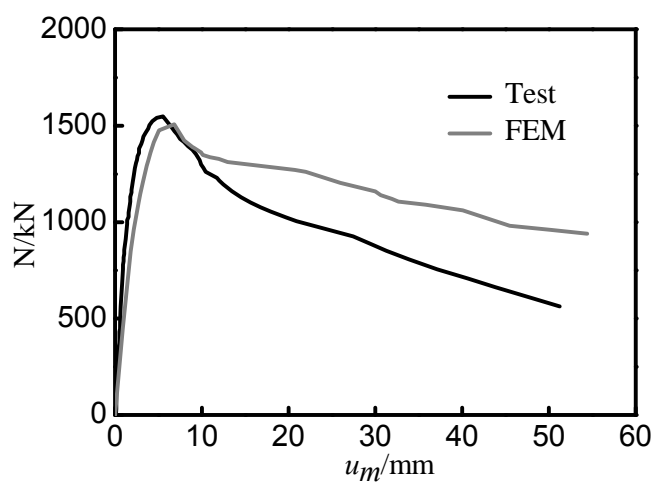

(o) ES6-4-71

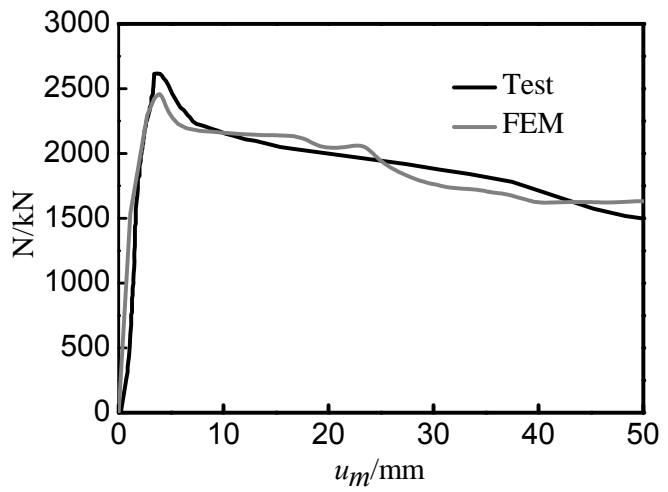

(j) ESF10-5-28

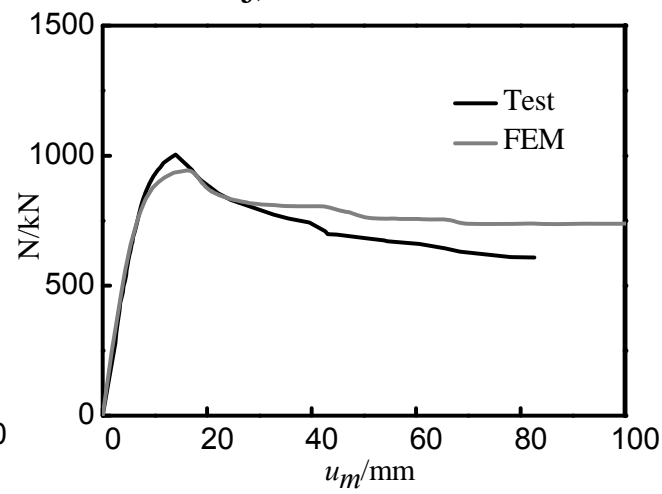

(l) ESF10-5-113

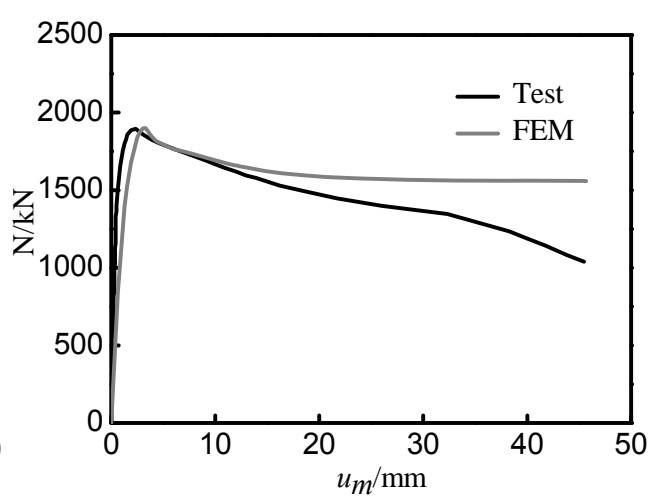

(n) ES4-6-71

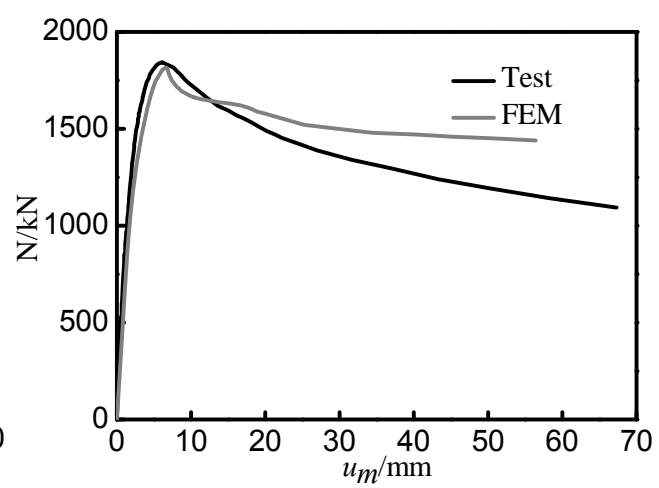

(p) ES6-6-71 


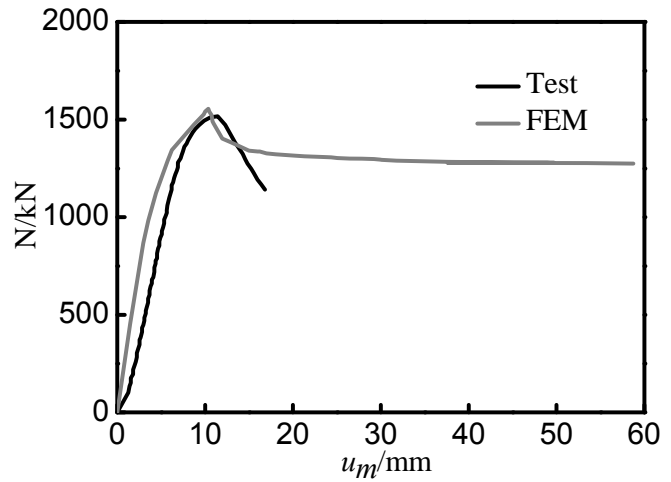

(q) ES8-4-71

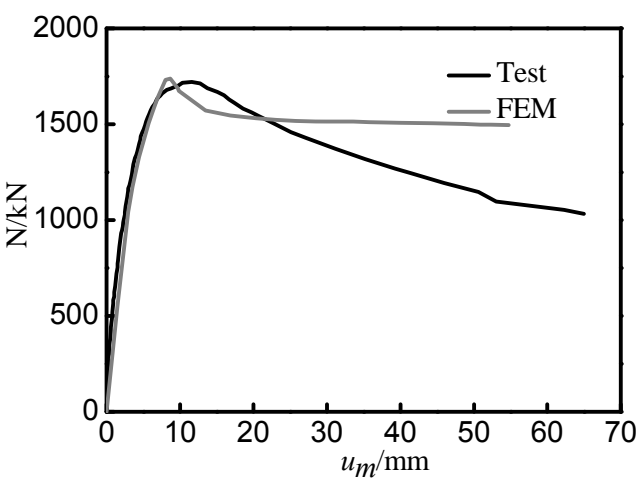

(r) ES8-6-71

Figure 4. Comparisons of Predicted Load Versus Deflection Curves of Columns with Tested Results

\subsubsection{Analysis on Load-deformation Curve}

The typical curve of load versus deflection was calculated and shown in Figures 5. The curve can be divided into four stages.

Elastic stage (OA): As lateral expansion of the steel tube is larger than that of the concrete during the initial loading stage, there is little interaction between the steel tube and the sandwich concrete. The steel and concrete bear the load independently in this stage. The steel is yielded at point A.

Elastic-plastic stage (AB): In this stage, the crack occurs in the concrete and lateral expansion of the concrete exceeds that of the steel tube. It makes the steel in biaxial stress condition and the concrete in tri-axial stress condition. And the steel tube begins to confine the concrete. The steel tube developes plastic from point $\mathrm{A}$ in the compression zone. As the load increases, the plastic zone expands to the peak point $B$.

Descent stage (BC): In this stage, load - deflection curve tends to decline after the steel tube has developed plasticity fully. At point $B$, the specimen achieves the ultimate bearing capacity. The bearing capacity lasts for a moment and then the curve goes down quickly. Local buckling of the steel tube on the compression side occurs at the mid height of the specimen. It makes the sandwich concrete lose confinement from steel tube. But the core concrete is still confined by CFRP tube and bear a large proportion of the vertical load. As the deflection reaches a certain value, the bearing capacity begins to descend slowly, and the deflection increase rapidly. The strain of CFRP tube increases until point $\mathrm{C}$.

Descent stage (CD): At point C, the CFRP tube reaches the ultimate strain, the confinement of CFRP tube disappears, and the bearing capacity declines again. Due to the increase of side deflection, the specimens finally quit working owing to unstable failure. 


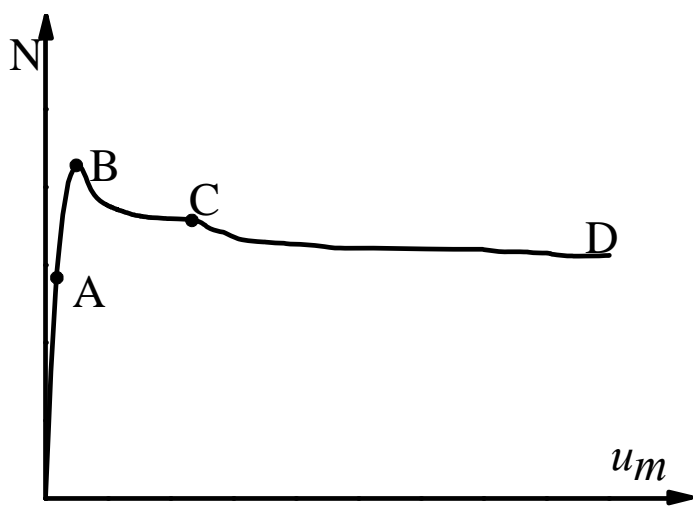

Figure 5. Load (N) to Deflection $\left(u_{m}\right)$ Relations

The concrete stress isoline of mid-height section of specimen ESF4-5-113 is illustrated in Figures 6. The picture of a1, a2 and a3 are stress isolines of sandwich concrete at point $\mathrm{B}, \mathrm{C}, \mathrm{D}$ respectively in Figures 5. The picture of b1, b2 and b3 are stress isolines of core concrete at point $\mathrm{B}, \mathrm{C}, \mathrm{D}$ respectively in the Figures 5 . It can be seen that the tension area expends and compression area reduces with the increasing of the load, and the neutral axis gradually approaches to compression zone from Figures 6. The stress ratio of the compression concrete and the confinement stress of corner concrete increases continuously after the CFRP rupture at point $\mathrm{C}$, which indicates that corner confinement is obvious.

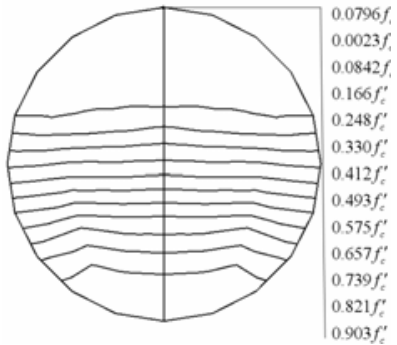

(a1) B

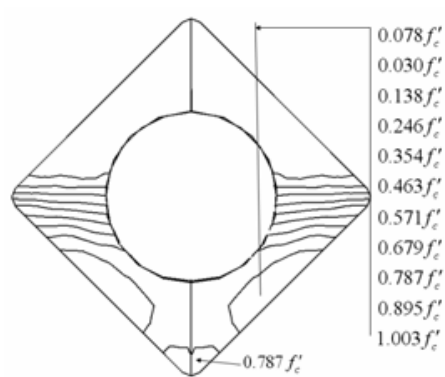

(b1) B

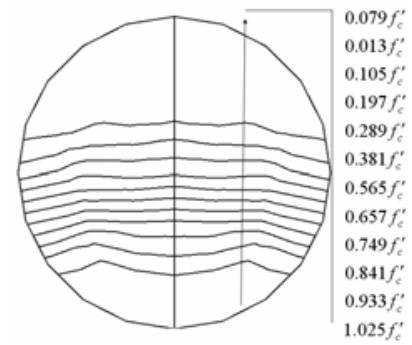

(a2) C

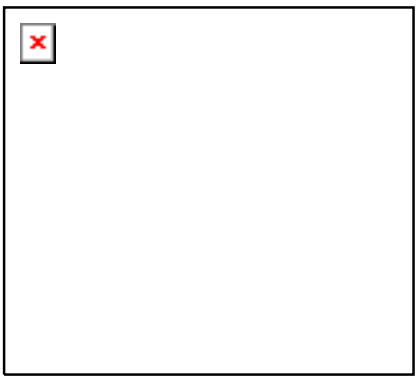

(b2) C

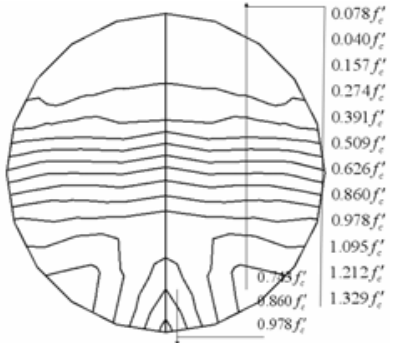

(a3) D

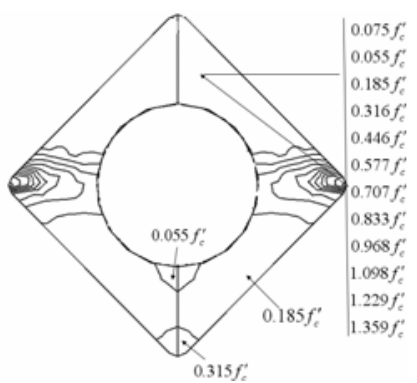

(b3) D

Figure 6. The Longitudinal Stress Isoline in the Core Concrete Section of Specimen ESF4-5-113

The longitudinal stress distribution of CFRP along the length of specimen ESF4-5-113 is illustrated in Figures 7. The pictures of a1, a2, a3 and a4 are longitudinal stress contour at point A, B, C, D respectively in the Figures 5. From Figures 7, the stress of CFRP in the tension zone is smaller than that in the compression zone. The stress increases with the load augmenting from point A to B , and mounts up with the increase of the deflection. 


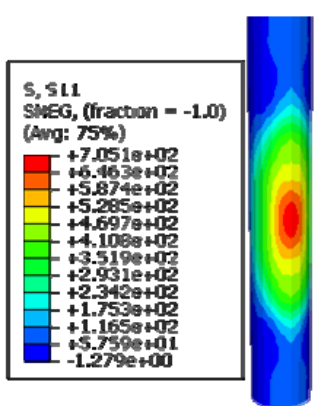

(a1) A

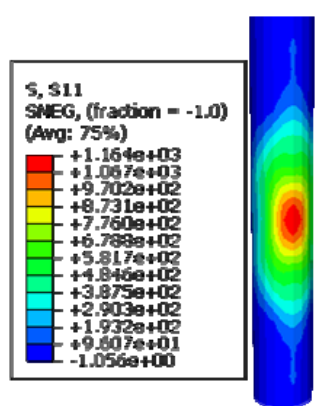

(a2) B

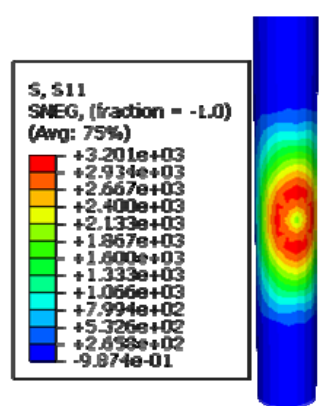

(a3) C

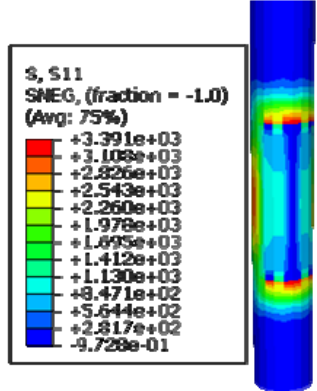

(a4) D

Figure 7. The Longitudinal Stress Distribution of CFRP along the Length

Figures 8 shows the Mises stress distribution of steel tube at mid-height section of specimen ESF4-5-113, at point A, B, C, D respectively in the Figures 5. From (a1), it can be seen that the corner area of HCFSTF steel tube yields earlier than flat area. It is similar to what HCFST does. The difference between the two members is that while the corners of HCFSTF close to the compression zone yield, the compression corners of HCFST yield . The result shows that the confining effect of steel corner area is improved by inner CFRP tube.

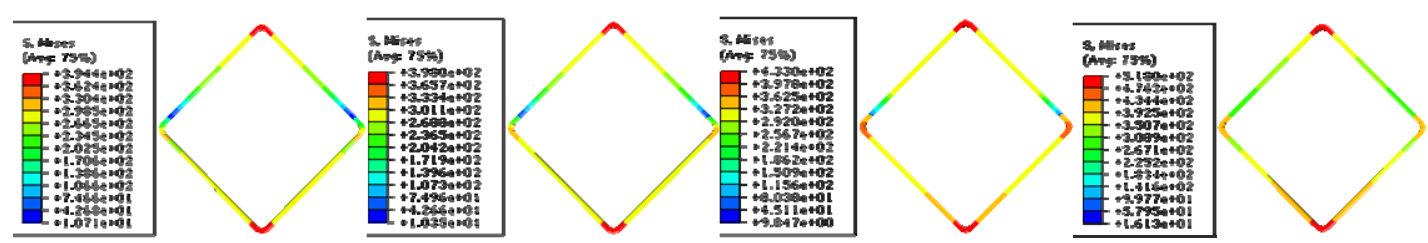

(a1) A

(a2) B

(a3) C

(a3) D

Figure 8. The Longitudinal Mises Stress Distribution of Mid-height Section

The longitudinal plastic strain distribution of sandwich concrete and core concrete along the length of specimen ESF4-5-113 is illustrated in Figures 9 at point B, C, D respectively in the Figures 5. At point $\mathrm{A}$, the specimen is in elastic stage, and the concrete has no plastic strain. With the increasing of deflection, plastic strain occurs at the mid-height and spreads to both ends. And then a plastic strain field develops at compression zone. In addition, the positions where the plastic strain develops of both sandwich and core concrete are at the same location. It indicates that the sandwich and core concrete work well together.

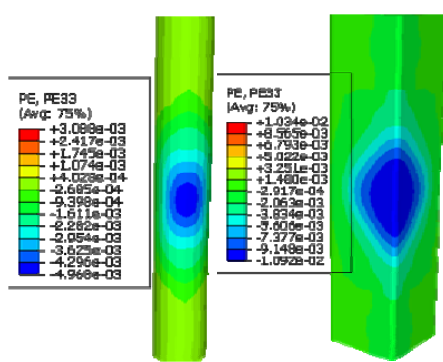

(a1) B

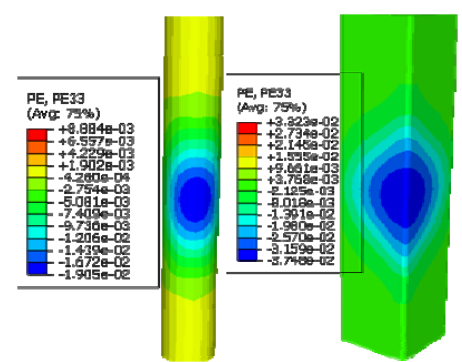

(a2) C

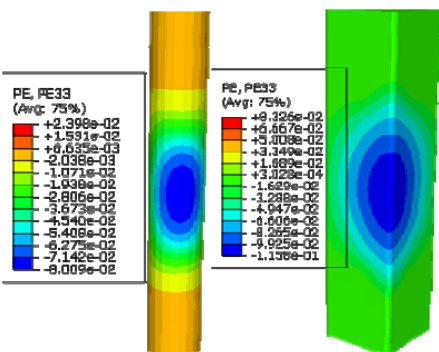

(a3) D

Figure 9. The Longitudinal Strain Distribution of Sandwich and Core Concrete of ESF4-5-113 


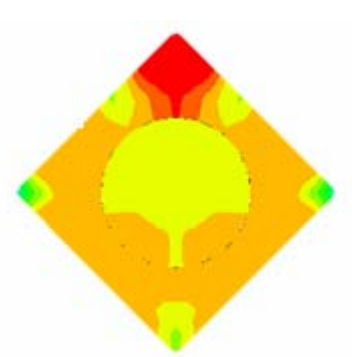

(a) $=28 m m$

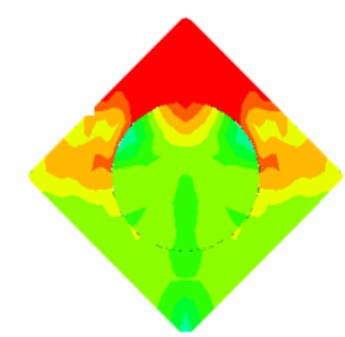

(b)e $=71 \mathrm{~mm}$

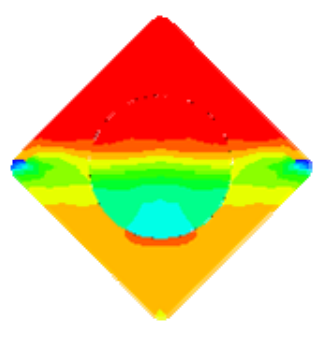

(c) $\mathrm{e}=113 \mathrm{~mm}$

Figure 10. The Longitudinal Stress Distribution in the Concrete Section of ESF4 Series

The concrete stress distribution of mid-height section of HCFSTF specimens at point B with different eccentricity is illustrated in Figures 10. The tension zone area and stress increase with the increasing of eccentricity.

\subsection{Failure Mode of the Specimen}

Figure 11 shows the typical failure modes of HCFSTF and HCFST member subjected to bi-axial eccentric loading. It can be seen from Figure 11 that the failure mode of high strength concrete-filled square steel tube columns with inner CFRP circular tube (HCFSTF) and high strength concrete-filled square steel tube columns (HCFST) are similar . And finally the specimens quit working because of unstable failure.

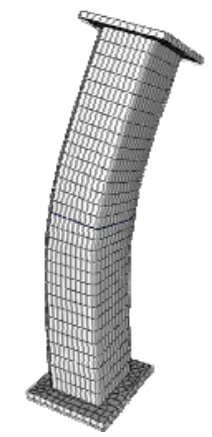

(a) HCFST

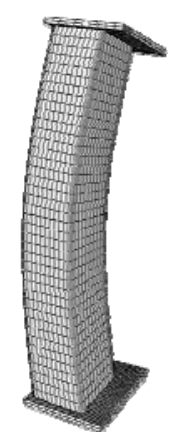

(b) HCFSTF

Figure 11. Typical Failure Mode of HCFSTF and HCFST Columns

Figure 12 is the numerical deflection curves of specimen ESF10-5-113 in the process of loading. It is compared with the ideal half-sine-wave. The vertical coordinate is values of $\mathrm{H} / L$ coincident with different positions at the column. The deflection $u_{\mathrm{m}}$ is calculated by the deflection of two tension sides $\left(u_{m}=\sqrt{u_{x}^{2}+u_{y}^{2}}\right), u_{\mathrm{x}}$ and $u_{\mathrm{y}}$ are the deflections of two tension sides respectively. The deflection curves of numerical results fit well with the ideal half-sine-wave curves. And the smaller the load is, the better the curves fit.

The comparison between the predicted load $(\mathrm{N})$ versus $\left(u_{\mathrm{m}}\right)$ curves of HCFSTF column and HCFST column is shown in Figures 13. The solid lines are the HCFST column, and the dotted lines are HCFSTF column. It can be seen that the ultimate bearing capacities of the two members are proximal. But HCFSTF column seems to have a significant influence on curvature ductility and the load capacity after the peak load. 


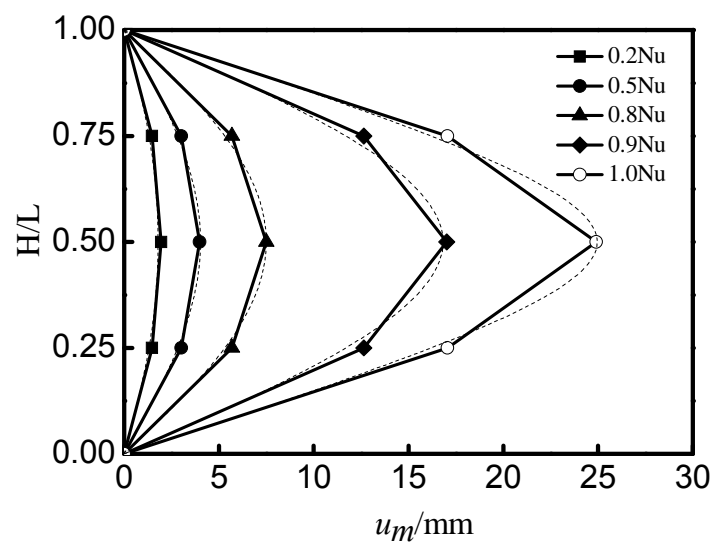

Figure 12. Deflections Curves of Specimen

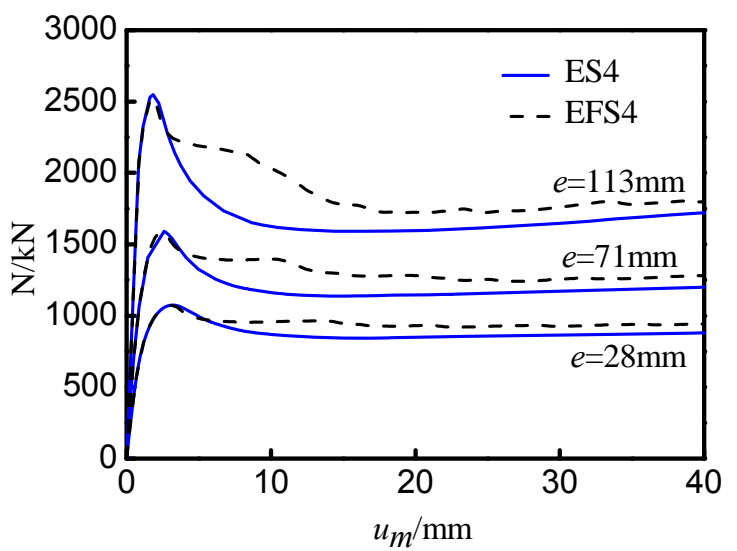

Figure 13. Load-deflections Curves of HCFSTF and HCFST Specimen

\subsection{Parameter Analysis}

\subsubsection{Effect of concrete strength}

Figures 14 shows the $N-M$ interaction curves of HCFSTF members with different concrete strength subjected to bi-axial eccentric loading . The parameters of these examples are: $\mathrm{B}=200 \mathrm{~mm}$ (size of section side for square steel tube,) $f_{\mathrm{y}}=291 \mathrm{Mpa}, \alpha=0.1$, and the eccentric angle is $45^{\circ}$. The values of abscissa $\left(M / M_{u}\right)$ of inflection point on the $N-M$ interaction curve increase with the increasing of concrete strength. The effect of concrete strength on the interaction curve is moderate.

\subsubsection{Effect of steel ratio}

Figures 15 shows the $N-M$ interaction curves of HCFSTF members subjected to bi-axial eccentric loading with different steel ratio. The values of vertical coordinate $\left(N / N_{u}\right)$ and abscissa $\left(M / M_{u}\right)$ of inflection point on the $N-M$ interaction curve increase with the increasing of steel ratio. When the steel ratio changes from $10 \%$ to $15 \%$, the curve changes obviously.

\subsubsection{Effect of steel yield strength}

Figures 16 shows the $N-M$ interaction curves of HCFSTF members subjected to bi-axial eccentric loading with different yield strength of steel. With the increasing of yield strength, the $N / N_{u}$ increases, but $M / M_{u}$ decreases. In addition, when yield strength changes from Q234 to Q345, the curves are much different.

\subsubsection{Effect of slenderness ratio}

Figures 17 shows the $N-M$ interaction curves of HCFSTF members subjected to bi-axial eccentric loading with different slenderness ratio. The slenderness ratio has a great influence on the interaction curves. When the slenderness ratio is small, the interaction curves show parabola model. With the increasing of the slenderness ratio, the ultimate bearing capacity decreases. And the $N-M$ interaction curves change from the parabola model to linear model. 


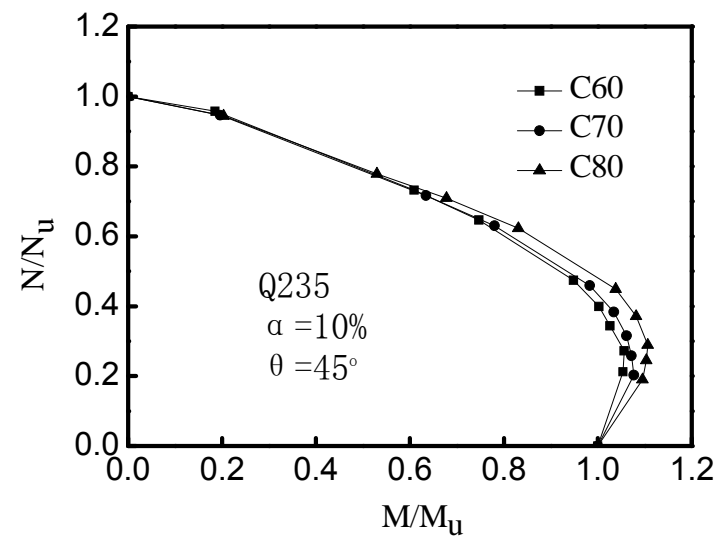

Figure 14. Effect of Concrete Strength

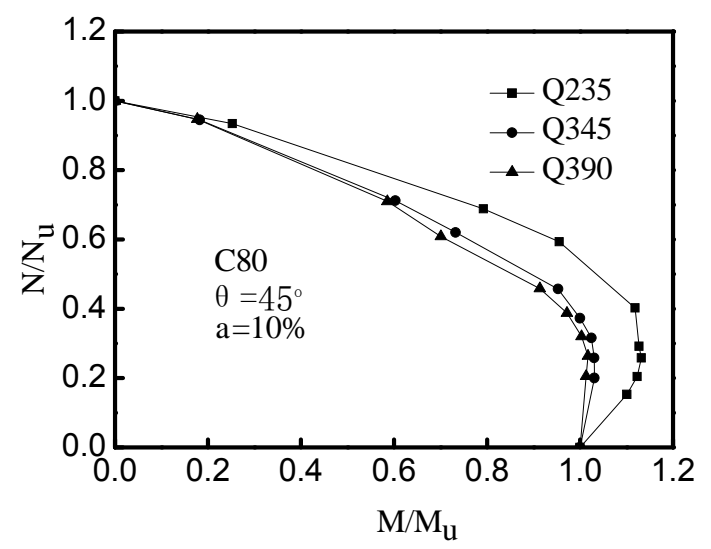

Figure 16. Effect of Steel Yield Strength

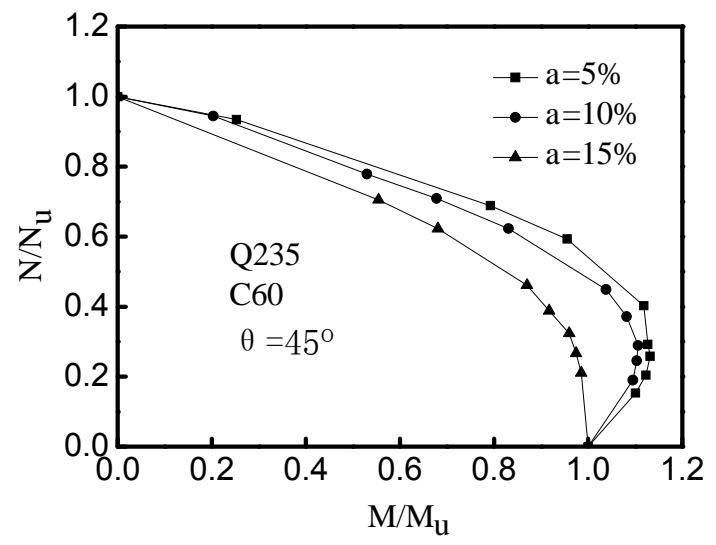

Figure 15. Effect of Steel Ratio

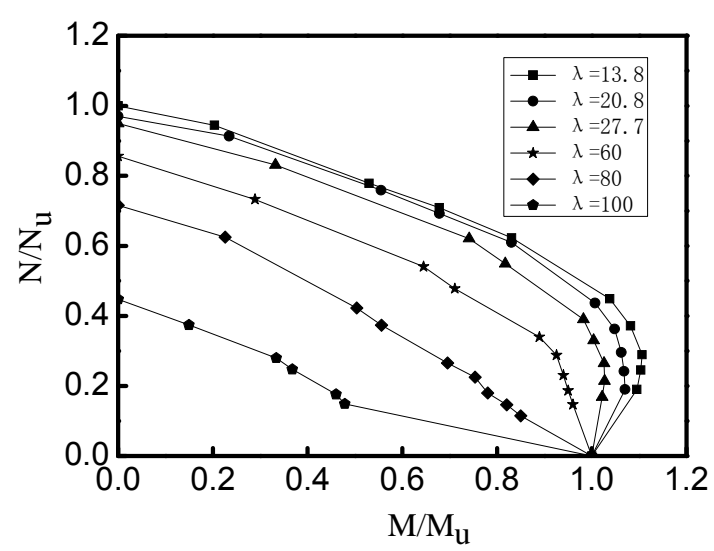

Figure 17. Effect of Slenderness Ratio

\section{SIMPLIFIED CALCULATION ON BEARING CAPACITY}

The parameter analysis results indicate that the factors mainly affecting the $N$ - $M$ interaction curves of HCFSTF members subjected to bi-axial eccentric loading are as follows: yield strength of steel, concrete strength, steel ratio and slenderness ratio. Figures 18 is the typical $N-M$ interaction curve. The equilibrium point A of the curve is similar to that of HCFST member. The vertical coordinate and abscissa of point $\mathrm{A}$ is defined to be $\zeta_{0}$ and $\eta_{0}$, respectively. Figures 14 shows that point A moves to the exterior and the value of $\zeta_{0}$ and $\eta_{0}$ increases with the increasing of concrete strength. Figures 15 and 16 show that point A moves to the interior and the values of $\zeta_{0}$ and $\eta_{0}$ decrease with the increasing of steel yield strength and steel ratio. It is because that the bigger the yielding strength of steel and steel ratio are, the more contribution steel tube makes in the composite column. On the contrary, the higher strength of concrete is, the more contribution concrete makes.

The vertical coordinate $\left(\zeta_{0}\right)$ and abscissa $\left(\eta_{0}\right)$ of the equilibrium point A can be expressed as function of the composite confinement factor $(\xi)$. Based on the regression analysis on a great deal of computed results, the formula to calculate $\zeta_{0}$ and $\eta_{0}$ are given as follows:

$$
\begin{aligned}
& \xi_{0}=1.03+0.005 \xi^{-2.9} \\
& \eta_{0}= \begin{cases}0.5-0.335 \xi & (\xi \leq 0.55) \\
0.1+0.127 \xi^{-0.82} & (\xi>0.55)\end{cases}
\end{aligned}
$$




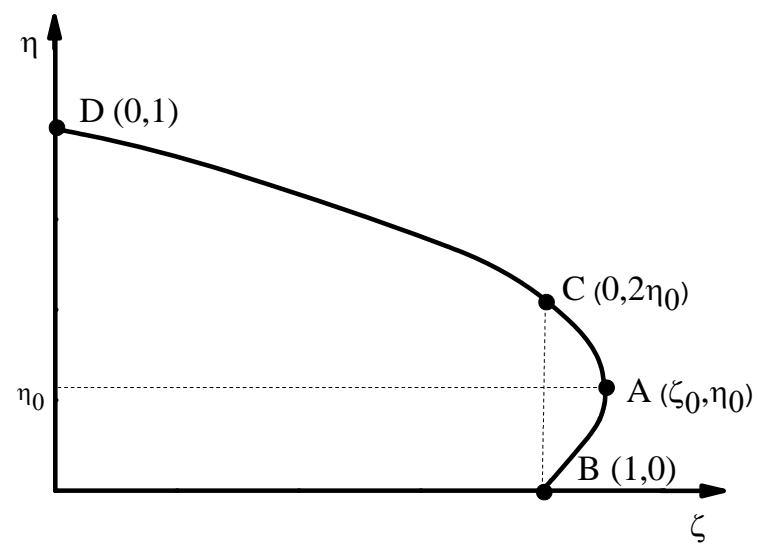

Figure 18. Typical $N / N_{\mathrm{u}}-M / M_{\mathrm{u}}$ Interaction Curve of HCFSTF

Where $\xi$ is confinement factor, which can be obtained as follows:

$\xi=\xi_{s}+\theta \xi_{c f r p}$

Where $\xi_{s}$ is the confinement factor of the steel tube $\xi_{s}=A_{s} f_{s y} / A_{c 1} f_{c k}$, $A_{s}$ is the cross-sectional area of the steel tube, $A_{c 1}$ is the cross-sectional area of the concrete, $f_{s y}$ is the yield stress of the steel tube, and $f_{c k}$ is the compression strength of concrete; $\xi_{c f r p}$ is the confinement factor of the inner CFRP tube $\xi_{c f r p}=A_{c f r p} f_{c f r p} / A_{c 2} f_{c k}, A_{c f r p}$ is the cross-sectional area of the CFRP tube, $A_{c 2}$ is the cross-sectional area of the core concrete, $f_{\text {cfrp }}$ is the ultimate stress of the CFRP tube. $\gamma$ is the relative confinement factor $\gamma=\xi_{\text {cfrp }} / \xi_{s} ; \theta=0.7$.

what is analyzed above shows that the mechanical behavior of high strength concrete-filled square steel tube slender columns with inner CFRP circular tube (HCFSTF) and high strength concrete-filled square steel tube slender columns (HCFST) are similar. The interaction equations of $N / N_{u}-M / M_{u}$ for HCFST [23] are referred, and the interaction equations of $N / N_{u}-M / M_{u}$ for HCFSTF can be divided into two parts, which are expressed as follows:

1. For $N / N_{u} \geq 2 \eta_{0}$

$\frac{N}{N_{u}}+a\left(\frac{M}{M_{u}}\right)=1$

2. For $N / N_{u}<2 \eta_{0}$

$-b\left(\frac{N}{N_{u}}\right)^{2}-c\left(\frac{N}{N_{u}}\right)+\left(\frac{M}{M_{u}}\right)=1$

Where $a=1-2 \eta_{o}, b=\frac{1-\zeta_{o}}{\eta_{o}{ }^{2}}, c=\frac{2\left(\zeta_{o}-1\right)}{\eta_{o}}$.

Taking into account the slenderness effect, the interaction equations of $N / N_{u}-M / M_{u}$ for HCFSTF can be expressed as follows: 
1. For $N / N_{u} \geq \varphi_{x y}^{3} 2 \eta_{0}$,

$$
\frac{N}{\varphi_{x y} N_{u}}+\frac{a}{d}\left[\left(\frac{M_{x}}{M_{u x}}\right)^{1.8}+\left(\frac{M_{y}}{M_{u y}}\right)^{1.8}\right]^{1 / 1.8} \leq 1
$$

2. For $N / N_{u}<2 \varphi_{x y}^{3} \eta_{0}$,

$$
-b \frac{N^{2}}{N_{u}^{2}}-c \frac{N}{N_{u}}+\frac{1}{d}\left[\left(\frac{M_{x}}{M_{u x}}\right)^{1.8}+\left(\frac{M_{y}}{M_{u y}}\right)^{1.8}\right]^{1 / 1.8} \leq 1
$$

Where $N_{u}$ is ultimate axial compressive strength of HCFSTF; $\varphi_{x y}$ is stability coefficient of CFST under bi-axial eccentric loading; $M_{x}$ and $M_{y}$ are moments along the x-axis and y-axis respectively, which are given by $M_{x}=N e_{x}$ and $M_{y}=N e_{y} ; M_{u x}$ and $M_{u y}$ are flexural bearing capacity along the x-axis and $y$-axis respectively; Where a,b,c,d is calculating coefficient, and $1 / \mathrm{d}$ is amplification factor of the moment considering the second-order effect. The calculations in details on these parameters are given by references [19] and [23].

The stability bearing capacity of experimental specimen was calculated with the above simplified formula. Table 1 shows calculating results $\left(N_{c 2}\right)$ and measured values $\left(N_{e}\right)$. The ratio of $N_{c 2} / N_{e}$ is listed in Table 1, which average is 1.027 . The standard deviation is 0.073 . The calculating results agree well with test data, so the simplified formula can be applied to calculating the bearing capacity of HCFSTF within the parameters of this test.

\section{CONLUSIONS}

(1) An FEA modeling developed through the ABAQUS/Standard solver is used to study the flexural performance of HCFSTF columns under bi-axial eccentric loading. The predicted load versus deflection curves and ultimate bearing capacity for composite columns have been found in good agreement with experimental results.

(2) The parametric studies indicate that the major factors affecting the $N / N_{u}-M / M_{u}$ interaction curves of HCFSTF members subjected to bi-axial eccentric loading are steel yield strength, concrete strength, steel ratio and slenderness ratio.

(3) Based on the experimental and FEA results, a simplified formula for the calculation of the bearing capacity of the composite column is proposed. The simplified formula is applied to calculate the bearing capacity of the experimental specimens. And the calculation results agree well with test data. So the simplified formula can be referred to calculate the bearing capacity of HCFSTF within the parameters of this test.

\section{ACKNOWLEDGEMENTS}

This project was supported by National Science Foundation of China (50678106), Shenyang Talent Development Fund (2009140403038), Liaoning BaiQianWan Talents Program(2010921001), Liaoning Talents Program(LR2011014) and Technology Development Program of Ministry of Housing and Urban-Rural Development (2011-k3-23). 


\section{REFERENCES}

[1] Fan, H., Li, Q.S., Tuan, A.Y. and Xu, L.H., "Seismic Analysis of the World's Tallest Building”, Journal of Constructional Steel Research, 2009, Vol. 65, No. 5, pp. 1206-1215.

[2] Liu, D.L., Gho, W.M. and Yuan, J., "Ultimate Capacity of High Strength Rectangular Concrete-filled Steel Hollow Section Stub Columns", Journal of Constructional Steel Research, 2003, Vol. 59, No. 12, pp. 1499-1515.

[3] Liu, D.L., "Behaviour of High Strength Rectangular Concrete-filled Steel Hollow Section Columns under Eccentric Loading”, Thin-Walled Structures, 2004, Vol. 42, No.12, pp. 1631-1644.

[4] Liu, D.L., "Behaviour of Eccentrically Loaded High-strength Rectangular Concrete-filled Steel Tubular Columns”, Journal of Constructional Steel Research, 2006, Vol. 62, No. 8, pp. 839-846.

[5] Ellobody, E. and Young, B., "Design and Behavior of Concrete-filled Cold-formed Stainless Steel Tube Columns”, Engineering Structures, 2006, Vol. 28, No. 5, pp. 716-728.

[6] Young, B. and Ellobody, E., "Experimental Investigation of Concrete-filled Cold-formed High Strength Stainless Steel Tube Columns”, Journal of Constructional Steel Research, 2006, Vol. 62, No. 5, pp. 484-492.

[7] Lu, F.W., Li, S.P. and Sun, G.J., "A Study on the Behavior of Eccentrically Compressed Square Concrete-filled Steel Tube Columns”, Journal of Constructional Steel Research, 2007, Vol. 63, No. 7, pp. 941-948.

[8] Chitawadagi, M.V., Narasimhan, M.C. and Kulkarni, S.M., “Axial Capacity of Rectangular Concrete-filled Steel Tube Columns-DOE Approach", Construction and Building Materials, 2010, Vol. 24, No. 4, pp. 585-595.

[9] Han, L.H., Zhao, X.L. and Tao, Z., “Tests and Mechanics Model for Concrete-filled SHS Stub Columns”, Steel and Composite Structures, 2001,Vol. 1, No. 1, pp. 51-74.

[10] Han, L.H., "Tests on Stub Columns of Concrete-filled RHS Sections”, Journal of Constructional Steel Research, 2002, Vol. 58, No. 3, pp. 353-372.

[11] Uy, B., "Strength of Short Concrete Filled High Strength Steel Box Columns”, Journal of Constructional Steel Research, 2001, Vol. 57, No. 2, pp. 113-134.

[12] Mursi, M. and Uy, B., "Strength of Concrete Filled Steel Box Columns Incorporating Interaction Buckling”, Journal of Structural Engineering, 2003, Vol. 129, No. 5, pp. 626-639.

[13] Mursi, M. and Uy, B., "Strength of Slender Concrete Filled High Strength Steel Box Columns”, Journal of Constructional Steel Research, 2004, Vol. 60, No. 12, pp. 1825-1848.

[14] Mursi, M, and Uy, B., "Behavior and Design of Fabricated High Strength Steel Columns Subjected to Biaxial Bending, Part 1: Experiments", Journal of Advanced Steel Construction, Hong Kong Institute of Steel Construction, 2006, Vol. 2, No. 4, pp. 286-315.

[15] Mursi, M. and Uy, B., "Behaviour and Design of Fabricated High Strength Steel Columns Subjected to Biaxial Bending, Part 2: Analysis and Design Codes”, Journal of Advanced Steel Construction, Hong Kong Institute of Steel Construction, 2006, Vol. 2, No. 4, pp. 316-354.

[16] Liu, J.P., Zhang, S.M. and Guo, L.H., "Behavior of Concrete-filled Steel RHS Subjected to Biaxial Eccentric Loading”, Journal of Harbin Institute of Technology, 2006, Vol. 38, No. 5, pp. 712-714.

[17] Tian, H., Guo, L.H. and Zhang, S.M., "Behavior of High-strength Concrete-filled RHS Steel Tubular Members Subjected to Axial Combined with Bi-axial Bending”, Journal of Harbin Institute of Technology, 2007, Vol. 39, No. 12, pp. 1854-1858. 
[18] Tokgoz, S. and Dundar, C., "Experimental Study on Steel Tubular Columns In-filled with Plain and Steel Fiber Reinforced Concrete”, Thin Walled Structure, 2010, Vol. 48, No. 6, pp. 414-422.

[19] Yang, Z.J, "Behavior of High Strength Concrete Filled Square Steel Tubes Slender High Columns with Inner CFRP Circular Tube under Bi-axial Eccentric Loading, Master's Thesis”, Shenyang Jianzhu University, 2010.

[20] Abdel, R.N. and Sivakumaran, K.S., "Material Properties Models for Analysis of Cold-formed Steel Members”, Journal of Structural Engineering, 1997, Vol. 123, No. 9, pp. 113-1143.

[21] Han, L.H., Yao, G.H. and Tao, Z., "Performance of Concrete-filled Thin-walled Steel Tubes under Pure Torsion”, Thin-Walled Structures, 2007, Vol. 45, No. 1, pp. 24-36.

[22] Jiang, J.J., Lu, X.Z. and Ye, L.P., "Finite Element Analysis of Concrete Structures", Tsinghua University Press, 2005.

[23] Han, L.H., "Concrete-Filled Steel Tube Structure-Theory and Practice (Second Edition)”, Science Press, 2008. 


\title{
EXPERIMENTAL STUDY AND APPLICATION IN STEEL STRUCTURE OF 'DUAL FUNCTIONS' METALLIC DAMPER
}

\author{
Gang $\mathrm{Li}^{1{ }^{1 *}}$ and Hong-Nan $\mathrm{Li}^{2}$ \\ ${ }^{1}$ Associate Professor, Faculty of Infrastructure Engineering, Dalian University of Technology, \\ Dalian, Liaoning Province, China \\ ${ }^{2}$ Professor, Faculty of Infrastructure Engineering, Dalian University of Technology, \\ Dalian, Liaoning Province, China \\ *(Corresponding author: E-mail: gli@dlut.edu.cn)
}

Received: 20 June 2012; Revised: 5 November 2012; Accepted: 26 November 2012

\begin{abstract}
A new type of metallic damper is presented in this study. It is so-called as "dual functions" metallic damper, since it has two characteristics of high initial stiffness and good energy-dissipating capability. Its initial stiffness is increased through making it bearing exterior in-plane force, and its energy-dissipating capability is improved through making it different shapes. Quasi-static tests with scale and full-scale models of the metallic dampers specimens designed with above idea are carried out, respectively. Two outstanding metallic dampers named round-hole metallic damper (RHMD) and double X-shaped metallic damper (DXMD) were selected and the DXMD was applied in an actual steel structure to improve initial stiffness of original structure under normal use or frequency earthquake and to dissipate inputting energy during great earthquakes. In addition, a three-dimensional model was established using finite element software and dynamic response comparison of the steel structure with and without DXMDs was conducted. The results shown that the metallic dampers presented here not only provide certain stiffness in the normal application, but also are of good ability of energy dissipation.
\end{abstract}

Keywords: Steel structure, metallic damper, hysteresis loop, seismic response

\section{INTRODUCTION}

Earthquake can make structures damaged and crumble. The traditional approach to seismic design has been based upon providing a combination of strength and ductility to resist the imposed loads. Thus, the level of the structural security cannot be achieved, because the disadvantage of the designing method is lack of adjusting capability subjected to an uncertain earthquake. Presence of some damping (energy dissipation) in buildings has been recognized and developed by most professional researchers (Lackner and Rotea [1]; Housner et al. [2]; Li [3]; Tanaka [4]). Passive energy-dissipating system, as a vibration control method, leads inputting energy from earthquake to special elements, thereby reduces energy-dissipating demand on primary structural members and minimizes possible structural damage.

The inelastic deformation of metallic is an effective mechanism for input earthquake energy dissipation. In addition, metallic is also a popular and inexpensive choice for an energy dissipation device because of its relatively good ductility and high potential for dissipating energy in the post-yield region. The idea of utilizing separate metallic dampers in the structures to absorb a large portion of the seismic energy began with the conceptual and experimental work by Kelly [5]. Then, numerous of various types of energy-absorbed metallic devices have been proposed, i.e. X-shaped and triangular plate metallic dampers (Whittaker [6]; Tsai [7]). After a series of theoretical and experimental researches, more and more interests and attentions are turned on the application of metallic dampers in the actual projects (Skinner [8]; Martinesz-Romero [9]; Bartera [10]; Mualla [11]; Min [12]; Phocas [13]) and much researches about the structure with passive dissipation devices were carried out (Lin [14]; Singh [15]; Soong [16]; Tehranizadeh [17]; Zhang [18]). Ordinary metallic damper is dependent on its out-of-plane bending deformation so that provide additional damping for the structures, even to reduce dynamic response of the structures subjected to the environmental loadings (Moreschi [19]; Curadelli [20]). The advantage of this deformation 
mechanics is uniform distribution along the full height of the steel plate. However, inelastic deformation of conventional metallic damper probably occurs when it is subjected to a relatively small disturbance (wind or earthquake), since its out-of-plane stiffness is relatively low. As a result, it has to be replaced after the disturbance.

In this paper, the stiffness of the metallic damper is increased through making it bearing exterior in-plane force, and unfavorable deformation capability is solved through changing metallic plate shape. The metallic damper designed with above-mentioned idea is named "dual functions" metallic damper, because it not only provides certain stiffness in normal use for a building, but also are of good ability of the seismic energy-dissipation. Tests for scale and full-scale models of the "dual functions" metallic damper were conducted and two outstanding metallic dampers were selected and one of them applied in an actual steel structure. Numerical analysis results show the effectiveness of this type of metallic damper.

\section{QUASI-STATIC TEST FOR SCALE MODELS}

Although the initial stiffness of steel plate can be improved greatly when it is subjected to an imposed force in its own plane, it limits shearing deformation capability. This problem can be solved through following two ways: low yield strength steel plate selection and making steel plate reasonable geometrical shape. In this section, four various metallic dampers specimens made of 4 mm thickness steel plates were produced and the quasi-static tests for the scale models were conducted. The yield stress of the steel plate is $235 \mathrm{Mpa}$. The test setup is shown in Figure 1 . The objective of the scale test is to choose outstanding metallic damper with the best deformation capability and excellent energy-dissipating capability from them. These four metallic dampers have the same boundary dimension size. The criterion about damper selection is mainly based on their own hysteretic loops curves and performance observed during the tests. Each metallic damper is subjected to repeated cyclic loadings. These metallic dampers were regarded as disable as soon as the bearing strength decreasing exceeds $25 \%$ or obvious crack appears on its surface. Hysteretic relation of the cyclic loads and the displacement is discussed as follows :

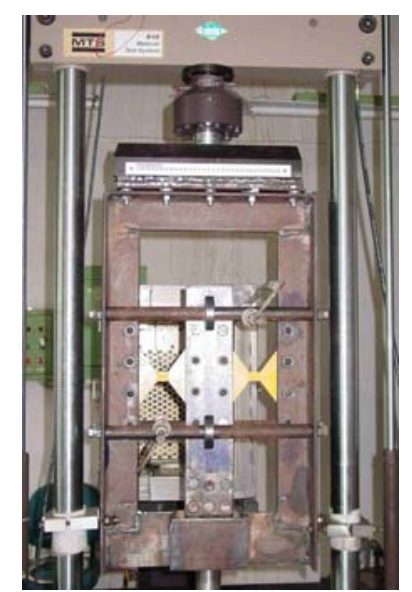

Figure 1. Test Setup for Scaled Models

\subsection{X-shaped Metallic Damper (XMD)}

A photograph and geometric sketch of the X-shaped metallic damper and its hysteretic loop curve are shown in Figure 2(a), 2(b) and 2(c). It was observed from Figure 2(b) that the X-shaped metallic damper has larger initial stiffness and higher yield strength. However, pinching phenomena found in the hysteretic loop curve shows that the X-shaped metallic damper is unable to provide 
stable working performance. The reason is sourced from the stress concentrations at steel plate corners. The hysteretic loop curve and deformation process during test indicated that the X-shaped damper is not an effective energy-dissipating device, because it is lack of enough deformation and energy dissipation capability.

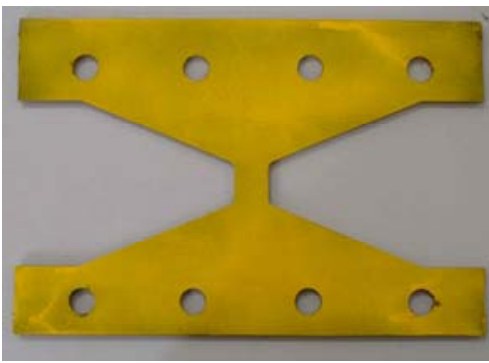

(a)

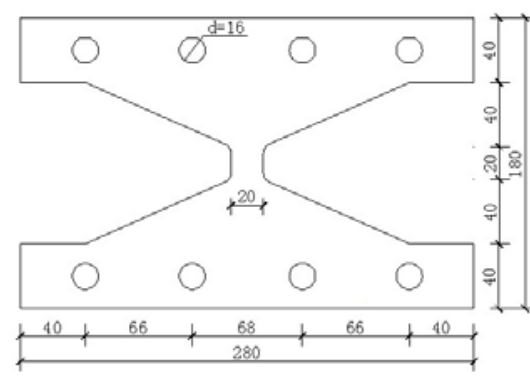

(b)

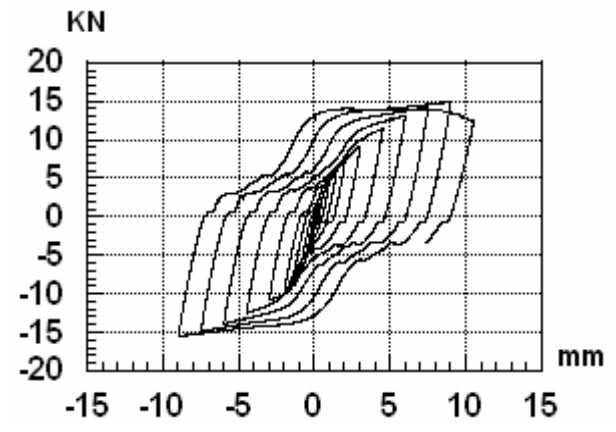

(c)

Figure 2. The Photograph, Geometric Sketch and Hysteretic Loop Curve of the XMD: (a) the Photograph; (b) Geometric Sketch (mm); (c) Hysteretic Curve

\subsection{Strip Metallic Damper (SMD)}

A photograph and geometric sketch of the metallic damper called as strip metallic damper and its hysteretic curve are shown in Figure 3(a), 3(b) and 3(c). The hysteretic curve reflects that the strip metallic damper has large initial stiffness, good deformation capability and energy-dissipating capability. However, an abrupt bearing strength reduction was observed due to out-of-plane buckling in strip region. Therefore, the large buckling deformation of whole damper probably appeared under slightly vertical load. Although the strip metallic damper exhibits good energy-dissipating capability and high initial stiffness, it is lack of enough stability while subjected to vertical load.
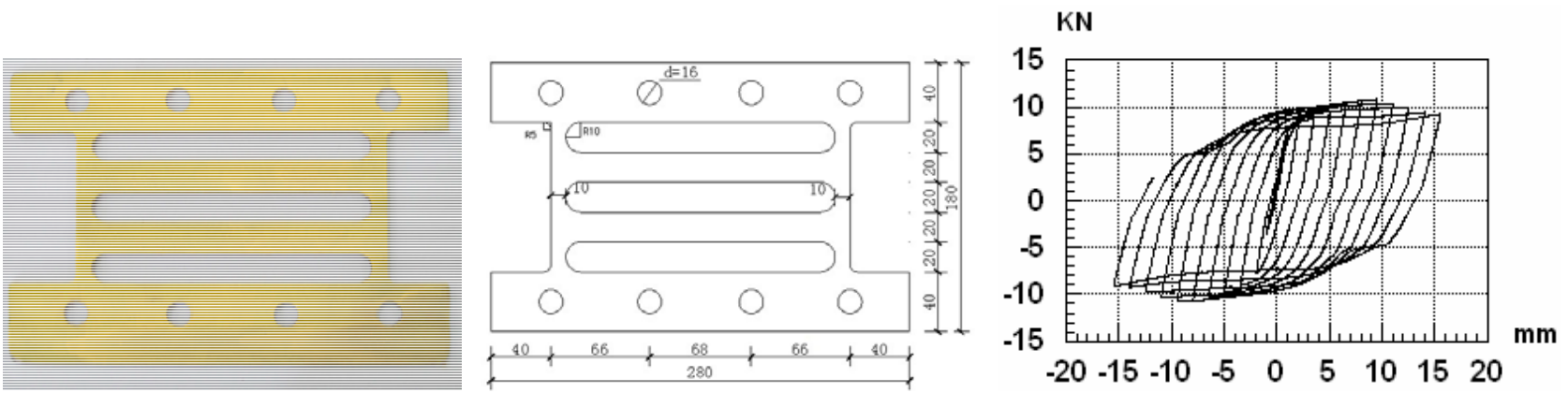

Figure 3. The Photograph, Geometric Sketch and Hysteretic Loop Curve of the SMD: (a) the Photograph; (b) Geometric Sketch (mm); (c) Hysteretic Curve

\subsection{Round-hole Metallic Damper (RHMD)}

A photograph and geometric sketch of the RHMD and its hysteretic curve are shown in Figure 4(a), 4(b) and 4(c). Stable hysteretic feature of the RHMD was observed during overall test process. The hysteretic loop curve revealed that the RHMD not only has large initial stiffness, but also is of excellent energy-dissipating capability. It is an outstanding and effective energy-dissipating device. 

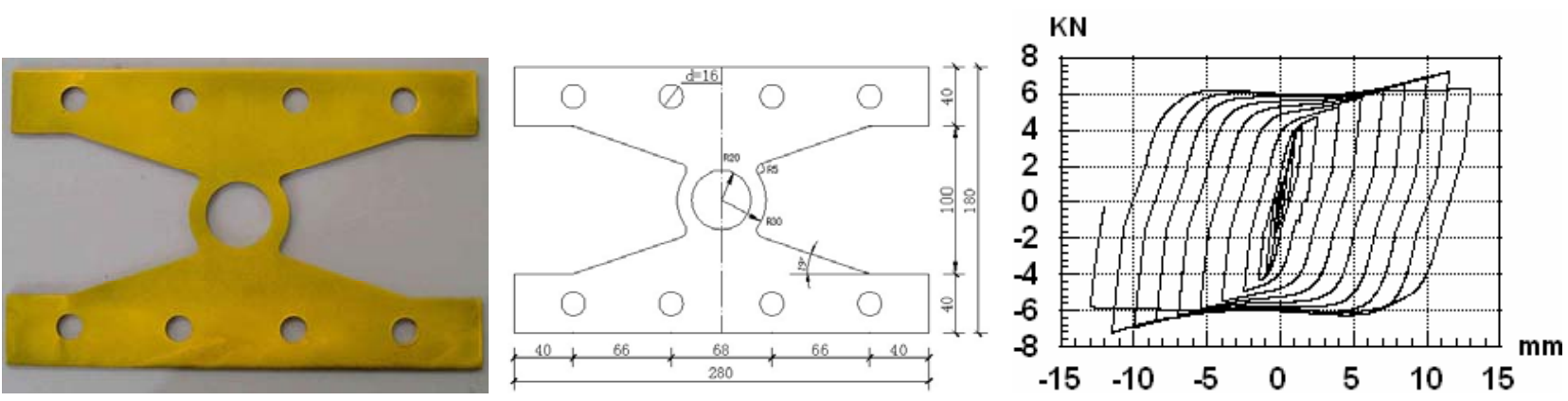

Figure 4. The Photograph, Geometric Sketch and Hysteretic Loop Curve of the RHMD: (a) the Photograph; (b) Geometric Sketch (mm); (c) Hysteretic Curve

\subsection{Double X-shaped Metallic Damper (DXMD)}

A photograph and geometric sketch of the DXMD and its hysteretic curve are illustrated in Figure 5(a) and 5(b). The buckling problem of the strip metallic damper described in section 2.2 is solved by making steel plate double X shape. The DXMD exhibits more stable hysteretic performance than the strip metallic damper. Hysteretic loop curve shows that the DXMD has both large initial stiffness and energy dissipating capability.
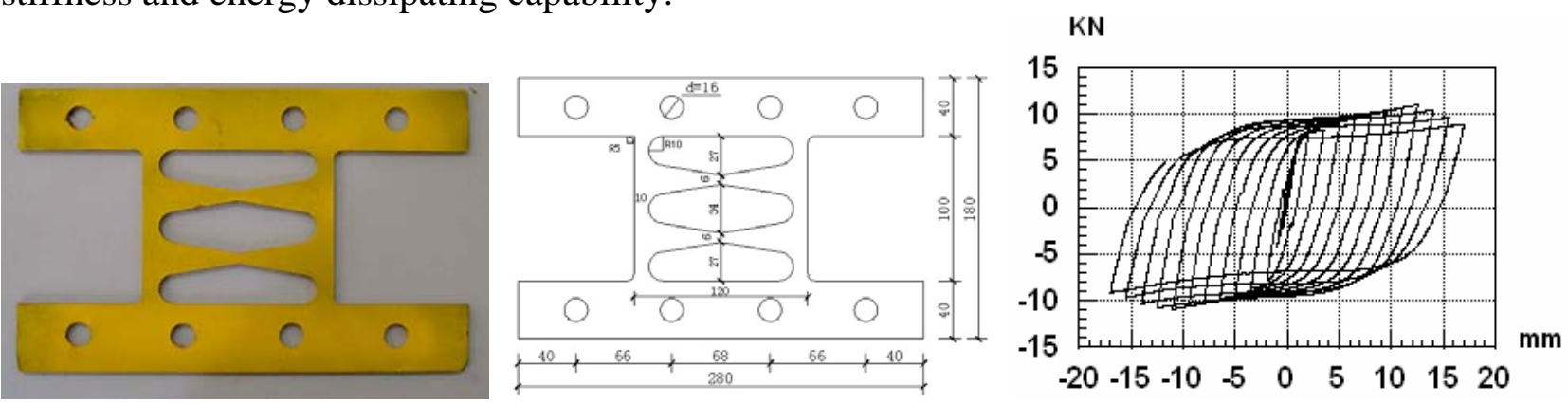

Figure 5. The Photograph, Geometric Sketch and Hysteretic Loop Curve of the DXMD: (a) the Photograph; (b) Geometric Sketch (mm); (c) Hysteretic Curve

On the basis of the above-presented results, the RHMD and the DXMD are better than others on energy-dissipating capability. Full-scale model test, numerical simulation and application in actual building below will focus on these two outstanding metallic dampers.

\section{QUASI-STATIC TEST FOR FULL-SCALE MODELS}

\subsection{Test for Full Scale Models}

Full-scale models of the RHMD and the DXMD were designed and product. These two types of metallic dampers are made of $50 \mathrm{~mm}$ thickness steel plate. The plane dimensions of these two dampers are shown in Figure 6. The test setup is shown in Figure 7. 


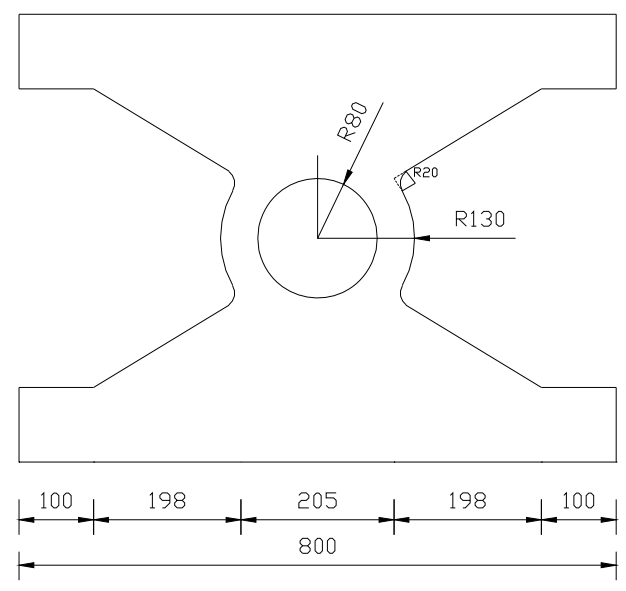

(a)
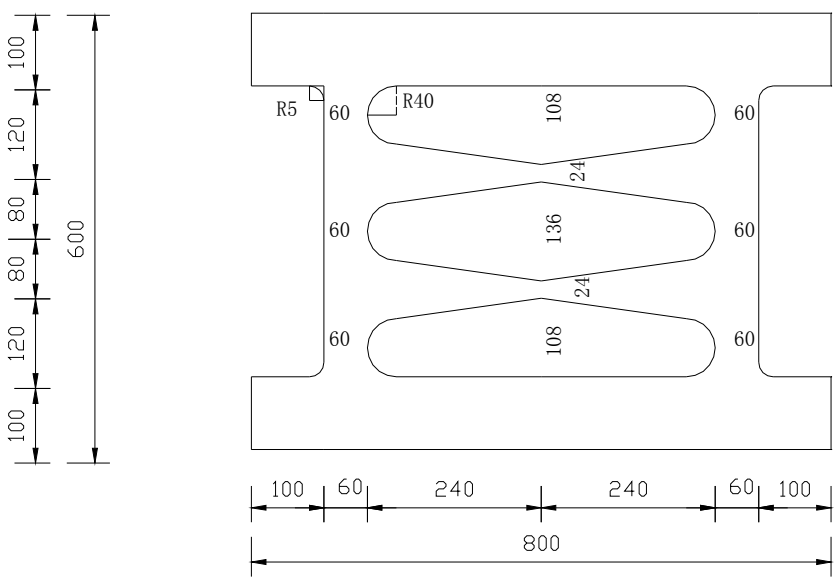

(b)

Figure 6. Plane Dimension of Full-scale Models: (a) RHMD; (b) DXSD (mm)

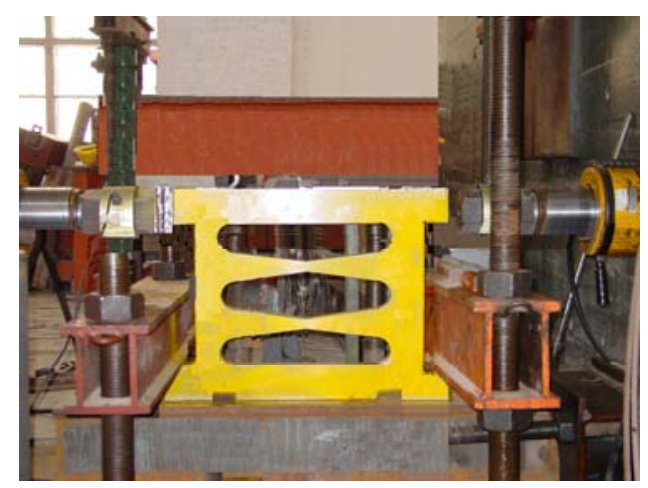

Figure 7. Test Setup for Full-scale Models

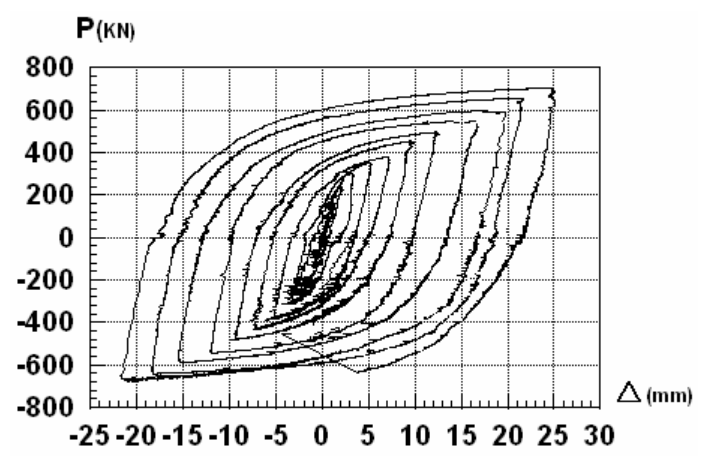

(a)

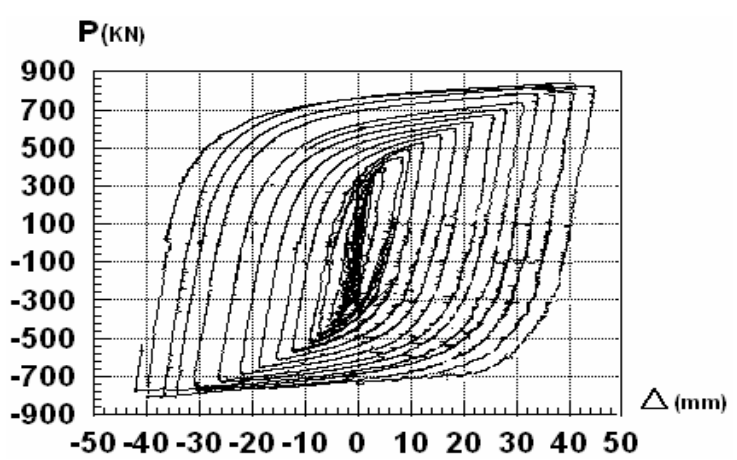

(b)

Figure 8. Hysteretic Curve of the Full-scale Model: (a) RHMD; (b) DXMD

Figures 8(a) and 8(b) show hysteretic curve of full-scale models of the RHMD and the DXMD. It was observed from these figures that these two metallic dampers have the same stable hysteretic behaviors and good energy-dissipating capability as the scale models and are suitable for application in actual structure. In addition, several key parameters of these two full-scale models were defined as: elastic lateral stiffness of the RHMD $K_{d l}=171 \mathrm{kN} / \mathrm{mm}$ and its yielding strength $P_{y l}=375 \mathrm{kN}$; elastic lateral stiffness of the DXMD $K_{d 2}=102.5 \mathrm{kN} / \mathrm{mm}$ and its yielding strength $P_{y 2}=410 \mathrm{kN}$. 


\subsection{Numerical Simulation}

Finite element models of the DXMD and the RHMD for simulating full-scale models test process were established using software ANSYS. Stress distributions and hysteretic loops of these two metallic dampers are shown in Figures 9 and 10. It can be seen from Figures 10(a) and 10(b) that the numerical simulation results agree well with the experimental data. Although experimental results exhibit slightly differences, they can represent true behavior of these two kinds of metallic dampers under cyclic loadings.

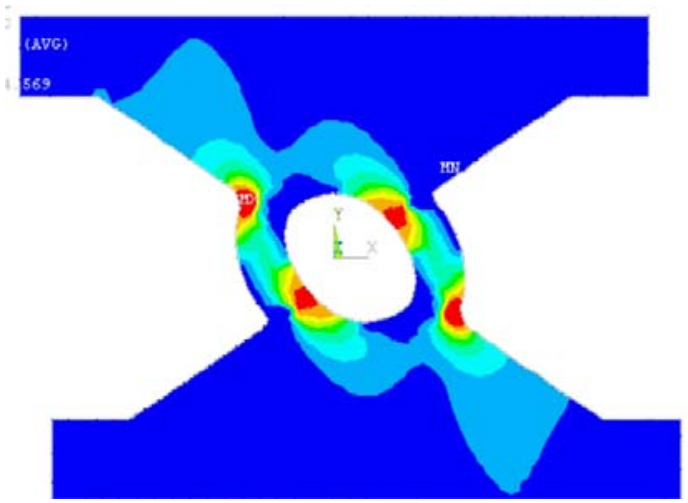

(a)

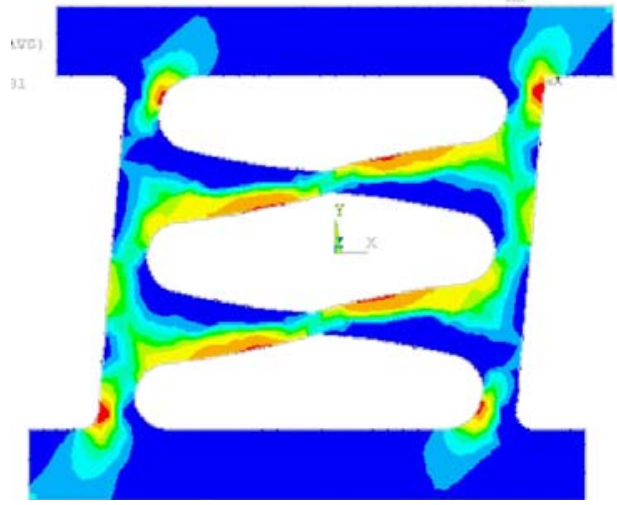

(b)

Figure 9. Stress Distribution of the Full-scale Model: (a) RHMD; (b) DXMD

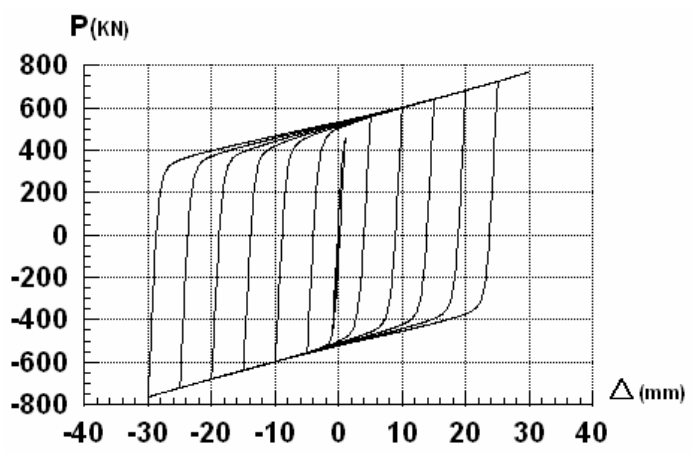

(a)

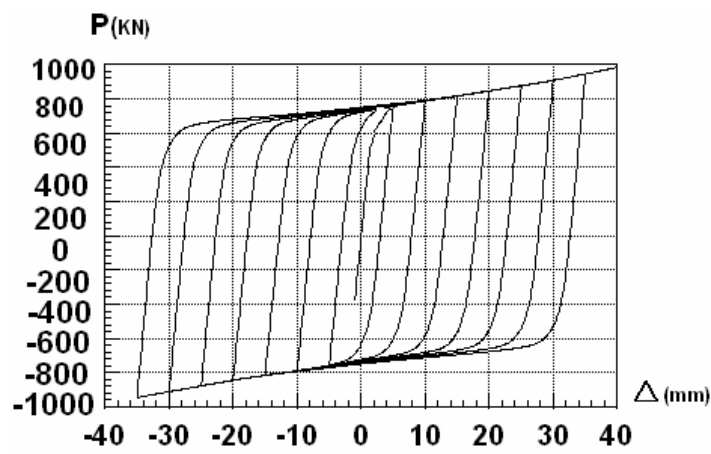

(b)

Figure 10. Numerical Hysteretic Curve of the Full-scale Mode: (a) RHMD; (b) DXMD

\section{APPLICATION IN AN ACUTUAL STEEL STRUCTURE}

\subsection{Description of the Steel Structure}

A steel structure with eight stories shown in Figure 11 is located in China. The sketch of this structure is depicted in Figure 12. The columns in the frame are square steel tubes and $\mathrm{H}$ type steel and the beams are $\mathrm{H}$ type steel. The DXMDs are installed on the each floor of the steel structure due to overall weak stiffness of this structure in $Y$ direction. The seismic protection intensity of the steel structure is degree VII, and the site soil belongs to the type $\Pi$ (medium hard soil) based on the China Seismic Code [21]. Two matched earthquakes acceleration records shown in Table 1 are selected according to the site where the structure is located. Two acceleration records, which peak are adjusted to $220 \mathrm{~cm} / \mathrm{s}^{2}$ are inputted in two dimensions of the steel structure, i.e. $X$ and $Y$ directions. 
Table 1. Earthquake Records

\begin{tabular}{cccc}
\hline Serial number & Station & Earthquake & Components \\
\hline \multirow{2}{*}{1} & 0453 Taft Lincoln & Kern County & Taf021(Y) \\
& School & $(21 / 7 / 1952)$ & TAF111(X) \\
\hline \multirow{2}{*}{2} & LA - BALDWIN & Northridge & BLD090(Y) \\
& HILLS & $(17 / 1 / 1994)$ & BLD360(X) \\
\hline
\end{tabular}

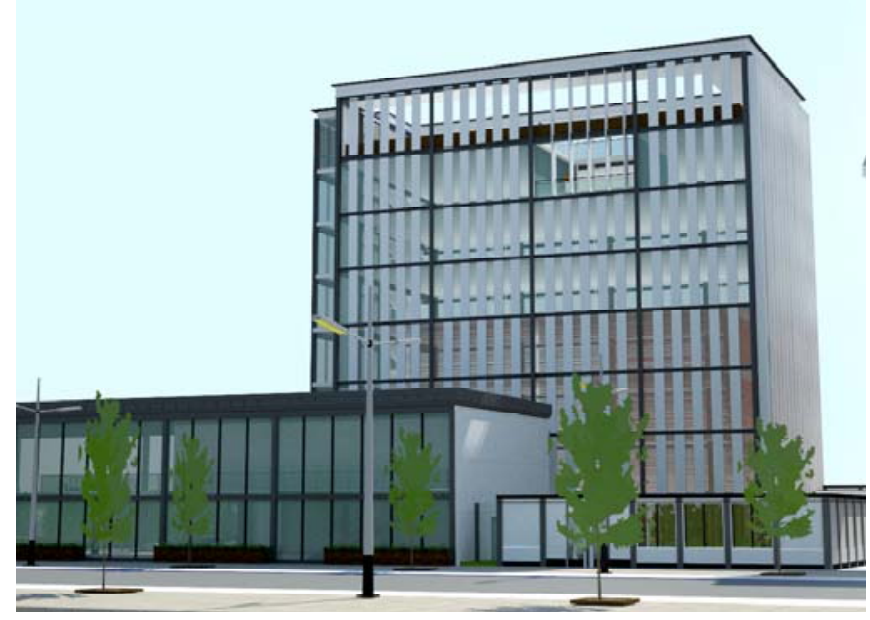

Figure 11. The Sketch of the Steel Structure
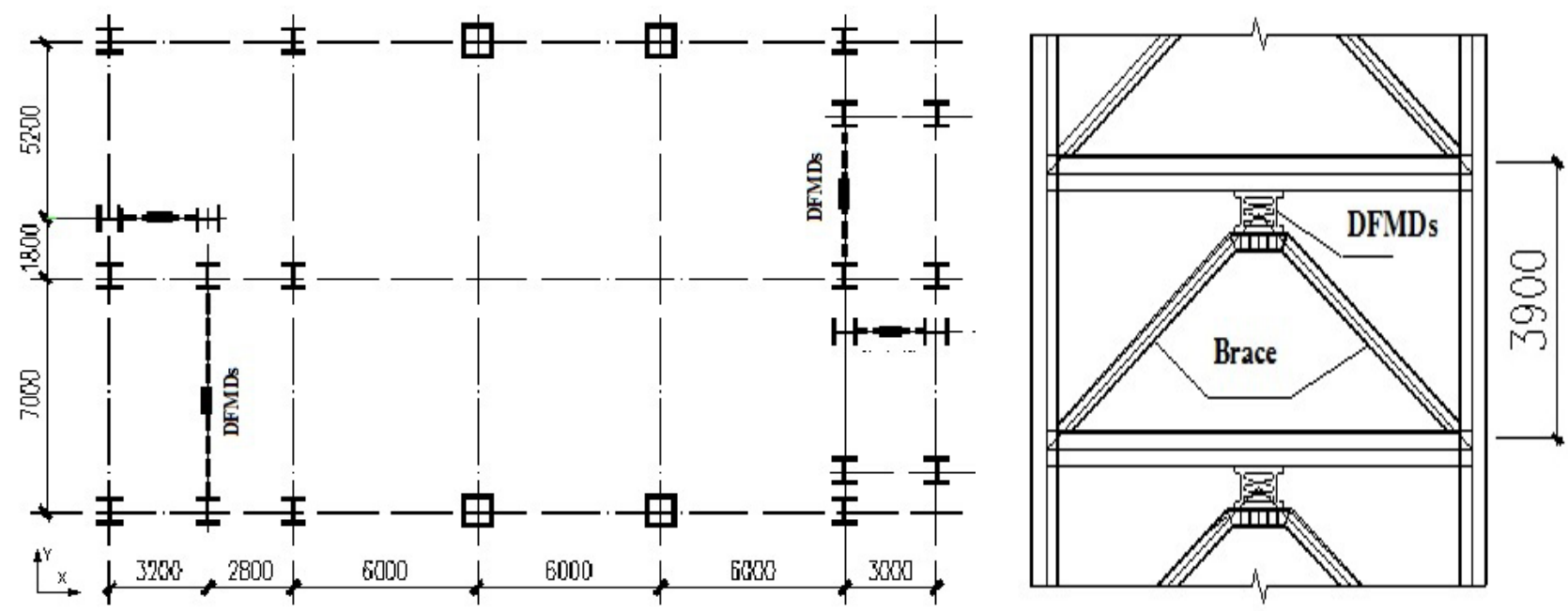

Figure 12. Plane and Elevation Sketch

The DXMDs are fixed on the cross-points of the beams and the braces. Its upper side is connected to the beams and its underside is attached with the braces. Installation position of the DXMD was shown in Figure 13. 


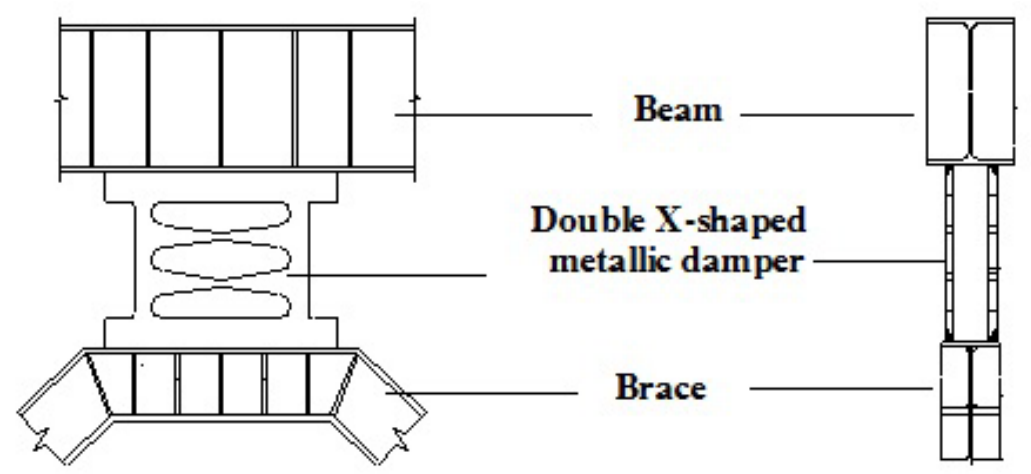

Figure 13. Installation of the DXMD

\subsection{Establishment of Finite Element Model}

To obtain more exact structural story-drifts and evaluate the DXMDs effectiveness on the structural vibration reduction, a three-dimensional frame model is established with ADPL language in the ANSYS program. BEAM188 in the ANSYS program is usually used to model beams and columns according to the Timoshenko's beam theory which apply a linear or a quadratic three-dimensional beam element. Material properties for beams, braces and columns are $E=2.1 \mathrm{GPa}$ and $\sigma_{y}=345$ MPa. Overall finite element model is shown in Figure 14 and detailed configuration about the DFMDs connecting with beam and brace is illustrated in Figure 15. In the solution of structural dynamics equation, the Rayleigh damping method is used and the damping ratio of 0.4 is selected here due to considering plastic behavior of the steel structure.

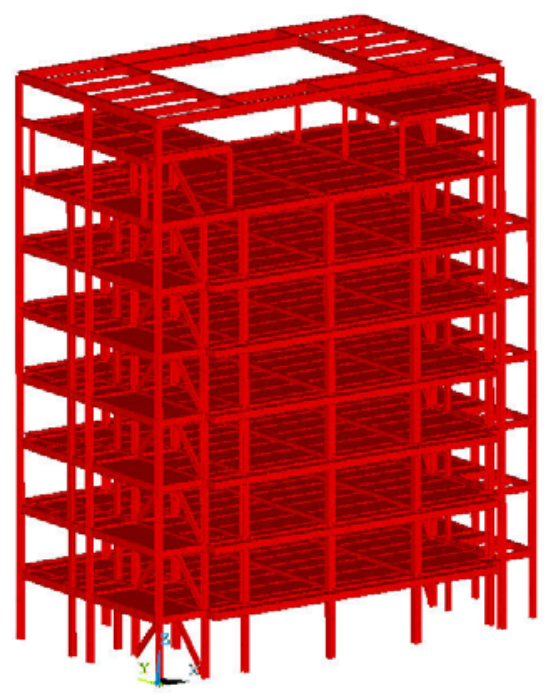

Figure 14. Overall Finite Element Model

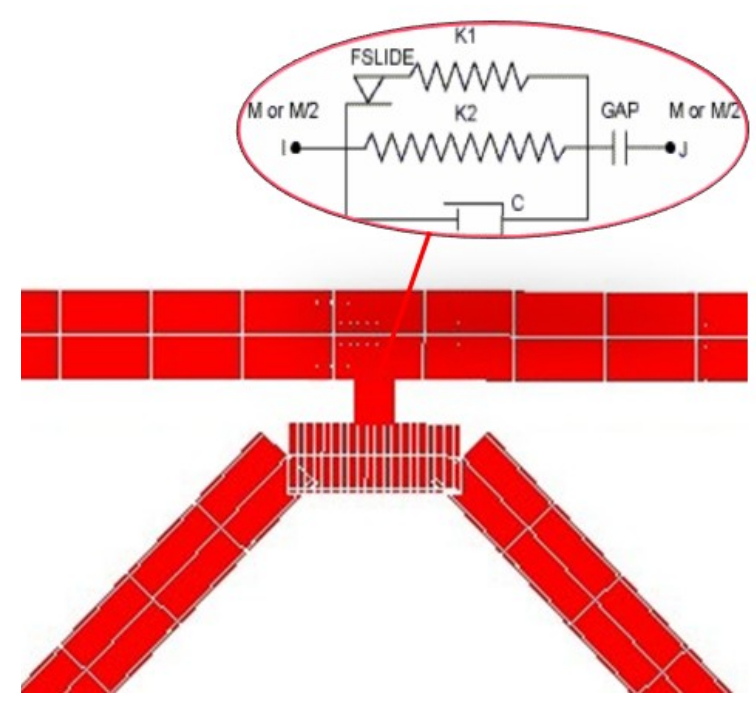

Figure 15. Finite Element Model of the Local Connection

\subsection{Modal Analysis}

As an important step of numerical simulation, the natural frequencies and modal shapes of the structures are used to identify its elastic property. The first three natural periods calculated by the ANSYS are listed in Table 2, and corresponding modal shapes are shown in Figures 16 and 17. It was observed that the natural periods of the steel structure with the DXMDs are obviously smaller than that without the DXMDs, because assemble of the steel braces and DXMDs provide additional stiffness to the original steel structure. Figures 16 and 17 also show that the basic modal shapes of the steel structure with the DXMDs is close to that of without DXMDs because of the symmetrical arrangement of the DXMDS. 
Table 2. Natural Periods Calculated by ANSYS (Unit: second)

\begin{tabular}{cccc}
\hline Structures & $1^{\text {st }}$ period & $2^{\text {st }}$ period & $3^{\text {st }}$ period \\
\hline Structure without DXMDS & 1.98 & 1.81 & 1.49 \\
Structure with DXMDs & 1.77 & 1.29 & 1.13 \\
\hline
\end{tabular}

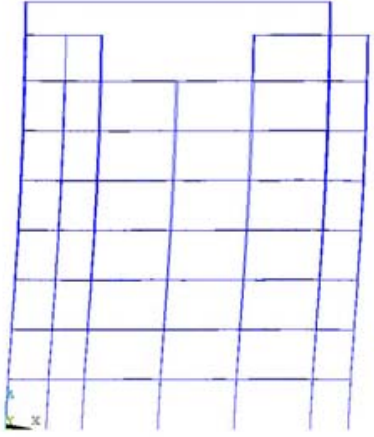

(a)

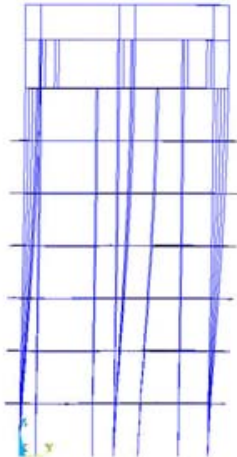

(b)

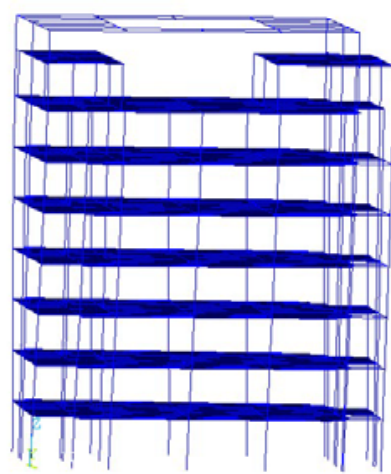

(c)

Figure 16. First Three Modes of the Structure without DXMDs: (a) $1^{\text {st }}$ Modal Vibration; (b) $2^{\text {nd }}$ Modal Vibration; (c) $3^{\text {th }}$ Modal Vibration

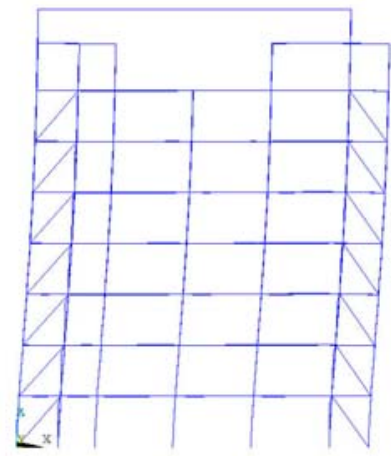

(a)

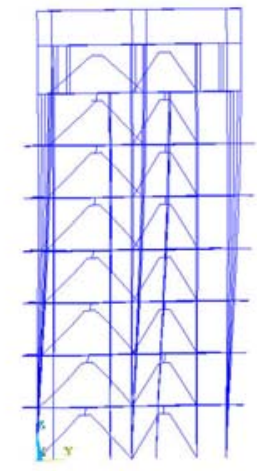

(b)

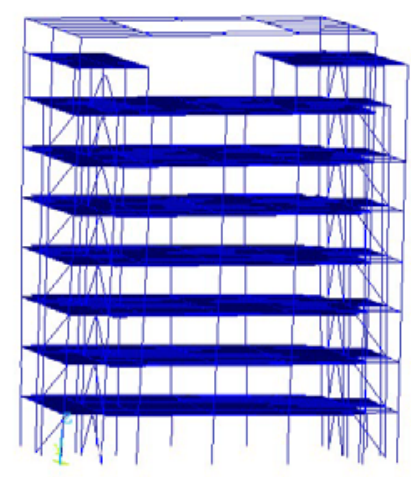

(c)

Figure 17. First Three Modes of the Structure with DXMDs: (a) $1^{\text {st }}$ modal vibration;

(b) $2^{\text {nd }}$ Modal Vibration; (c) $3^{\text {th }}$ Modal Vibration

\subsection{Dynamical Response Results}

Displacement and acceleration responses of the steel structures with and without the DXMDs shown in Figures 18 (a) to 18(d) were plotted together for validating the DXMDs effectiveness.

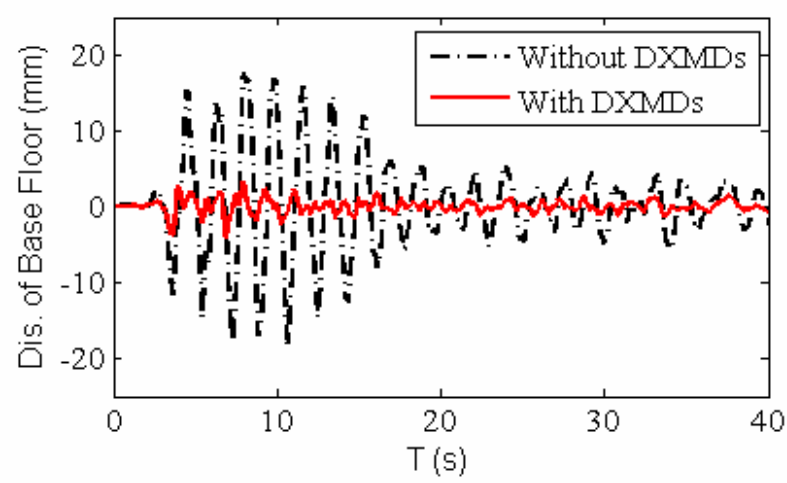

(a)

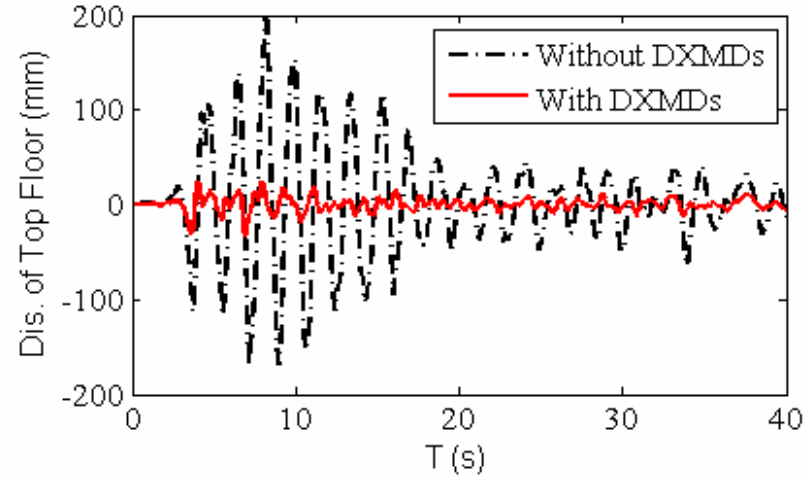

(b) 


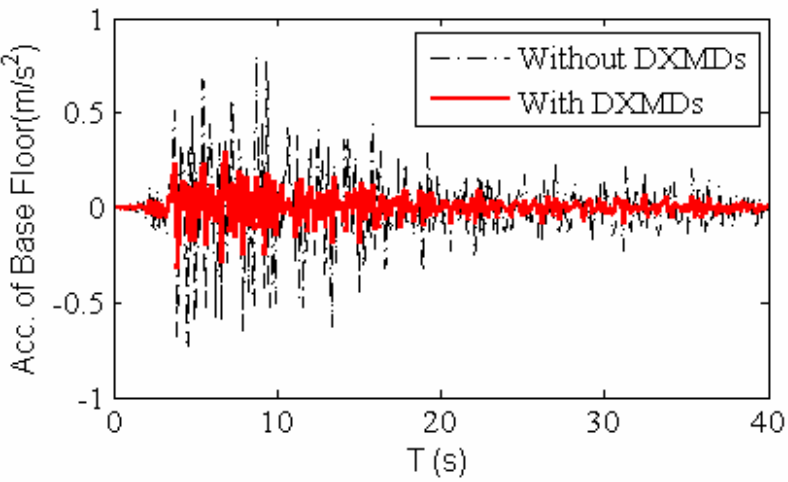

(c)

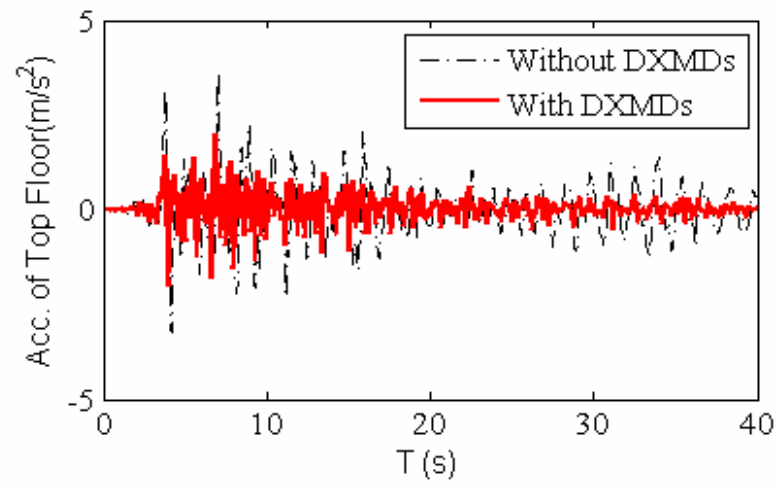

(d)

Figure 18. Displacement Response of the Structure with and without DFMDs under 1\# record: (a)

Base Floor; (b) Top Floor

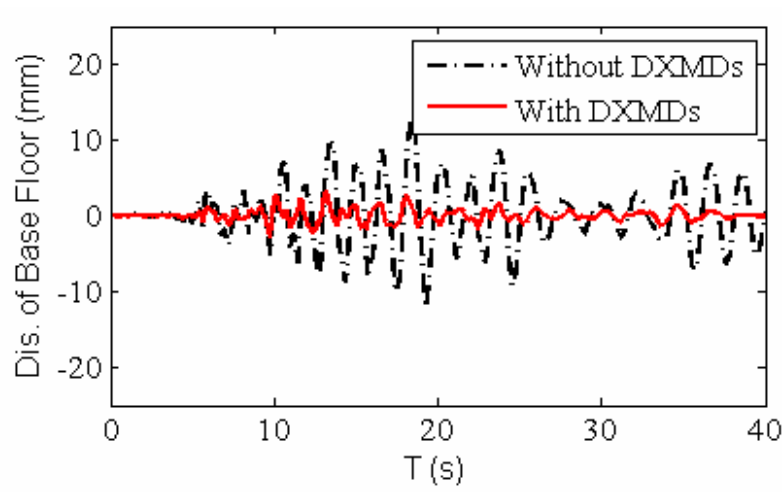

(a)

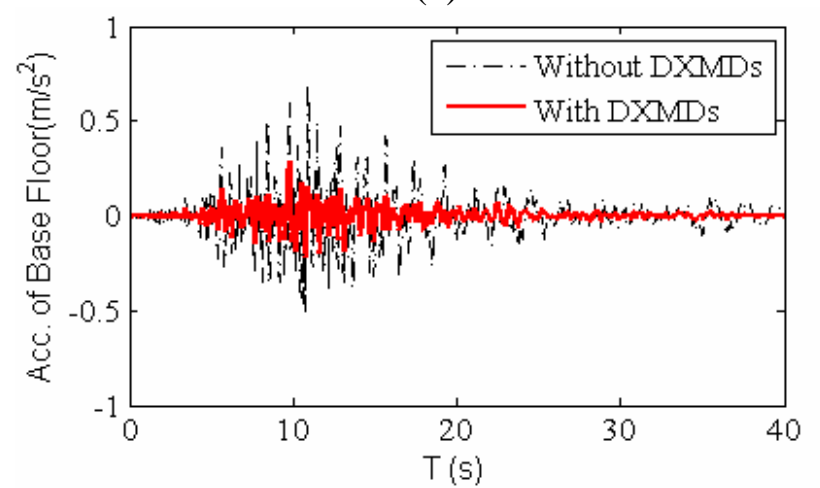

(c)

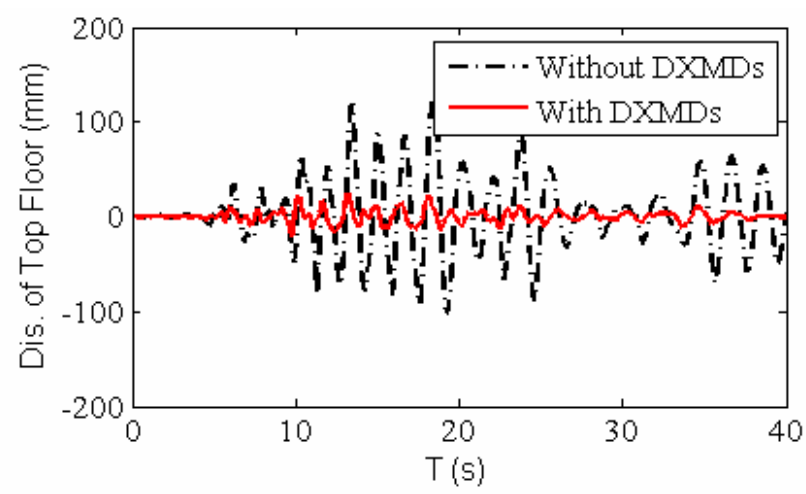

(b)

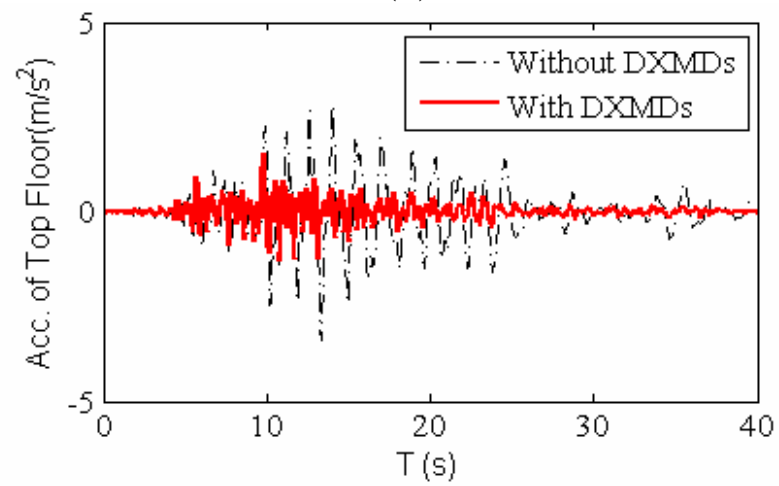

(d)

Figure 19. Displacement Response of the Structure with and without DFMDs under 2\# Record:

(a) Base Floor; (b) Top Floor

It can also be seen from Figure 18(a) that peak displacement at the base of the steel structure without the DFMDs is approximately $17.9 \mathrm{~mm}$ in Y direction, which is approximately 4 times peak displacements of the steel structure with the DFMDs. Figure 18(b) shows that the maximum displacement occurs also at the top floor and is decreased from $197 \mathrm{~mm}$ to $34 \mathrm{~mm}$. Similar results were obtained and were shown in Figure 19 and summarized in Tables 3 and 4. The reason of obvious displacement reduction is that the DXMDs contributed not only additional damping ratio the same as ordinary metallic dampers, but also additional relatively higher stiffness to the original steel structure. In addition, acceleration responses of each floor were decreased corresponding to the structure without the DXMDs because of its additional damping effect. However, the acceleration and base shear of the structure with the DXMDs are amplified under small earthquake due to obvious additional stiffness from the dampers. More attentions should be paid during seismic design. 
Table 3. Responses of the Structure in Y Direction under 1\# Record (unit: mm)

\begin{tabular}{|c|c|c|c|c|c|c|c|c|}
\hline \multirow{2}{*}{ Displacement Response } & \multicolumn{8}{|c|}{ Floor } \\
\cline { 2 - 9 } & 1 & 2 & 3 & 4 & 5 & 6 & 7 & 8 \\
\hline $\begin{array}{c}\text { Max inter-story displacement } \\
\text { (without DFMDs) }\end{array}$ & 17.9 & 47.6 & 78.8 & 100.8 & 132.0 & 152.2 & 166.0 & 196.5 \\
\hline $\begin{array}{c}\text { Max inter-story displacement } \\
\text { (with DFMDs) }\end{array}$ & 4.3 & 9.8 & 15.0 & 19.7 & 23.7 & 26.7 & 28.7 & 33.7 \\
\hline
\end{tabular}

Table 4. Responses of the Structure in Y Direction under 2\# Record (unit: mm)

\begin{tabular}{|c|c|c|c|c|c|c|c|c|}
\hline \multirow{2}{*}{ Displacement Response } & \multicolumn{8}{|c|}{ Floor } \\
\cline { 2 - 9 } & 1 & 2 & 3 & 4 & 5 & 6 & 7 & 8 \\
\hline $\begin{array}{c}\text { Max inter-story displacement } \\
\text { (without DFMDs) }\end{array}$ & 13.3 & 34.2 & 55.0 & 73.6 & 89.0 & 101.2 & 108.3 & 120.0 \\
\hline $\begin{array}{c}\text { Max inter-story displacement } \\
\text { (with DFMDs) }\end{array}$ & 3.1 & 7.3 & 11.1 & 14.5 & 17.4 & 19.6 & 21.2 & 25.0 \\
\hline
\end{tabular}

\section{SUMMARY AND CONCLUSIONS}

A new type of metallic damper is proposed in this study. Its stiffness was improved greatly relative to conventional metallic damper through it bearing in-plane exterior force, and its deformation and energy-dissipating capabilities are enhanced through making it various geometric shapes. Scaled model and full-scaled model test are carried out, respectively. Two outstanding metallic dampers named as RHMD and DXMD are selected, and the DXMD was applied in an actual steel structure. Some conclusions and suggestions are presented as follows:

(1) The steel plate shape has an important influence on deformation and energy-dissipating capability of the metallic damper;

(2) The RHMD and the DXMD exhibit good performance on stiffness and energy dissipation;

(3) The dynamic analysis of the steel structure revealed that the DXMD presented in this study reduced the displacement response effectively.

(4) The acceleration response of the structure with the DXMD or RHMD is amplified corresponding to original structure under normal use and small earthquake, so more attention must be focused on the issue during elastic seismic design;

(5) The ratio of the height and width of these two dampers equals and less than 1.0 is suggested, because relatively larger ratio probably results in out-plane buckling of the damper;

(6) Yield displacement and yield strength of these two dampers as basic parameters have directly influence on controlling displacement response.

\section{ACKNOWLEDGEMENTS}

Funding for authors was provided by the Science Fund for Creative Research Groups of the National Natural Science Foundation of China (Grant No. 51121005).

\section{REFERENCES}

[1] Lackner, M.A. and Rotea, M.A., "Passive Structural Control of Offshore Wind Turbines", Wind Energy, 2011, Vol. 14, No. 3, pp. 373-388.

[2] Housner, G.W., Bergman, L.A. and Caughey, T.K., et al. "Structural Control: Past, Present and Future”, ASCE Journal of Engineering Mechanics, 1997, Vol. 123, No. 8, pp. 897-972. 
[3] Li, H.N., Yin, Y.W. and Wang, S.Y., "Studies on Seismic Reduction of Story-increased Buildings with Friction Layer and Energy-dissipated Devices”, Earthquake Engineering \& Structural Dynamics, 2003, Vol. 32, No. 14, pp. 2143-2160.

[4] Tnanka, T., Makii, K., Ueda, H. and Kushibe, A., etc., "Study on Practical Application of a New Seismic Damper Using a Zn-Al Alloy with a Nanocrystalline Microstructure”, Mechanical Sciences, 2003, Vol. 45, pp. 1599-1612.

[5] Kelly, J.M., Skinner, R.I. and Heine, A.J., "Mechanisms of Energy Absorption in Special Devices for Use in Earthquake-resistant Structures”, Bull. N.Z. National Society for Earthquake Engineering, 1972, Vol. 5, No. 3, pp. 63-88.

[6] Whittaker, A.S., Bertero, V.V., Thompson, C.I. and Alsonson, L.J., "Seismic Testing of Steel Plate Energy Dissipation Devices”, Earthquake Spectra, 1991, Vol. 7, No. 4, pp. 563-604.

[7] Tsai, K.C., Chen, H.W., Hong, C.P. and Su, Y.F., "Design of Steel Triangular Plate Energy Absorbers for Seismic Resistant Construction”, Earthquake Spectra, 1993, Vol. 19, No. 3, pp. 505-528.

[8] Skinner, R.I., Kelly, I.M., Heine, A.J and Robinson, W.H., "Hysteresis Dampers for the Protection for the Protection of Structures from Earthquake". Bull. N.Z. Nat. Soc. for Earthquake Engineering, 1980, Vol. 13, No. 1, pp. 22-26.

[9] Martinesz-Romero, E., "Experiences on the Use of Supplemental Energy Dissipators on Building Structures”, Earthquake Spectra, 1993, Vol. 9, No. 3, pp. 581-624.

[10] Bartera, F., Giacchetti, R., "Steel Dissipating Braces for Upgrading Existing Building Frames”, Journal of Constructional Steel Research, 2004, Vol. 60, pp. 751-769.

[11] Mualla, I.H., Belev, B., "Performance of Steel Frames with a New Friction Damper Device under Earthquake Excitation”, Engineering Structures, 2002, Vol. 24, pp. 365-371.

[12] Min, K.W., Kim, J., Lee, S.H., "Vibration Tests of 5-story Steel Frame with Viscoelastic Dampers”, Engineering Structures, 2004, Vol. 26, pp. 831-839.

[13] Phocas, M.C., Pocanschi, A., "Steel Frames with Bracing Mechanism and Hysteretic Dampers”, Earthquake Engineering and Structural Dynamics, 2003, Vol. 32, pp. 811-825.

[14] Moreschi, L.M., Singh, M.P., "Design of Yielding Metallic and Friction Dampers for Optimal Seismic Performance”, Earthquake Engineering and Structural Dynamics, 2003, Vol. 32, pp. 1291-1311.

[15] Curadelli, R.O., Riera, J.D., "Reliability Based Assessment of the Effectiveness of Metallic Dampers in Buildings under Seismic Excitations”, Engineering Structures, 2004, Vol. 26, pp.1931-1938.

[16] Seismic Design Code for Buildings (GB 50011 - 2001). China Architectural Industry Press, Beijing, 2001.

[17] Lin, Y.Y., Tsai, M.H., Hwang, J.S. and Chang, C.K., "Direct Displacement-based Design for Building with Passive Energy Dissipation Systems”, Engineering Structures, 2003, Vol.25, pp. 25-37.

[18] Singh, M.P., Moreschi, L.M., “Optimal Placement of Dampers for Passive Response Control”, Earthquake Engineering and Structural Dynamics, 2002, Vol. 31, pp. 955-976.

[19] Soong, T.T., Dargush, G.F., Passive Energy Dissipation Systems in Structural Engineering, John Weley \& Sons, 1997.

[20] Tehranizadeh, M. "Passive Energy Dissipation Device for Typical Steel Frame Building in Iran”, Engineering Structures, 2001, Vol. 23, No. 6, pp. 643-655.

[21] Zhang, R.H., Soong, T.T., "Seismic Design of Viscoelastic Dampers for Structural Applications”, ASCE Journal of Structural Engineering, 1992, Vol. 118, No. 5, pp.1375-1392. 